\title{
Physical functioning in low back pain : exploring different activity-related behavioural styles
}

Citation for published version (APA):

Huijnen, I. P. J. (2011). Physical functioning in low back pain : exploring different activity-related behavioural styles. [Doctoral Thesis, Maastricht University]. Universitaire Pers Maastricht. https://doi.org/10.26481/dis.20111117ih

Document status and date:

Published: 01/01/2011

DOI:

10.26481/dis.20111117ih

Document Version:

Publisher's PDF, also known as Version of record

\section{Please check the document version of this publication:}

- A submitted manuscript is the version of the article upon submission and before peer-review. There can be important differences between the submitted version and the official published version of record. People interested in the research are advised to contact the author for the final version of the publication, or visit the DOI to the publisher's website.

- The final author version and the galley proof are versions of the publication after peer review.

- The final published version features the final layout of the paper including the volume, issue and page numbers.

Link to publication

\footnotetext{
General rights rights.

- You may freely distribute the URL identifying the publication in the public portal. please follow below link for the End User Agreement:

www.umlib.nl/taverne-license

Take down policy

If you believe that this document breaches copyright please contact us at:

repository@maastrichtuniversity.nl

providing details and we will investigate your claim.
}

Copyright and moral rights for the publications made accessible in the public portal are retained by the authors and/or other copyright owners and it is a condition of accessing publications that users recognise and abide by the legal requirements associated with these

- Users may download and print one copy of any publication from the public portal for the purpose of private study or research.

- You may not further distribute the material or use it for any profit-making activity or commercial gain

If the publication is distributed under the terms of Article $25 \mathrm{fa}$ of the Dutch Copyright Act, indicated by the "Taverne" license above, 


\section{Physical functioning in Low Back Pain}

Exploring different activity-related behavioural styles 
ISBN 9789461590824

Printed by: Datawyse | Universitaire Pers Maastricht

Cover design: Esther Theeven-van Hinsberg

Huijnen, Ivan Peter Jozef. Physical functioning in low back pain; exploring different activity-related behavioural styles.

Thesis Maastricht University, the Netherlands - With ref. - With summary in Dutch.

Copyright (C IPJ Huijnen, Maastricht 2011

All rights reserved. No part of this publication may be reproduced or transmitted in any form or by any means, electronical or mechanical, including photocopy, recording or any other information storage or retrieval system, without the prior written permission of the copyright owner. 


\section{Physical functioning in Low Back Pain}

Exploring different activity-related behavioural styles

\section{Proefschrift}

ter verkrijging van de graad van doctor

aan de Universiteit Maastricht, op gezag van Rector Magnificus,

Prof.mr. G.P.M.F. Mols,

volgens het besluit van het College van Decanen,

in het openbaar te verdedigen

op donderdag 17 november 2011 om 16.00 uur

door

Ivan Peter Jozef Huijnen

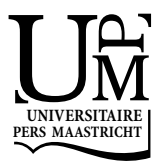




\section{Promotores}

Prof. dr. R.J.E.M. Smeets

Prof. dr. M.L. Peters

\section{Copromotores}

Dr. J.A. Verbunt

Dr. H.A.M. Seelen

\section{Beoordelingscommissie}

Prof. dr. J.W.S. Vlaeyen (voorzitter)

Prof. dr. R.A. de Bie

Dr. J.B. Bussmann, Erasmus MC, Rotterdam

Prof. dr. M.I. Hasenbring, Ruhr-University, Bochum, Germany

Prof. dr. J.A. Knottnerus

The research presented in this thesis was conducted at the School for Public Health and Primary Care: CAPHRI, Department of Rehabilitation Medicine, of Maastricht University. CAPHRI participates in the Netherlands School of Primary Care Research CaRe. CAPHRI was classified as 'excellent' by the external evaluation committee of leading international experts that reviewed CAPHRI in December 2010.

The studies presented in this thesis have been supported by:

The Council for Medical and Health Research of the Netherlands (ZON-MW), grant nr. 14350042

Further financial support has been kindly provided by:

Wetenschappelijk College Fysiotherapie van het KNGF

Nederlandse Vereniging van Rugpatiënten “de Wervelkolom"

Adelante

Maastricht University Medical Center (MUMC+) 


\section{Contents of the thesis}

$\begin{array}{lll}\text { Chapter } 1 & \text { Introduction } & 7\end{array}$

$\begin{array}{lll}\text { Part I Assessment of activity-related behaviour } & 17\end{array}$

$\begin{array}{lll}\text { Chapter } 2 & \text { Physical performance measurement in pain: measuring } & 19\end{array}$ behaviour or physical capacity?

Chapter 3 Is physical functioning in patients with subacute low back pain influenced by activity-related pain prediction and fear of movement?

Chapter 4 Assessment of physical activity in daily life in patients with musculoskeletal pain.

Chapter 5 Do depression and pain intensity interfere with physical activity in daily life in patients with chronic low back pain?

Part II Identification of subgroups based on activity-related behaviour

Chapter 6 The disabling role of pain and physical activity in patients with chronic low back pain.

Chapter 7 Differences in activity-related behaviour among patients with chronic low back pain

Part III The self-discrepancy model for chronic pain to explain persistence and avoidance behaviour

Chapter 8 "Being" in pain: the role of self-discrepancies in the emotional experience and activity patterns of patients with chronic low back pain

Chapter 9 Explaining disability and quality of life; the role of selfdiscrepancies on activity-related behaviour in patients with chronic low back pain

Chapter 10 General discussion

Chapter 11 Summary

Samenvatting

Dankwoord

About the author

Publications 


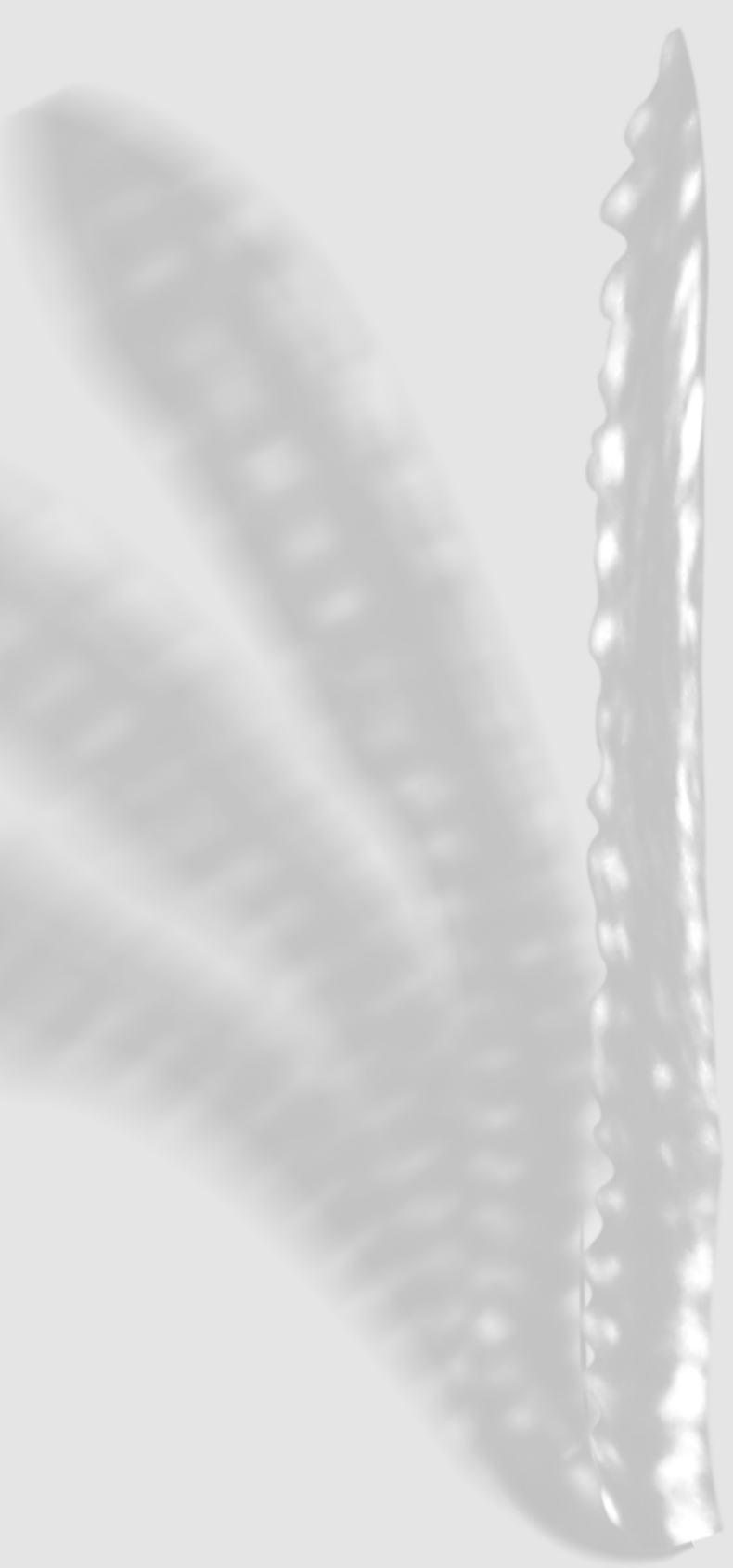


Chapter 1

Introduction 


\section{Introduction}

\section{Background}

Impact of chronic low back pain on individuals and society

Low back pain is defined as pain localized below the scapulae and above the gluteal folds (20). Low back pain is regarded as being chronic when a patient perceives pain for at least three months. Nonspecific chronic low back pain (CLBP) is defined as low back pain not attributable to a specific pathology like a fracture or inflammatory disorder (1).

Nonspecific CLBP is an important public health problem in Western societies. Chronic pain can have a high impact on the individual patient. It can influence one's daily life functioning and quality of life tremendously. In the Netherlands 2.4 million people suffer from CLBP (21). It is expected that the incidence and prevalence of CLBP in the Netherlands will further increase (21). As a result, the societal impact of CLBP will remain high, not only due to health care costs but also based on indirect costs, such as sick leave.

The treatments currently available to improve the functioning of a patient with CLBP are still less effective as hoped for all patients. Individually tailored treatment may result in a higher number of patients taking advantage of a treatment. In order to improve the efficacy of the treatment of patients with CLBP, factors contributing to the development and maintenance of pain and its associated disability need to be identified. Innovation in treatments specifically targeting at these factors identified may result in more effective treatments and improve the prognosis of patients with CLBP.

This thesis is part of the LOBADIS research program. This LOw BAck DISability and rehabilitation strategy program aims to further expand the knowledge of modelbased treatments for patients with CLBP. The ultimate goal of the LOBADIS program is to reduce CLBP-associated disability by matching rehabilitation treatment to individual patient needs and characteristics.

\section{Explanatory models}

Several models have been proposed to explain the development and maintenance of CLBP. Initially, research mainly focused on biomedical explanations. However, not for all patients with disabling pain syndromes, a biomedical explanation could be identified as the origin of their disability $(5,10,28)$. It became clear that a patient's pain behaviour not only depends on physical factors but also on psychological and social factors. This insight resulted in a shift from biomedical models to biopsychosocial models to explain the pain problem (9). In the mid 90's the cognitive behavioural fear-avoidance model was proposed to explain the development of 
chronic nonspecific pain (27). This model describes how in a subgroup of patients, due to catastrophizing thoughts about pain, fear of movement will develop. Fear of movement is characterized by avoidance of activities that, to the patient's expectation, will result in an increase of his pain. In the long run, avoidance behaviour may have several negative health consequences; it may lead to disability, depression and/or disuse (27). Disuse is defined as a decreased physical activity level, leading to physical deconditioning, characterized by a lower physical capacity and reduced muscle strength (25). These negative consequences are assumed to be associated with lower pain tolerance and higher pain perception. Eventually, these negative consequences will result in a vicious circle. Although several associations in the fearavoidance model have been confirmed, results on studies focussing on the existence of disuse and physical deconditioning in patients with chronic pain remain equivocal. Also evidence regarding the assumed lower level of physical fitness due to physical deconditioning remains lacking. Whereas several studies found lower levels of physical capacity, defined as the subject's maximal physiological possibilities, for patients with $\operatorname{CLBP}(8,18,19,22)$ others found a comparable level of physical capacity in patients with CLBP and healthy volunteers $(4,7,30)$. Furthermore, studies using movement registration to assess physical activity in daily life did not find a lower level of physical activity of patients with CLBP compared to healthy volunteers $(3,23,24,26)$. In addition, no significant association between fear of movement and the objectively assessed level of physical activity in daily life could be found (26). It was also found that patients with CLBP who have a rather high daily life activity level also perceive limitations in daily life functioning (3). These findings seem to indicate that not all patients apply avoidance behaviour as a coping style to deal with their CLBP problem.

Complementary to the fear-avoidance model in 1995, Hasenbring and colleagues proposed another model, i.e. the avoidance-endurance model. This model describes that patients with CLBP may apply different activity-related behaviour styles (12-14). The avoidance-endurance model describes in line with the fearavoidance model, a subgroup of patients, 'the avoiders', who develop a lower daily life activity level due to elevated pain-related fear. In addition, another subgroup of patients showing persistence behaviour is proposed. The behaviour style of a 'persister' is characterized by a continuation of activities despite pain, until completion of the task is reached $(2,11)$. When the activity is completed, the level of pain will increase due to overload, which, in turn, will force a persister to take rest until the pain subsides. Eventually, this pain decrease will result in a renewed start of activities that may lead to another episode of increased pain. This variation in daily life activities over time results in a so-called saw tooth pattern of activity. Both activityrelated styles, i.e. avoidance and persistence, are hypothesized to be associated with high disability levels and lower quality of life. 


\section{The self-discrepancy model}

Although several studies mention the presence of persistence and avoidance behavioural styles, the underlying mechanism explaining both styles has not yet been identified $(2,11,13)$. The self-discrepancy model for chronic pain might provide an explanation for both avoidance and persistence behaviour. The original SelfDiscrepancy Theory developed by Higgins, proposes that discrepancies exist between the attributes one actually possesses ('actual self'), and the attributes one ideally possesses ('ideal self') or ought to possess ('ought self') (16). In addition, Carver et al. introduced the role of the 'feared self' (the attributes one fears to possess) (6). Self-discrepancies motivate self-regulatory behaviours in order to reduce discrepancies (or enlarge discrepancies in case of the feared self). Regardless of the effort to influence discrepancies between selves, every person will experience discrepancies (of varying degrees) between his selves. These discrepancies are associated with negative emotions. Discrepancies between the actual and ideal self are related to dejection-related emotions (e.g. depression), whereas discrepancies between the actual and ought self are related to agitation-related emotions (e.g. anxiety) (17). The discrepancy between the actual and feared self is related to both agitation and dejection-related emotions $(6,15)$. The associations between selfdiscrepancies and negative emotions in asymptomatic volunteers have been confirmed in patients with chronic pain (29).

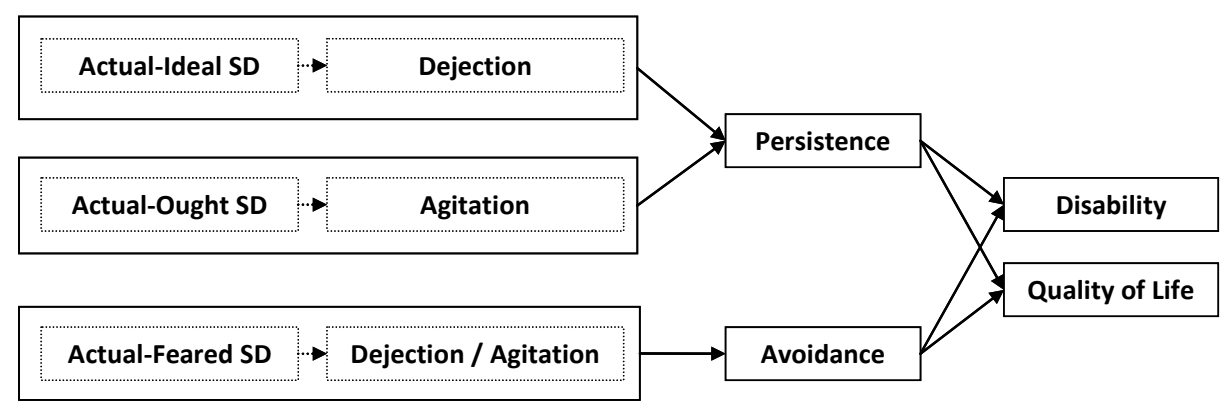

Figure 1: The self-discrepancy model for chronic pain

A potential model to identify the underlying mechanism explaining avoidance and persistence behaviour in patients with CLBP is the self-discrepancy model for chronic pain (as presented in figure 1). In this model, it is hypothesized that both ideal and ought self-discrepancies lead to persistence behaviour because the patient's behaviour is driven by a focus on a desired (ideal self) or obliged (ought self) target. In contrast, the actual-feared discrepancy is hypothesized to predict avoidance behaviour since the focus is on an undesired target (i.e. the feared self). Both avoidance and persistence behaviour are proposed to lead to increased disability and a diminished quality of life. To evaluate the self-discrepancy model for chronic 
pain, a further challenge is to measure the different activity-related behaviour styles.

\subsection{Outline of this thesis}

In order to identify different activity-related behaviour styles within the population of patients with CLBP, the first aim of the present thesis is to identify and describe the best assessment methods to measure a patients' activity-related behaviour style during performance testing and activities in daily life, as well as its influencing factors. During physical activity testing in a laboratory, physiological (muscle strength, aerobic capacity etc.) and non-physiological factors (environmental and psychological factors) all contribute to the patient's actual physical performance. In order to evaluate a patient's behaviour with a performance test, a test has to be chosen in which the influence of psychological factors is prominent. The second aim is to identify specific characteristics in a person's activity pattern reflecting his activity-related behaviour style (i.e. avoidance and persistence). Subsequently, the third aim of the present thesis is to evaluate whether the self-discrepancy model for chronic pain can explain differences in activity-related behaviour styles. This thesis comprises eight studies and is organized in three parts:

\section{Part I: Assessment of activity-related behaviour}

Till now, in research and clinical practice focus has been on quantifying avoidance behaviour. However, in order to also identify persistence behaviour as proposed in the self-discrepancy model of chronic pain, characteristics of both types of activityrelated behaviour have to be identified. These types of activity-related behaviour can be studied in two main ways:

First, one can challenge a person to show his activity-related behaviour style by exposing him to a strenuous physical performance test in a laboratory setting. For the assessment of physical performance several tests have been used to represent a patients' level of functioning. However, it is important to realize that besides pain, physiological and non-physiological factors will have an influence on the outcome of a performance test. As a result of this, in Chapter 2 addresses the topic whether during performance testing a patient's maximum physiological possibilities or a patient's behaviour will be addressed. The impact of pain, physiological and nonphysiological factors on four different types of physical performance tests is analysed and discussed. The ability of a patient with sub acute low back pain to accurately predict pain associated with physical performance is evaluated in chapter 3 . This study also evaluates whether pain-related fear is associated with the performance in patients who overpredict their activity-related pain, and, in addition, whether this overprediction of pain generalizes to daily life functioning. 
Second, one can observe the patients' behaviour during daily life and assess its characteristics using a questionnaire, a diary or an objective daily life activity assessment like accelerometry. Chapter 4 presents a systematic evaluation of selfreported and objective registration methods available to assess daily life activities in patients with musculoskeletal pain. In addition, psychometric properties of the measurement methods are evaluated. To evaluate whether patients with CLBP can accurately estimate their own daily life activity level, the association between a patient's self-reported activity level and his level of actual daily life activities is studied in chapter 5. Furthermore, the impact of potential influencing factors, like pain intensity and depression on the discrepancy between the self-reported and objectively assessed daily life activity level in patients with CLBP is studied.

\section{Part II: Identification of subgroups, based on activity-related behaviour}

In the second part of this thesis, the different activity-related behaviour styles (i.e. avoidance and persistence) of patients with CLBP will be identified and furthermore specific characteristics in a person's activity pattern reflecting these identified styles will be explored. More insight is needed in the complex associations between physical activity, pain and disability in order to unravel the characteristics of persistence and avoidance behaviour. 'Persisters' are assumed to continue with activities until completion of the task is reached. When the activity is completed pain prevents them from any further activity which will force a persister to take rest until pain subsides or frustration over inactivity stimulates them to start a new activity. This results in fluctuations in activity over time. Whether these self-reported fluctuations in daily life activity have a negative influence on the disability level of patients with CLBP is evaluated in chapter 6 . In chapter 7 the characteristics of different subgroups in activity-related behaviour are identified. Based on objective daily life assessment, it will be evaluated whether persisters are more physically active, show more fluctuations in activity and have a longer daily uptime, compared to avoiders. It is hypothesized that both persisters and avoiders feel disabled in daily life functioning.

\section{Part III: The self-discrepancy model for chronic pain to explain persistence and avoidance behaviour}

In this part of the thesis, the associations between self-discrepancies, avoidance/persistence behaviour and disability/quality of life will be focussed upon. In chapter 8 , the association between the type of self-discrepancies and the different activity-related styles is evaluated, using self-reported data. Also the association between different activity-related styles and disability and quality of life will be studied.

Whether the influence of a person's self-discrepancy or a change within one's self-discrepancy over time is associated with the objectively registered characteris- 
tics of a person's activity-related behaviour style (avoidance or persistence behaviour), or changes within these characteristics will be evaluated in chapter 9. Furthermore, the association between the objectively registered activity-related characteristics of both avoidance and persistence behaviour and a patients' disability level and quality of life is evaluated.

Finally, chapter 10 provides a general discussion, evaluating the main results, the methodological considerations, and the conclusions of all studies presented in this thesis. Furthermore, implications for clinical practice will be given and recommendations for future research will be discussed. 


\section{References}

(1) Airaksinen O, Brox JI, Cedraschi C, Hildebrandt J, Klaber-Moffett J, Kovacs F, Mannion AF, Reis S, Staal JB, Ursin H, and Zanoli G. Chapter 4. European guidelines for the management of chronic nonspecific low back pain. Eur Spine J 2006; 15 Suppl 2:S192-300.

(2) Birkholtz M, Aylwin M, and Harman RM. Activity pacing in chronic pain management: One aim, but which method? Part one: Introduction and literature review. Br J Occup Ther 2006; 67(10):447452.

(3) Bousema EJ, Verbunt JA, Seelen HA, Vlaeyen JW, and Knottnerus JA. Disuse and physical deconditioning in the first year after the onset of back pain. Pain 2007; 130(3):279-86.

(4) Brox JI, Storheim K, Holm I, Friis A, and Reikeras O. Disability, pain, psychological factors and physical performance in healthy controls, patients with sub-acute and chronic low back pain: a casecontrol study. J Rehabil Med 2005; 37(2):95-9.

(5) Burton AK, Tillotson KM, and Troup JD. Variation in lumbar sagittal mobility with low-back trouble. Spine (Phila Pa 1976) 1989; 14(6):584-90.

(6) Carver CS, Lawrence JW, and Scheier MF. Self-Discrepancies and affect: Incorporating the role of feared selves. Pers Soc Psychol Bull 1999; 25 (7):783-792.

(7) Duque I, Parra JH, and Duvallet A. Physical deconditioning in chronic low back pain. J Rehabil Med 2009; 41(4):262-6.

(8) Duque I, Parra JH, and Duvallet A. Maximal aerobic power in patients with chronic low back pain: a comparison with healthy subjects. Eur Spine J 2011; 20(1):87-93.

(9) Fordyce WE. Learned pain; pain as behaviour. In: J.D. Loeser, S.H. Butler, C.R. Chapman, and D.C. Turk, editors. Bonica's management of pain. Lippincott: Williams \& Wilkins; 2001. p.

(10) Gronblad M, Hurri H, and Kouri JP. Relationships between spinal mobility, physical performance tests, pain intensity and disability assessments in chronic low back pain patients. Scand J Rehabil Med 1997; 29(1):17-24.

(11) Harding V, Williams A. Activities training: Intergrating behavioral and cognitive methods with physiotherapy in pain management. J Occup Rehabil 1998; 8(1):47-60.

(12) Hasenbring $M$, Hallner D, and Klasen B. (Psychological mechanisms in the transition from acute to chronic pain: over- or underrated?). Schmerz 2001; 15(6):442-7.

(13) Hasenbring MI, Plaas H, Fischbein B, and Willburger R. The relationship between activity and pain in patients 6 months after lumbar disc surgery: Do pain-related coping modes act as moderator variables? Eur J Pain 2006; 10(8):701-9.

(14) Hasenbring MI, Verbunt JA. Fear-avoidance and endurance-related responses to pain: new models of behavior and their consequences for clinical practice. Clin J Pain 2010; 26(9):747-53.

(15) Heppen JB, Ogilvie DM. Predicting affect from global self-discrepancies: The dual role of the undesired self. J Soc Clin Psych 2003; 22:347-68.

(16) Higgins ET. Self-discrepancy: a theory relating self and affect. Psychol Rev 1987; 94(3):319-40.

(17) Higgins ET. When do self-discrepancies have specific relations to emotions? The second-generation question of Tangney, Niedenthal, Covert, and Barlow (1998). J Pers Soc Psychol 1999; 77(6):1313-7.

(18) Hodselmans AP, Dijkstra PU, Geertzen JH, and van der Schans CP. Nonspecific chronic low back pain patients are deconditioned and have an increased body fat percentage. Int J Rehabil Res 2010; 33(3):268-70.

(19) Keller A, Hellesnes J, and Brox Jl. Reliability of the isokinetic trunk extensor test, Biering-Sorensen test, and Astrand bicycle test: assessment of intraclass correlation coefficient and critical difference in patients with chronic low back pain and healthy individuals. Spine 2001; 26(7):771-7.

(20) Merskey H, Bogduk N. Classification of chronic pain. IASP Task force on taxonomy, ed. S. edition. 1994, Seattle: IASP press.

(21) Picavet HS. Chronische ziekten: Aspecifieke lage rugklachten: omvang en gevolgen, ed. C.v.P.-e.Z. 2005/2007. 2005/2007: RIVM. 
(22) Smeets RJ, Wittink H, Hidding A, and Knottnerus JA. Do patients with chronic low back pain have a lower level of aerobic fitness than healthy controls?: are pain, disability, fear of injury, working status, or level of leisure time activity associated with the difference in aerobic fitness level? Spine 2006; 31(1):90-7; discussion 98.

(23) van den Berg-Emons RJ, Schasfoort FC, de Vos LA, Bussmann JB, and Stam HJ. Impact of chronic pain on everyday physical activity. Eur J Pain 2007; 11(5):587-93.

(24) van Weering MG, Vollenbroek-Hutten MM, Tonis TM, and Hermens HJ. Daily physical activities in chronic lower back pain patients assessed with accelerometry. Eur J Pain 2009; 13(6):649-54.

(25) Verbunt JA, Seelen HA, Vlaeyen JW, van de Heijden GJ, Heuts PH, Pons K, and Knottnerus JA. Disuse and deconditioning in chronic low back pain: concepts and hypotheses on contributing mechanisms. Eur J Pain 2003; 7(1):9-21.

(26) Verbunt JA, Westerterp KR, van der Heijden GJ, Seelen HA, Vlaeyen JW, and Knottnerus JA. Physical activity in daily life in patients with chronic low back pain. Arch Phys Med Rehabil 2001; 82(6):72630.

(27) Vlaeyen JW, Linton SJ. Fear-avoidance and its consequences in chronic musculoskeletal pain: a state of the art. Pain 2000; 85(3):317-32.

(28) Waddell G, Somerville D, Henderson I, and Newton M. Objective clinical evaluation of physical impairment in chronic low back pain. Spine (Phila Pa 1976) 1992; 17(6):617-28.

(29) Waters SJ, Keefe FJ, and Strauman TJ. Self-discrepancy in chronic low back pain: relation to pain, depression, and psychological distress. J Pain Symptom Manage 2004; 27(3):251-9.

(30) Wittink H, Hoskins Michel T, Wagner A, Sukiennik A, and Rogers W. Deconditioning in patients with chronic low back pain: fact or fiction? Spine 2000; 25(17):2221-8. 


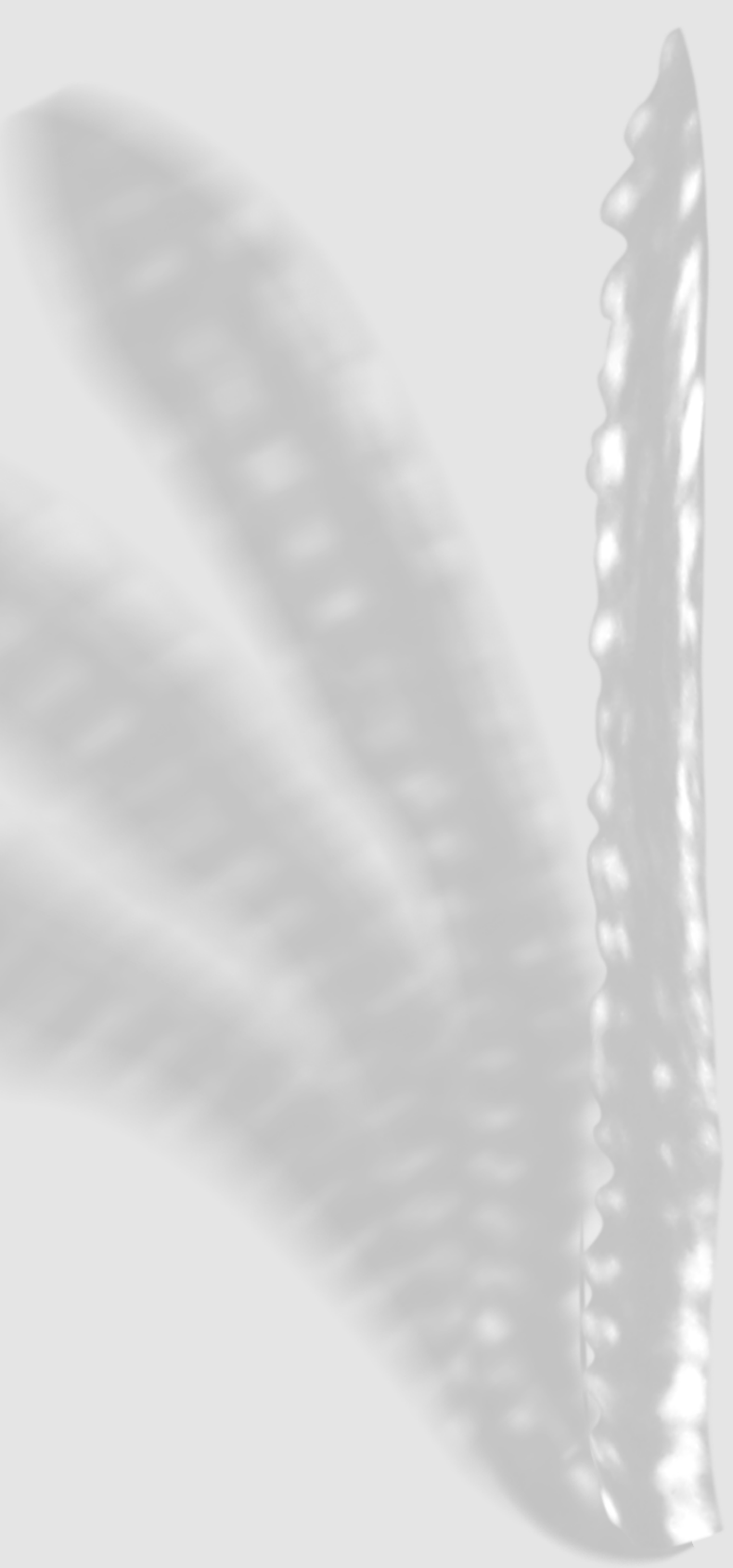


Part I

Assessment of activity-related

\section{behaviour}




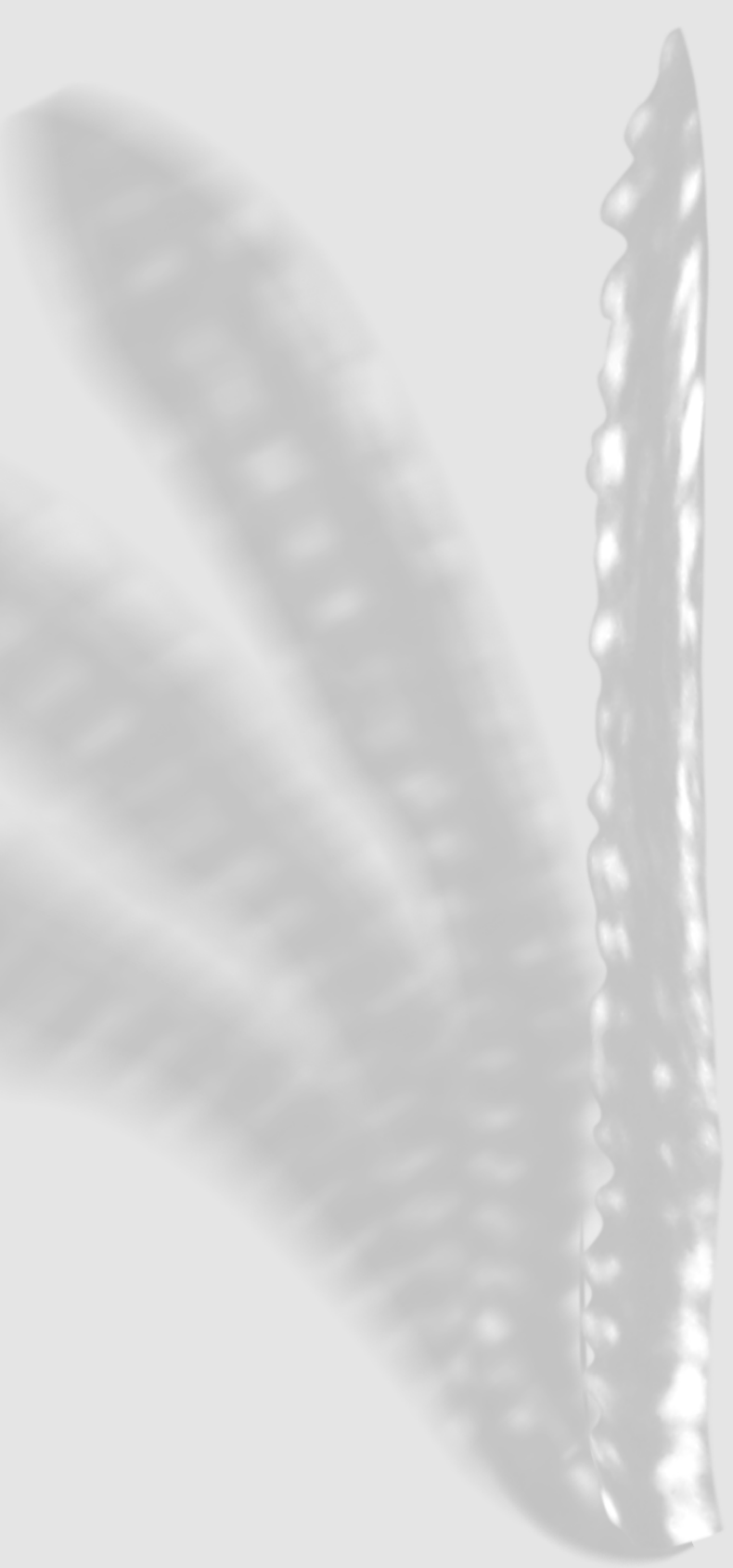




\section{Chapter 2 \\ Physical performance measurement in chronic low back pain: measuring physical capacity or behaviour?}

This chapter is submitted for publication in revised form as:

Huijnen IP, Verbunt JA, Peters ML, Wittink HM, Smeets RJ. Physical performance measurement in chronic low back pain: measuring physical capacity or pain-related behaviour? 


\section{Abstract}

In patients with chronic low back pain (CLBP), the level of physical functioning is often evaluated to determine the impact of pain on daily life. When the maximum level of physical performance, defined by the physical capacity, is desired, a test which intends to quantify a person's best physiological possibilities is needed. It seems impossible to eliminate the influence of all non-physiological factors. It appears that in various performance tests the individual influence of physiological and non-physiological factors differ. The main aim of the present review is to discuss the influence of both physiological and non-physiological factors on test performance in patients with CLBP.

Four frequently used types of physical performance tests, with increasing influence of pain-related and psychological factors during test performance will be discussed in depth.

The degree physiological and non-physiological factors influence test outcome differs between the performance tests. The influence of physiological factors is most prominent in (sub)maximal exercise testing, followed by muscle strength testing, and lifting tasks. The influence of non-physiological factors is most prominent in holding endurance tasks, followed by functional performance tasks.

In order to decide which assessment tool for physical performance can best be used for the evaluation of physical functioning in patients with CLBP, one should specifically consider the question that has to be answered. In case a patients' physical capacity has to be objectified, another assessment tool is preferred as compared to a situation in which a patient's behaviour is aimed to be assessed.

\section{Introduction}

In both scientific research and clinical practice, the level of physical functioning in patients with chronic low back pain (CLBP) is often evaluated in order to determine the impact of pain on daily life performance. Valid assessment of physical performance starts with an exact definition of the desired variable to measure. When the maximum level of physical performance, defined by physical capacity, is aimed for, a test that accurately quantifies a person's best physiological possibilities is needed. In this situation, physiological factors (e.g. physical fitness, age, and gender) should, in the most optimal situation, fully explain test outcome. However, in almost every performance test, besides physiological factors also non-physiological (environmental and psychological) factors will influence the eventual test result. The degree to which these physiological and non-physiological factors contribute to outcome differs between the various performance tests. Whereas the outcome of some tests will mainly be influenced by physiological factors and thus approach a person's 
physical capacity, others are mainly influenced by non-physiological factors and will thus better reflect a person's behaviour during testing.

The interpretation of differences on physical performance tests between CLBP patients and pain-free volunteers is complex. On the one hand, patients with CLBP may show physical deconditioning as a result of pain-related inactivity, characterized by a decrease in aerobic capacity and muscle strength. On the other hand, task performance may be influenced by psychological factors, such as fear of movement and pain catastrophizing. Furthermore, current pain intensity and pain increases during task performance can lead to an unwillingness or inability to initiate or carry on with a certain physical exercise.

A review of papers using physical performance testing revealed that comparable performance tests have been used for different purposes: the same tests have been used for the assessment of either a patient's physical capacity level or his (avoidance) behaviour. For example, Kankaanpää et al. used an isometric back extension test to assess physical capacity in patients with CLBP (19) whereas others used a similar trunk extension-flexion test to assess (avoidance) behaviour during physical performance $(1,8)$. It seems that those researchers with a special interest in individuals' maximum physical possibilities, such as physiologists, tend to neglect the influence of non-physiological factors and primarily focus on physiological factors that contribute to test outcome. Whereas researchers in psychology using performance tests as a behavioural measure, tend to underestimate the role of physiological factors and are primarily interested in the influence of psychological and pain-related factors on test outcome.

The aim of the present review is to discuss the influence of both physiological and non-physiological factors on test performance in patients with CLBP. In order to do this, four frequently used types of physical performance tests will be discussed in depth. These types of tests were selected because they are assumed to differ in the relative degree of physiological versus psychological factors that impact on test performance. Finally, advice will be provided, which test is preferable for what study aim.

\section{The influence of physiological and non-physiological factors on performance tests}

\section{1. (Sub)maximal exercise testing to predict VO2-max}

Submaximal exercise tests are designed to reflect a person's level of peak aerobic capacity. Test outcome, maximum oxygen consumption, is estimated from the linear relation between heart rate and oxygen consumptions at a submaximal workload (4). Non-physiological factors are believed to have only a limited influence on 
test outcome. In studies with patients with CLBP, physiological variables such as age, gender, body weight and body composition appeared to be significantly related to the outcome of submaximal exercise testing, whereas psychological (e.g. pain catastrophizing and fear of movement) or pain-related (e.g. pain intensity) factors were not associated with a patient's level of aerobic capacity $(39,40,44)$. Based on this, it could be concluded that the outcome of a submaximal exercise test in fact reflects one's level of peak aerobic capacity.

On the other hand, it has also been reported that pain-related factors can have an indirect influence on test outcome. For instance, Smeets et al. found that, as a result of pain or fatigue, $10-12 \%$ of the patients with CLBP did not reach a predefined heart rate threshold ( 120 beats/min) during cycling necessary to estimate the level of maximal aerobic capacity. Due to this, these patients were excluded from the final study-population, which could create selection bias $(38,39)$. However, although these patients had to stop the test due to pain or fatigue, behavioural factors, such as the level of pain catastrophizing or fear of movement did not differ from those who completed the test $(39,40)$. Another study found that $54 \%$ of patients with CLBP stopped maximal treadmill testing prematurely because of a significant increase in pain intensity (49). Those who stopped because of increased pain scored lower on the mental health subscale of the Short Form 36 Health Survey (49). The test protocol used in this study revealed however, that a maximum heart rate of at least $90 \%$ of the age predicted maximum heart rate (220 - age) had to be reached. This could explain the higher percentage of patients who could not perform a maximal treadmill test in comparison to the percentage of drop-outs in most studies based on submaximal bicycle testing. It can therefore be concluded that (sub)maximal exercise testing can indeed reflect a valid representation of a person's level of physical capacity for patients who are capable of performing and completing the test according to the predefined protocol.

\subsection{Lifting and holding endurance tasks}

Two frequently used lifting tasks are the lifting tasks subset within the Functional Capacity Evaluations (FCEs) and the Progressive Isoinertial Lifting Evaluation (PILE) $(29,32)$. FCEs are standardized batteries of tests aimed to measure a persons' capacity level related to work (32). In FCE assessment, an estimation of one's physical capacity is aimed for. Especially physiological factors should explain test result, whereas psychological and pain-related factors ought to be of minor influence. One of the subsets of the FCE consists of tasks that specifically assess a person's lifting capacity. The PILE measures lifting capacity with a floor-to-waist and waist-to shoulder lift of a box (29).

A review of studies that have evaluated the impact of different factors on performance in these lifting tasks revealed that both physiological and non- 
physiological factors determine outcome. Pain intensity $(13,23,47)$ as well as a patients' expectancy of his/her performance $(3,23,24,32)$ appear to be important determinants of lifting task performance on the FCE. Fear of movement, depression, coping style, and general self-efficacy did not have a significant influence on FCE performance $(33-35,41)$. For the PILE, the level of depressed mood and fear of movement of patients with CLBP negatively affected performance $(2,12,38)$. Thus performance on the FCE lifting tasks as well as the PILE are affected by pain-related and psychological factors and cannot be interpreted as a pure representation of a patient's maximum level of functional capacity.

In addition to these functional lifting tasks, holding endurance tasks have been described that evaluate the duration a patient can hold a specific weight (e.g. holding a bag as long as possible) $(8,45)$. This task has mostly been used to objectify patients' behaviour during testing, instead of someone's level of physical capacity. Pain intensity and the psychological factors fear of movement and pain catastrophizing have all been reported to negatively influence performance during a holding endurance tasks $(8,45)$. Noteworthy is that in contrast to the protocols of the FCE and PILE both studies using this holding endurance task have ignored the impact of physiological factors on task performance. The weight that had to be lifted was identical for all patients independent of age, sex or stature. This means that variability in test performance cannot be uniquely ascribed to voluntary behaviour. Nevertheless, there were clear effects of psychological variables on task performance; taking physiological factors into account could even increase the validity of this test as an indicator of behaviour.

\subsection{Functional tasks}

In several studies functional tasks, such as the 50-foot walk, 5-minute walk test, repeated sit-to-stand, and climbing stairs, have been evaluated $(11,31,36,38)$. These functional tasks have been used to represent the level of physical functioning during the performance of basic daily activities (36). Several studies discussed the influence of non-physiological factors during test performance $(11,31,36,38)$. A higher level of pain intensity had a negative influence on both climbing stairs and sit-to-stand performance. Conflicting or non-significant associations between pain intensity and the duration of walking on the 50-foot walk test and distance walked on the 5-minute walk test were reported $(11,31,36,38)$. Psychological factors appeared to influence test results of functional tasks: Patients with a depressed mood scored worse on the distance walked on the 5-minute walk test, performed slower on the sit-to-stand task and climbed less stairs on the climbing stair task (38). A higher level of internal control of pain was associated with a better performance on the 50-foot walk and stair climbing test (38). No associations were found between fear of movement and performance on the walking, sit-to-stand and climbing tasks 
(38)) or self-efficacy and walking and sit-to-stand tasks (11). Summarizing the findings, the influence of non-physiologcial factors on the outcome of functional performance task were either absent or quite modest. One consideration in interpreting these results is that all of these functional tasks represent common and simple daily life activities that may be very easy to perform for most patients and therefore may not be very sensitive to reflect the effect of either physiological or nonphysiological factors. Also, patients with pain may apply an altered strategy to execute these daily life activities. This last assumption seems to be confirmed by a finding in a study of Slaboda et al. 2008. In this study, lifting patterns of patients with CLBP and healthy volunteers were analyzed. Patients reporting more pain and lower self-efficacy showed a different lifting pattern compared to patients with less pain and higher self-efficacy, whose patterns were similar to that of healthy controls (37). In conclusion, outcomes on functional performance tasks can be affected by pain-related and psychological factors and may be more reflective of pain behaviour then of actual capacity.

\subsection{Muscle strength and muscle endurance testing}

In CLBP research, muscle strength and muscle endurance testing have often been used to evaluate a patient's level of physical fitness. In this way, muscle strength and endurance tests intent to express a patient's physical capacity. One frequently used muscle endurance test is the Biering-Sorensen test which intends to provide information about the maximum endurance of the back extensor muscles (5). During testing, a participant is instructed to keep the unsupported upper part of the body in a horizontal position until maximum fatigue forces one to stop and maximum isometric back endurance is reached. Patients with subacute and chronic low back pain show poorer performance on the Biering Sorensen test than healthy volunteers, $(7,21,26)$. One explanation for the poorer performance may be that due to physical deconditioning, patients with CLBP have a higher proportion of fasttwitch and a lower proportion slow-twitch fibres in the paraspinal muscles as compared to healthy individuals (43). As a consequence, patients with CLBP will fatigue faster and terminate the test earlier than healthy volunteers (28). Several studies indeed reported a decrease in paraspinal muscle size in patients with pain as compared to healthy individuals $(10,15,17,48)$, and in line with the deconditioning paradigm, Keller et al. and Kaser et al. both found that patients with a larger muscle area of paraspinal muscles were those with a higher back muscle strength performance $(20,22)$. However, not all studies found supporting evidence for an explanation in terms of deconditioning and changes in muscle composition. Crossman et al. could not confirm changes in muscle fibre composition in patients with CLBP as compared to healthy volunteers (9). In addition, in other studies, no association between back muscle strength and the size of the paraspinal muscle area $(17,30)$ 
nor the degree of muscle density could be found $(17,22)$. An alternative explanation for the poorer performance in patients with subacute or chronic low back pain could be that patients with CLBP discontinue the Biering-Sorensen test before maximum fatigue is reached because of pain-related fear or because of an actual or expected pain increase due to the exercise. As far as we know, no study so far has evaluated the influence of psychological or pain-related factors on the performance in the Biering-Sorensen test.

A second task, frequently used to evaluate back muscle strength is the Cybex isokinetic trunk extension flexion test $(1,8,22)$. For this task, the influence of psychological and pain-related factors on test performance has been established. Lower anticipation of pain, a lower expected pain increase due to task performance, and a lower level of fear of movement were all associated with better test performance $(1,8)$. Moreover, a higher level of self-efficacy and a lower level of pain at exertion were associated with a higher score during muscle strength testing, although this was only found in male CLBP patients (22). In conclusion, like most other tests, muscle strength and endurance tests seem to be susceptible to the influence of both physiological and non-physiological factors.

However, it might be possible to disentangle the impact of physiological versus non-physiological factors on performance using innovative measurement techniques. Verbunt et al. used a measurement technique allowing to differentiate between actual and maximal muscle strength and the impact of psychological variables during isometric quadriceps muscle strength testing in patients with CLBP (42). Patients were instructed to fully activate the quadriceps muscle to reach a maximum voluntary contraction. During voluntary contraction, the maximal muscle strength of the quadriceps muscle was then activated using a superimposed electrical stimulation. The additional power resulting from electrical stimulation on top of the voluntary contraction resulted in the highest level of muscle strength possible. Subsequently, the voluntary muscle contraction strength was expressed as a percentage of the maximal muscle strength possible, resulting in a measure of one's contraction level. Results showed that for patients with CLBP the voluntary muscle strength was lower than that of healthy individuals. But in addition, their voluntary contraction constituted a lower percentage of the maximal contraction than in healthy controls indicating that patients with CLBP performed submaximally. In addition, within the patients group, muscle contraction level, but not actual muscle strength, was negatively related to both the level of pain intensity and the level of distress (42).

By using this or similar techniques, it may be possible to differentiate between physiological and psychological factors influencing test performance. If this is further developed and optimized, muscle strength testing may be considered as appropriate tasks to assess actual capacity of patients with CLBP. 


\section{Discussion and conclusion}

This review aimed to discuss the influence of both physiological and nonphysiological factors during performance testing in patients with CLBP. In order to achieve information of a patients' level of maximum physical capacity one should choose a test with a minimum influence of pain intensity and psychological factors. In patients with CLBP, we recommend to use a (sub)maximal exercise test for this purpose. However, when a patients' behaviour during testing is the primary interest, a task with a potential high influence of pain-related and psychological factors during testing may be favoured. For this purpose, a holding endurance task is recommended. However, for a valid reflection, one should also consider the influence of age, gender, and deconditioning processes in this situation. In addition, in case one wants to identify the individual influence of physiological and non-physiological during testing, additional measurement techniques, such as the superimposed electrical stimulation, have to be added to the study protocol (42).

In interpreting the results of this review, it is important to consider that pain intensity can have either a direct (short term) or indirect (long term) effect on physical performance. Firstly, on short term, pain can have a direct negative influence on physical functioning, which is non-physiological of origin: Due to a pain increase during testing, a patient can decide to stop or perform sub maximally, which will immediately result in a lower score on the performance test. In addition, as assumed in the pain adaptation model, pain can also have a direct negative physiological influence on test performance by decreasing agonist activity and an increasing antagonist activity (27). In the long term, pain can have an additional negative effect, that is physiological of origin: As assumed in the fear-avoidance model, in patients with a higher level of fear, more pain can lead to fear of movement, characterized by avoidance behaviour (46). Avoidance of activities can lead to physical deconditioning, characterized by lower aerobic capacity and lower muscle strength. Thus a higher pain intensity can cause deconditioning which will cause lower physical functioning, based on a long term physiological origin.

Furthermore, it is important to realize that the influence of physiological and non-physiological factors on physical performance may vary within individuals with CLBP (18). A person's perception on the association between future pain and functioning seems to play an important role in this. Huijnen et al. reported that in patients with CLBP who overpredict their level of activity-related pain, fear of movement was associated with lower muscle strength, whereas no association between performance and fear of movement was present in patients who correctly predict their activity-related pain (16). In addition, a lower back muscle endurance performance was found in patients showing high catastrophizing compared to patients showing low catastrophizing (25). Further differentiation between physiological and non-physiological factors can increase our knowledge of underlying mechanisms for 
performance and can extend the knowledge of subgroups who apply different activity-related strategies. So far, most of the research has focused on the negative influence of fear of movement on physical functioning (46). However, not in all patients perceiving CLBP, fear of movement has a negative effect on functioning (14). There seems to be a subgroup who feels disabled in their functioning but have similar functioning levels compared to healthy volunteers $(6,14)$.

It can be concluded that in order to decide which assessment tool for physical performance can best be used for the evaluation of physical functioning in patients with CLBP, one should specifically consider the question that has to be answered. In case a patients' physical capacity has to be objectified, another assessment tool is preferred as compared to a situation in which a patients' behaviour is aimed to be assessed.

\section{Acknowledgements}

This study was supported by the Council for Medical and Health Research of the Netherlands (ZON-MW), grant nr. 14350042. The authors have no conflicts of interest relevant to this work. 


\section{References}

(1) Al-Obaidi SM, Nelson RM, Al-Awadhi S, and Al-Shuwaie N. The role of anticipation and fear of pain in the persistence of avoidance behavior in patients with chronic low back pain. Spine 2000; 25(9):1126-31.

(2) Alschuler KN, Theisen-Goodvich ME, Haig AJ, and Geisser ME. A comparison of the relationship between depression, perceived disability, and physical performance in persons with chronic pain. Eur J Pain 2008; 12(6):757-64.

(3) Asante AK, Brintnell ES, and Gross DP. Functional self-efficacy beliefs influence functional capacity evaluation. J Occup Rehabil 2007; 17(1):73-82.

(4) Astrand PO, Rodahl K. Textbook of work physiology: physiological base of exercise. 1986, New York: McGraw-Hill.

(5) Biering-Sorensen F. Physical measurements as risk indicators for low-back trouble over a one-year period. Spine (Phila Pa 1976) 1984; 9(2):106-19.

(6) Bousema EJ, Verbunt JA, Seelen HA, Vlaeyen JW, and Knottnerus JA. Disuse and physical deconditioning in the first year after the onset of back pain. Pain 2007; 130(3):279-86.

(7) Brox JI, Storheim K, Holm I, Friis A, and Reikeras O. Disability, pain, psychological factors and physical performance in healthy controls, patients with sub-acute and chronic low back pain: a casecontrol study. J Rehabil Med 2005; 37(2):95-9.

(8) Crombez G, Vlaeyen JW, Heuts PH, and Lysens R. Pain-related fear is more disabling than pain itself: evidence on the role of pain-related fear in chronic back pain disability. Pain 1999; 80(1-2):329-39.

(9) Crossman K, Mahon M, Watson PJ, Oldham JA, and Cooper RG. Chronic low back pain-associated paraspinal muscle dysfunction is not the result of a constitutionally determined "adverse" fibertype composition. Spine (Phila Pa 1976) 2004; 29(6):628-34.

(10) Danneels LA, Vanderstraeten GG, Cambier DC, Witvrouw EE, and De Cuyper HJ. CT imaging of trunk muscles in chronic low back pain patients and healthy control subjects. Eur Spine J 2000; 9(4):26672.

(11) Filho IT, Simmonds MJ, Protas EJ, and Jones S. Back pain, physical function, and estimates of aerobic capacity: what are the relationships among methods and measures? Am J Phys Med Rehabil 2002; 81(12):913-20.

(12) Geisser ME, Haig AJ, and Theisen ME. Activity avoidance and function in persons with chronic back pain. J Occup Rehabil 2000; 10:215-27.

(13) Gross DP, Battie MC. Factors influencing results of functional capacity evaluations in workers' compensation claimants with low back pain. Phys Ther 2005; 85(4):315-22.

(14) Hasenbring MI, Plaas H, Fischbein B, and Willburger R. The relationship between activity and pain in patients 6 months after lumbar disc surgery: Do pain-related coping modes act as moderator variables? Eur J Pain 2006; 10(8):701-9.

(15) Hides J, Gilmore C, Stanton W, and Bohlscheid E. Multifidus size and symmetry among chronic LBP and healthy asymptomatic subjects. Man Ther 2008; 13(1):43-9.

(16) Huijnen IP, Verbunt JA, Peters ML, and Seelen HA. Is physical functioning influenced by activityrelated pain prediction and fear of movement in patients with subacute low back pain? Eur J Pain 2010; 14(6):661-6.

(17) Hultman G, Nordin M, Saraste H, and Ohlsen H. Body composition, endurance, strength, crosssectional area, and density of MM erector spinae in men with and without low back pain. J Spinal Disord 1993; 6(2):114-23.

(18) Hutten MM, Hermens HJ, ljzerman MJ, Lousberg R, and Zilvold G. Distribution of psychological aspects in subgroups of chronic low back pain patients divided on the score of physical performance. Int J Rehabil Res 1999; 22(4):261-8.

(19) Kankaanpaa M, Taimela S, Laaksonen D, Hanninen O, and Airaksinen O. Back and hip extensor fatigability in chronic low back pain patients and controls. Arch Phys Med Rehabil 1998; 79(4):4127. 
(20) Kaser L, Mannion AF, Rhyner A, Weber E, Dvorak J, and Muntener M. Active therapy for chronic low back pain: part 2. Effects on paraspinal muscle cross-sectional area, fiber type size, and distribution. Spine (Phila Pa 1976) 2001; 26(8):909-19.

(21) Keller A, Hellesnes J, and Brox Jl. Reliability of the isokinetic trunk extensor test, Biering-Sorensen test, and Astrand bicycle test: assessment of intraclass correlation coefficient and critical difference in patients with chronic low back pain and healthy individuals. Spine (Phila Pa 1976) 2001; 26(7):771-7.

(22) Keller A, Johansen JG, Hellesnes J, and Brox JI. Predictors of isokinetic back muscle strength in patients with low back pain. Spine 1999; 24(3):275-80.

(23) Lackner JM, Carosella AM. The relative influence of perceived pain control, anxiety, and functional self efficacy on spinal function among patients with chronic low back pain. Spine 1999; 24(21):2254-60; discussion 2260-1.

(24) Lackner JM, Carosella AM, and Feuerstein M. Pain expectancies, pain, functional self-efficacy expectancies as determinants of disability in patients with chronic low back disorders. Journal of consulting and clinical psychology 1996; 64(1):212-220.

(25) Lariviere C, Bilodeau M, Forget R, Vadeboncoeur R, and Mecheri H. Poor back muscle endurance is related to pain catastrophizing in patients with chronic low back pain. Spine (Phila Pa 1976) 2010; 35(22):E1178-86.

(26) Latimer J, Maher CG, Refshauge K, and Colaco I. The reliability and validity of the Biering-Sorensen test in asymptomatic subjects and subjects reporting current or previous nonspecific low back pain. Spine 1999; 24(20):2085-9; discussion 2090.

(27) Lund JP, Donga R, Widmer CG, and Stohler CS. The pain-adaptation model: a discussion of the relationship between chronic musculoskeletal pain and motor activity. Can J Physiol Pharmacol 1991; 69(5):683-94.

(28) Mannion AF, Weber BR, Dvorak J, Grob D, and Muntener M. Fibre type characteristics of the lumbar paraspinal muscles in normal healthy subjects and in patients with low back pain. J Orthop Res 1997; 15(6):881-7.

(29) Mayer TG, Barnes D, Nichols G, Kishino ND, Coval K, Piel B, Hoshino D, and Gatchel RJ. Progressive isoinertial lifting evaluation. II. A comparison with isokinetic lifting in a disabled chronic low-back pain industrial population. Spine (Phila Pa 1976) 1988; 13(9):998-1002.

(30) Mooney V, Gulick J, Perlman M, Levy D, Pozos R, Leggett S, and Resnick D. Relationships between myoelectric activity, strength, and MRI of lumbar extensor muscles in back pain patients and normal subjects. J Spinal Disord 1997; 10(4):348-56.

(31) Murphy D, Lindsay S, and Williams AC. Chronic low back pain: predictions of pain and relationship to anxiety and avoidance. Behav Res Ther 1997; 35(3):231-8.

(32) Reneman MF, Geertzen JH, Groothoff JW, and Brouwer S. General and specific self-efficacy reports of patients with chronic low back pain: are they related to performances in a functional capacity evaluation? J Occup Rehabil 2008; 18(2):183-9.

(33) Reneman MF, Jorritsma W, Dijkstra SJ, and Dijkstra PU. Relationship between kinesiophobia and performance in a functional capacity evaluation. J Occup Rehabil 2003; 13(4):277-85.

(34) Reneman MF, Schiphorts Preuper HR, Kleen M, Geertzen JH, and Dijkstra PU. Are pain intensity and pain related fear related to functional capacity evaluation performances of patients with chronic low back pain? J Occup Rehabil 2007; 17(2):247-58.

(35) Schiphorst Preuper HR, Reneman MF, Boonstra AM, Dijkstra PU, Versteegen GJ, Geertzen JH, and Brouwer S. Relationship between psychological factors and performance-based and self-reported disability in chronic low back pain. Eur Spine J 2008; 17(11):1448-56.

(36) Simmonds MJ, Olson SL, Jones S, Hussein T, Lee CE, Novy D, and Radwan H. Psychometric characteristics and clinical usefulness of physical performance tests in patients with low back pain. Spine 1998; 23(22):2412-21.

(37) Slaboda JC, Boston JR, Rudy TE, and Lieber SJ. Classifying subgroups of chronic low back pain patients based on lifting patterns. Arch Phys Med Rehabil 2008; 89(8):1542-9. 
(38) Smeets RJ, van Geel AC, Kester AD, and Knottnerus JA. Physical capacity tasks in chronic low back pain: what is the contributing role of cardiovascular capacity, pain and psychological factors? Disabil Rehabil 2007; 29(7):577-86.

(39) Smeets RJ, van Geel KD, and Verbunt JA. Is the fear avoidance model associated with the reduced level of aerobic fitness in patients with chronic low back pain? Arch Phys Med Rehabil 2009; 90(1):109-17.

(40) Smeets RJ, Wittink H, Hidding A, and Knottnerus JA. Do patients with chronic low back pain have a lower level of aerobic fitness than healthy controls?: are pain, disability, fear of injury, working status, or level of leisure time activity associated with the difference in aerobic fitness level? Spine 2006; 31(1):90-97.

(41) Soer R, Poels BJ, Geertzen JH, and Reneman MF. A comparison of two lifting assessment approaches in patients with chronic low back pain. J Occup Rehabil 2006; 16(4):639-46.

(42) Verbunt JA, Seelen HA, Vlaeyen JW, Bousema EJ, van der Heijden GJ, Heuts PH, and Knottnerus JA. Pain-related factors contributing to muscle inhibition in patients with chronic low back pain: an experimental investigation based on superimposed electrical stimulation. Clin J Pain 2005; 21(3):23240.

(43) Verbunt JA, Seelen HA, Vlaeyen JW, van de Heijden GJ, Heuts PH, Pons K, and Knottnerus JA. Disuse and deconditioning in chronic low back pain: concepts and hypotheses on contributing mechanisms. Eur J Pain 2003; 7(1):9-21.

(44) Verbunt JA, Seelen HA, Vlaeyen JW, van der Heijden GJ, and Knottnerus JA. Fear of injury and physical deconditioning in patients with chronic low back pain. Arch Phys Med Rehabil 2003; 84(8):1227-32.

(45) Vlaeyen JW, Kole-Snijders AM, Boeren RG, and van Eek H. Fear of movement/(re)injury in chronic low back pain and its relation to behavioral performance. Pain 1995; 62(3):363-72.

(46) Vlaeyen JW, Linton SJ. Fear-avoidance and its consequences in chronic musculoskeletal pain: a state of the art. Pain 2000; 85(3):317-32.

(47) Vowles KE, Gross RT. Work-related beliefs about injury and physical capability for work in individuals with chronic pain. Pain 2003; 101(3):291-8.

(48) Wallwork TL, Stanton WR, Freke M, and Hides JA. The effect of chronic low back pain on size and contraction of the lumbar multifidus muscle. Man Ther 2009; 14(5):496-500.

(49) Wittink H, Rogers W, Gascon C, Sukiennik A, Cynn D, and Carr DB. Relative contribution of mental health and exercise-related pain increment to treadmill test intolerance in patients with chronic low back pain. Spine 2001; 26(21):2368-74. 



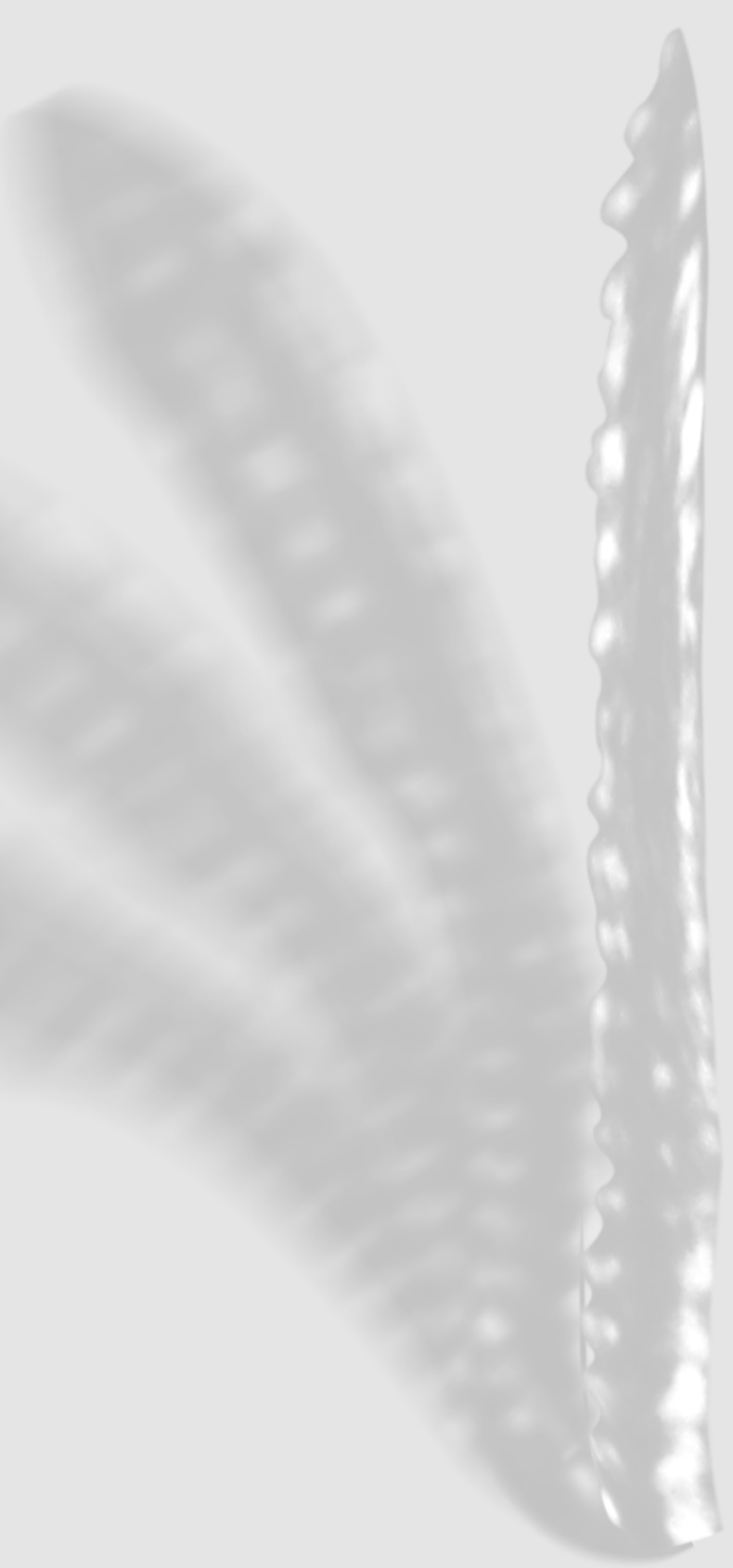




\section{Chapter 3 \\ Is physical functioning influenced by activity-related pain prediction and fear of movement in patients with subacute low back pain?}

This chapter is published as:

Huijnen IP, Verbunt JA, Peters ML, Seelen HA. Is physical functioning influenced by activity-related pain prediction and fear of movement in patients with subacute low back pain? Eur J Pain 2010;14(6):661-666 


\begin{abstract}
In patients with low back pain (LBP), physical functioning may be negatively influenced by both expectations on pain and pain-related fear. It is unclear whether these factors influence both physical functioning in the laboratory as well as in dailylife. The aim of this study was to test if a combination of persistent overprediction of pain and fear of movement predicts lab-based performance and whether these factors are relevant for predicting daily-life functioning.

One hundred and twenty four patients with subacute LBP performed a laboratory-based performance test twice. Maximum voluntary contraction, pre-test pain expectations, perceived pain during testing and fear of movement were measured. Patients were classified as correct or incorrect predictors, based on differences between expected and perceived pain on the second attempt. Next, physical activity in daily-life was measured with an accelerometer.

In explaining physical functioning in the laboratory and in daily-life an interaction effect between fear and pain prediction was observed. In overpredictors, fear was negatively associated with lab-based performance $(\beta=-0.48, p<0.01)$, and positively associated with daily-life functioning $(\beta=0.50, p<0.05)$. No significant association between fear and performance or daily-life functioning were found in correct predictors.

In contrast to correct predictors, in overpredictors lab-based performance and daily-life functioning was additionally explained by fear of movement. Thus it appears that fear of movement is only predictive of performance in patients with LBP who simultaneously overpredict the consequences of movements in terms of painfulness.
\end{abstract}

\title{
1. Introduction
}

Patients with low back pain (LBP) and a high level of fear of movement often show poorer performance on laboratory-based physical tests and feel disabled in daily-life $(14,31)$. However, the association between fear of movement and objectively assessed performance has not consistently been found $(28,33)$. Another factor that may influence physical functioning is overprediction of pain $(6,15)$. Patients with LBP that anticipate more pain than the actual activity may cause, might show avoidance (18). Only two studies directly examined the association between overprediction of pain and poor physical performance in the laboratory. One found that pain prediction was predictive of performance (15) The other did not find an association (8). One reason may be that both studies used the pain prediction score during the first confrontation with the physical performance test. Several studies demonstrated that most patients readily correct an initial overprediction after repeated 
exposure to the same test $(5,6,9,15)$. It may be speculated that patients that do not correct their expectations and persistently overpredict pain are prone to activity avoidance and performance decline.

It is, however, unclear whether fear of movement and overprediction of pain are independent or interdependent risk factors for performance decline. It may be assumed that especially patients with high fear of movement are prone to overestimate the activity-related pain, although previous studies found only weak or contradictory evidence for this $(5,8,9,15)$. An alternative interpretation could be that fear of movement and overprediction of pain interact in the explanation of physical performance, i.e., lower functioning levels may be especially prominent in patients who overpredict activity-related pain and have a higher level of fear of movement.

It can also be questioned whether the results from laboratory-based performance test generalize to daily-life functioning. In the laboratory, patients are confronted with unfamiliar tasks, whereas in daily-life activities are usually recurrent, offering greater potential for adjustments of pain predictions. However, persistent overprediction in the laboratory may be indicative of patients' anticipation of activity-related pain more generally and thereby of activity avoidance in real life as well, thus limiting opportunities to correct an overprediction.

In sum, we tested whether laboratory-based performance is better predicted by the combination of (persistent) overprediction of pain and fear of movement and whether overprediction in the laboratory has relevance for daily-life functioning. Two hypotheses were specified.

1. In patients with subacute LBP who do not correct their overprediction after one repetition of a novel movement, fear of movement has a greater negative impact on performance than in patients who correctly predict pain on the second occasion.

2. Patients persistently overpredicting pain in the laboratory in combination with high pain-related fear also show declines in daily-life functioning.

\section{Methods}

\subsection{Participants}

In this study 124 patients with subacute low back pain (i.e., 4-7 weeks after pain onset) participated (29). Inclusion criteria were: (a) low back pain: pain localized below the scapulae and above the gluteal folds (16), (b) no significant activity limitations due to back pain in the last three months before the actual episode started, (c) age between 18 and 60 (d) no specific cause or strong suspicion of a specific cause, such as lumbar disc herniation with neurological complaints, major structural back abnormality, evidence of inflammatory, systemic or neoplastic disease. Exclusion 
criteria were (a) pregnancy; (b) muscle diseases; (c) serious psychiatric diseases; (d) cardiac pacemaker; and (e) non-fluency in Dutch. Patients were included in two different ways: they were referred by one of 29 general practitioners in South Limburg in the Netherlands or they responded to an advertisement in a local newspaper. To check the above mentioned selection criteria, a physician performed a medical screening according to the clinical guideline for low back pain of the Dutch College of General Practitioners (7). All patients gave their written informed consent prior to participation in the study. The Medical Ethics Committee of the Rehabilitation Foundation Limburg and the Institute for Rehabilitation Research, Hoensbroek, The Netherlands, approved the experimental protocol.

\subsection{Physical measures}

\subsubsection{Physical functioning in a laboratory setting}

Physical functioning in a laboratory setting was measured as the subject's maximum muscle strength, based on isometric muscle strength testing of the quadriceps muscle (Cybex II isokinetic dynamometer, Cybex, Ronkonkoma, NY). This task was chosen as representation for daily-life functioning because, in this test, patients need to anticipate on a new physical challenge. This situation resembles a daily-life situation, in which patients have to deal with many unfamiliar activities. The reliability of isometric muscle strength testing of the quadriceps has been reported as moderate to high (4). Furthermore, the isometric quadriceps torque is related to self-reported physical functioning in patients with osteoarthritis (19). Subjects were asked to gradually build up force to a maximum level and then hold the muscle contraction for 5 seconds. Measurements were performed unilaterally on the preferred leg of the subject and expressed as maximum isometric peak torque. The maximum voluntary contraction (MVC) was standardized per kilogram lean body mass (MVC/LBM). Verbunt described the measurement protocol in detail (27).

\subsubsection{Physical functioning in daily-life}

Physical functioning in daily-life was expressed as the subject's level of physical activity in daily-life assessed by a tri-axial accelerometer (RT3; Stayhealthy Inc., Monrovia, USA). Acceleration signals from the three measurement directions (the sagittal, the mediolateral and the longitudinal axes of the trunk) were amplified and filtered. The resultant of the rectified acceleration from all three directions was calculated. The number of occasions per minute on which this signal exceeded a predefined threshold (counts) was counted. For every minute the number of counts was stored in a database within the accelerometer. Subjects were instructed to wear the RT3 during waking hours for 7 consecutive days. The final total activity

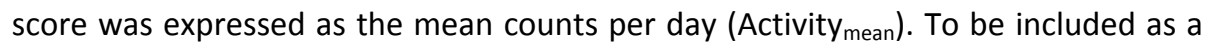
valid physical functioning in daily-life score, at least 5 measurement days, including 
1 weekend day, had to be available (10). The tri-axial accelerometer is a valid instrument for the measurement of physical functioning in daily-life in patients with $\operatorname{LBP}(30)$.

\subsection{Self-report measures}

\subsubsection{Pain intensity}

Immediately prior to the muscle strength effort, when the patient was already sitting on the Cybex chair, expected pain intensity during task performance was rated verbally on a numerical rating scale with extremes of 0 (no pain) and 100 (unbearable pain) (2). In addition, after performing the task, patients were also asked to rate their perceived pain during task performance in an identical way.

\subsubsection{Fear of movement/(re)injury}

The Dutch version of the Tampa Scale for Kinesiophobia measures fear of movement. This questionnaire contains 17 items and is aimed the assessment of fear of (re)injury due to movement. This version has a moderate internal consistency ( $\alpha$ $=0.77)$ and validity (32).

\subsubsection{Disability}

Low back disability was assessed using the Quebec Back Pain Disability Scale (QBPDS). This scale contains 20 items of which each item is rated from 0 (No difficulty performing this activity) to 5 (Impossible to perform this activity). The original as well as the Dutch version of the QBPDS are valid and reliable $(13,23)$.

\subsection{Procedure}

Questionnaires were filled out in the laboratory directly prior to the muscle strength assessment. Both the experimenter and patient were blinded for the exact strength assessment outcome. Data were stored on a computer. Patients were asked to predict pain intensity associated with the muscle strength task. Before the first attempt, each participant verbally rated the expected intensity of pain during test performance. After actual test performance (s)he rated the pain intensity he/she actually perceived during testing. Subsequently, a second attempt based on an identical procedure was made. Before the second attempt patients were again asked to rate their expected pain. After the task perceived pain during the task was rated.

Since we were interested in persistent overprediction of pain, for further analyses the discrepancy in predicted and perceived pain scores during the second attempt were used. The first attempt was performed to become familiar with the task and to allow initial overprediction to be corrected. Differences (D) in pain prediction 
before and perceived pain during physical performance were then calculated by subtracting the level of perceived pain from the level of predicted pain. Based on this score for pain prediction accuracy, patients were classified in three pain prediction subgroups: patients who scored a D of -5 or below were classified as "underpredictor". Patients who scored in between -5 and 5 were labelled as "correct predictor". And finally, patients who scored a D of 5 or above were classified as "overpredictor".

\subsection{Data analysis}

In order to study the association between both fear of movement and pain prediction and physical functioning in the laboratory a hierarchical regression analysis was used. In the first step, MVC/LBM was the dependent variable in the model, and fear of movement (TSK), age, gender, and pain prediction group were introduced in the model as independent variables. In the second step the interaction term (fear $\mathrm{x}$ pain prediction group) was introduced. Furthermore, in case of a significant interaction, additional regression analyses were performed for both groups separately to identify influencing factors for physical functioning.

In order to study whether pain prediction in the laboratory is also associated with physical functioning in daily-life, a hierarchical regression analysis was performed with Activity mean as the dependent variable and MVC/LBM, TSK, age, gender, and pain prediction group as the independent variables in the first step. We included MVC/LBP as an independent variable in the model to verify that the chosen performance test has indeed relevance for daily-life performance. In the second step of the regression analyses the interaction between fear of movement and the pain prediction groups was added. If this interaction was significant, again additional regression analyses were performed for both pain prediction groups separately. In this, Activity mean was the dependent variable and MVC/LBM, TSK, age, and gender were the independent variables. For all regression analyses, a colinearity check was performed. Colinearity was considered a problem when the variance inflation factor (VIF) was above 3. Alpha was set at 0.05. All statistical analyses were performed using SPSS software (SPSS Inc., Chicago, III.).

\section{Results}

\subsection{Descriptive analyses}

Mean age of the 124 patients (66 male and 58 female) was 44.1 years (SD=10.3). Thirteen patients were excluded from the analyses. Reasons for exclusions were; no measurement of physical functioning in daily-life $(N=9)$ or laboratory $(N=2)$, no 
registration of the pain prediction $(\mathrm{N}=1)$ or non-completion of the questionnaire ( $N$ $=1$ ). Reasons for the absence of data on physical functioning in daily-life measurement were failure of the RT3 $(\mathrm{N}=6)$ or an inadequate assessment period (less than 5 days) for the RT3 $(\mathrm{N}=3)$. Patients included and excluded from further analysis were not significantly different as to age, gender or disability level. Frequencies per pain prediction group showed that for the first pain prediction, 62 patients overpredicted, 43 correctly predicted and five underpredicted their pain. As expected, overprediction of pain was readily corrected after the initial experience with the performance test in many patients. Prediction of pain for the second performance was accurate in 73 patients, 30 patients still overpredicted pain. Table 1 presents the patient characteristics per pain prediction group (based on the second performance test). The sample of the group "underpredictors" comprised only eight persons and was not included in any further analysis. There were no differences in age, gender, paid job, sick leave, or disability payment, between patients that overpredicted their pain $(\mathrm{N}=30)$ and patients that predicted their level of activity-related pain correctly ( $N=73$ ). Furthermore, the level of fear of movement, and disability did not differ between the overprediction and correct prediction group.

Table1: Characteristics of the study population

\begin{tabular}{llll}
\hline & $\begin{array}{l}\text { Underprediction } \\
\text { group }(\mathrm{n}=8)\end{array}$ & $\begin{array}{l}\text { Overprediction group } \\
(\mathrm{n}=30)\end{array}$ & $\begin{array}{l}\text { Correct prediction } \\
\text { group }(\mathrm{n}=73)\end{array}$ \\
\hline Male/Female & $5 / 3$ & $18 / 12$ & $36 / 37$ \\
Age & $42.2(13.6)$ & $44.1(11.0)$ & $44.7(9.9)$ \\
Work status (percentage) & & & \\
- Paid job & $6(75 \%)$ & $22(73 \%)$ & $50(69 \%)$ \\
- Sick leave & 0 & $3(10 \%)$ & $12(16 \%)$ \\
- Disability payment & 0 & $1(3 \%)$ & $7(10 \%)$ \\
TSK * & $38.8(6.1)$ & $35.1(8.6)$ & $36.1(7.3)$ \\
QBPDS ** & $41.9(16.4)$ & $36.5(18.0)$ & $42.2(17.7)$ \\
\hline
\end{tabular}

* TSK = Tampa Scale for Kinesiophobia; ** QBPDS = Quebec Back Pain Disability Scale

\subsection{The influence of pain prediction and fear of movement on physical functioning in the laboratory}

In table 2 the outcome of the regression analysis with physical functioning in the lab as dependent variable is presented. The inclusion of the variables in the first step did not yield a significant model. Thus, neither fear of movement nor overprediction of pain were associated with laboratory-based performance on their own. In the second step of this regression model the interaction term fear $\mathrm{x}$ pain prediction group was added which resulted in a significant model. The interaction contributed to the explanation of physical functioning in the lab. Figure 1 presents the interaction between fear of movement and prediction subgroup for physical functioning in 
the laboratory. As can be seen from the figure, in correct predictors, fear of movement was not associated with physical functioning in the lab.

Table 2: Regression analyses with physical functioning in the laboratory as dependent variable

\begin{tabular}{|c|c|c|c|c|}
\hline & Independent variables & $\mathbf{R}^{2}$ & Adjusted $\mathbf{R}^{2}$ & Standardized $\beta$ \\
\hline \multicolumn{5}{|l|}{ Step 1: } \\
\hline \multirow[t]{4}{*}{ MVC/LBM } & Age & 0.08 & 0.04 & -0.12 \\
\hline & Gender & & & 0.18 \\
\hline & TSK & & & -0.16 \\
\hline & Pain prediction subgroups & & & -0.00 \\
\hline \multicolumn{5}{|l|}{ Step 2: } \\
\hline MVC/LBM & Pain prediction $\mathrm{x}$ TSK & $0.16 * *$ & $0.12 * *$ & $0.49 * *$ \\
\hline
\end{tabular}

$* * \mathrm{p}<0.01$

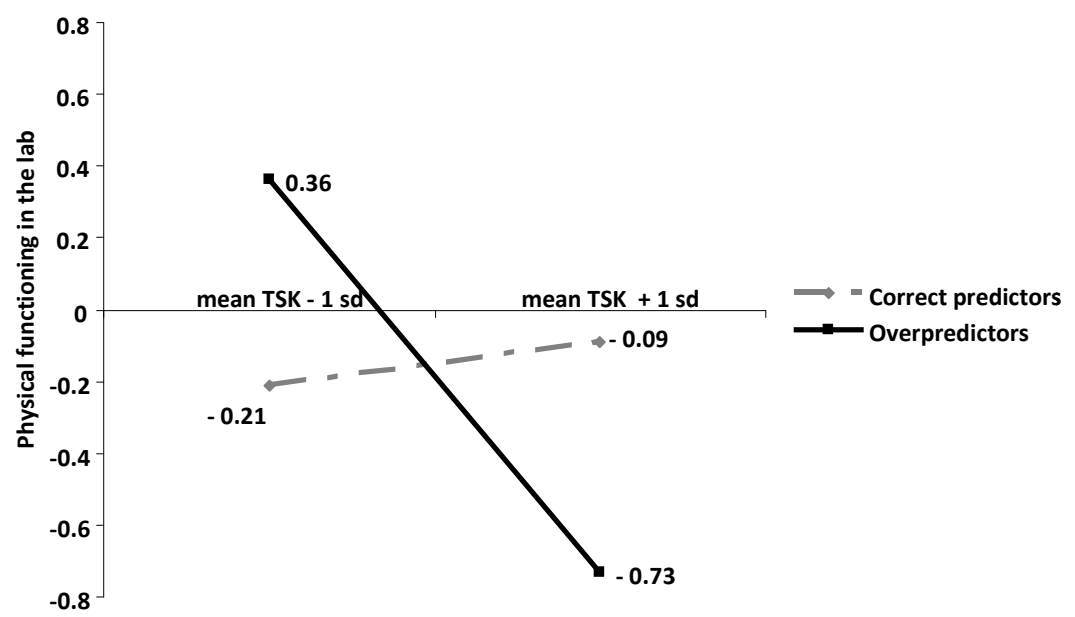

Figure 1: The interaction between fear of movement and pain prediction subgroup for physical functioning in the lab

However, for overpredictors an increase in the level of fear was associated with a decrease in laboratory-based physical functioning. To further explore the influencing factors for physical functioning within the overpredictor and correct predictor subgroup additional regression analyses per pain prediction group were performed (Table 3). In the overpredictor group a significant model was found. Age and fear of movement were significant predictors. In the correct predictor group no significant model was found. 
Table 3: Regression analyses with physical functioning in the laboratory as dependent variable within the overprediction and correct prediction group

\begin{tabular}{llccc}
\hline & Independent variables & $\mathbf{R}^{\mathbf{2}}$ & Adjusted $\mathbf{R}^{\mathbf{2}}$ & Standardized $\boldsymbol{\beta}$ \\
\hline Overpredictors: & & & & \\
MVC/LBM & Age & $0.45^{* *}$ & $0.39^{* *}$ & $-0.35^{*}$ \\
& Gender & & & 0.05 \\
& TSK & & & $-0.48^{* *}$ \\
\hline Correct predictors: & & & \\
MVC/LBM & Age & 0.04 & 0.00 & 0.01 \\
& Gender & & & 0.19 \\
& TSK & & & 0.06 \\
\hline
\end{tabular}

$* p<0.05, * * p<0.01$

\subsection{The association between pain prediction in the lab and daily-life physical functioning}

Table 4 presents the regression model with physical functioning in daily-life as dependent variable. As the first step in the analysis shows, physical functioning in daily-life is related to physical functioning in the lab and age. There were no main effects of pain prediction group or fear of movement. However, in the second step of the analyses, a significant interaction was found between pain prediction group and fear of movement.

Table 4: $\quad$ Regression analyses with physical functioning in daily life as dependent variable

\begin{tabular}{|c|c|c|c|c|}
\hline & Independent variables & $\mathbf{R}^{2}$ & Adjusted $\mathbf{R}^{2}$ & Standardized $\beta$ \\
\hline \multicolumn{5}{|l|}{ Step 1: } \\
\hline \multirow[t]{5}{*}{ Activity $_{\text {mean }}$} & $\mathrm{MVC} / \mathrm{LBM}$ & $0.17 * *$ & $0.12^{* *}$ & $0.20 *$ \\
\hline & Age & & & $-0.23^{*}$ \\
\hline & Gender & & & 0.15 \\
\hline & TSK & & & 0.12 \\
\hline & Pain prediction subgroups & & & -0.07 \\
\hline \multicolumn{5}{|l|}{ Step 2: } \\
\hline Activity $_{\text {mean }}$ & Pain prediction $\mathrm{x}$ TSK & $0.20 * *$ & $0.15^{* *}$ & $-0.33 *$ \\
\hline
\end{tabular}

$* \mathrm{p}<0.05, * * \mathrm{p}<0.01$ 


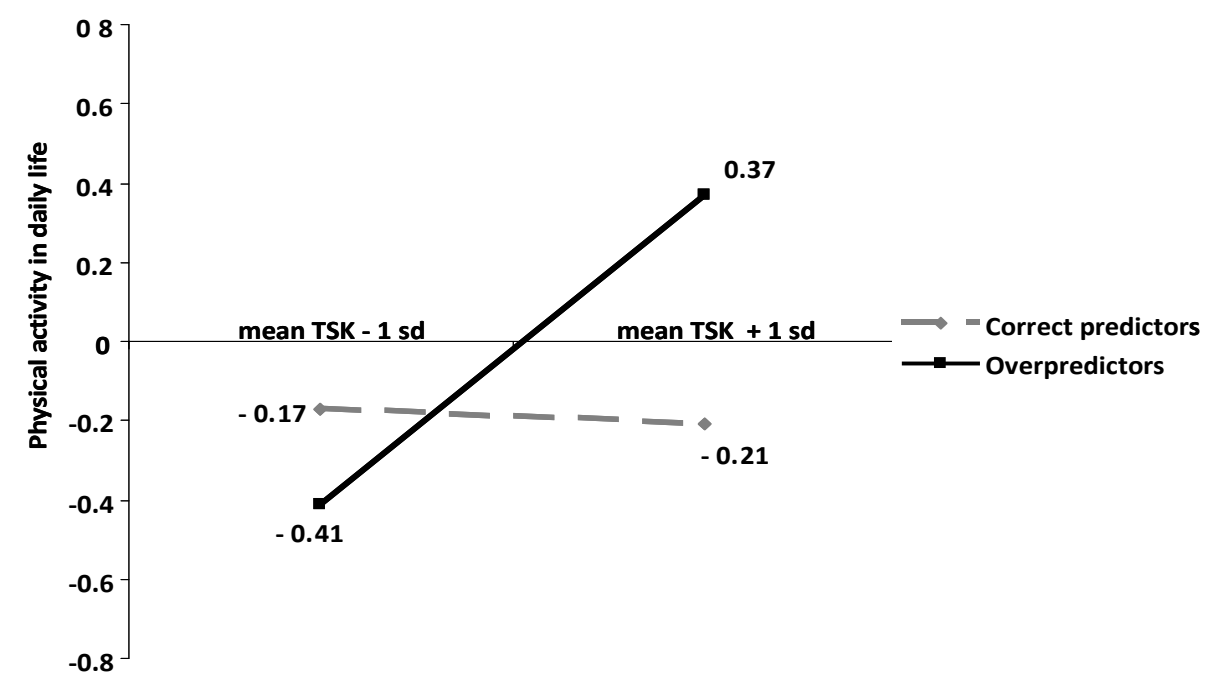

Figure 2: The interaction between fear of movement and pain prediction subgroup for physical functioning in daily life

Figure 2 presents the interaction between fear of movement and pain prediction group for physical functioning in daily-life. Whereas for the correct predictors fear of movement was not associated with daily-life functioning, for overpredictors, an increase in the level of fear of movement was associated with an increase in the level of physical functioning in daily-life. Table 5 presents the regression models per pain prediction group with physical functioning in daily-life as dependent variable. Only in the overpredictor group, fear of movement was significantly related to physical functioning in daily-life. In all analyses, VIF factors were below 1.9 and no outliers appeared to be present.

Table 5: $\quad$ Regression analyses with physical functioning in daily life as dependent variable within the overprediction and correct prediction group

\begin{tabular}{|c|c|c|c|c|}
\hline & Independent variables & $\mathbf{R}^{2}$ & Adjusted $\mathrm{R}^{2}$ & Standardized $\beta$ \\
\hline \multicolumn{5}{|c|}{ Overpredictors: } \\
\hline \multirow[t]{4}{*}{ Activity $_{\text {mean }}$} & MVC/LBM & 0.29 & 0.17 & 0.25 \\
\hline & Gender & & & -0.13 \\
\hline & Age & & & -0.41 \\
\hline & TSK & & & $0.50^{*}$ \\
\hline \multicolumn{5}{|c|}{ Correct predictors: } \\
\hline \multirow[t]{4}{*}{ Activity $_{\text {mean }}$} & MVC/LBM & $0.19 * *$ & $0.15^{* *}$ & $0.25^{*}$ \\
\hline & Gender & & & $0.23^{*}$ \\
\hline & Age & & & $-0.22 *$ \\
\hline & TSK & & & -0.03 \\
\hline
\end{tabular}

$* p<0.05, * * p<0.01$ 


\section{Discussion}

This study aimed to evaluate the influence of persistent overprediction of activityrelated pain prediction and fear of movement on physical performance in the laboratory for patients with subacute low back pain. A second aim was to examine the influence of fear of movement and pain prediction on daily-life functioning.

The results indicated that in patients that correctly predict activity-related pain, fear of movement does not influence their lab-based performance, in contrast to persistent overpredictors in whom a higher level of fear was associated with a lower performance level. This last finding supports the role of fear of movement in the overprediction group as described in the fear-avoidance model $(14,31)$. This model describes how pain patients who are afraid of injury will have lower physical functioning levels compared to healthy individuals and who thus are prone to develop a deconditioning syndrome. In cases where persistent overprediction of activityrelated pain is associated with higher levels of fear of movement, these patients may belong to a subgroup at risk for chronification of pain and development of this deconditioning syndrome. Deconditioning could not be confirmed in patients with chronic low back pain. However, pain-related fear and persistently overpredictions of activity-related pain were not taken into account $(3,28,33,34)$.

Furthermore, the influence of pain-related fear on physical capacity could not be unequivocally established. Whereas some studies indicate that, based on painrelated fear, patients who have lower levels of physical functioning can be distinguished from those who have levels comparable to healthy individuals $(1,8,22,27)$, others found no influence of fear on functional capacity and maximum oxygen consumption $(21,24)$. A possible reason for this could be that in the latter studies the patients with LBP were not divided into correct predictors and overpredictors of activity-related pain, and thus masking any influence of pain-related fear in the whole population of patients with LBP. Since lab performance testing is often used to simulate a patient's functioning in daily-life, it is important to realise that for patients who overpredict activity-related pain a result from a performance test may be influenced by pain-related fear, which, in turn, may limit the generalizability to daily-life functioning.

In all patients, physical performance in the laboratory was marginally associated with their daily-life functioning, but in contrast to the laboratory findings, in dailylife it appeared that patients who overpredicted their activity-related pain and experience more fear have a higher physical activity level in daily-life. These contrasting findings on the effect of fear and the accuracy of activity-related pain prediction in either a lab-based or daily-life situation are intriguing. It could be that patients who have high fear scores, will perform activities in daily-life, but in a different manner $(25,26)$. In the experiments by Thomas, patients with subacute low back pain had to reach three targets at a comfortable and a fast pace. Motion of the 
thoracic spine, lumbar spine, and hip were recorded. Patients with high pain-related fear indeed completed the movement but with a different strategy; they avoided motion of their lumbar spine (25). Furthermore, they performed the fast pace reaching tasks with smaller peak velocities and smaller accelerations (26). In a lab situation, patients are not able to choose their own performance strategy, since the activity often has to be performed according to a fixed protocol. The only possible way to cope with a feared activity is to submaximally perform during this activity. In our study, there was no alternative strategy possible to perform the quadriceps task, which could have resulted in submaximal performance for patients with high pain-related fear and overprediction. In contrast, in daily-life, patients can use different performance strategies in order to reach the same goal. To avoid a feared activity (e.g., cycling) an alternative activity (e.g., walking) might be chosen to, eventually, reach the same goal (e.g., arriving at the shop). In this example the alternative strategy (walking) necessitates even more energy expenditure as compared to the avoided activity (cycling), eventually resulting in a higher level of physical activity in daily-life as a result of fear.

One limitation of the current study is the low number of patients that underpredicted their pain, which hampered processing the data of this group in the statistical analyses. The question thus remains, whether underpredictors, who do not seem to anticipate on an activity-related pain increase, indeed experience a pain increase after strenuous activities in their daily-life functioning. It is hypothesized that this could be the group of patients with chronic pain with the highly fluctuating activity pattern as described in the avoidance endurance model $(11,12)$. In addition, in the current study, information on expected pain and perceived pain out of the lab situation was used as an indicator for activity-related pain prediction during physical performance in daily-life. This raises the question whether patients that overpredict pain in the laboratory also overestimate a pain increase as a result of a strenuous activity resulting in avoidance of these activities during the day. It was hypothesized that this group of patients do not participate in many strenuous activities that lead to an increase of pain. To further unravel the interaction between activity, fear and pain in daily-life, additional information could be gathered by combining daily activity assessment using an accelerometer, in combination with a diary in which pain, fear and even expectations will be registered.

An other limitation of this study is the use of a verbal numerical rating scale for expected and perceived pain that is a 101 point scale. However, patients tend to use 5 or 10 point steps reducing it to a 21 points scale. Furthermore, patients remember their expected pain score and this may influence their perceived pain. In this study we chose to interpret a score between -5 and 5 as a correct prediction in contrast to research on the match-mismatch model. In the latter studies pain was rated on a 10 $\mathrm{cm}$ visual analogue scale and a score between -2 and 2 was interpreted as a correct prediction $(17,20)$. 
This study has several clinical implications. In evaluating the functioning of the patient with subacute LBP with a physical task, in patients that persistently overpredict their activity-related pain, higher levels of fear of movement are associated with a lower performance. This group of patients could be prone to develop a deconditioning syndrome with a higher disability level as described in the fear-avoidance model. Furthermore, in evaluating functioning with a performance task in which nonphysiological factors can influence performance, it is important to realise that overpredictions of pain and pain-related fear can influence with the test outcome.

In summary, in the current study in patients who do not correct their overprediction of pain after a physical performance in the laboratory, higher levels of painrelated fear were associated with a lower performance level in a laboratory setting, whereas in daily-life functioning this was associated with a higher functioning level. For patients that predicted their pain correctly, pain-related fear had no influence on lab-based performance or daily-life functioning.

\section{Acknowledgement}

This study was supported by the Council for Medical and Health Research of the Netherlands (ZON-MW), Grant No. 14350042. 


\section{References}

(1) Al-Obaidi SM, Nelson RM, Al-Awadhi S, and Al-Shuwaie N. The role of anticipation and fear of pain in the persistence of avoidance behavior in patients with chronic low back pain. Spine 2000; 25(9):1126-31.

(2) Bolton JE. Accuracy of recall of usual pain intensity in back pain patients. Pain 1999; 83(3):533-9.

(3) Brox Jl, Storheim K, Holm I, Friis A, and Reikeras O. Disability, pain, psychological factors and physical performance in healthy controls, patients with sub-acute and chronic low back pain: a casecontrol study. J Rehabil Med 2005; 37(2):95-9.

(4) Carpenter MR, Carpenter RL, Peel J, Zukley LM, Angelopoulou KM, Fischer I, Angelopoulos TJ, and Rippe JM. The reliability of isokinetic and isometric leg strength measures among individuals with symptoms of mild osteoarthritis. J Sports Med Phys Fitness 2006; 46(4):585-9.

(5) Crombez G, Eccleston C, Vlaeyen JW, Vansteenwegen D, Lysens R, and Eelen P. Exposure to physical movements in low back pain patients: restricted effects of generalization. Health Psychol 2002; 21(6):573-8.

(6) Crombez G, Vervaet L, Baeyens F, Lysens R, and Eelen P. Do pain expectancies cause pain in chronic low back patients? A clinical investigation. Behav Res Ther 1996; 34(11-12):919-25.

(7) Faas A, Chavannes AW, Koes BW, van den Hoogen JMM, Mens JMA, Smeele LM, Romeijnders ACM, and van der Laan JR. NHG-standaard M54 lage-rugpijn. 1996.

(8) Goubert L, Crombez G, and Lysens R. Effects of varied-stimulus exposure on overpredictions of pain and behavioural performance in low back pain patients. Behav. Res. Ther. 2005; 43(10):1347-1361.

(9) Goubert L, Francken G, Crombez G, Vansteenwegen D, and Lysens R. Exposure to physical movement in chronic back pain patients: no evidence for generalization across different movements. Behav Res Ther 2002; 40(4):415-29.

(10) Gretebeck RJ, Montoye HJ. Variability of some objective measures of physical activity. Med Sci Sports Exerc 1992; 24(10):1167-72.

(11) Hasenbring $M$, Hallner $D$, and Klasen B. (Psychological mechanisms in the transition from acute to chronic pain: over- or underrated?). Schmerz 2001; 15(6):442-7.

(12) Hasenbring MI, Plaas $\mathrm{H}$, Fischbein B, and Willburger $\mathrm{R}$. The relationship between activity and pain in patients 6 months after lumbar disc surgery: Do pain-related coping modes act as moderator variables? Eur J Pain 2006; 10(8):701-9.

(13) Kopec JA, Esdaile JM, Abrahamowicz M, Abenhaim L, Wood-Dauphinee S, Lamping DL, and Williams JI. The Quebec Back Pain Disability Scale. Measurement properties. Spine 1995; 20(3):341-52.

(14) Leeuw M, Goossens ME, Linton SJ, Crombez G, Boersma K, and Vlaeyen JW. The fear-avoidance model of musculoskeletal pain: current state of scientific evidence. J Behav Med 2007; 30(1):77-94.

(15) McCracken LM, Gross RT, Sorg PJ, and Edmands TA. Prediction of pain in patients with chronic low back pain: effects of inaccurate prediction and pain-related anxiety. Behav Res Ther 1993; 31(7):647-52.

(16) Merskey H, Bogduk N. Classification of chronic pain. IASP Task force on taxonomy, ed. S. edition. 1994, Seattle: IASP press.

(17) Murphy D, Lindsay S, and Williams AC. Chronic low back pain: predictions of pain and relationship to anxiety and avoidance. Behav Res Ther 1997; 35(3):231-8.

(18) Philips HC. Avoidance behaviour and its role in sustaining chronic pain. Behav Res Ther 1987; 25(4):273-9.

(19) Pua YH, Wrigley TV, Collins M, Cowan SM, and Bennell KL. Self-report and physical performance measures of physical function in hip osteoarthritis: relationship to isometric quadriceps torque development. Arthritis Rheum 2009; 61(2):201-8.

(20) Rachman S, Lopatka C. Accurate and inaccurate predictions of pain. Behav Res Ther 1988; 26(4):291-6. 
(21) Reneman MF, Schiphorts Preuper HR, Kleen M, Geertzen JH, and Dijkstra PU. Are pain intensity and pain related fear related to functional capacity evaluation performances of patients with chronic low back pain? J Occup Rehabil 2007; 17(2):247-58.

(22) Rudy TE, Lieber SJ, Boston JR, Gourley LM, and Baysal E. Psychosocial predictors of physical performance in disabled individuals with chronic pain. Clin J Pain 2003; 19(1):18-30.

(23) Schoppink LE, van Tulder MW, Koes BW, Beurskens SA, and de Bie RA. Reliability and validity of the Dutch adaptation of the Quebec Back Pain Disability Scale. Phys Ther 1996; 76(3):268-75.

(24) Smeets RJ, Wittink H, Hidding A, and Knottnerus JA. Do patients with chronic low back pain have a lower level of aerobic fitness than healthy controls?: are pain, disability, fear of injury, working status, or level of leisure time activity associated with the difference in aerobic fitness level? Spine 2006; 31(1):90-7; discussion 98.

(25) Thomas JS, France CR. Pain-related fear is associated with avoidance of spinal motion during recovery from low back pain. Spine 2007; 32(16):E460-6.

(26) Thomas JS, France CR, Lavender SA, and Johnson MR. Effects of fear of movement on spine velocity and acceleration after recovery from low back pain. Spine 2008; 33(5):564-70.

(27) Verbunt JA, Seelen HA, Vlaeyen JW, Bousema EJ, van der Heijden GJ, Heuts PH, and Knottnerus JA. Pain-related factors contributing to muscle inhibition in patients with chronic low back pain: an experimental investigation based on superimposed electrical stimulation. Clin J Pain 2005; 21(3):23240.

(28) Verbunt JA, Seelen HA, Vlaeyen JW, van der Heijden GJ, and Knottnerus JA. Fear of injury and physical deconditioning in patients with chronic low back pain. Arch Phys Med Rehabil 2003; 84(8):1227-32.

(29) Verbunt JA, Sieben JM, Seelen HA, Vlaeyen JW, Bousema EJ, van der Heijden GJ, and Knottnerus JA. Decline in physical activity, disability and pain-related fear in sub-acute low back pain. Eur.J.Pain 2005; 9(4):417-425.

(30) Verbunt JA, Westerterp KR, van der Heijden GJ, Seelen HA, Vlaeyen JW, and Knottnerus JA. Physical activity in daily-life in patients with chronic low back pain. Arch Phys Med Rehabil 2001; 82(6):72630.

(31) Vlaeyen JW, Linton SJ. Fear-avoidance and its consequences in chronic musculoskeletal pain: a state of the art. Pain 2000; 85(3):317-32.

(32) Vlaeyen JWS, Kole-Snijders AMJ, Rotteveel AM, Ruesink R, and Heuts PH. The role of fear of movement/(re)injury in pain disability. Journal of occupational rehabilitation 1995; 5(5):235-252.

(33) Wittink H, Hoskins Michel T, Wagner A, Sukiennik A, and Rogers W. Deconditioning in patients with chronic low back pain: fact or fiction? Spine 2000; 25(17):2221-8.

(34) Wittink H, Michel TH, Sukiennik A, Gascon C, and Rogers W. The association of pain with aerobic fitness in patients with chronic low back pain. Arch Phys Med Rehabil 2002; 83(10):1467-71. 


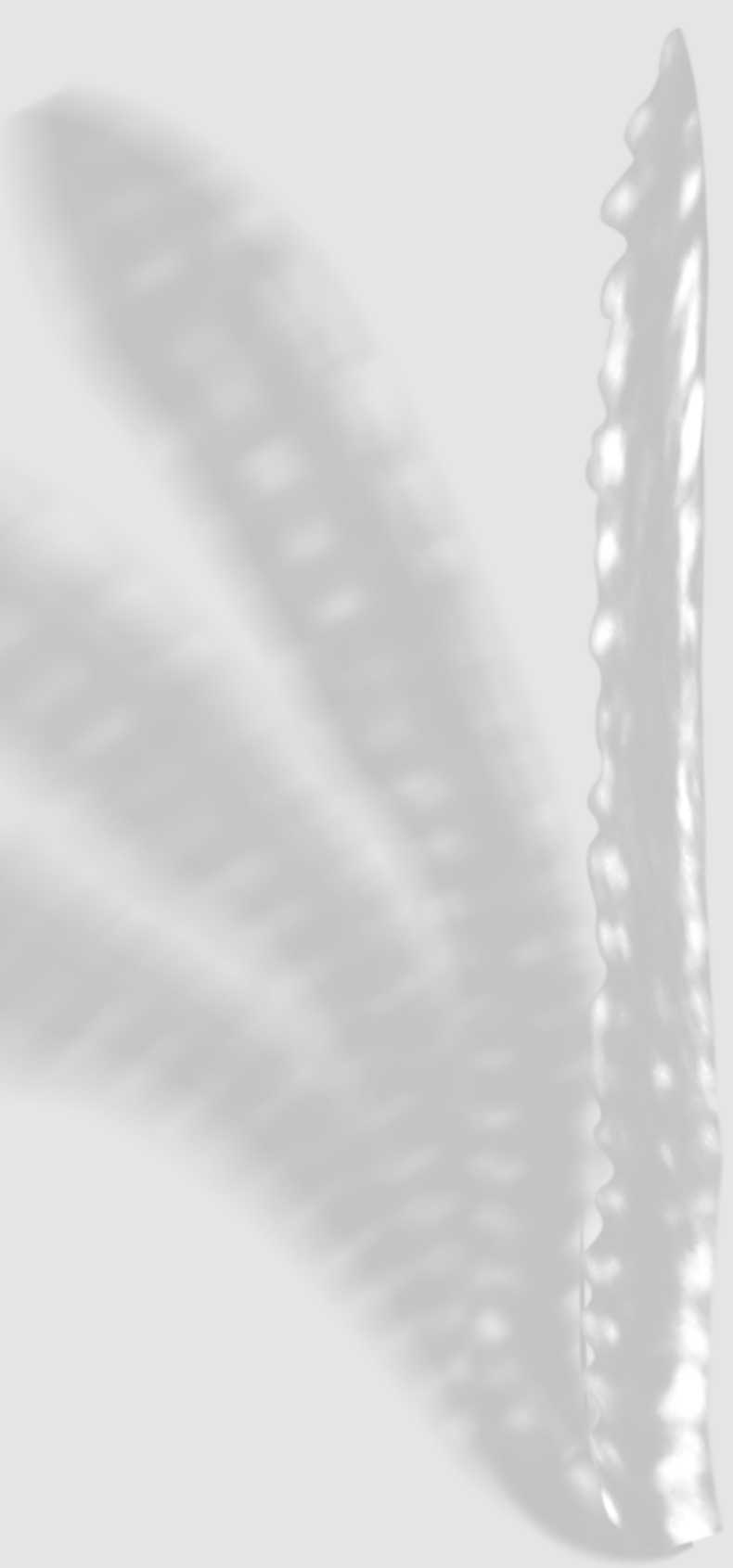




\section{Chapter 4}

\section{Assessment of physical activity in daily life in patients with musculoskeletal pain}

This chapter is published as:

Verbunt JA, Huijnen IP, Köke A. Assessment of physical activity in daily life in patients with musculoskeletal pain. Eur J Pain 2009;13(3):231-242 


\begin{abstract}
Patients with musculoskeletal pain often report limitations in daily functioning due to pain. Recently, the World Health Organisation (WHO) recommended in their International Classification of Functioning, Disability and Health (ICF) to accentuate patients remaining possibilities in functioning instead of focussing on restrictions. In patients with musculoskeletal pain, this would imply that a person's "daily activity level" rather than his/her "disability level" has to be focussed upon. At this moment, broad consensus about how to measure physical activity in daily life in patients with pain has not been established.

The objectives of this study were twofold, firstly to identify instruments assessing the level of physical activity in daily life in patients with musculoskeletal pain and secondly to review psychometric properties of the instruments identified. In all, 42 articles derived from the literature on musculoskeletal pain were included in the review. Thirty four assessment instruments for physical activity were identified; fourteen questionnaires, ten diaries and ten instruments based on movement registration. Only, 10 out of these 34 instruments contained full or partial information regarding pain specific psychometric properties. At this moment, for quantitative assessment of physical activity, movement registration seems to be favoured based on its higher degree of objectivity in comparison with self report. Taken together more research is needed to evaluate psychometric properties of instruments measuring physical activity in musculoskeletal pain.
\end{abstract}

\title{
1. Introduction
}

Patients with musculoskeletal pain often report an undesired reduction of their daily activity level. This impact of pain on a patient's daily functioning is generally expressed as a patient's level of disability. According to the International Classification of Impairments, Disabilities and Handicaps (ICIDH) disability has been defined as "any restriction or lack of ability to perform an activity in the manner or within the range considered normal for a human being" (WHO, 66). Consequently, numerous assessment instruments for disability have been developed and evaluated. In recent years, however, interest has shifted to the patient's remaining possibilities in functioning instead of his/her disability level. In 2001 the WHO replaced the ICIDH by the International Classification of Functioning, disability and health (ICF: WHO, 67). Whereas the ICIDH concentrated on impairment, disability, and handicap to illustrate the impact of illness or disease, the ICF focusses on the patient's residual functional capacity despite disease. In the ICF concept "activity" more than "disability" has become an important parameter for daily functioning. 
However, regardless this conceptual change daily functioning is most of the time still evaluated as pain related disability instead of accentuating remaining abilities despite pain. Although the concepts of "activity" and "disability" share many similarities as they both reflect the impact of pain on daily functioning, they are not identical. The association between a patient's disability level and the level of daily physical activity appeared to be only low or non-existing in patients with chronic low back pain (57). In addition, in clinical (rehabilitation) practice, assessment of a patient's activity level seems favoured above disability assessment. Activity plans representing a gradual increase of a patient's activity level rather than assessing a decrease in disability during treatment seem better related to a patient's perspective and emphasize self management. Although the advantage of activity assessment in pain seems clear, a recent overview of available information on activity assessment is still lacking.

In order to review literature on physical activity and musculoskeletal pain, it is important to set a clear definition of the concept "physical activity". The WHO refers to physical activity as "any bodily movement produced by skeletal muscle that results in a substantial increase over the resting energy expenditure" $(10, \mathrm{WHO}, 68)$. In the WHO classification of functioning (ICF) activity is referred to as "the execution of a task or action by an individual". In addition activity limitations are "difficulties an individual may have in executing activities." A clear distinction between the concepts physical activity and physical exercise has to be made. Physical exercise is defined as a particular type of physical activity that is not incidental but planned and structured, with the aim of improving or maintaining various aspects of physical fitness (WHO, 68).

The aims of the present study are:

- To identify methods for the assessment of the level of physical activity in daily life as presented in the literature on musculoskeletal pain.

- To present psychometric properties of the instruments identified.

\section{Methods}

\subsection{Search strategy}

A systematic search was conducted including the following literature databases: Medline, Cinahl, Embase and PsycINFO. All databases were searched from the beginning of each database up to December 2006. Keywords used in the search strategy were:

Outcome and assessment with the synonyms: (Questionnaire OR Observation OR Diary OR ESM OR Actometer OR Pedometer OR Accelerometer OR Activity and monitoring OR Ambulatory and monitoring) AND Activities and daily and living with 
the synonyms:(Leisure and activities OR Work and activities OR Sport and activities OR Physical and activity) AND Musculoskeletal and pain with the synonyms: (Back and pain OR Neck and pain OR Shoulder and pain OR Fibromyalgia OR Whiplash OR (Cumulative AND trauma AND disorders)).

Articles describing a study based on animal research, and research focussing on acute post surgery pain were excluded by entering the search term "NOT" in the search strategy. Inclusion criteria were defined and used to acquire all relevant literature. In order to be included a paper had to meet the following criteria:

The article had to:

- Describe results based on a study in patients with musculoskeletal pain.

- Describe a study in adults.

- Be written in English, Dutch, French or German.

- Express results based on at least one assessment instrument of physical activity in daily life.

\subsection{Study Selection}

In the first step, two of the authors (JV and IH) independently reviewed the titles of the studies that were selected based on a search with the presented key words and their synonyms. The above presented inclusion criteria one to three were applied. In the second step, the abstracts of the studies selected in the initial step were read and all inclusion criteria were applied. Both reviewers reviewed the abstracts independently. The abstracts that fulfilled all four inclusion criteria were included for the full text selection. In case not enough information was presented in the abstract, the study was included for full text reading. Furthermore, the selection of papers was extended by screening the reference lists of all selected articles for additional articles that fulfilled the inclusion criteria. The reference lists of the papers that were selected based on this hand search were not searched for additional studies. In addition, experts in the field of physical activity in daily life measurement in chronic pain were asked for any additional articles. A total number of four experts was consulted with an expertise in patient care on low back pain (rehabilitation medicine and physiotherapy) as well as expertise in research on the topic of back pain (movement sciences and epidemiology). Disagreements at any stage of the study selection were dealt with by consulting the third author (AK).

Based on full text reading, all articles were systematically reviewed. Seven characteristics (author and year of publication; name of instrument; patient population; variable measured; method of assessment; timeframe; psychometric properties) were systematically reviewed for every article.

Detailed information of the characteristics is presented in the appendix.

The following advice regarding physical activity assessment as reported in the literature, were taken into account: Firstly, an accurate evaluation needs an assessment 
instrument with good psychometric properties. Secondly, to measure a mean daily activity level, an assessment period needs at least 3 to 5 days (51) and inclusion of both week and weekend days is preferred (21). Thirdly, information on a patient's physical activity pattern or fluctuations of activities over time will provide additional information. And finally, to calculate energy expenditure based on physical activity, the type of activities performed (walking, cycling, running, occupational activities etc...) has to be scored. In patients with musculoskeletal pain, specifications of occupational activities seem especially of interest. Losing one's job due to pain can have an enormous influence on daily energy expenditure. For this reason, Protas suggested that questionnaires regarding physical activity in pain should contain questions about occupational activities (1999).

Psychometric properties were evaluated as regarding the following criteria: Validity scores were scored as high in case $r>60$, moderate for $r>0.30$ and $<0.60$ and low for $r<0.30$. Test-retest reliability was scored as high for an ICC $>0.90$, moderate for ICC $0.75-0.90$ and low for scores below 0.75 . Test-retest reliability scored based on a Pearson or Spearman correlation coefficients were classified as high in case $r>$ 0.80 , moderate for $0.50-0.80$ and low for $r<0.50(65)$.

\section{Results}

The results of the selection procedure are presented in Fig. 1. The literature search identified 420 articles. As a result of step one, the first and the second reviewer had $86.9 \%$ agreement in the selection of the titles. Based on the final decision of the third reviewer a total number of 271 articles was selected for further evaluation. The initial agreement score between the first and the second reviewer was $74.2 \%$. Eventually, after the selection of the third reviewer, a total of 49 articles were selected for full text evaluation. In addition, the hand search resulted in 7 articles. Experts in the field recommended 6 additional articles. Finally, a total of 62 articles were selected for full text evaluation.

After full text evaluation it appeared that 16 of the 62 articles did not contain an instrument assessing physical activity in daily life. For these articles, full text reading revealed that the decision made in the second step of the selection procedure wasn't appropriate. In most of the 16 articles, the presented instrument focussed on impairment or disability assessment instead of the assessment of physical activity in daily life. Two additional articles mentioned physical activity in their text, but did not contain any assessment method. In addition, in two articles physical activity was measured, although it wasn't in a population of patients with musculoskeletal pain and the articles were hence excluded. In both articles, physical activity was assessed in healthy individuals, who were followed over time to identify persons at risk for musculoskeletal pain. Finally, 42 articles presented at least one assessment 
instrument for physical activity in daily life in patients with musculoskeletal pain and fulfilled all selection criteria, and were selected (Fig. 1). In four of the 42 articles even more than one assessment method is discussed $(4,18,37,64)$. Based on the assessment instruments presented in all evaluated articles, three main categories of activity assessment in musculoskeletal pain were identified: questionnaires, diaries and movement registration.

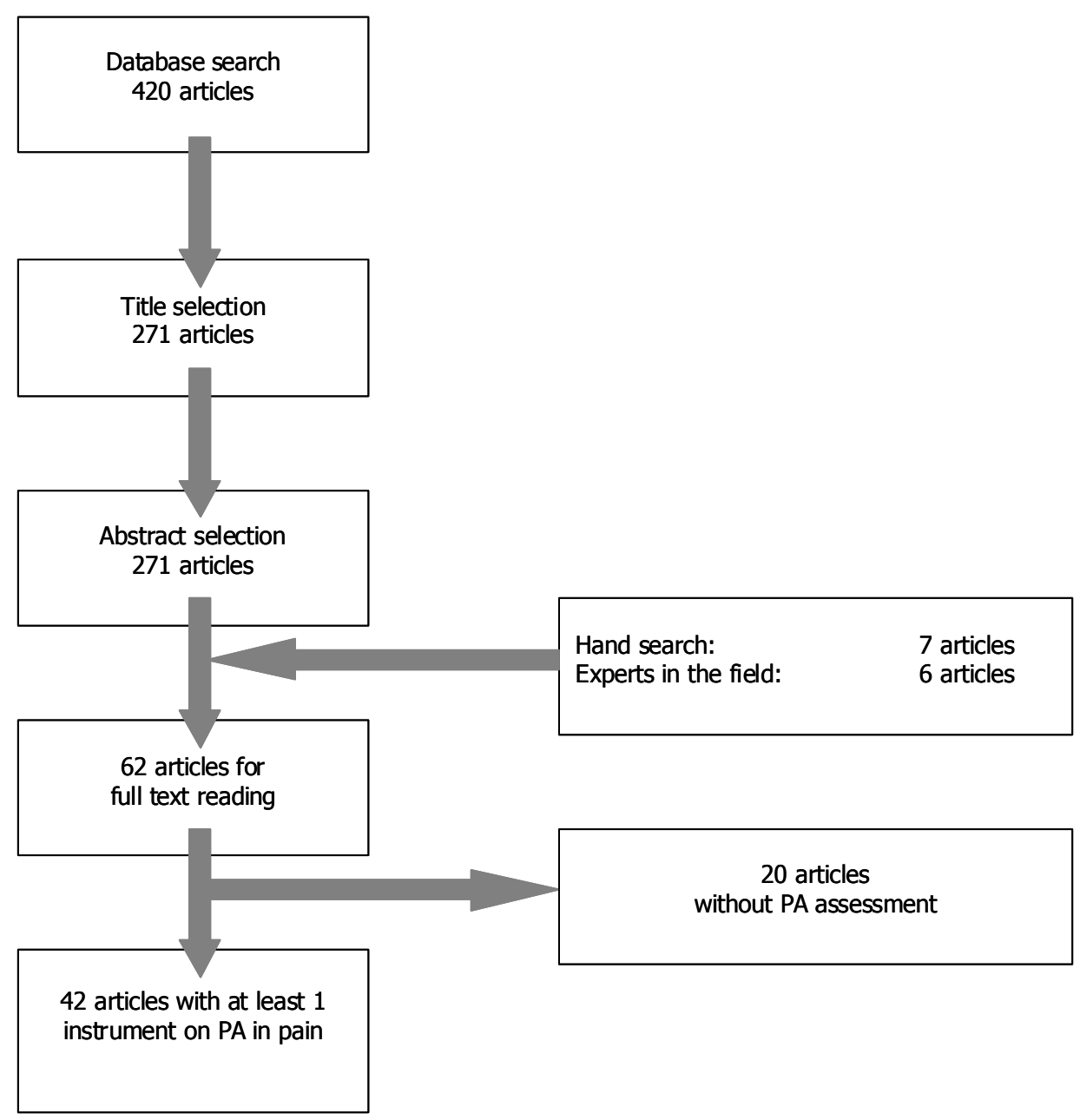

Figure 1: The selection procedure of assessments instruments on physical activity (PA) 


\section{Questionnaires}

Twenty four articles presented a questionnaire to assess physical activity in daily life. In four of these 24 articles, the level of physical activity was assessed based on one single self prepared question. In none of these four articles, further information on the assessment quality of the presented self prepared question was available. Although these articles fulfilled the inclusion criteria of this review article, they were not included for further presentation in the tables. The remaining twenty articles reported on 14 questionnaires assessing physical activity in daily life in patients with musculoskeletal pain and are presented in Table 1. The design of the questionnaires ranged from a set of self prepared questions to well evaluated questionnaires. The time frame of the questionnaires varies from one day to one year.

Information on psychometric properties for physical activity assessment in a population of patients with musculoskeletal pain was only available for four questionnaires: the Baecke Physical Activity Questionnaire (BPAQ; (26), the General Activity Scale of the Multidimensional Pain Inventory (MPI; $(27,36,38)$, the Leisure Time Physical Activity Instrument (LTPAI; (37)) and the Physical Activity at Home and Work Instrument (PAWHI; (37)). The reported validity scores for the various questionnaires were only low to moderate ( $r=0.30$ PASIPD; $r=0.40$ LTPAI and SQUASH $r$ $=0.45$ ). Test retest reliability were either high (Baecke OAI ICC $=0.90$; PAWHI ICC 0.91 ) or moderate (LTPAI ICC $=0.86$; Baecke LAI ICC $=0.71$; Baecke SAI ICC $=0.70$; SQUASH $r_{s p}=0.58$; GAS $r_{\text {pearson }}>0.62$; PASIPD $\left.r_{s p}=0.77\right)$. The psychometric evaluation of the Physical Activity Scale for Individuals with Physical Disabilities (PASIPD) was performed for patients with disabilities (60). Although in this study, patients with pain were included, no specific information on psychometric properties for the subgroup of patients with pain was presented.

Five questionnaires contained specific questions or a subscale regarding occupational activities. These are the Baecke Physical Activity Questionnaire (BPAQ; (26); the questionnaire of (32), the Physical Activity Scale for Individuals with Physical Disabilities (PASIPD; (60), the Five City Project 7 day recall physical activity questionnaire (41) and the Physical Activity at Home and Work Instrument (PAHWI; (37).

\subsection{Diaries}

Twelve articles reported on ten different diaries (Table 2). In most cases, patients were asked to report the activities in their diary during an assessment period of one week. Only Vendrig and Lousberg, asked patients to complete their diary during 6 days (55). In the study of Liedberg, a diary was assessed digitally on a notebook. Regular activities were entered in a computer program and then presented and scored (33). 


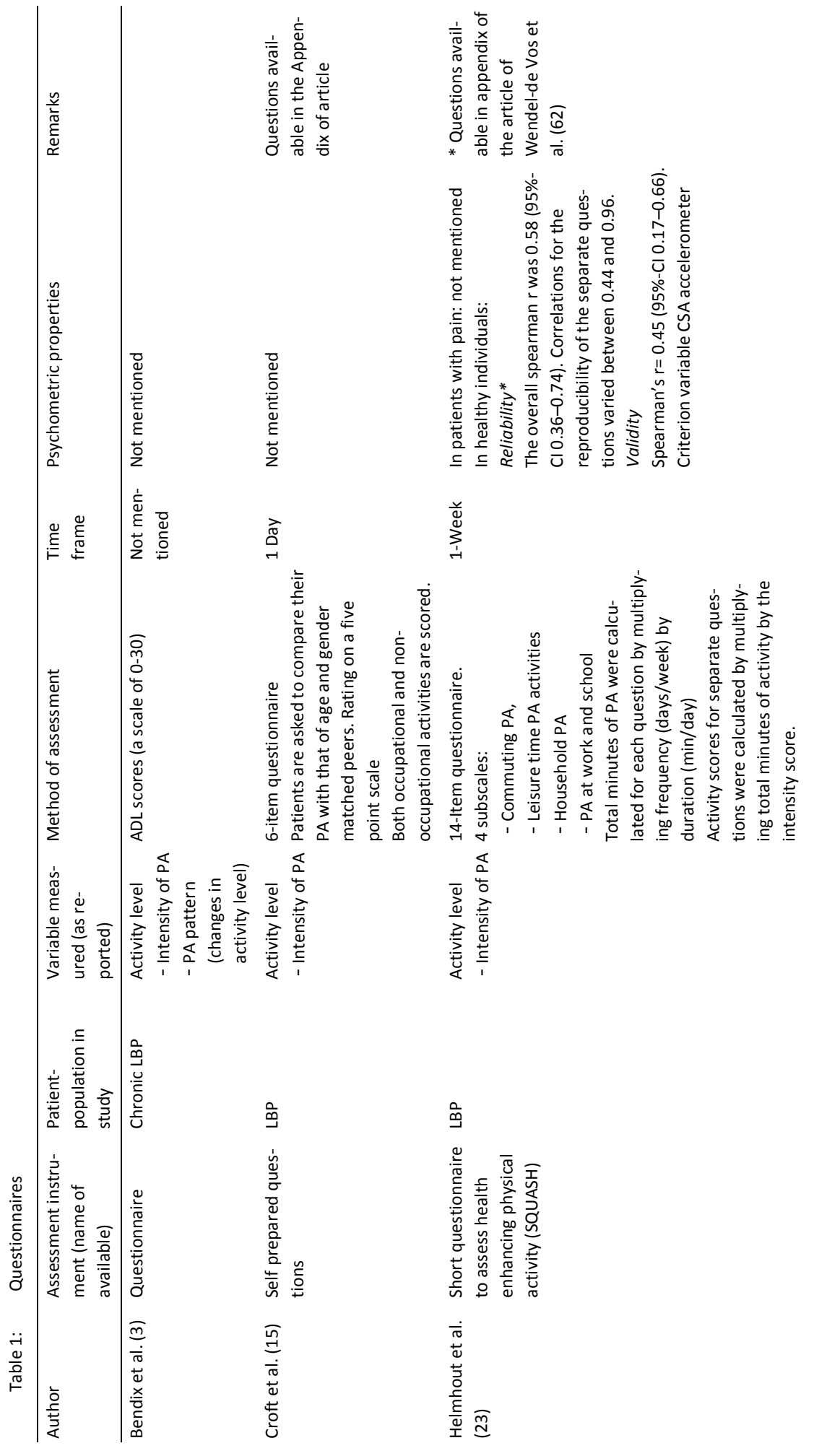




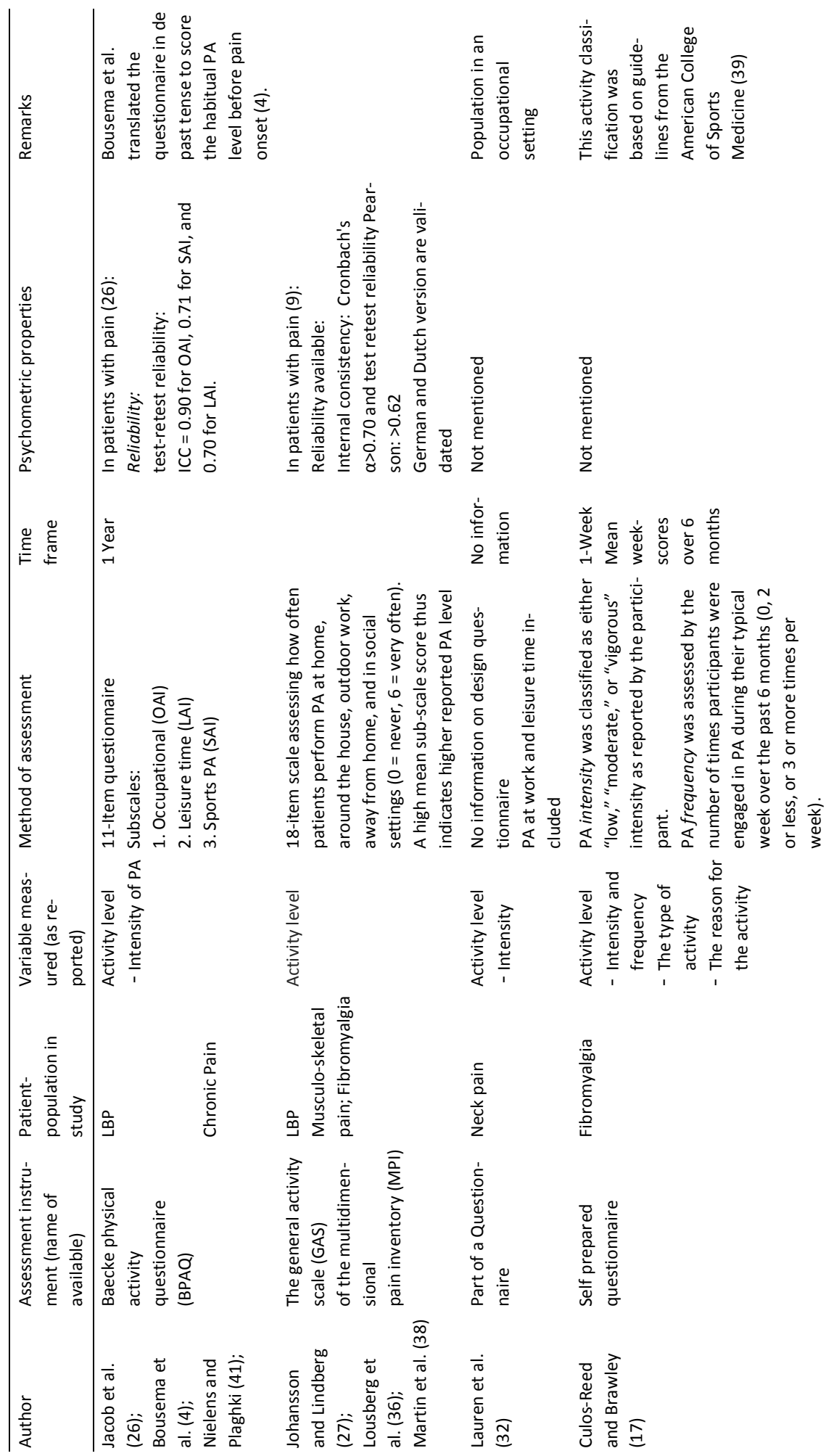




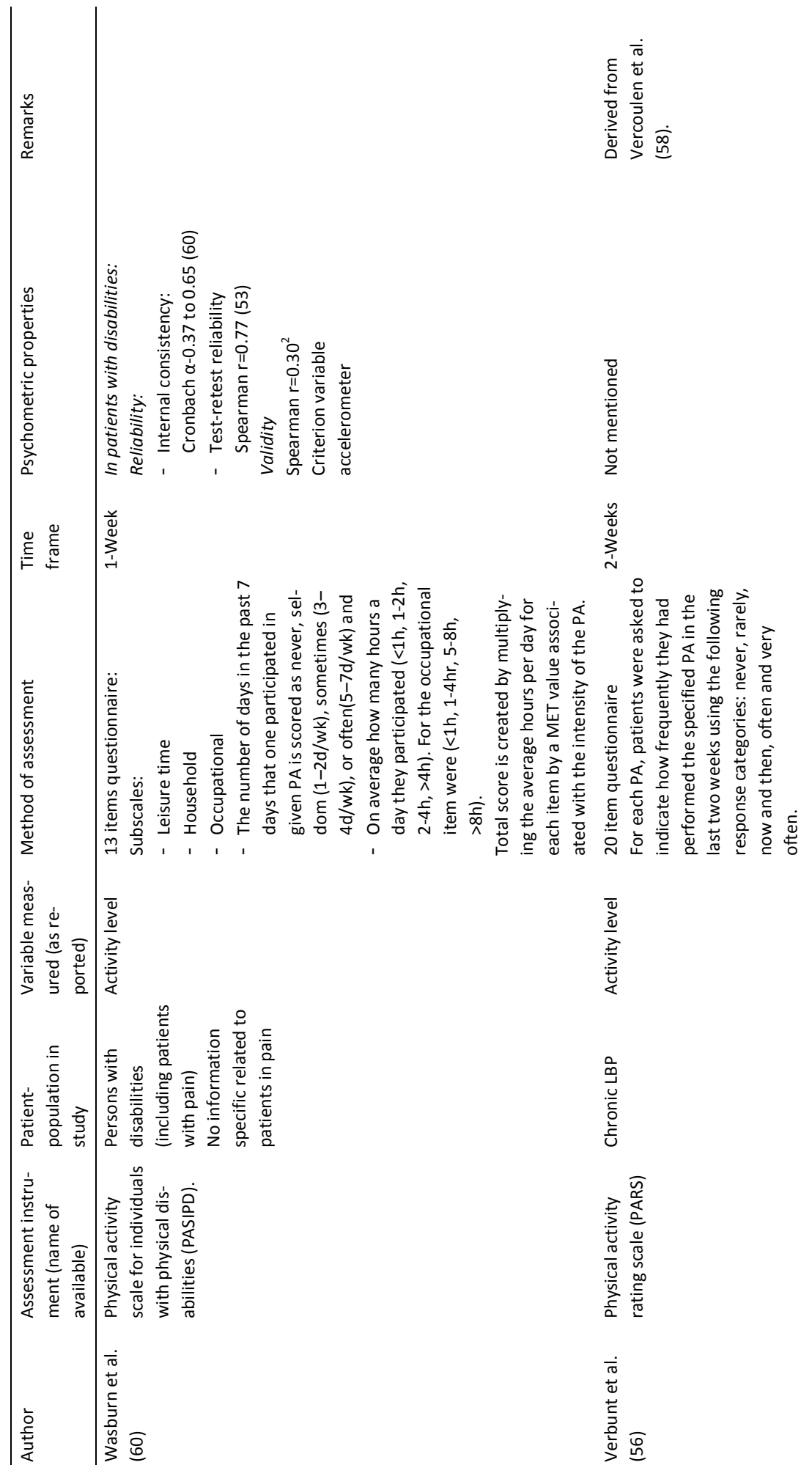




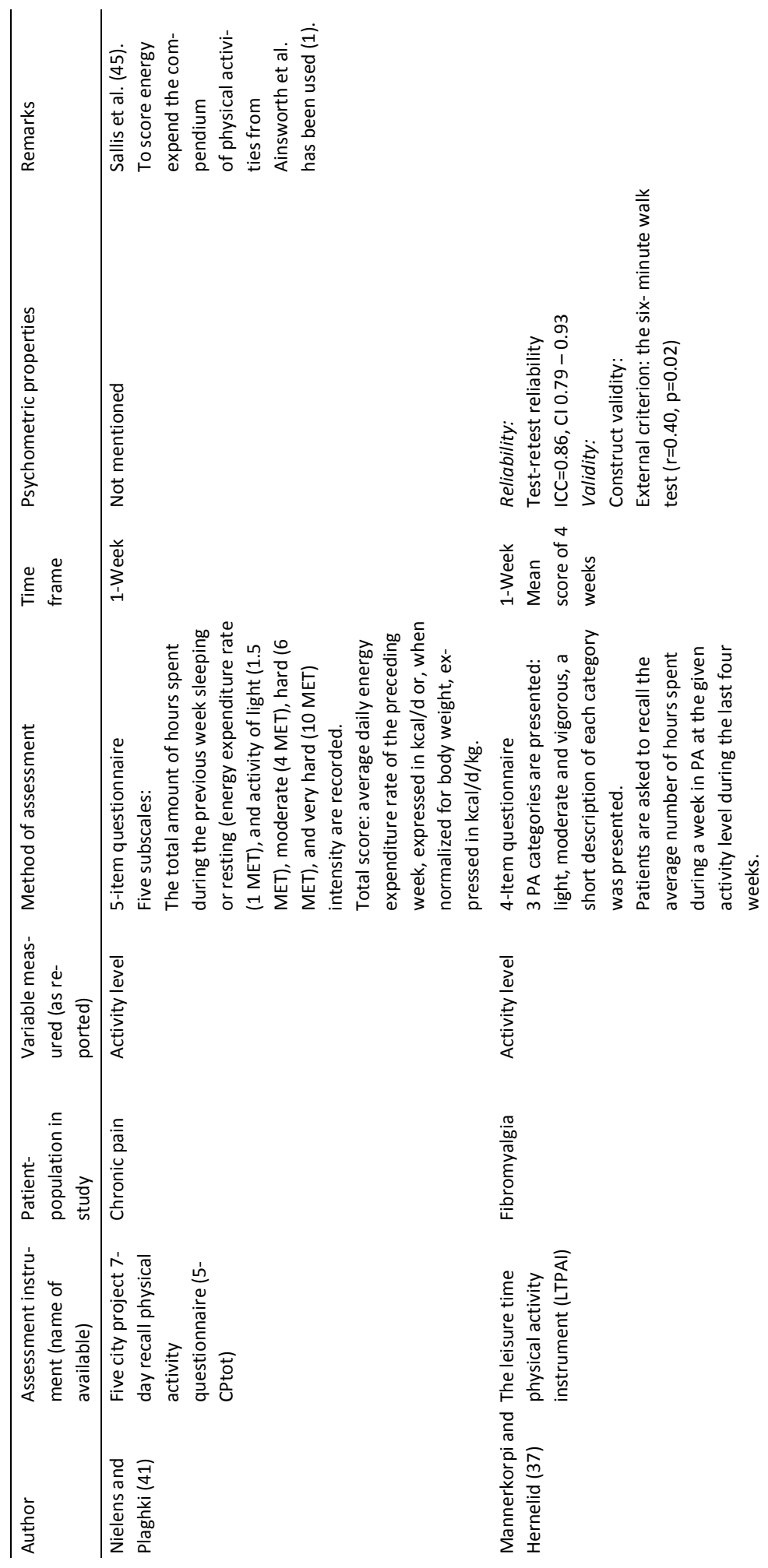




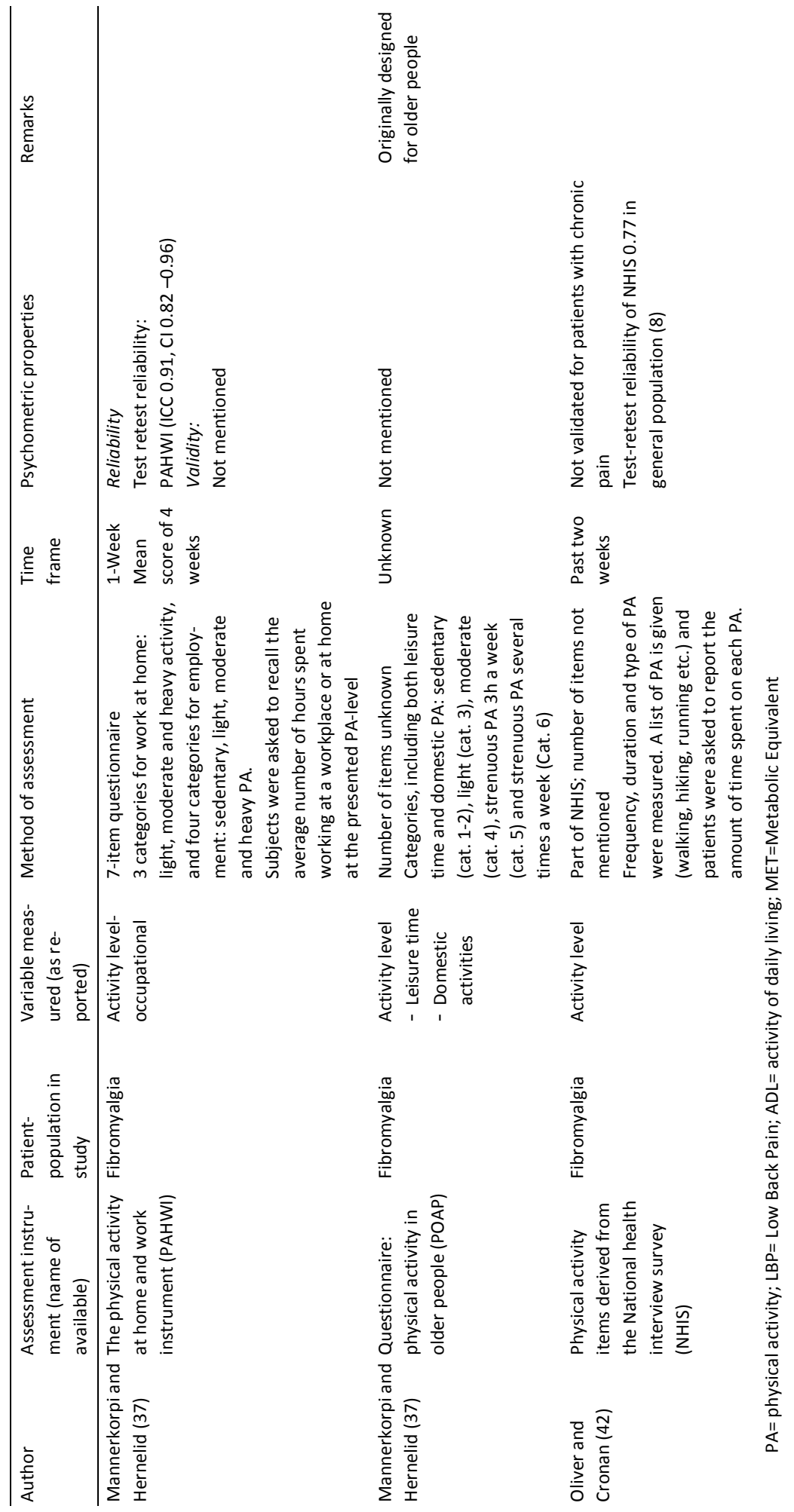




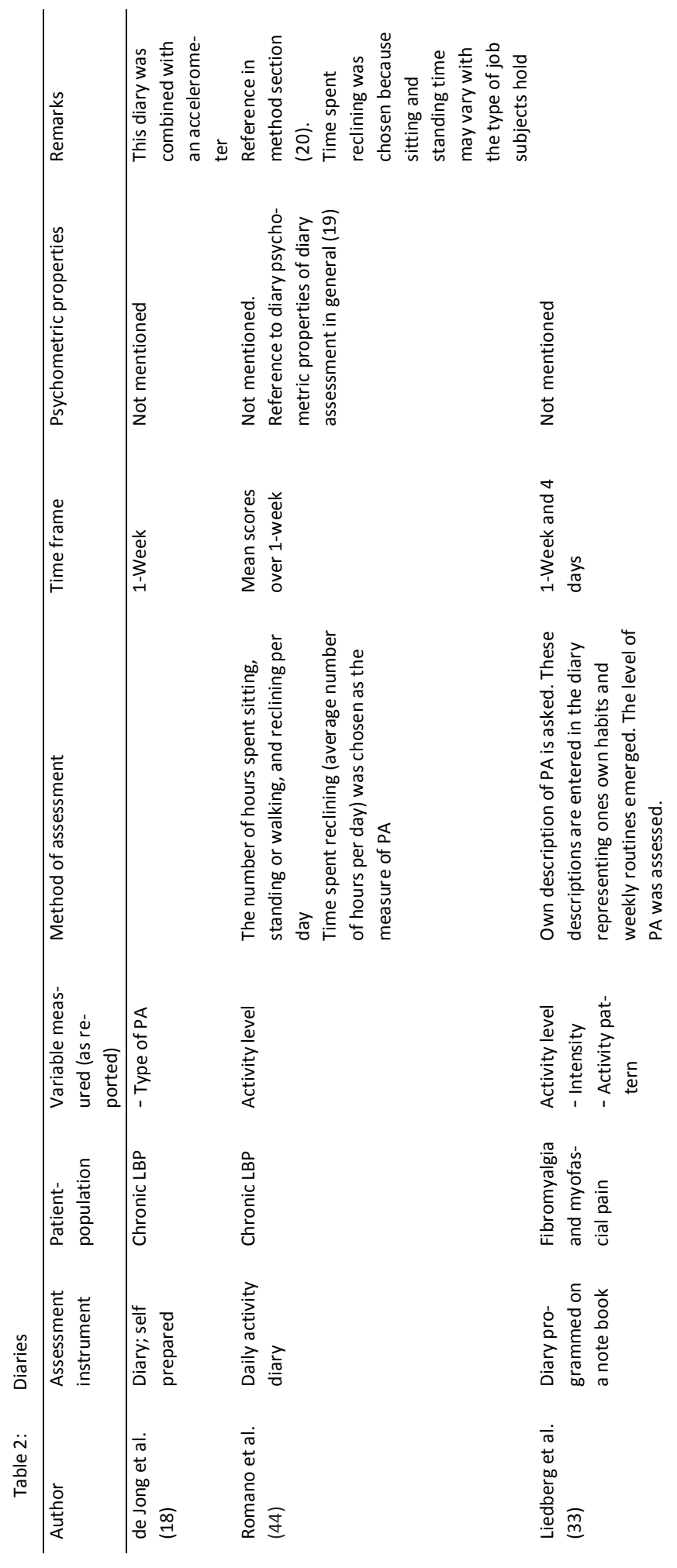




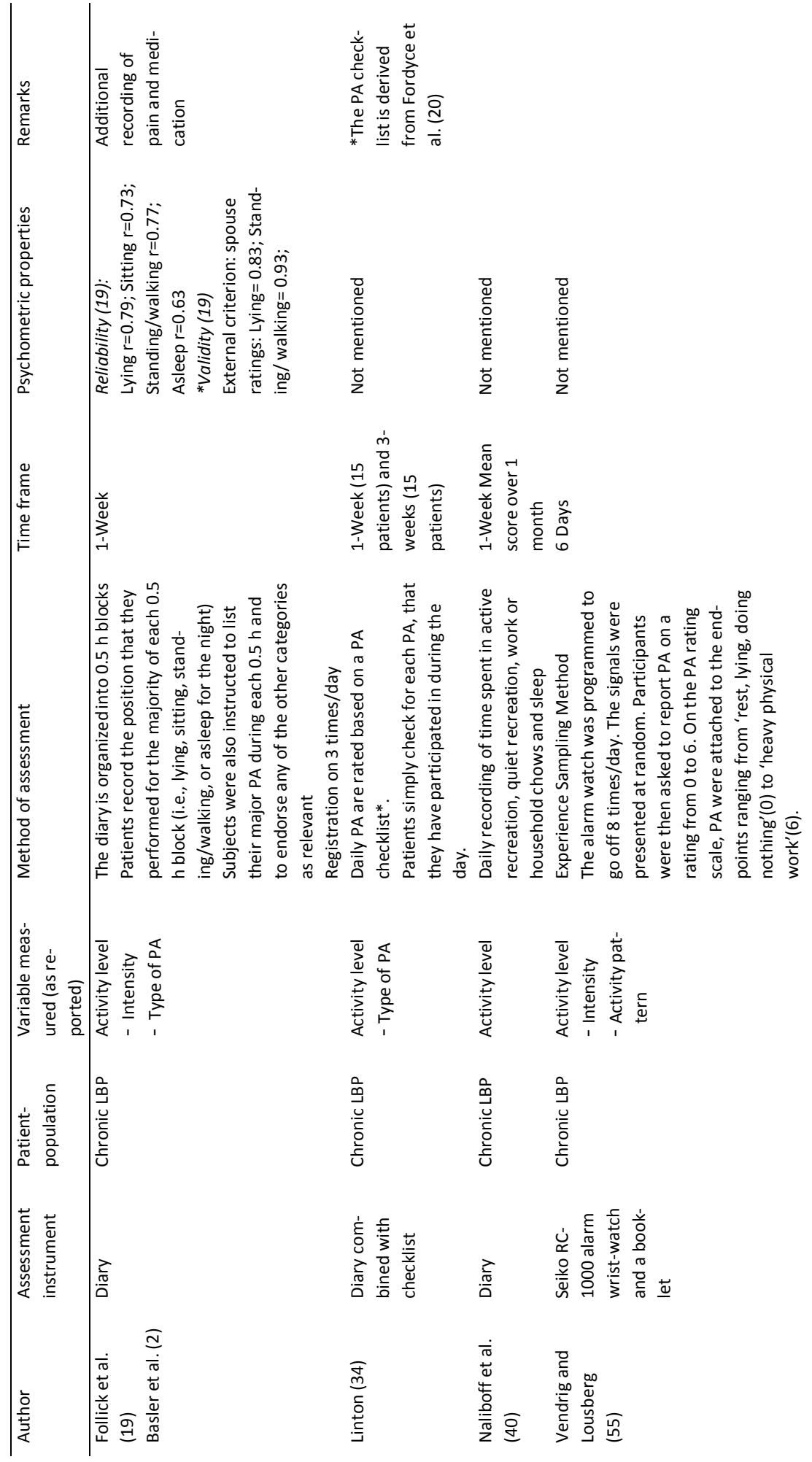




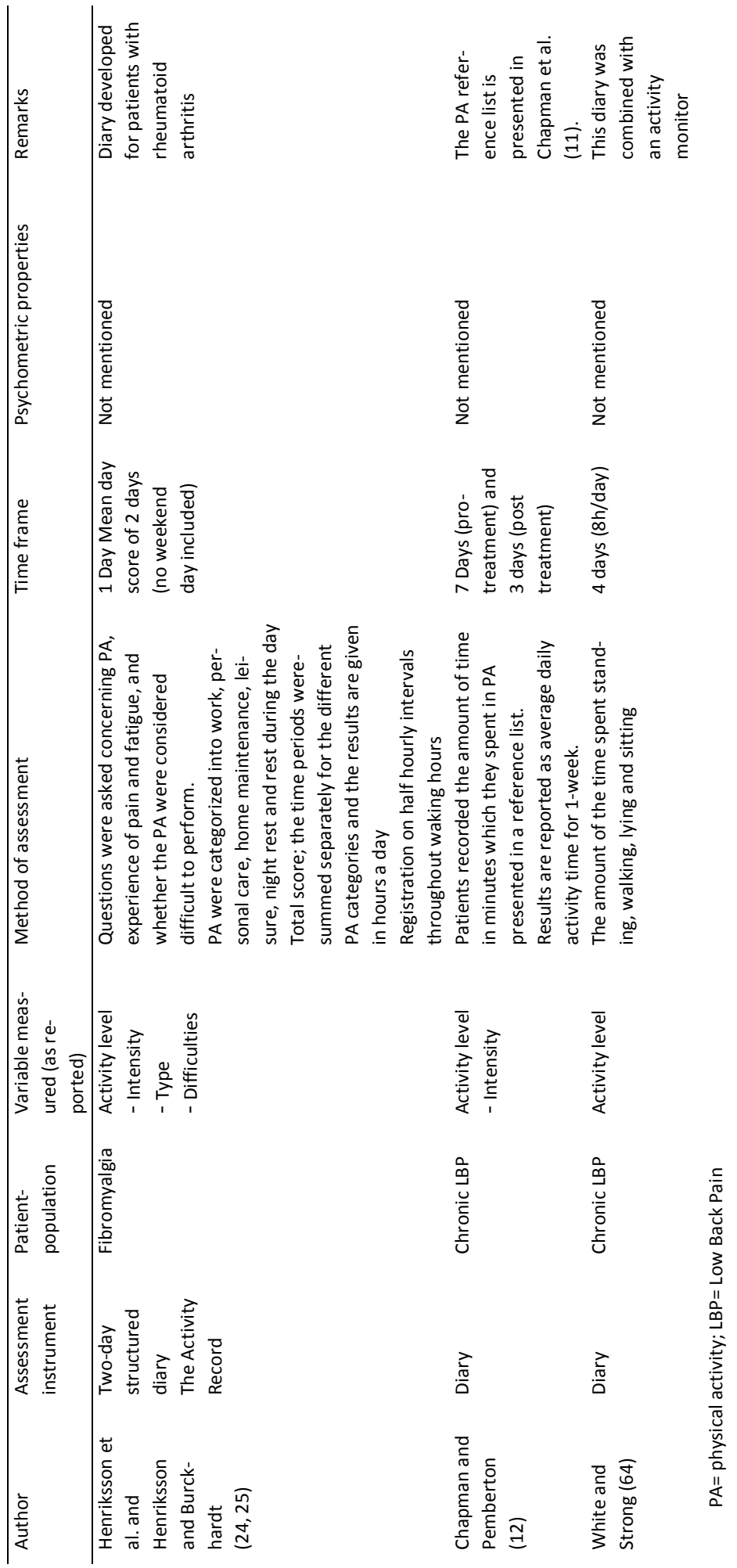


Regular activities were entered in a computer program and then presented and scored (33).

In all diaries, the intensity of performed activities was scored. In addition, in the diaries of the studies of Follick et al. (19); Linton (34); Henriksson et al. (25); Henriksson and Burckhardt (24); de Jong et al. (18); Basler et al. (2) the type of activities performed was also assessed. For this, Linton included a checklist in which all kind of activities were presented (34). Patients were asked to evaluate whether they had performed any of the activities presented in the checklist and to report in their diary the activities in which they participated during the last registration period. Based on two diaries $(33,55)$, physical activity patterns were studied. The study of Vendrig et al. reported daily activity registration based on Experience Sampling Method (ESM) in which patients are asked to fill in a set of questions on randomly chosen moments during the day $(16,55)$. An alarm watch beeped randomly at a fixed number of times a day to indicate an assessment moment. At that moment the patient had to score activities (together with other pain related items) in a paper booklet. Only for one of the presented diaries $(2,19)$ information regarding psychometric properties was included. The validity of this diary as compared to the external criterion spouse rating appeared to be high. Reliability with a range of $r=0.63$ to $r=0.77$ for different activities seemed to be moderate.

\subsection{Movement registration}

Twelve articles presented information on ten assessment instruments using movement registration (Table 3). In three studies, an uni-dimensional accelerometer was used $(28,29,35)$. Four other studies used a triaxial accelerometer $(4,18,22,57)$. Six articles reported on activity assessment based on an activity monitor $(7,47,48,50$, $52,64)$. Most of the activity monitors presented contained three or more accelerometers fixed on different parts of the body. Schasfoort presented information on an activity monitor especially designed for upper extremity activity assessment, which can be used to assess upper extremity related physical activity in case of upper extremity disorders such as complex regional pain syndrome (CRPS).

The minimum reported registration period of an activity monitor was one day $(47,48,52)$. Maximum reported registration time was three weeks using the AW-64 Actiwatch (35). Only for one accelerometer validity testing in a population of patients with pain was reported and appeared to be moderate $\left(r_{\text {pearson }}=0.72\right)$ (TRACMOR; (57)). For the activity monitors presented by White and Strong (64), Bussmann et al. (7) and van den Berg-Emons et al. (52) psychometric properties were tested and all appeared to be high. Six out of these ten assessment instruments based on movement registration were also used to identify physical activity patterns over time in addition to a patients mean physical activity level. 


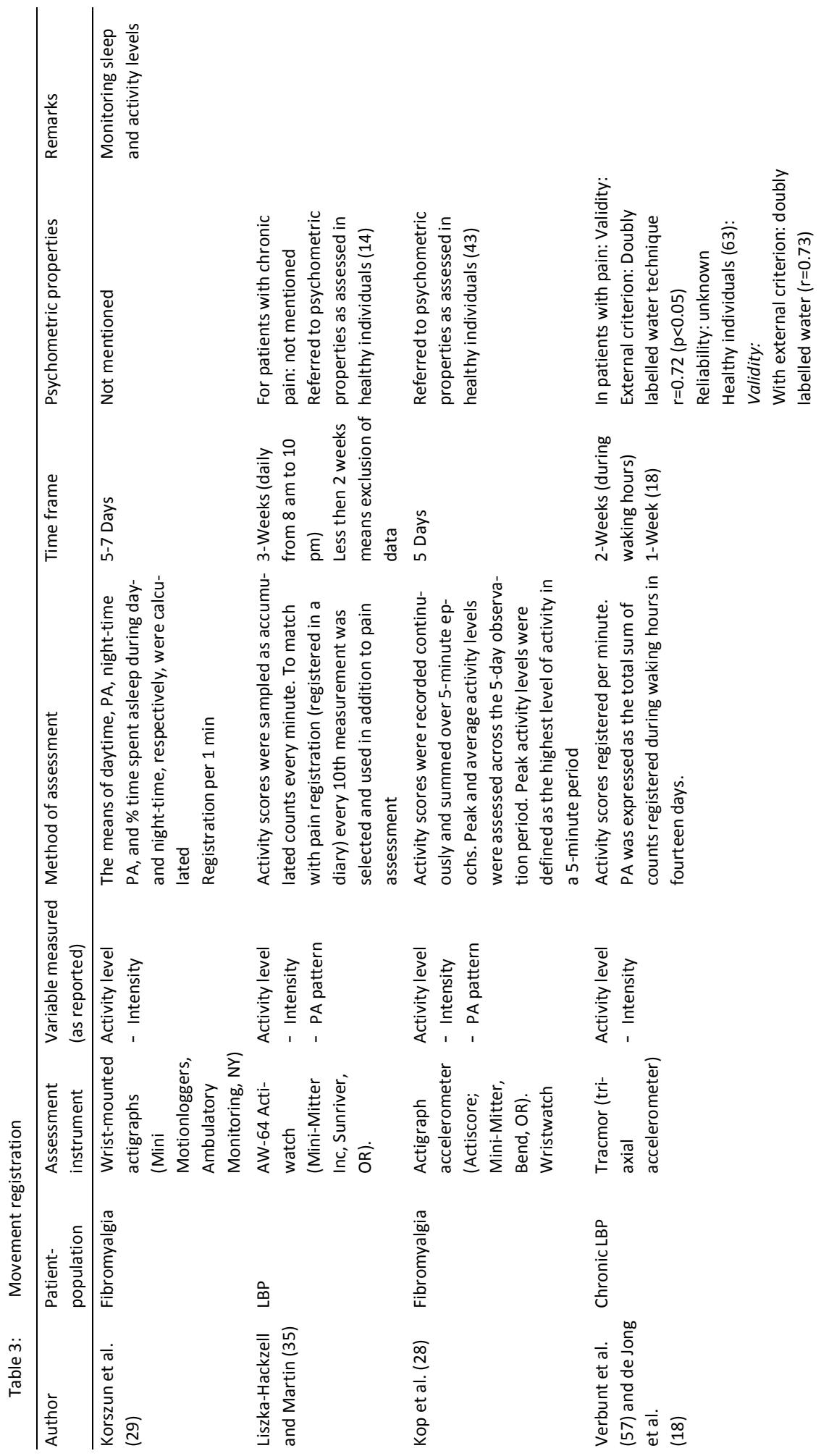




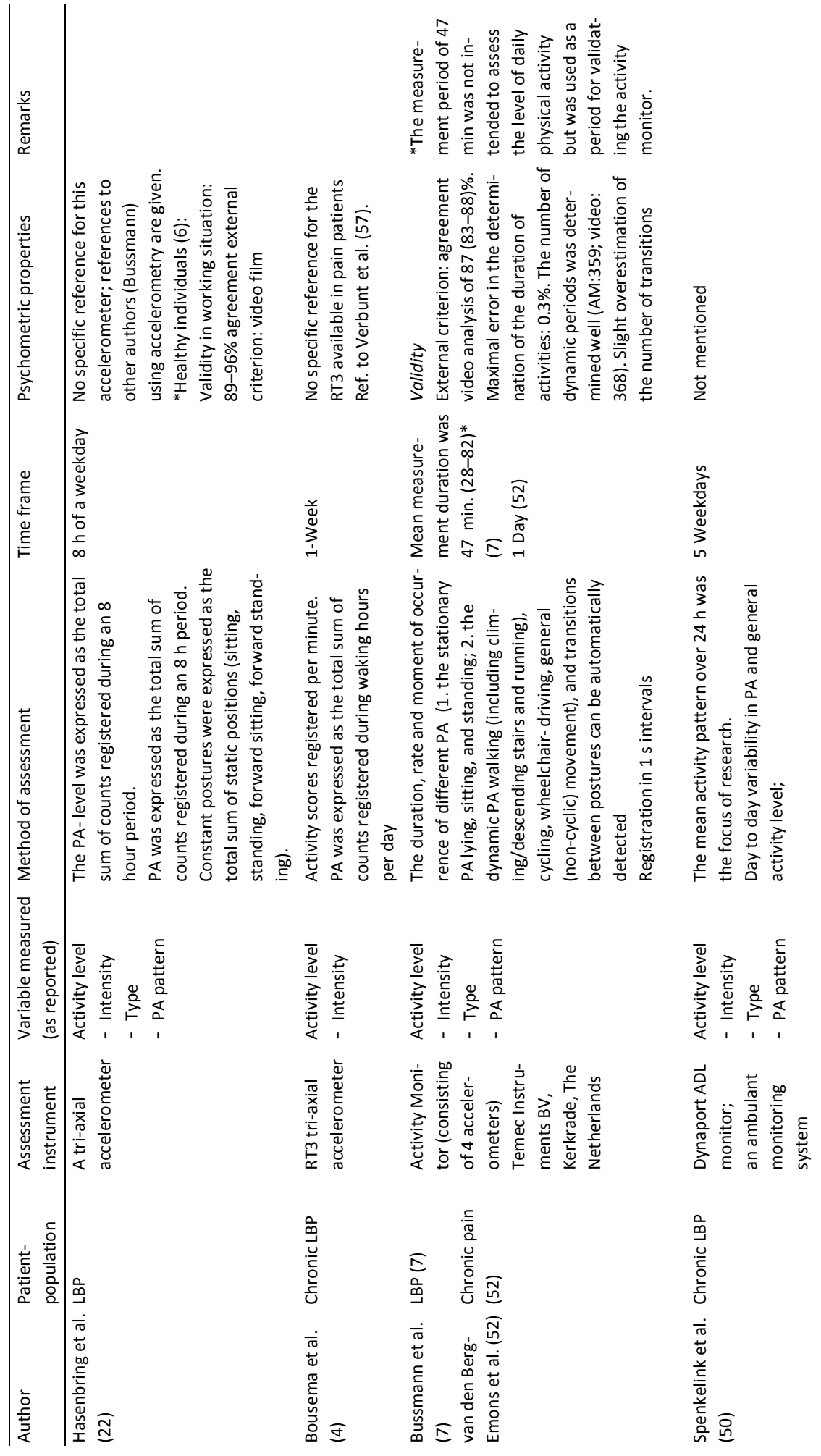




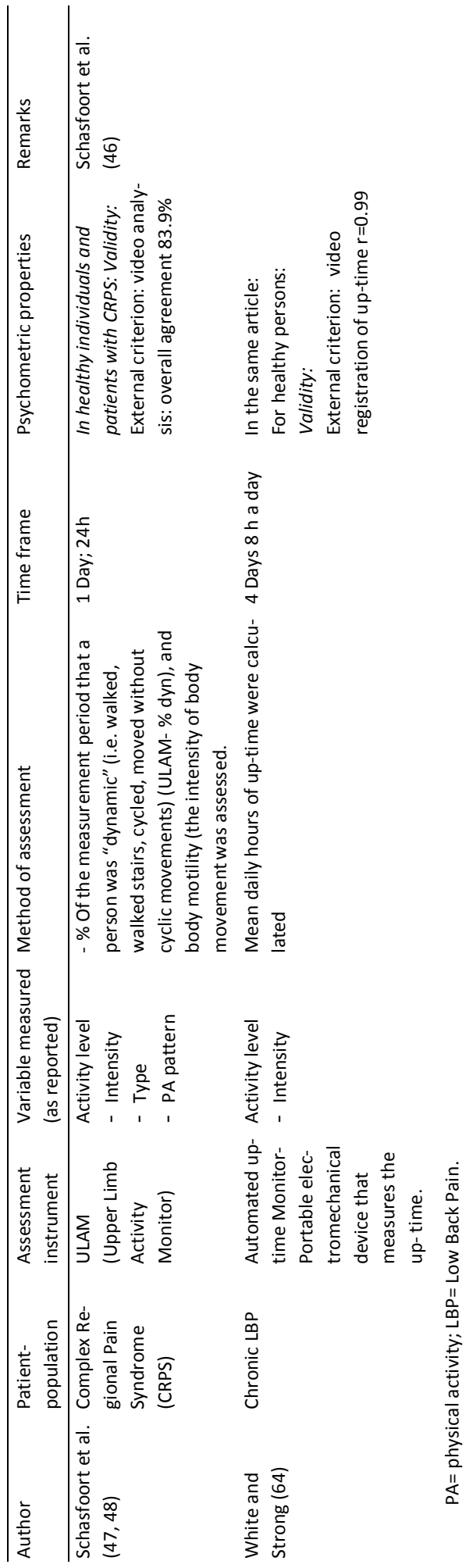




\section{Discussion}

A total number of 42 articles reporting on instruments for the assessment of physical activity in studies in musculoskeletal pain were reviewed. A total number of 34 assessment instruments for physical activity were identified; fourteen measures were based on a questionnaire, ten on diary assessment and ten on movement registration. Only, for ten out of these 34 assessment instruments full or partial information was available on psychometric properties for patients with musculoskeletal pain.

\subsection{Study selection}

It appeared that sixteen of the 62 articles selected for further reading contained an instrument measuring disability or impairment instead of physical activity in daily life. Although abstracts reading suggested assessment of physical activity, further evaluation revealed, that in fact disability or impairment was measured. This finding suggests that unclarity regarding differences between both concepts of "disability" and "physical activity" as presented consecutively in the ICIDH and ICF still exists. In future research, a detailed description of the variable selected for operationalisation concerning any aspect of functional performance seems therefore important. A focus on physical performance/physical activity or on limitations in physical performance will result in the choice of a different kind of assessment instrument. It could be that some of the authors selected an assessment method especially based on its reputation in the research area, and paid less attention to the instrument's validity for the concept they specifically wanted to objectify.

\subsection{Quality of assessment instruments}

Although we initially intended to perform a systematic quality evaluation of all assessment instruments used to assess physical activity in a population comprising patients with musculoskeletal pain, psychometric properties relating to usage with a pain population were only available for a small number of instruments. For some instruments, psychometric properties are presented for healthy individuals but not specifically for patients with chronic pain, since this information was not available. In this, it is essential to differentiate the need for disease/syndrome specific research of psychometric properties of the various instruments. Activity reporting in a questionnaire seems more vulnerable to encounter a low back pain specific risk on bias as compared with activity monitoring. 


\subsection{Questionnaires and diaries}

Twenty four of the presented assessment instruments were based on self report. Self-report measures, such as questionnaires or diaries, are easy to administer, require little time, and are inexpensive. This makes self report measures popular in epidemiological studies featuring large sample studies. In addition, questionnaires give the opportunity to score the type of activities performed and to gather additional information on preferences and self-evaluation. In the current study, it appeared that only for seven self report instruments information on psychometric properties was available for patients with pain. In general the validity scores of the questionnaires reported in the current article were only low to moderate, whereas the test-retest reliability seemed moderate to high. A risk on bias which can influence validity negatively can be introduced based on the fact that a self-report measure on physical function can reflect a difference between how patients with pain function and how they believe they function, resulting in a differently reported physical activity level compared to the actually observed active behaviour (20). In a study of Kremer et al. it appeared that patients with pain significantly underestimated their level of activity (30). In line with this finding, Schmidt and Brands (49), found that patients were less capable of estimating their physiological level of exertion during a performance test situation than healthy controls (36). For some assessment instruments without psychometric scores for patients in pain psychometric properties as assessed in healthy individuals are given. However, whether these results can be applied in patients with musculoskeletal pain can be argued. Unfortunately, little information on this topic in chronic pain is available. With questionnaires on physical activity designed for a healthy population, the lack of discriminative validity occurs especially in low physical activity levels, which may result in a socalled "floor effect" in a population of chronic pain patients. Modified questionnaires, especially designed for sedentary people, deal with this "floor effect". In particular, low intensity activities, such as routine light activity, household chores and spontaneous activity, tend to be underrepresented (31). In general, however, the available modified questionnaires are validated for a healthy older population and concentrate on habitual activities of this specific age group. This means that occupation-oriented questions are often absent. Nevertheless, these activities are of special interest in a population of chronic pain patients. This limits the usefulness of a modified activity questionnaire designed for older persons in chronic pain. In general, the low to moderate scores on validity for questionnaires are important to consider in choosing an instrument to assess physical activity in chronic pain.

For self report measures based on diaries and activity logs less information on psychometric properties is presented in the included articles. Only for the diary used in the study of Follick and Basler both validity and reliability scores are presented and appeared to be adequate, which makes this diary currently the best option in case of a choice for diary assessment $(2,19)$. For both diary and activity 
logs the recording process in itself can produce changes in physical activity patterns during the time of recording (31). In diary assessment based on ESM the influence of pain related factors on self report in ESM still exists, however, the influence of recall bias is decreased using this method. On each ESM assessment moment, information is instantly collected instead of retrospectively. In addition, based on ESM assessment, changes in variables over time and thus a physical activity pattern can be determined. Recently, more ESM research has been performed by using a palmtop. In this, questions are presented at random moments on a touch screen. Although the ESM method produces valuable information, especially regarding time related changes in variables, it can give an overburden for participants which can influence compliance and as in diaries and activity logs in general, it can contain the risk of influencing the recording process of physical activity patterns itself.

\subsection{Movement registration}

Twelve articles reported on 10 different methods to assess physical activity based on movement registration. In comparison with self report, accelerometry-based activity registration provides more objectivity regarding frequency, intensity, and duration of physical activity with minimal burden on participants. A variety of movement registration systems exist, ranging from simple pedometers, counting steps, to three-dimensional activity monitors giving more specific data on both postures and activities during physical activity.

In this overview, the use of three uni-axial and four tri-axial accelerometers was reported. In a tri-axial accelerometer accelerations from three (the posterior, the mediolateral and the longitudinal axes of the trunk) instead of one measurement direction are calculated, which improves the prediction of energy expenditure using accelerometry (13). Although the tri-axial accelerometer is an improvement in comparison with the uni-axial accelerometer, validity is still a topic for debate in accelerometry, as illustrated in a study of Welk et al. (61). In this study, in healthy individuals, the association of several accelerometers with a person's oxygen uptake during exercise as assessed by indirect calorimetry was adequate to high during treadmill walking/running $(r=0.87-0.93 ; 2000)$. However, during the performance of a standardized activity protocol including an abundance of static loaded activities or activities needing lots of upper extremity movements (such as cleaning, vacuum cleaning, weeding) the association between indirect calorimetry and accelerometer outcome decreased to $r=0.48-0.59$ (61). Validity of assessment by a single accelerometer could also be compromised based on an asymmetric gait (limping) due to pain. For example in patients with an unilateral complex regional pain syndrome on the lower extremity, there will be an increasing risk on limping. Validity for tri-axial accelerometry for assessment in daily life situations over longer periods (e.g. one week) which is relatively less influenced by these specific activities appeared to be 
adequate for both healthy individuals (5) as in patients with pain (57). Based on the fact that the latest accelerometers are very compact, no substantial interference of the recording process itself during assessment has to be expected.

The inaccuracy of uni and tri-axial accelerometers in static loaded situations is compensated during activity monitoring. During activity monitoring, not only mean activity levels, but also a classification of activities (such as standing, sitting and locomotion) can be presented. White and Strong presented the first activity monitor in chronic pain research in 1992 (64). Nowadays, activity monitors become more and more convenient. Their reduced assessment period and its high costs are however still disadvantages. Due to large data registration, the assessment period of most currently available activity monitors can not cover the advised minimum registration time for activity assessment of three to five days. Research is directed to improve this.

For both individual accelerometers as activity monitors, reliability data are available in healthy individuals but not yet in patients with pain. In addition, neither information on responsiveness of accelerometry in pain is yet available. In favour of the responsiveness of accelerometry, are the findings of Vlaeyen et al. and de Jong et al., who reported a significant activity increase based on accelerometry after graded exposure for patients with back pain $(18,59)$. Research to identify chronic pain specific psychometric properties seems however less warranted for the activity monitor as compared to a single accelerometer. The monitor is able to identify pain related abnormalities in activity, such as assymmetric gait, and as a result of that, can control for it. In summary, although assessment based on movement registration techniques still have to be improved, these techniques seem promising for activity assessment in patients with pain based on their objectivity as compared with self report. Especially, activity monitoring will have great possibilities as a result of its capacity to combine quantitative and qualitative activity assessment. At the moment, its high costs and restricted registration time are still barriers.

The scope of the current study focussed on assessment of physical activity in daily life. Articles were selected to address differences in measuring physical activity and were not intended to address the results on physical activity of patients in musculoskeletal pain in the various articles. Recently, a review article was published aiming at gaining insight into the daily physical activity levels of patients with musculoskeletal pain or fatigue compared with asymptomoatic controls (54). In the current study, articles regarding assessment instruments were evaluated on main characteristics, such as patient population; method of assessment; timeframe and psychometric properties. 


\section{Conclusion}

Although the ICF classification favours activity measurement to objectify a patient's level of functioning, currently, assessment instruments for physical activity in musculoskeletal pain with adequate psychometric properties are scarce. It seems that, especially in order to guarantee test validity of activity assessment, movement registration is favoured above self report to present the level of physical activity. Activity monitoring seems promising for both quantitative and qualitative assessment of physical activity in musculoskeletal pain.

\section{Acknowledgement}

The authors want to thank Mari Lundberg for her valuable comments on an earlier version of this manuscript. This study was supported by the Council for Medical and Health Research of the Netherlands (ZON-MW), grant nr. 14350042. 


\section{Appendix A}

Full text evaluation included a systematic evaluation of the following characteristics:

Author and year of publica-

tion:

Assessment instrument:

Patient population:

Variable measured

Method of assessment

Timeframe:

Psychometric properties:
The first author of the article is presented combined with the publication year of the article.

The name of the instrument or in case no specific name is mentioned a description of the instrument.

A specification of the group of patients with musculoskeletal pain presented in the article.

Dimensions of physical activity studied.

The operationalisation of physical activity as presented in the method section.

The period in which data were collected (f.e.: mean activity level over one week in a time frame of 6 months).

Validity, reliability and responsiveness of the instrument of interest as reported by the author and presented in the text of the selected article. In case a reference was given to another article, this information is presented. 


\section{References}

(1) Ainsworth BE, Haskell WL, Leon AS, Jacobs DR, Jr., Montoye HJ, Sallis JF, and Paffenbarger RS, Jr. Compendium of physical activities: classification of energy costs of human physical activities. Med Sci Sports Exerc 1993; 25(1):71-80.

(2) Basler HD, Bertalanffy H, Quint S, Wilke A, and Wolf U. TTM-based counselling in physiotherapy does not contribute to an increase of adherence to activity recommendations in older adults with chronic low back pain - A randomised controlled trial. Eur J Pain 2007; 11(1):31-37.

(3) Bendix AF, Bendix T, Haestrup C, and Mayer TG. Can it be predicted which patients with chronic low back pain should be offered tertiary rehabilitation in a functional restoration program?: A search for demographic, socioeconomic, and physical predictors. Spine 1998; 23(16):1775-1784.

(4) Bousema EJ, Verbunt JA, Seelen HA, Vlaeyen JW, and Knottnerus JA. Disuse and physical deconditioning in the first year after the onset of back pain. Pain 2007; 130(3):279-86.

(5) Bouten CV, Verboeket-van de Venne WP, Westerterp KR, Verduin M, and Janssen JD. Daily physical activity assessment: comparison between movement registration and doubly labeled water. J Appl Physiol 1996; 81(2):1019-26.

(6) Busser HJ, De Korte WG, Glerum EBC, and Van Lummel RC. Method for objective assessment of physical work load at the workplace. Ergonomics 1998; 41(10):1519-1526.

(7) Bussmann JB, van de Laar YM, Neeleman MP, and Stam HJ. Ambulatory accelerometry to quantify motor behaviour in patients after failed back surgery: a validation study. Pain 1998; 74(2-3):15361.

(8) Calfas KJ, Sallis JF, Nichols JF, Sarkin JA, Johnson MF, Caparosa S, Thompson S, Gehrman CA, and Alcaraz JE. Project GRAD: two-year outcomes of a randomized controlled physical activity intervention among young adults. Graduate Ready for Activity Daily. Am J Prev Med 2000; 18(1):28-37.

(9) Carlsson S, Bergstrom G, and Jensen I. The Multidimensional Pain Inventory: A Swedish version 1994, Gothenburg: Department of Psychology University Gothenburg.

(10) Caspersen CJ, Powell KE, and Christenson GM. Physical activity, exercise, and physical fitness: definitions and distinctions for health-related research. Public Health Rep 1985; 100(2):126-131.

(11) Chapman SL, Brena SF, and Bradford LA. Treatment outcome in a chronic pain rehabilitation program. Pain 1981; 11(2):255-68.

(12) Chapman SL, Pemberton JS. Prediction of treatment outcome from clinically derived MMPI clusters in rehabilitation for chronic low back pain. Clin J Pain 1994; 10(4):267-276.

(13) Chen KY, Sun M. Improving energy expenditure estimation by using a triaxial accelerometer. J Appl Physiol 1997; 83(6):2112-22.

(14) Cole RJ, Kripke DF, Gruen W, Mullaney DJ, and Gillin JC. Automatic sleep/wake identification from wrist activity. Sleep 1992; 15(5):461-9.

(15) Croft PR, Papageorgiou AC, Thomas E, Macfarlane GJ, and Silman AJ. Short-term physical risk factors for new episodes of low back pain: Prospective evidence from the South Manchester back pain study. Spine 1999; 24(15):1556-1561.

(16) Csikszentmihalyi M, Larson R. Validity and reliability of the Experience-Sampling Method. J Nerv Ment Dis 1987; 175(9):526-36.

(17) Culos-Reed SN, Brawley LR. Fibromyalgia, physical activity, and daily functioning: the importance of efficacy and health-related quality of life. Arthritis Care Res 2000; 13(6):343-51.

(18) De Jong JR, Vlaeyen JWS, Onghena P, Goossens M, Geilen M, and Mulder H. Fear of movement/(re)injury in chronic low back pain: Education or exposure in vivo as mediator to fear reduction? Clin J Pain 2005; 21(1):9-17.

(19) Follick MJ, Ahern DK, and Laser-Wolston N. Evaluation of a daily activity diary for chronic pain patients. Pain 1984; 19(4):373-82.

(20) Fordyce WE, Lansky D, Calsyn DA, Shelton JL, Stolov WC, and Rock DL. Pain measurement and pain behavior. Pain 1984; 18(1):53-69. 
(21) Gretebeck RJ, Montoye HJ. Variability of some objective measures of physical activity. Med Sci Sports Exerc 1992; 24(10):1167-72.

(22) Hasenbring MI, Plaas $\mathrm{H}$, Fischbein B, and Willburger $\mathrm{R}$. The relationship between activity and pain in patients 6 months after lumbar disc surgery: do pain-related coping modes act as moderator variables? Eur J Pain 2006; 10(8):701-9.

(23) Helmhout PH, Harts CC, Staal JB, and De Bie RA. Rationale and design of a multicenter randomized controlled trial on a 'minimal intervention' in Dutch army personnel with nonspecific low back pain (ISRCTN19334317). BMC Musculoskelet Disord 2004; 5(1):40.

(24) Henriksson C, Burckhardt C. Impact of fibromyalgia on everyday life: A study of women in the USA and Sweden. Disabil Rehabil 1996; 18(5):241-248.

(25) Henriksson C, Gundmark I, Bengtsson A, and Ek AC. Living with fibromyalgia: Consequences for everyday life. Clin J Pain 1992; 8(2):138-144.

(26) Jacob T, Baras M, Zeev A, and Epstein L. Low back pain: Reliability of a set of pain measurement tools. Arch Phys Med Rehabil 2001; 82(6):735-742.

(27) Johansson E, Lindberg P. Subacute and chronic low back pain. Reliability and validity of a Swedish version of the Roland and Morris Disability Questionnaire. Scand J Rehabil Med 1998; 30(3):139143.

(28) Kop WJ, Lyden A, Berlin AA, Ambrose K, Olsen C, Gracely RH, Williams DA, and Clauw DJ. Ambulatory monitoring of physical activity and symptoms in fibromyalgia and chronic fatigue syndrome. Arthritis Rheum 2005; 52(1):296-303.

(29) Korszun A, Young EA, Engleberg NC, Brucksch CB, Greden JF, and Crofford LA. Use of actigraphy for monitoring sleep and activity levels in patients with fibromyalgia and depression. J Psychosom Res 2002; 52(6):439-43.

(30) Kremer EF, Block A, and Gaylor MS. Behavioral approaches to treatment of chronic pain: the inaccuracy of patient self-report measures. Arch Phys Med Rehabil 1981; 62(4):188-91.

(31) Lagerros YT, Lagiou P. Assessment of physical activity and energy expenditure in epidemiological research of chronic diseases. Eur J Epidemiol 2007; 22(6):353-62.

(32) Lauren $\mathrm{H}$, Luoto S, Alaranta $\mathrm{H}$, Taimela S, Hurri $\mathrm{H}$, and Heliovaara M. Arm motion speed and risk of neck pain: A preliminary communication. Spine 1997; 22(18):2094-2099.

(33) Liedberg GM, Hesselstrand ME, and Henriksson CM. Time use and activity patterns in women with long-term pain. Scand J Occup Ther 2004; 11(1):26-35.

(34) Linton SJ. The relationship between activity and chronic back pain. Pain 1985; 21(3):289-94.

(35) Liszka Hackzell JJ, Martin DP. An analysis of the relationship between activity and pain in chronic and acute low back pain. Anesth Analg 2004; 99(2):477-481.

(36) Lousberg R, Van Breukelen GJP, Groenman NH, Schmidt AJM, Arntz A, and Winter FAM. Psychometric properties of the Multidimensional Pain Inventory, Dutch language version (MPI-DLV). Behav Res Ther 1999; 37(2):167-182.

(37) Mannerkorpi K, Hernelid C. Leisure Time Physical Activity Instrument and Physical Activity at Home and Work Instrument. Development, face validity, construct validity and test-retest reliability for subjects with fibromyalgia. Disabil Rehabil 2005; 27(12):695-701.

(38) Martin DP, Sletten CD, Williams BA, and Berger IH. Improvement in fibromyalgia symptoms with acupuncture: Results of a randomized controlled trial. Mayo Clin Proc 2006; 81(6):749-757.

(39) Mazzeo R, Cavanaugh P, and Evans W. Exercise and Physical Activity for Older Adults. Med Sci Sports Exerc 1998; 30:992-1008.

(40) Naliboff BD, Cohen MJ, Swanson GA, Bonebakker AD, and McArthur DL. Comprehensive assessment of chronic low back pain patients and controls: physical abilities, level of activity, psychological adjustment and pain perception. Pain 1985; 23(2):121-34.

(41) Nielens H, Plaghki L. Cardiorespiratory fitness, physical activity level, and chronic pain: are men more affected than women? Clin J Pain 2001; 17(2):129-37.

(42) Oliver K, Cronan TA. Correlates of physical activity among women with fibromyalgia syndrome. Ann Behav Med 2005; 29(1):44-53. 
(43) Puyau MR, Adolph AL, Vohra FA, and Butte NF. Validation and calibration of physical activity monitors in children. Obes Res 2002; 10(3):150-7.

(44) Romano JM, Turner JA, and Jensen MP. The Chronic Illness Problem Inventory as a measure of dysfunction in chronic pain patients. Pain 1992; 49(1):71-5.

(45) Sallis JF, Haskell WL, Wood PD, Fortmann SP, Rogers T, Blair SN, and Paffenbarger RS, Jr. Physical activity assessment methodology in the Five-City Project. Am J Epidemiol 1985; 121(1):91-106.

(46) Schasfoort FC, Bussmann JB, and Stam HJ. Ambulatory measurement of upper limb usage and mobility-related activities during normal daily life with an upper limb-activity monitor: a feasibility study. Med Biol Eng Comput 2002; 40(2):173-82.

(47) Schasfoort FC, Bussmann JB, and Stam HJ. Correlation between a novel upper limb activity monitor and four other instruments to determine functioning in upper limb complex regional pain syndrome type I. J Rehabil Med 2005; 37(2):108-14.

(48) Schasfoort FC, Bussmann JB, Zandbergen AM, and Stam HJ. Impact of upper limb complex regional pain syndrome type 1 on everyday life measured with a novel upper limb-activity monitor. Pain 2003; 101(1-2):79-88.

(49) Schmidt AJ, Brands AM. Persistence behavior of chronic low back pain patients in an acute pain situation. J Psychosom Res 1986; 30(3):339-46.

(50) Spenkelink CD, Hutten MM, Hermens HJ, and Greitemann BO. Assessment of activities of daily living with an ambulatory monitoring system: a comparative study in patients with chronic low back pain and nonsymptomatic controls. Clin Rehabil 2002; 16(1):16-26.

(51) Trost SG, Mclver KL, and Pate RR. Conducting accelerometer-based activity assessments in fieldbased research. Med Sci Sports Exerc 2005; 37(11 Suppl):S531-43.

(52) van den Berg-Emons RJ, Schasfoort FC, de Vos LA, Bussmann JB, and Stam HJ. Impact of chronic pain on everyday physical activity. Eur J Pain 2007; 11(5):587-93.

(53) van der Ploeg HP, Streppel KR, van der Beek AJ, van der Woude LH, Vollenbroek-Hutten M, and van Mechelen W. The Physical Activity Scale for Individuals with Physical Disabilities: test-retest reliability and comparison with an accelerometer. J Phys Act Health 2007; 4(1):96-100.

(54) van Weering $M$, Vollenbroek-Hutten MM, Kotte EM, and Hermens HJ. Daily physical activities of patients with chronic pain or fatigue versus asymptomatic controls. A systematic review. Clin Rehabil 2007; 21(11):1007-23.

(55) Vendrig AA, Lousberg R. Within-person relationships among pain intensity, mood and physical activity in chronic pain: a naturalistic approach. Pain 1997; 73(1):71-6.

(56) Verbunt JA, Sieben JM, Seelen HA, Vlaeyen JW, Bousema EJ, van der Heijden GJ, and Knottnerus JA. Decline in physical activity, disability and pain-related fear in sub-acute low back pain. Eur J Pain 2005; 9(4):417-25.

(57) Verbunt JA, Westerterp KR, Van der Heijden GJ, Seelen HA, Vlaeyen JW, and Andre Knottnerus J. Physical activity in daily life in patients with chronic low back pain. Arch Phys Med Rehabil 2001; 82(6):726-730.

(58) Vercoulen JH, Bazelmans E, Swanink CM, Fennis JF, Galama JM, Jongen PJ, Hommes O, Van der Meer JW, and Bleijenberg G. Physical activity in chronic fatigue syndrome: assessment and its role in fatigue. J Psychiatr Res 1997; 31(6):661-73.

(59) Vlaeyen JW, de Jong J, Geilen M, Heuts PH, and van Breukelen G. The treatment of fear of movement/(re)injury in chronic low back pain: further evidence on the effectiveness of exposure in vivo. Clin J Pain 2002; 18(4):251-61.

(60) Washburn RA, Zhu W, McAuley E, Frogley M, and Figoni SF. The physical activity scale for individuals with physical disabilities: development and evaluation. Arch Phys Med Rehabil 2002; 83(2):193200.

(61) Welk GJ, Blair SN, Wood K, Jones S, and Thompson RW. A comparative evaluation of three accelerometry-based physical activity monitors. Med Sci Sports Exerc 2000; 32(9 Suppl):S489-97. 
(62) Wendel-Vos GC, Schuit AJ, Saris WH, and Kromhout D. Reproducibility and relative validity of the short questionnaire to assess health-enhancing physical activity. J Clin Epidemiol 2003; 56(12):1163-9.

(63) Westerterp KR, Wouters L, and van Marken Lichtenbelt WD. The Maastricht protocol for the measurement of body composition and energy expenditure with labeled water. Obes Res 1995; 3 Suppl 1:49-57.

(64) White J, Strong J. Measurement of activity levels in patients with chronic pain. Occup Ther J Res 1992; 12(4):217-228.

(65) Wind H, Gouttebarge V, Kuijer PP, and Frings-Dresen MH. Assessment of functional capacity of the musculoskeletal system in the context of work, daily living, and sport: a systematic review. J Occup Rehabil 2005; 15(2):253-72.

(66) World Health Organization. International Classification of Impairments, Disabilities, and Health (ICIDH). 1980: Geneva.

(67) World Health Organization. International Classification of Functioning, Disability, and Health (ICF). 2001: Geneva.

(68) World Health Organization. Steps to health; A European framework to promote physical activity for health. 2007: Denmark. 


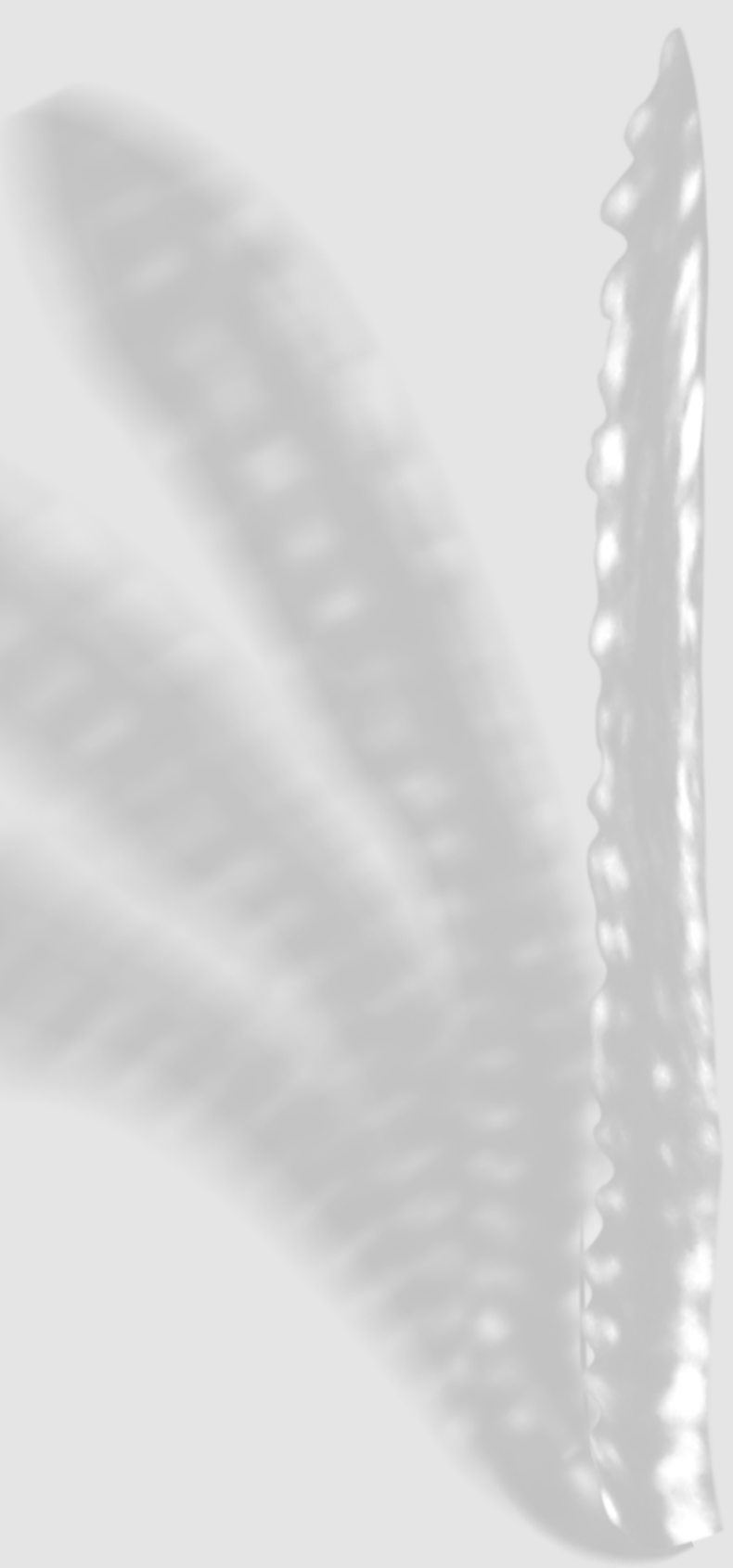




\section{Chapter 5 \\ Do depression and pain intensity interfere with physical activity in daily life in patients with Chronic Low Back Pain?}

This chapter is published as:

Huijnen IP, Verbunt JA, Peters ML, Delespaul P, Kindermans HP, Roelofs J, Goossens $M$, Seelen HA. Do depression and pain intensity interfere with physical activity in daily life in patients with Chronic Low Back Pain? Pain 2010;150(1):161-166 


\section{Abstract}

Patients with chronic pain may have difficulties estimating their own physical activity level in daily life. Pain-related factors such as depression and pain intensity may affect a patients' ability to estimate their own daily life activity level. This study evaluates whether patients with Chronic Low Back Pain (CLBP) who are more depressed and/or report more pain indeed have a lower objectively assessed daily life activity level or whether they only perceive their activity level as lower.

Patients with CLBP were included in a cross-sectional study. During 14 days physical activity in daily life was measured, with both an electronic diary and an accelerometer. Multilevel analyses were performed to evaluate whether a higher level of depression and/or pain intensity was associated with a lower objectively assessed activity level or the discrepancy between the self-reported and objectively assessed daily life activity levels.

Results, based on 66 patients with CLBP (mean RDQ score 11.8), showed that the objectively assessed daily life activity level is not associated with depression or pain intensity. There was a moderate association between the self-reported and objectively assessed activity levels $(\beta=0.39, p<0.01)$. The discrepancy between the two was significantly and negatively related to depression $(\beta=-0.19, p=0.01)$, indicating that patients who had higher levels of depression judged their own activity level to be relatively low compared to their objectively assessed activity level. Pain intensity was not associated with the perception of a patient's activity level ( $\beta$ $=0.12$, ns).

\section{Introduction}

The main aim of many pain rehabilitation programs is to improve a patient's daily life functioning. However, patients with chronic pain often have difficulties estimating their own level of physical activity in daily life (17). This is supported by studies in which a less pronounced association is found between physical activity based on self-report and objective movement registrations in patients with Chronic Low Back Pain (CLBP) $(30,31)$, whereas other studies report moderate to high associations in healthy individuals $(21,23)$. For patients with CLBP, a daily life activity measurement based on self-report can result in an incorrect presentation of their actual activity level $(10,17)$.

In patients with chronic pain, several pain-related factors have been reported that have a negative influence on their self-reported daily life activities. In previous studies, depression and pain intensity were found to be negatively associated with a patient's self-reported activity level $(15,17)$. However, in studies using objective measures for daily life activities no significant associations were found $(11,31)$. 
Furthermore, in patients with CLBP who had a lower score on the mental health domain of the SF-36 quality of life scale, a lower level of physical functioning was found compared to patients with a higher score on mental health, in spite of a comparable level of objective performance in the laboratory (32). It may therefore be hypothesized that patients with CLBP who are more depressed underestimate their daily life activity level. This means that although depression may be associated with the perception of the level of physical activity this may not be the case for objectively assessed daily life activity level. Another potential influencing factor for a patient's perception of their daily life activity level is pain intensity. Patients with higher levels of pain reported to be less physically active $(10,15)$. However, in other studies in which physical activity was assessed with objective measures such as accelerometry, physical capacity or physical performance measures, the association between physical activity and pain intensity appeared to be only weak or nonexistent $(1,9,19,25,31)$.

In this study, we test whether patients with CLBP who are more depressed and/or experience more pain have indeed a lower level of objectively assessed activity in daily life or whether they only judge their activity level as lower. We predicted that especially the discrepancy between the self-reported and objectively measured activity level would be influenced by pain and depression, with patients reporting more severe pain and higher levels of depression showing a relative underestimation of their objectively assessed physical activity.

\section{Methods}

\subsection{Participants}

This study included a subset of patients participating in a longitudinal cohort study, aiming at defining different activity-related strategies in patients with CLBP and testing a new theoretical model in which the role of self-discrepancies in explaining these different types of activity-related strategies will be evaluated. Inclusion criteria for this study were (a) low back pain: pain localized below the scapulae and above the gluteal folds for longer than 3 months (20), (b) age between 18 and 65, (c) no specific cause or strong suspicion of a specific cause, such as lumbar disc herniation with neurological complaints, major structural back abnormality, evidence of inflammatory, systemic or neoplastic disease, (d) agreement to participate in a daily life study, measuring daily life activity with both an accelerometer and a diary for 14 days. Exclusion criteria were (a) pregnancy, (b) non-fluency in Dutch, (c) serious psychiatric diseases. Patients in the cohort study were included in two different ways: 81 patients were referred by consultants in rehabilitation medicine in the Southern part of The Netherlands (one rehabilitation centre, six hospital depart- 
ments of rehabilitation) and 35 patients responded to an advertisement in a local newspaper. In case patients responded to the advertisement the above-mentioned selection criteria were checked by a consultant in rehabilitation medicine, who performed a medical screening according to the clinical guideline for low back pain of the Dutch College of General Practitioners (8). The Medical Ethics Committee of the Maastricht University/University Hospital Maastricht, The Netherlands, approved the protocol.

\subsection{Measures}

\subsubsection{Disability}

Low back disability was assessed using the Roland Disability Questionnaire (RDQ) $(26,27)$. This questionnaire contains 24 items measuring limitations in different activities in daily life that can be answered by Yes or No. The item scores are summed resulting in total scores ranging from 0 to 24 , with higher scores reflecting higher levels of disability. The Dutch version of the RDQ has a high reproducibility and validity and is responsive to change $(5,12,18)$.

\subsubsection{Habitual physical activity in daily life}

To score the habitual physical activity level, which reflects the level of daily life activities during the last year, the Baecke Physical Activity Questionnaire (BPAQ) was used (2). The BPAQ consists of three indices of habitual physical activity: the occupational activity index; sport activity index and the leisure time index. The reliability of the BPAQ in patients with LBP appears to be sufficient (16).

\subsubsection{Pain intensity}

Pain intensity was measured with three $100 \mathrm{~mm}$ Visual Analogue Scales (VAS; 24). Patients were asked to rate their actual pain (at that moment) and their highest and lowest pain levels of the past week on three separate VAS scales. The mean of the three VAS scales was calculated to form a composite score, which was used in further analyses.

\subsubsection{Depression}

The level of depression was measured by the Beck Depression Inventory II (BDI-II; 4). The BDI-II contains 21 items scored from 0 to 3 . Total scores are obtained by summing the item scores resulting in total scores ranging from 0 (not depressed at all) to 63 (severely depressed). The questionnaire has good psychometric properties and is a valid questionnaire to measure the severity of depression in patients with chronic pain $(3,14)$. 


\subsection{Physical activity assessment}

\subsubsection{Diary assessment of physical activity}

To assess a patient's perception of his/her activity level an electronic diary was used. This self-assessment technique allows multiple random assessments based on the Experience Sampling Method $(\operatorname{ESM})(6,7)$. Based on this registration method, activity changes over time can be registered, which can overcome the recall bias of a questionnaire (29). During a 14-day measurement period patients carried a palmtop computer (type palm m100) during waking hours. Patients were instructed that an alarm (beep) would randomly go off eight times a day and at that moment they had to fill in questions. Diary questions were presented on-screen for completion via a touch screen $(50 \times 50 \mathrm{~mm})$ and entries were time and date stamped. A total number of 43 questions were included in each momentary assessment. Two selfconstructed questions were directed to assess a patient's physical activity level. The first question was "Right now, I am active". Answer categories were presented in seven point Likert scales ranging from 1, "not at all" to 7, "very". The second question was "What was my effort between this and the previous beep?". Answer categories were: 1 , lying down; 2, sitting; 3, standing; 4, walking; 5, cycling; 6, sports; 7, sports vigorously. The maximum number of completed set of palm-top questions for the measurement period is 112 . Patients were instructed to respond to as many beeps as possible.

\subsubsection{Accelerometry}

Physical activity in daily life was assessed by a tri-axial accelerometer (RT3; Stayhealthy Inc., Monrovia, USA). Subjects were instructed to wear the RT3 during waking hours for 14 consecutive days. The accelerometer was not worn during activities in case of potential damage to the equipment (e.g. contact sports, swimming or taking a shower). To be included as a valid score on physical activity in daily life, at least 5 valid measurement days, including 1 weekend day, had to be available (13). A valid measurement day was defined as a registration period for at least $600 \mathrm{~min}$ $(10 \mathrm{~h})$. Acceleration signals from the three measurement directions (the sagittal, the mediolateral and the longitudinal axes of the trunk) were recorded. The 3D resultant of the acceleration signal was calculated and the number of occasions per minute (counts) on which this signal exceeded a predefined threshold was stored in a database within the accelerometer. Data processing was performed using MATLAB software (The Math Works Inc., Natick, MA). An algorithm was designed in which night time was identified and excluded for further analysis. In this algorithm first, a second order zero time lag low pass Butterworth filter was used to reduce signal noise. Next, a predefined threshold was determined to identify start and endpoints in the activity signal. The original signal counts were used for further data process- 
ing. The activity signal was processed at the intervals that lay between subsequent beeps of the electronic diary.

\subsection{Procedure}

Prior to participation, all subjects were informed about the purpose of the study and signed a written consent form. Participants completed the self-report measures (containing assessment of disability, habitual physical activity, pain intensity and depression) in a paper-based or computerized internet-based questionnaire. Patients were explained that the interest of the study was to evaluate their daily life functioning and factors that influence their functioning. During a 14-day measurement period patients carried the accelerometer and the palm-top computer simultaneously during waking hours. A short training session on handling both the palmtop and the RT3 was given. During the measurement period stand-by assistance to handle technical problems was available.

\subsection{Data reduction and analysis}

Registration days were only included in case they contained both a valid registration of the accelerometer and the palm-top diary. To check this, first, every day was checked for the availability of a registration time of accelerometer-data of at least $600 \mathrm{~min}$. Subsequently, an additional check was performed on the availability of at least 25 completed ESM reports for all registration days together in which at least $600 \mathrm{~min}$ are registered. For all assessment days that fulfilled both criteria, data of the first completed ESM report of that day were excluded from the final data-file, since answering a question concerning activities since the last beep, on that moment would include a timeframe in which patients were sleeping and not wearing the accelerometer. As a result of this, the maximum achievable number of completed ESM reports in the diary was 98.

In order to study if patients who are more depressed and experience more pain, also have a lower objectively measured activity level, a two-level hierarchical linear regression analysis was performed. In multilevel modelling the repeated observations (in this model the processed activity signal of the accelerometer) are presented as Level 1 units. These observations were organized within Level 2 units, which constitute persons. A critical feature of Level 1 and Level 2 observations are the independency of Level 1 and Level 2 measurements. This method anticipates on the level of variation within and between patients. In the model physical activity based on accelerometry was the dependent variable and depression and pain intensity were the independent variables.

To analyse the association between the level of physical activity assessed by the diary and by the accelerometer again a two-level hierarchical linear regression 
analysis was performed. Since we have two diary questions measuring physical activity, two different models were built. In both models self-reported physical activity based on the diary was the dependent variable. The independent variable was physical activity assessed with an accelerometry.

In addition, in order to test the influence of both depression and pain intensity on the discrepancy between the self-reported and objectively assessed physical activity levels, these variables were introduced in a multilevel model. This procedure was performed separately for both diary questions on self-reported physical activity. In each model, the self-reported physical activity variable assessed with the diary and the objectively assessed physical activity variable assessed with the accelerometer were first standardized and then subtracted, resulting in a discrepancy score between the self-reported and objectively assessed level of physical activity in daily life. Both discrepancy scores were the dependent variable in two different models and in both models depression and pain intensity were the independent variables.

Multilevel modelling was performed using Stata 10 software (Stata Corp., 2007, College Station Texas).

\section{Results}

One hundred and one patients (54 male/47 female) participated in this study and agreed to carry both the palm-top diary and the accelerometer for the assessment of physical activity. Mean age of this group was 47.0 years (SD $=11.0$ ) and $47 \%$ had a paid job. Mean disability level was 11.8 (SD = 4.7). In Fig. 1 , a flow chart is shown, representing the data of patients that were eventually used for further analysis in the current study. Overall, the 66 patients that met the criteria set for inclusion filled in $73.1 \%$ of electronic diary assessments. The median Baecke score of the 66 patients included in the final analyses was 8.7 (interquartile range 7.6-9.8). This score is comparable with scores of healthy Dutch individuals (2). More characteristics of the 66 patients are presented in Table 1. Patients who did not meet the criteria to be included in the data analysis or dropped out of the final analysis due to failure of the diary or palm-top were not significantly different on gender or habitual physical activity level. However, patients who did not meet the criteria for a valid registration were significantly more disabled $(p=0.05)$. Furthermore, patients who had no registration caused by failure of either the diary or the accelerometer were significantly younger. 
Table 1: Characteristics of the study population of patients with CLBP

\begin{tabular}{ll}
\hline Male/Female (N) & $37 / 29$ \\
Age (years) & $48.4+/-9.9$ \\
Work status (N and percentage) & \\
- Paid job & $34(52 \%)$ \\
- Sick leave & $3(8 \%)$ \\
- Disability payment & $11(17 \%)$ \\
Disability level (RDQ ${ }^{*}$ ) & $11.4(4.5)$ \\
Depression (BDI-II **) & $11.0(6.5-15.0)$ \\
Habitual activity level (BPAQ***) & $8.7(7.6-9.8)$
\end{tabular}

Normally distributed data are represented by a mean score (SD). Not normally distributed data are represented by a median score (interquartile ranges). ${ }^{*} \mathrm{RDQ}=$ Roland Disability Questionnaire; ${ }^{* *} \mathrm{BDI}-\mathrm{II}$ = Beck Depression Inventory II; ** BPAQ = Baecke Physical Activity Questionnaire

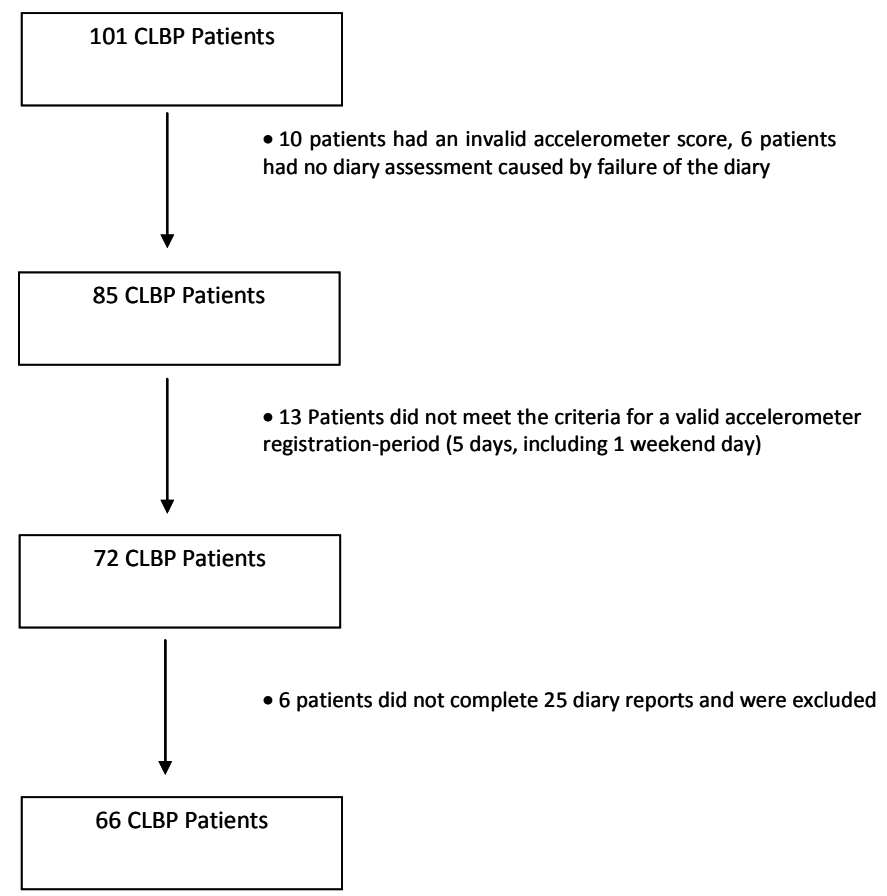

Figure 1: $\quad$ Flow chart

In Table 2, the multilevel analysis with the objective measured activity level as the dependent variable and depression, and pain intensity as independent variables is shown. No significant associations were found in this model. The association between the self-reported physical activity score based on the item "Right now, I am active." and the objectively assessed activity level based on accelerometry was $\beta=$ $0.21, \mathrm{p}<0.01$ (Wald $\mathrm{chi}^{2}=174.94, \mathrm{p}<0.01$ ). The association between the item 
"What was my effort between this and the previous beep?" in the diary and the objectively assessed activity level was $\beta=0.39, p<0.01$ (Wald chi $^{2}=694.75, p<$ 0.01).

Table 2: $\quad$ Multi level analysis with the objective activity in daily life level as dependent variable

\begin{tabular}{llcccc}
\hline Wald $=3.22, p=0.20$ & & & & \\
& Main Effects & $\boldsymbol{\beta}$ & SE & $\mathbf{Z}$ & $\mathbf{P}$ \\
\hline Objective activity level & Pain intensity & -0.08 & 0.06 & -1.25 & 0.21 \\
& Depression & 0.10 & 0.06 & 1.69 & 0.09 \\
\hline
\end{tabular}

In Table 3, the multilevel analysis with the discrepancy between the self-reported activity score related to the question "What was my effort between this and the previous beep?" and the objectively measured activity level as the dependent variable and depression, and pain intensity as independent variables is shown. A significant association was found between depression and the discrepancy score $(\beta=-$ $0.19, \mathrm{p}=0.01$ ), whereas pain intensity did not contribute significantly. In addition, the second model with the discrepancy between the score on the diary item "Right now, I think I am active." and the objectively assessed activity level as dependent variable showed similar results. In this last model, the Wald $\mathrm{chi}^{2}$ appeared to be $7.15, p<0.05$. Depression was found to be significantly associated with the discrepancy score $(\beta=-0.22, p=0.01)$ whereas pain intensity did not $(\beta=0.14, n s)$.

Table 3: $\quad$ Multi level analysis with the discrepancy between the self-reported activity level and the objectively assessed activity level as dependent variable

\begin{tabular}{llcccc}
\hline Wald $=6.58, \mathrm{p}<0.05$ & & & & \\
& Main Effects & $\boldsymbol{\beta}$ & SE & $\mathbf{Z}$ & $\mathbf{P}$ \\
\hline Subjective - Objective & Pain intensity & 0.12 & 0.08 & 1.54 & 0.12 \\
Activity level & Depression & -0.19 & 0.08 & -2.50 & 0.01 \\
\hline
\end{tabular}

\section{Discussion}

This study aimed at evaluating the extent to which higher levels of depression and pain experience are associated with a lower daily life activity level in patients with CLBP. Furthermore, the influence of pain intensity and depression on the discrepancy between the self-reported level of physical activity and the objective measured activity level was tested.

In this study, depression was not associated with the objectively assessed level of physical activity. But patients that were more depressed reported a relatively lower level of physical activity in daily life as compared to their actual level of physical activity. Consequently, depression was significantly associated with the discrepancy between self-reported and objectively assessed physical activity in daily life 
significantly. This finding seems in accordance with results of a study of Kremer et al. who found that patients who were more depressed underreported their activity level as compared to the observed activity level by staff members (17). Furthermore, Wittink et al. found that the score on the mental health domain of the SF-36, measuring quality of life, of patients with CLBP was not associated with their performance on a treadmill, although patients with lower scores on the mental health domain reported a higher level of pain intensity and a lower level of physical functioning (32). In contrast to the lack of association between depression and the objectively assessed daily life activity level in the present and another study (11), several studies reported a negative influence of depression on physical performance and physical capacity testing in patients with $\operatorname{CLBP}(1,22,28)$. However, this negative influence of depression on physical activity measured in a standardized laboratory setting with a performance or capacity test could not be determined when physical activity is measured during actual daily life activities. Based on the findings of this study, it could be hypothesized that a depressed mood can distort a patients' view on his/her own activities. Although depression and actual level of daily life activity are not related, the influence of depression seems especially focussed on the discrepancy between perceived and actual level of physical activity. In interpreting this, it should however be taken into account that the median BDI-II score for depression in the current study was only 11.0 (interquartile range 6.5-15.0), which is below the cut-off score for moderate clinical depression of 20 (14).

Based on the results of the current study, it appeared that pain intensity was not associated with a patient's actual daily life activity level. Furthermore, we hypothesized that a higher score on pain intensity would distort a patient's view of their actual activity level, resulting in a higher discrepancy between actual and perceived level of physical activity. In earlier studies using self-report as outcome measure for physical activity, the association between pain intensity and physical activity was indeed found $(10,15)$. However, in studies using objective daily life activity measurements or performance testing as outcome assessments for physical activity these results could not be confirmed $(1,9,19,25,31)$. In the current study, both subjective and objective assessments of physical activity were included. The assumption that a higher level of pain intensity would have a negative impact on the discrepancy between a patient's perception and the objectified registration of his/her level of physical activity in daily life could however not be confirmed based on these data.

In the current study, a diary assessment was used. A drawback of this assessment is that in one question limited information can be asked for. Therefore, in this study two questions that measure different aspects of physical activity in daily life were evaluated to answer the research questions. One diary question ("What was my effort between this and the previous beep?") asked for the quality of move- 
ments (such as walking and cycling), whereas the other question ("Right now, I am active") asked for the level of intensity.

The current study has some limitations that have to be addressed. The first limitation is the absence of a continuous accelerometry registration due to swimming or being involved in contact sports. This means that the accelerometer has to be taken off which can result in an underestimation of a patient's actual activity level. In the current study, all patients were asked to register when they had to remove the accelerometer. Nine of the 66 patients reported indeed an interruption of their activity registration due to swimming or performing contact sports. Four of them removed the accelerometer for more than $4 \mathrm{~h}$. Since it seemed highly unlikely that they were continuously swimming, imputation would have resulted in an overestimation of a patient's actual activity level. For the other 5 patients, data were imputed with two times the mean score per minute of the previous day which resulted in only a small increase of maximal $3 \%$. Based on this, we eventually decided to abandon imputation for swimming or contact sports.

A second limitation is that the number of patients had to be excluded. The sample size was reduced to 66 patients. The data of 35 patients could not be used for the final analysis: 16 had an invalid RT3 score or problems with the electronic diary, and the data of 19 patients did not meet the predefined data selection criteria. In this study, it appeared that patients who had a registration that did not fulfil the data selection criteria were significantly more disabled. Focusing on this drop-out group revealed that two extreme disability scored 21, with a mean score of 11.4 (SD = 4.5) for the 66 included participants. As a result of this, inclusion of these two patients would disturb a valid presentation of an objective daily life activity level. Even though we used this strict criteria, the sample size in the present study is still higher than in other studies evaluating daily life activities in patients with CLBP (15, 19, 31).

This study has clinical implications. In evaluating a patient's level of activity based on self-report (for instance, as a part of an anamnesis during a clinical consultation or based on a questionnaire as a part of an assessment tool) differences between the activity level as reported by a patient and his/her actual level of physical activity have to be taken into account. Especially in patients who are depressed, an underestimation of a patient's actual activity level has to be taken in mind. Based on this, generalization of results on physical activity retrieved based on self-report to a situation of daily life functioning should be performed with caution. Furthermore, in evaluating treatment, it is important to measure physical activity in daily life objectively because changes in mood during therapy can also influence a patient's perception over time of his/her activity level.

In summary, in the current study it was shown that patients with CLBP, who had a higher level of depression, underestimated their daily activity level, although their actual activity level did not differ. 


\section{Acknowledgements}

This study was supported by the Council for Medical and Health Research of The Netherlands (ZON-MW), Grant No. 14350042. Participation of Dr. Roelofs was supported by the EFIC-Grünenthal-Grant (EGG). The authors want to thank Sita van Riet, Astrid Dello and Truus Custers for their contribution in the data collection. We are also grateful to all physicians referring patients to our study, and to the patients willing to participate. The authors have no conflicts of interest relevant to this work. 


\section{References}

(1) Alschuler KN, Theisen-Goodvich ME, Haig AJ, and Geisser ME. A comparison of the relationship between depression, perceived disability, and physical performance in persons with chronic pain. Eur J Pain 2008; 12(6):757-64.

(2) Baecke JA, Burema J, and Frijters JE. A short questionnaire for the measurement of habitual physical activity in epidemiological studies. Am J Clin Nutr 1982; 36(5):936-42.

(3) Beck AT, Steer RA, and Brown GK. Manual for the Beck Depression Inventory, 2nd ed. San Antonio. TX: The Psychological Corporation 1996.

(4) Beck AT, Steer RA, Brown GK, and Van der Does AJW. BDI-II-NL Handleiding (BDI-II-Dutch Manual). 2002, Lisse: The Netherlands: Psychological Corporation.

(5) Brouwer S, Kuijer W, Dijkstra PU, Goeken LN, Groothoff JW, and Geertzen JH. Reliability and stability of the Roland Morris Disability Questionnaire: intra class correlation and limits of agreement. Disabil.Rehabil. 2004; 26(3):162-165.

(6) Csikszentmihalyi M, Larson R. Validity and reliability of the Experience-Sampling Method. J Nerv Ment Dis 1987; 175(9):526-36.

(7) Delespaul PAEG. Assessing schizophrenia in daily life. 1995, Maastricht: Universitaire press.

(8) Faas A, Chavannes AW, Koes BW, van den Hoogen JMM, Mens JMA, Smeele LM, Romeijnders ACM, and van der Laan JR. NHG-standaard M54 lage-rugpijn. 1996.

(9) Filho IT, Simmonds MJ, Protas EJ, and Jones S. Back pain, physical function, and estimates of aerobic capacity: what are the relationships among methods and measures? Am J Phys Med Rehabil 2002; 81(12):913-20.

(10) Fordyce WE, Lansky D, Calsyn DA, Shelton JL, Stolov WC, and Rock DL. Pain measurement and pain behavior. Pain 1984; 18(1):53-69.

(11) Geisser ME, Haig AJ, and Theisen ME. Activity avoidance and function in persons with chronic back pain. J Occup Rehabil 2000; 10:215-27.

(12) Gommans JHB, Koes BW, and M.W.van T. Validiteit en responsiviteit Nederlandstalige Roland Disability Questionnaire. Vragenlijst naar functionele status bij patienten met lage rugpijn. nederlands tijdschrift voor fysiotherapie 1999; 1997:107;2;:28-33.

(13) Gretebeck RJ, Montoye HJ. Variability of some objective measures of physical activity. Med Sci Sports Exerc 1992; 24(10):1167-72.

(14) Harris CA, D'Eon JL. Psychometric properties of the Beck Depression Inventory--second edition (BDI-II) in individuals with chronic pain. Pain 2008; 137(3):609-22.

(15) Hasenbring MI, Plaas H, Fischbein B, and Willburger R. The relationship between activity and pain in patients 6 months after lumbar disc surgery: Do pain-related coping modes act as moderator variables? Eur J Pain 2006; 10(8):701-9.

(16) Jacob T, Baras M, Zeev A, and Epstein L. Low back pain: reliability of a set of pain measurement tools. Arch Phys Med Rehabil 2001; 82(6):735-42.

(17) Kremer EF, Block A, and Gaylor MS. Behavioral approaches to treatment of chronic pain: the inaccuracy of patient self-report measures. Arch Phys Med Rehabil 1981; 62(4):188-91.

(18) Kuijer W, Brouwer S, Dijkstra PU, Jorritsma W, Groothoff JW, and Geertzen JH. Responsiveness of the Roland-Morris Disability Questionnaire: consequences of using different external criteria. Clin Rehabil 2005; 19(5):488-95.

(19) Liszka-Hackzell JJ, Martin DP. An analysis of the relationship between activity and pain in chronic and acute low back pain. Anesth Analg 2004; 99(2):477-81, table of contents.

(20) Merskey H, Bogduk N. Classification of chronic pain. In: IASP Task force on taxonomy. 2nd ed. Seattle: IASP Press; 1994.

(21) Miller DJ, Freedson PS, and Kline GM. Comparison of activity levels using the Caltrac accelerometer and five questionnaires. Med Sci Sports Exerc 1994; 26(3):376-82.

(22) Novy DM, Simmonds MJ, and Lee CE. Physical performance tasks: what are the underlying constructs? Arch Phys Med Rehabil 2002; 83(1):44-7. 
(23) Philippaerts RM, Westerterp KR, and Lefevre J. Comparison of two questionnaires with a tri-axial accelerometer to assess physical activity patterns. Int J Sports Med 2001; 22(1):34-9.

(24) Price DD, McGrath PA, Rafii A, and Buckingham B. The validation of visual analogue scales as ratio scale measures for chronic and experimental pain. . Pain 1983; 17(1):45-56.

(25) Reneman MF, Schiphorts Preuper HR, Kleen M, Geertzen JH, and Dijkstra PU. Are pain intensity and pain related fear related to functional capacity evaluation performances of patients with chronic low back pain? J Occup Rehabil 2007; 17(2):247-58.

(26) Roland M, Morris R. A study of the natural history of back pain. Part I: development of a reliable and sensitive measure of disability in low-back pain. Spine 1983; 8(2):141-4.

(27) Roland M, Morris R. A study of the natural history of low-back pain. Part II: development of guidelines for trials of treatment in primary care. Spine 1983; 8(2):145-50.

(28) Smeets RJ, van Geel AC, Kester AD, and Knottnerus JA. Physical capacity tasks in chronic low back pain: what is the contributing role of cardiovascular capacity, pain and psychological factors? Disabil Rehabil 2007; 29(7):577-86.

(29) Stone AA, Broderick JE. Real-time data collection for pain: appraisal and current status. Pain Med 2007; 8 Suppl 3:S85-93.

(30) van der Ploeg HP, Streppel KR, van der Beek AJ, van der Woude LH, Vollenbroek-Hutten M, and van Mechelen W. The Physical Activity Scale for Individuals with Physical Disabilities: test-retest reliability and comparison with an accelerometer. J Phys Act Health 2007; 4(1):96-100.

(31) Verbunt JA, Westerterp KR, van der Heijden GJ, Seelen HA, Vlaeyen JW, and Knottnerus JA. Physical activity in daily life in patients with chronic low back pain. Arch Phys Med Rehabil 2001; 82(6):72630.

(32) Wittink H, Rogers W, Sukiennik A, and Carr DB. Physical functioning: self-report and performance measures are related but distinct. Spine 2003; 28(20):2407-13. 



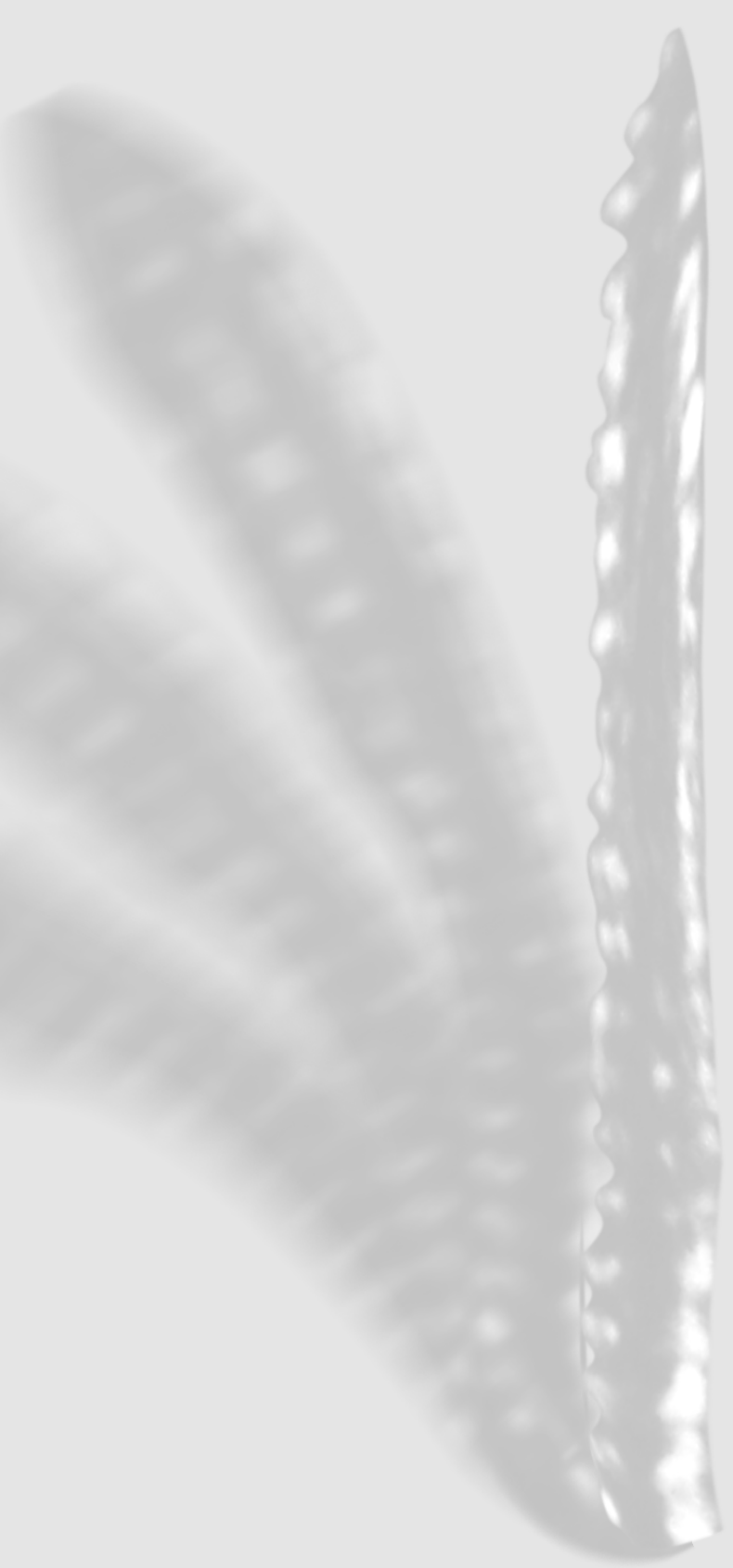


Part II

Identification of subgroups based on activity-related behaviour 


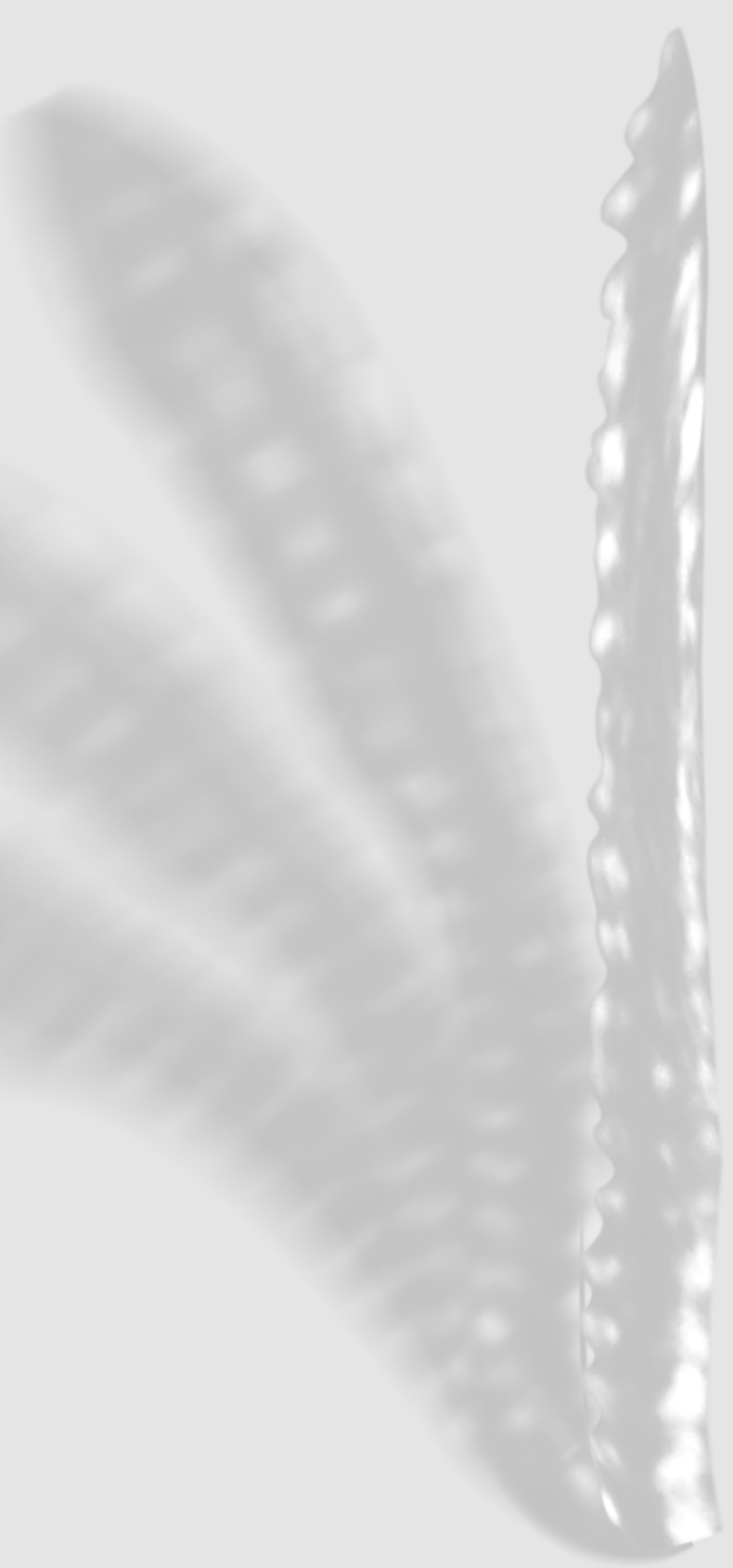




\section{Chapter 6 \\ The disabling role of fluctuations in physical activity in patients with chronic low back pain}

This chapter is published as:

Huijnen IP, Verbunt JA, Roelofs J, Goossens M, Peters M. The disabling role of fluctuations in physical activity in patients with chronic low back pain. Eur J Pain 2009;13(10):1076-1079 


\section{Abstract}

Patients with chronic low back pain (CLBP) often report a disabling decrease in their activity level due to pain. The nature of the association between disability, activity, and pain over time is however, unclear. An intriguing issue here is whether a high level of pain-related disability is associated with a low activity level or are changes in the level of activity over time pain provoking and thus more disabling? The objectives of this study were to investigate associations between disability, pain intensity, pain-related fear, and characteristics of physical activity in patients with CLBP. A total of 42 patients with CLBP were recruited from the Pain Clinic of the Maastricht University Hospital. Each pain patient carried an electronic diary for one week, in which questions about current pain intensity, and the level of physical activity were completed at 8 moments a day. Disability was scored by the Quebec Back Pain Disability Scale (QBPDS), Fear of movement by the Tampa Scale for Kinesiophobia (TSK). To explain the level of disability regression analyses were performed with disability as dependent variable and pain intensity, pain-related fear, and consecutively the level of physical activity in daily life and fluctuations in physical activity as independent variables. Results, based on 34 patients, showed that activity fluctuations $(\beta=0.373, p<0.05)$ rather than the mean activity level over time $(\beta=-0.052$, ns) contributed significantly in explaining disability. The results are discussed in the light of current theories, previous research, and clinical implications.

\section{Introduction}

Patients with chronic low back pain (CLBP) often feel disabled in performing daily activities. According to the fear-avoidance model of chronic pain, these patients may have catastrophic thoughts about their pain resulting in fear of pain, which is characterised by escape and avoidance behaviour. Eventually, avoidance leads to disability, depression, and disuse, which fuel the pain experience resulting in a vicious cycle. Individuals who do not catastrophize about their pain will not become fearful and will expose themselves to daily activities leading to recovery $(11,26)$. Although the role of fear avoidance in explaining disability has been confirmed in a wide range of patients with chronic pain, not all patients show a decreased activity level $(12,15,16,21,24)$. In addition, several studies could not confirm the hypothesized association between physical activity and disability $(12,23,24)$.

In order to unravel the complex associations between physical activity, pain and disability in chronic pain, Hasenbring proposed an alternative strategy. According to the avoidance-endurance model, some patients apply endurance coping and tend to finish their activities despite pain (8). Like avoiders, this subgroup of "persisters" will report an increased level of disability, but their activity level seems to be normal to 
even high as compared to healthy individuals $(8,9)$. Recently, McCracken and Samuel (13) have identified a group of "doers" which closely resemble the "persisters". "Persisters" are likely to continue with activities until pain prevents them from any further activity. This results in complete rest until pain subsides or frustration over inactivity stimulates them to start a new activity $(7,8)$. As a result of this, their level of activity seems to be characterised by a "sawtooth" pattern, indicating that it fluctuates highly over time. According to this theory, for a subgroup of patients, activity fluctuations could even be more disabling than the actual activity level.

In order to study the disabling role of changes in activity, the level of activities has to be assessed in a certain timeframe. Most studies addressing the association between activity and disability relied on self-report measures that are prone to selfreport bias. In the present study we used a momentary sampling strategy method, called experience-sampling method (ESM), to diminish the chance of bias (4). ESM uses randomly sampled self reported measures to gain more insight in relationships of variables assessed over time and to avoid retrospective recall (5).

In the current study, the influence of pain intensity, pain-related fear, level of physical activity and fluctuations in the activity level in explaining disability in patients with CLBP was studied.

\section{Methods}

\subsection{Participants and procedure}

Patients with chronic low back pain, who were referred to the Pain Clinic of Maastricht University Hospital, were recruited for participation in this study (18). Inclusion criteria were (a) experiencing low back pain for at least 6 months and (b) age between 18 and 65. Exclusion criteria were (a) serious visual deficit and deafness; (b) being non-fluent in Dutch; (c) having difficulty holding a pen or writing; (d) serious psychiatric diseases; (e) alcohol and/or drug problems; and ( $f$ ) having participated in a previous ESM study. After signing the informed consent, all participants were informed that the main aim of this study was to investigate how pain was experienced during the day and what factors influence pain. Participants completed a battery of self-report measures and carried a palm-top computer (type palm $\mathrm{m} 100$ ) with a dairy function in a protective case during 7 days. Participants were instructed that an alarm would randomly go off eight times a day and that at that moment patients had to fill in questions. Diary questions were presented on-screen for completion via a touch screen $(50 \times 50 \mathrm{~mm})$ and entries were time- and datestamped. Participants could delay answering for 20 min when engaged in an activity that could not be interrupted. The maximum number of beeps per week was 56 . In case less than $50 \%$ of all registration moments were entered in the palmtop by the 
patient, data were excluded from further analyses. Participants were paid 25 Euro in return for participation in the study. The study protocol was approved by the Ethics Committee of the Maastricht University Hospital and Maastricht University.

\subsection{Measurement}

All participants completed the Tampa Scale for Kinesiophobia (TSK;(14) and the Quebec Back Pain Disability Scale (10). The TSK contains 17 items aimed at assessing fear of (re)injury due to movement. The Dutch version has been reported to be reliable and valid $(6,17,25)$. Low back disability was assessed using the Quebec Back Pain Disability Scale (QBPDS). This scale contains 20 items of which each item is rated from 0 (No difficulty performing this activity) to 5 (Impossible to perform this activity). The original as well as the Dutch version of the QBPDS are valid and reliable $(10,19)$.

With respect to the diary assessment, current pain intensity was assessed with the item "Right now, I am in pain". Answer categories were presented in seven point Likert scales ranging from 1 to 7 , with 1 indicating the lowest possible score and 7 indicating the highest possible score. Furthermore, the level of subjectively reported physical activity level was assessed based on a self constructed item: "What was your effort between this and the previous beep?" Answer categories were: 7 = exercise vigorously; 6 = exercise; $5=$ cycling; 4 = climbing stairs; $3=$ walking; 2 = sitting; 1 = lying down.

\subsection{Data analysis}

For every participant, mean values are calculated for pain intensity, and the activity level assessed in the diary. These values (Pain ESM $_{\text {, and }}$ activity ${ }_{E S M}$ ) were used in the analyses.

In addition, in order to study activity fluctuations in daily life over time a Root Mean Square score for activities (Activity ${ }_{\mathrm{RMS}}$ ) was calculated. The difference scores of all activity values as related to one score earlier were calculated. These difference scores can be positive or negative values and were squared. Thereafter, a mean value was calculated and finally, the root from this mean value was taken. The final score Activity $_{\text {RMS }}$ represents the intensity of activity fluctuations in daily life over time.

To provide a description of the study group, mean scores or percentages for demographic and pain-related variables were calculated. Furthermore, in order to study the interrelation between a patient's level of pain intensity, level of physical activity and fluctuations in the level of physical activity, associations between these variables were calculated based on Pearson correlations coefficients. 
In order to study the relation between a patient's level of disability, pain intensity, pain-related fear, level of physical activity, and fluctuations in the level of physical activity the interrelation between variables was studied in a hierarchical multiple regression analysis. A blockwise entry of variables with disability as dependent variable was used. In the first step fear of movement, Pain ESM, $_{\text {Activity }}$ ESM $_{\text {were entered. }}$ In the second step, Activity ${ }_{\mathrm{RM}}$ was added to the equation, in order to study its unique contribution.

For all regression analyses, a colinearity check was performed. Colinearity was considered a problem when the variance inflation factor (VIF) was above 3. All statistical analyses were performed using SPSS software (SPSS Inc. Chicago, III).

\section{Results}

Forty-two participants (17 males, 25 females) with non-specific CLBP participated in the study. Five patients answered questions for less then $50 \%$ of the beeps of the palmtop, and their data were excluded for further analyses. None of the patients reported that he/she could not fill in the electronic diary due to their back pain. For three patients no Quebec Back Pain Disability Score was available. The final analyses were performed on 34 patients.

The mean age of all participating patients was 45.4 years $(S D=9.9)$. Mean pain duration was 156.5 months (SD=116.9 range 18 - 444). Mean disability level (QBPDS) for all patients was 55.97 (15.3) and their mean level for fear of injury

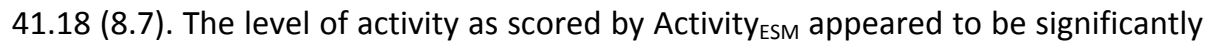
associated with the intensity of activity fluctuations over time (Activity RMS $_{\text {) }}$ (0.57, p < 0.01). Both Activity ESM $_{\text {as well as Activity }}$ RMS were not associated with Pain $_{\text {ESM }}$.

In figure 1 an example of the result of a one-day ESM-registration of one patient is given. The diary recordings of all participants showed a mean Pain ${ }_{E S M}$ score of

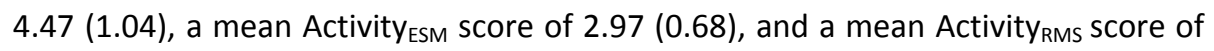
1.53 (0.59).

\subsection{Associations between disability, pain intensity, fear of movement fluctuations in the activity level and the activity level for patients with CLBP}

Table 1 presents the regression model explaining disability in patients with CLBP. In the first step Pain ESM $_{(}(p<0.01)$ explains disability. Fear of movement and Activity ESM had no significant contribution. In the second step Activity RMS was added in the regression model. In this step, Pain $_{\text {ESM }}(p<0.01)$ and Activity RMS $_{(}(p<0.05)$ both explained disability. In the second step, the contribution of fear of movement was nearly significant $(\beta=0.295, p=0.056)$. Activity ${ }_{E S M}$ did not have a significant contri- 
bution. In the final step, $32 \%$ of the variance in the level of disability could be explained $(p<0.01)$. All VIF factors were below 1.53 which indicated that there was no

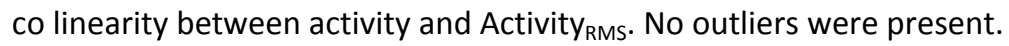

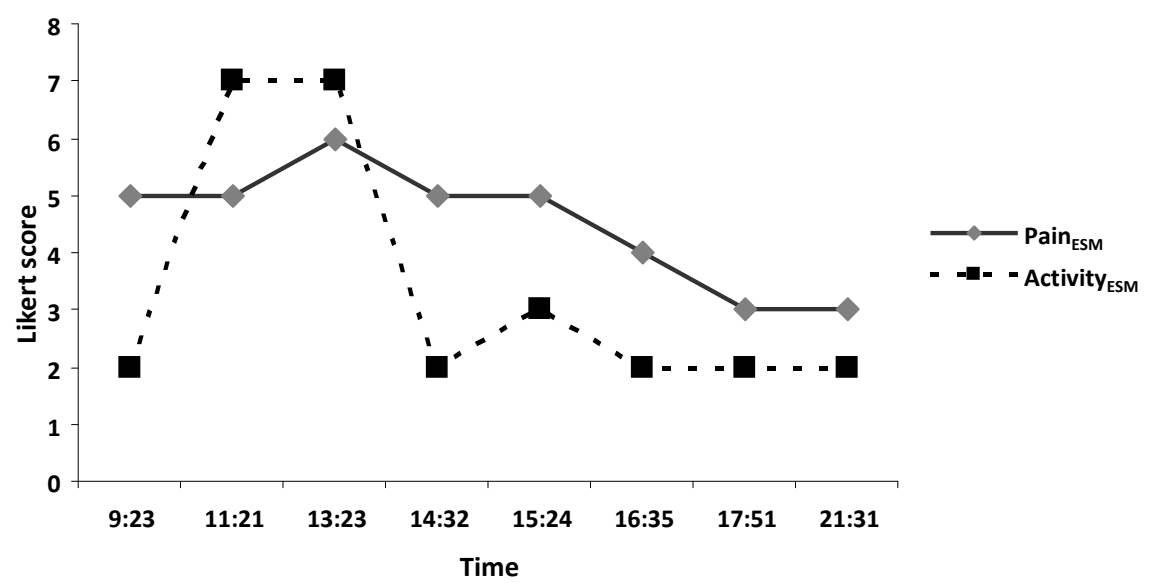

Figure 1: An example of a day registration based on the ESM-method based on 8 at random samples

Table 1: $\quad$ Regression analyses with disability as dependent variable

\begin{tabular}{lll}
\hline Step 1: Disability & $\mathrm{R}^{2}=0.309^{*}$, Adjusted $\mathrm{R}^{2}=0.240^{*}$ & \\
\hline & Fear of movement & $\beta=0.236$ \\
& Pain $_{\mathrm{ESM}}$ & $\beta=0.525 * *$ \\
& Activity $_{\mathrm{EMS}}$ & $\beta=0.158$ \\
\hline Step 2: Disability & $\mathrm{R}^{2}=0.401^{* *}$, Adjusted $\mathrm{R}^{2}=0.318^{* *}$ & \\
\hline & Fear of movement & $\beta=0.295$ \\
& Pain & $\beta=0.502 * *$ \\
& Activity $_{\mathrm{EMS}}$ & $\beta=-0.052$ \\
& Activity $_{\mathrm{RMS}}$ & $\beta=0.373 *$ \\
\hline
\end{tabular}

$* \mathrm{p}<0.05, * * \mathrm{p}<0.01$

\section{Discussion}

The main aim of the present study was to study the role of physical activity and fluctuations in the activity level over time in explaining disability in patients with CLBP. Results indicated that fluctuations in the activity level seemed more associated with the level of disability as compared to the mean activity level over time in patients with CLBP.

The intensity of activity fluctuations over time was positively associated with a patient's perceived level of disability, whereas his/her mean activity level did not 
have any significant disabling influence. Although a high level of activity fluctuations seems natural in healthy individuals, for patients with chronic pain this could represent an activity pattern characterised by interfering involuntary rest stops due to pain. The high level of fluctuations could be a representation of the sawtooth pattern in their activities. Patients go on with their activities till the activity is finished and afterwards they have to take rest to recover. It could even be that, a lack of control regarding the performance of activities at any time is the underlying disabling factor. It might be possible that patients with more fluctuations in activity represent a pattern as described for the group of "doers" in the study of McCracken (13) or the "persisters" with endurance coping in the avoidance endurance model of Hasenbring (8). However, this hypothesis cannot be confirmed based on the current results. More research is needed.

No association could be determined between pain intensity and the mean activity level or the fluctuations in activity. Earlier studies addressed the association between pain intensity and activity over time in patients with low back pain (12, 23). Pain intensity was associated with activity in the first 7 days of acute low back pain (Liszka-Hackzell). However, in patients with chronic pain, in both studies, no association between pain and activity was found which is in accordance with our findings. In addition, we checked whether pain intensity was associated with the level of fluctuations in activity but could not confirm the presence of any relationship.

The current study contributes to the explanation of disability within the population of patients with CLBP and may have clinical implications. Till now, most research has been focused on explaining disability in "avoiders" based on the fact that a low activity level would be disabling. As a result, exposure in vivo and graded activities are evidence based interventions that now are regularly applied in clinical practice to reduce the disability level in "avoiders". However, it could be that patients who have a disabling fluctuating pattern in their activities, benefit more from learning strategies to fine tune their activities during the day instead of increasing their activity level. However, currently, no scientific basis is yet available to prove this statement.

The current study has some limitations that need to be addressed. The activity level and fluctuations in activity were derived from subjectively reported diary measures. It is known that for patients with chronic pain it is difficult to estimate their own physical activity level. However, it is important to note that thus far only self-report measures have been used and this diary study gives more insight in daily life functioning. Interestingly, a recent study by Bousema et al. (2007) and van der Werf et al. (2000) made an activity related classification based on activity assessment by accelerometry $(2,22)$, which is also a promising direction for future research. More research is needed to further elucidate the characteristics of patients with chronic low back pain and to incorporate the various findings into a theoretical 
framework that can be used to apply treatment for activity related subgroups in chronic pain. A second limitation of this study might be that using an electronic diary at several time points during a day could influence a patients' natural behaviour. However, this assumed reactivity effect based on electronic dairy assessment in pain patients could not be confirmed in earlier studies on this topic $(1,3,20)$.

In summary, in the current study it appeared that fluctuations in the activity level instead of the mean activity level over time could explain the level of disability.

\section{Acknowledgements}

This study was supported by the Council for Medical and Health Research of the Netherlands (ZON-MW), Grant No. 14350042. Participation of Dr. J. Roelofs was supported by the EFIC Grünenthal Grant. 


\section{References}

(1) Aaron LA, Turner JA, Mancl L, Brister H, and Sawchuk CN. Electronic diary assessment of painrelated variables: is reactivity a problem? J Pain 2005; 6(2):107-15.

(2) Bousema EJ, Verbunt JA, Seelen HA, Vlaeyen JW, and Knottnerus JA. Disuse and physical deconditioning in the first year after the onset of back pain. Pain 2007; 130(3):279-86.

(3) Cruise CE, Broderick J, Porter L, Kaell A, and Stone AA. Reactive effects of diary self-assessment in chronic pain patients. Pain 1996; 67(2-3):253-8.

(4) Csikszentmihalyi M, Larson R. Validity and reliability of the Experience-Sampling Method. J Nerv Ment Dis 1987; 175(9):526-36.

(5) deVries MW. Investigating mental disorders in their natural settings. J Nerv Ment Dis 1987; 175(9):509-13.

(6) Goubert L, Crombez G, Vlaeyen J, Van Damme S, Van Den Broeck A, and Van Houdenhove B. De Tampa Schaal voor Kinesiofobie: Psychometrische karakteristieken en normering (The Tampa scale Kinesiophobia: Psychometric properties and norms. Gedrag en Gezondheid 2000; 28:54-62.

(7) Harding V, Williams A. Activities training: Intergrating behavioral and cognitive methods with physiotherapy in pain management. J Occup Rehabil 1998; 8(1):47-60.

(8) Hasenbring $M$, Hallner D, and Klasen B. (Psychological mechanisms in the transition from acute to chronic pain: over- or underrated?). Schmerz 2001; 15(6):442-7.

(9) Hasenbring MI, Plaas H, Fischbein B, and Willburger R. The relationship between activity and pain in patients 6 months after lumbar disc surgery: Do pain-related coping modes act as moderator variables? Eur J Pain 2006; 10(8):701-9.

(10) Kopec JA, Esdaile JM, Abrahamowicz M, Abenhaim L, Wood-Dauphinee S, Lamping DL, and Williams JI. The Quebec Back Pain Disability Scale. Measurement properties. Spine 1995; 20(3):341-52.

(11) Leeuw M, Goossens ME, Linton SJ, Crombez G, Boersma K, and Vlaeyen JW. The fear-avoidance model of musculoskeletal pain: current state of scientific evidence. J Behav Med 2007; 30(1):77-94.

(12) Liszka-Hackzell JJ, Martin DP. An analysis of the relationship between activity and pain in chronic and acute low back pain. Anesth Analg 2004; 99(2):477-81, table of contents.

(13) McCracken LM, Samuel VM. The role of avoidance, pacing, and other activity patterns in chronic pain. Pain 2007; 130(1-2):119-25.

(14) Miller R, Kori S, and Todd D. The Tampa scale, Unpublished report. 1991.

(15) Naliboff BD, Cohen MJ, Swanson GA, Bonebakker AD, and McArthur DL. Comprehensive assessment of chronic low back pain patients and controls: physical abilities, level of activity, psychological adjustment and pain perception. Pain 1985; 23(2):121-34.

(16) Nielens H, Plaghki L. Cardiorespiratory fitness, physical activity level, and chronic pain: are men more affected than women? Clin J Pain 2001; 17(2):129-37.

(17) Roelofs J, Goubert L, Peters ML, Vlaeyen JW, and Crombez G. The Tampa Scale for Kinesiophobia: further examination of psychometric properties in patients with chronic low back pain and fibromyalgia. Eur J Pain 2004; 8(5):495-502.

(18) Roelofs J, Peters ML, Patijn J, Schouten EG, and Vlaeyen JW. Electronic diary assessment of painrelated fear, attention to pain, and pain intensity in chronic low back pain patients. Pain 2004; 112(3):335-342.

(19) Schoppink LE, van Tulder MW, Koes BW, Beurskens SA, and de Bie RA. Reliability and validity of the Dutch adaptation of the Quebec Back Pain Disability Scale. Phys Ther 1996; 76(3):268-75.

(20) Stone AA, Broderick JE, Schwartz JE, Shiffman S, Litcher-Kelly L, and Calvanese P. Intensive momentary reporting of pain with an electronic diary: reactivity, compliance, and patient satisfaction. Pain 2003; 104(1-2):343-51.

(21) van den Berg-Emons RJ, Schasfoort FC, de Vos LA, Bussmann JB, and Stam HJ. Impact of chronic pain on everyday physical activity. Eur J Pain 2007; 11(5):587-93. 
(22) van der Werf SP, Prins JB, Vercoulen JH, van der Meer JW, and Bleijenberg G. Identifying physical activity patterns in chronic fatigue syndrome using actigraphic assessment. J.Psychosom. Res. 2000; 49(5):373-379.

(23) Vendrig AA, Lousberg R. Within-person relationships among pain intensity, mood and physical activity in chronic pain: a naturalistic approach. Pain 1997; 73(1):71-76.

(24) Verbunt JA, Westerterp KR, van der Heijden GJ, Seelen HA, Vlaeyen JW, and Knottnerus JA. Physical activity in daily life in patients with chronic low back pain. Arch Phys Med Rehabil 2001; 82(6):72630.

(25) Vlaeyen JW, Kole-Snijders AM, Boeren RG, and van Eek H. Fear of movement/(re)injury in chronic low back pain and its relation to behavioral performance. Pain 1995; 62(3):363-72.

(26) Vlaeyen JW, Linton SJ. Fear-avoidance and its consequences in chronic musculoskeletal pain: a state of the art. Pain 2000; 85(3):317-32. 



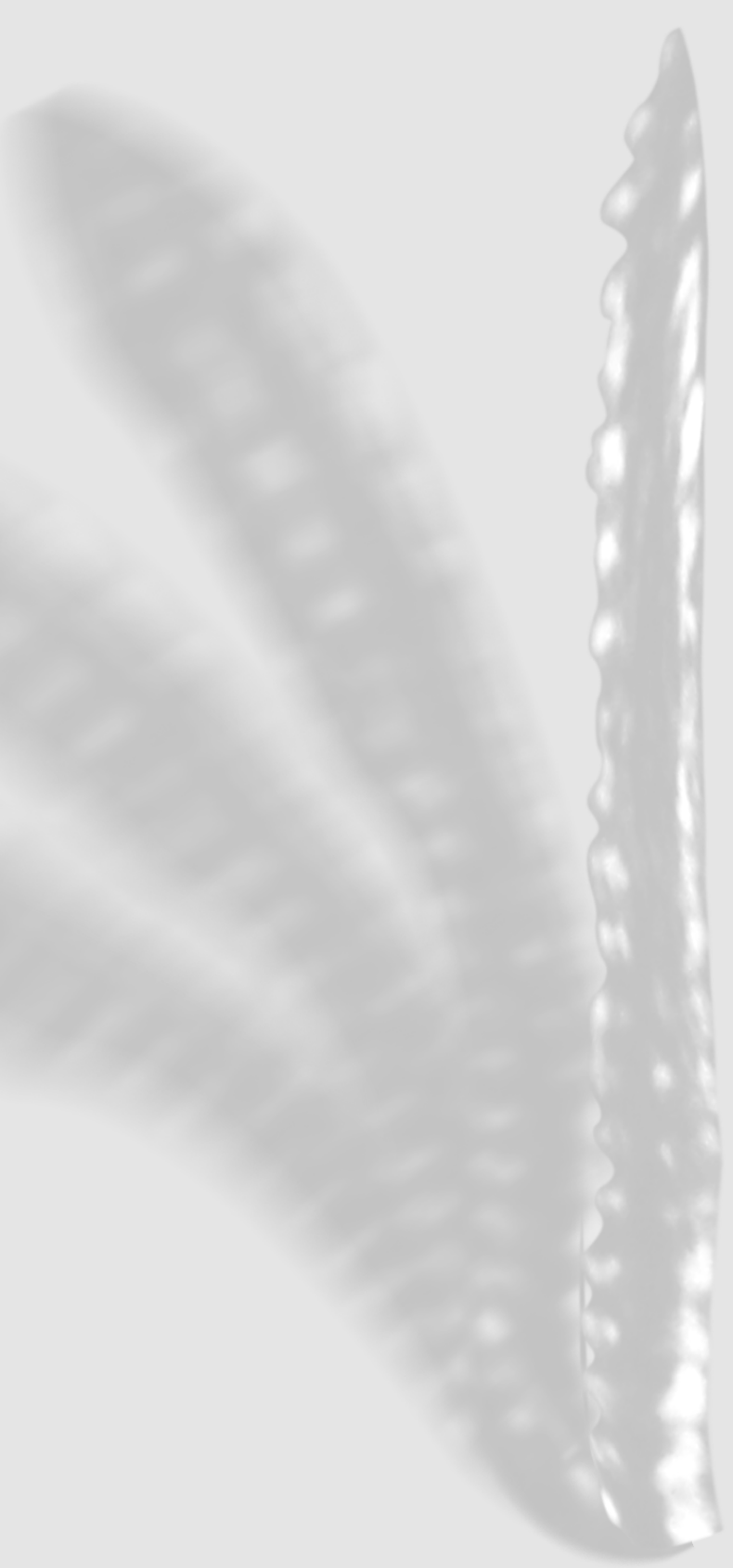




\section{Chapter 7 \\ Differences in activity-related behaviour among patients with chronic low back pain}

This chapter is published as:

Huijnen IP, Verbunt JA, Roelofs J, Goossens M, Peters M. Huijnen IP, Verbunt JA, Peters ML, Smeets RJ, Kindermans HP, Roelofs J, Goossens M, Seelen HA. Differences in activity-related behaviour among patients with chronic low back pain. Eur J Pain 2011;15(7):748-755 


\begin{abstract}
The aim of the present study was to compare the subjectively reported and objectively assessed activity-related characteristics of patients with Chronic Low Back Pain (CLBP) who were classified according to their scores on the Patterns of Activity Measure-Pain (POAM-P) into avoiders, persisters, mixed performers (i.e. high scores on both avoidance and persistence behaviour) or functional performers (i.e. low scores on avoidance and persistence behaviour).

Patients carried an electronic diary during 14 days to assess the self-reported activity and pain intensity levels in daily life. An accelerometer was used to objectively assess their activity level during the same time period.

Results were available for 79 patients. Avoiders, persisters and mixed performers showed a higher level of self-reported disability than functional performers. Avoiders were characterized by a low level of self-reported habitual activities and persisters by long objectively measured daily uptime. The objectively assessed level of physical activity did not differ between the four groups. A further analysis tested the association between pain intensity levels and self-reported and objectively assessed daily life activity levels in avoiders and persisters. In persisters, a higher level of self-reported activities in daily life was related to increased pain. The objectively assessed activity level was not associated with pain intensity.
\end{abstract}

\title{
1. Introduction
}

One of the most prominent models to explain disability in patients with chronic low back pain (CLBP) is the cognitive behavioural fear-avoidance model (40). This model proposes that catastrophic interpretations about pain and elevated pain-related fear levels might lead to avoidance behaviour. In the long run this may lead to a chronic pain problem, characterized by disability in daily life functioning, depression, and a lower daily life activity level. Although numerous studies have confirmed the different steps in this model, no consistent evidence exists for the assumed lower activity level of patients with $\operatorname{CLBP}(23,38)$. In acute low back pain higher levels of pain-related fear and longer periods of bed rest were found. However in CLBP this finding could not be confirmed (36). Furthermore, several studies showed that the mean activity level of patients with CLBP did not differ from that of healthy individuals $(6,34,38)$. It seems therefore that not all patients with CLBP who are disabled avoid activities (6).

The avoidance-endurance model postulates that there are two different routes to increased pain-related disability. According to this model chronic pain patients can display two alternative activity-related strategies: an avoidant strategy which is characterized by low activity levels, or a strategy that is characterized by persistence 
in activities $(17,19)$. Whereas avoiders will try to escape from activities for which they expect an increase of pain or injury, persisters tend to continue their activities despite pain, until completion is reached. However, after completion of the activity, pain might increase, which, in turn, force persisters to take rest until the pain subsides $(5,15)$. This eventually results in a sawtooth pattern of their daily life activity level. In addition, because persisters force themselves to complete the activities they set out to do and therefore postpone rest they are hypothesized to show longer daily uptime than avoiders. The avoidance-endurance model further assumes that the most adaptive coping strategy is a combination of low avoidance and low persistence behaviour, which results in less limitations in daily life functioning (17, 18).

The main aim of the present study is to compare characteristics of persisters and avoiders among patients with CLBP. Three hypotheses were specified:

1. Patients identified as persister or avoider will report more limitations in daily life functioning compared to patients that show low persistence and avoidance behaviour.

2. Persisters will have a higher physical activity level in daily life; will show more fluctuations in daily life activities; and will have a longer daily uptime compared to avoiders.

3. Increased activity in daily life will be associated with increased pain intensity afterwards in persisters but not in avoiders.

\section{Methods}

\subsection{Participants}

This study is part of a longitudinal cohort study in which 116 patients with CLBP participated (20). Inclusion criteria were: (a) low back pain: pain localized below the scapulae and above the gluteal folds for longer than three months (28); (b) age between 18 and 65; (c) the low back pain is not attributable to a recognisable, known specific pathology (e.g. infection, tumour, osteoporosis, fracture, structural deformity, inflammatory disorder (e.g. ankylosing spondylitis), radicular syndrome or cauda equina syndrome) (1). Exclusion criteria were (a) pregnancy; (b) serious psychiatric diseases; (c) non-fluency in Dutch. Patients were included in two different ways: 81 patients were referred by consultants in rehabilitation medicine in the southern part of the Netherlands (one rehabilitation centre, six hospital departments of rehabilitation), and 35 patients responded to an advertisement in a local newspaper. In case patients responded to the advertisement, the above mentioned selection criteria were checked by a consultant in rehabilitation medicine who performed a medical screening according to the clinical guideline for low back pain of 
the Dutch College of General Practitioners (11). The Medical Ethics Committee of the Maastricht University/University Hospital Maastricht, the Netherlands, approved the study protocol.

\subsection{Procedure}

Prior to participation, all subjects were informed about the purpose of the study and signed a consent form. Participants completed the self-report measures on disability, activity-related strategies, fear of movement, habitual physical activity level, pain intensity level, and depressed mood using either a paper-based or internet-based questionnaire. During a 14 day measurement period patients carried an accelerometer to measure physical activity in daily life and an electronic diary during waking hours. A short training session on using the electronic diary and the accelerometer was given. During the measurement period stand-by assistance to handle technical problems was available.

\subsection{Measures}

\subsubsection{Questionnaire assessment}

\subsubsection{Demographic and pain-related information}

Gender, age, work status and duration of complaints were recorded. Pain intensity was measured with three $100 \mathrm{~mm}$ Visual Analogue Scales (VAS; 29). Patients rated their current pain and their highest and lowest pain level during the past week. $A$ composite score was calculated from the mean of the three VASs.

\subsubsection{Fear of movement}

Fear of movement/ (re)injury was assessed with the Dutch version of the Tampa Scale for Kinesiophobia (TSK). This questionnaire contains 17 items that are rated on a 4-point scale ranging from 'strongly disagree' to 'strongly agree'. A total score can be obtained by summing all items after recoding of the reverse-keyed items. The Dutch version has been reported to be reliable and valid $(13,39)$.

\subsubsection{Depressive symptoms}

Depressive symptoms were assessed by the Beck Depression Inventory II (BDI-II; 4). The BDI-II contains 21 items scored from 0 to 3 . Total scores are obtained by summing the item scores resulting in total scores ranging from 0 (not depressed at all) to 63 (severely depressed). The questionnaire has good psychometric properties and is a valid questionnaire to measure the severity of depression in patients with chronic pain $(3,16)$ 


\subsubsection{Disability}

Low back disability was assessed using the Roland Disability Questionnaire (RDQ) $(30,31)$. This questionnaire contains 24 items measuring limitations in different activities in daily life that can be answered by yes or no. A total score is obtained by summing all items scored as "yes". The Dutch version of the RDQ has a high reproducibility and validity and is responsive to change $(7,12,22)$.

\subsubsection{Habitual physical activity in daily life}

To assess the level of daily life activities during the last year the Baecke Physical Activity Questionnaire (BPAQ) was used (2). The BPAQ has 16 items that are rated on a 5-point Likert-scale. Three indices of habitual physical activity can be derived: the occupational activity index; the sport activity index and the leisure time index. The patient also reports his main occupation which is then categorized as light, moderate, or heavy work according to the level of energy expenditure. Furthermore, the two most frequently played sports are reported together with the number of hours played per week and for how many months a year. The different sports are divided into low, middle, and high level sports. The sport activity index is calculated from the intensity of the sport, the amount of time per week playing that sport, and the proportion of the year the sport was played. A total BPAQ score can be obtained by summing the means of the three indices. This total score was used in the present study. The reliability of the BPAQ in patients with LBP appears to be sufficient (25).

\subsubsection{Classification of activity-related strategies}

Patients were labelled as 'avoider' or 'persister' based on their score on the Patterns Of Activity Measure-Pain (POAM-P) (9). The POAM-P is a 30-item self-report questionnaire, developed to measure three activity patterns in patients with chronic pain, namely avoidance (10 items), overdoing (10 items) and pacing (10 items). Patients rated each item describing how they usually perform their regular daily life activities on a five point scale ranging from 0 (not at all) to 4 (always). Total scores per subscale can range from 0 to 40 . The three-factor structure of the Dutch version of the POAM-P has been confirmed (21). The three subscales were found to be highly internal consistent (Cronbach alphas ranging from 0.80 to 0.94 ). Significant and meaningful associations with related constructs such as fear of movement and (re)injury, pain catastrophizing, depression, and disability, confirmed the validity of the subscales (21). Since the focus of the current study was on an avoidant versus persistent activity-related strategy, only the results of the subscales avoidance and overdoing were used to categorize patients. The score on the pacing subscale are presented for descriptive purposes only.

To label patients' activity-related strategies, the median score for the overdoing and avoidance subscale of the POAM-P of the patients in the present study was 
calculated. Patients with a score on the avoidance subscale at or above the median and a score on the overdoing subscale below the median score were defined as 'avoiders'. Patients with a score on the overdoing subscale at or above the median and below the median score on the avoidance subscale were defined as 'persisters'. In addition, patients with a score below the median on both the avoidance and the overdoing subscale were defined as 'functional performers'. Patients who scored above or at the median on both the overdoing and avoidance subscale were defined as 'mixed performers.

\subsubsection{Diary assessment}

To assess a patient's pain intensity and changes in pain intensity over time, an electronic diary was used. Furthermore, a patient's perception of his/her activity level and changes over time were registered. Diary assessment allows multiple random assessments based on the Experience Sampling Method (ESM) (10, 20). During a 14 day measurement period patients carried a palm-top computer (type palm m100) during waking hours. Diary questions were presented on-screen for completion via a touch screen $(50 \times 50 \mathrm{~mm})$ and entries were time- and date-stamped. Patients were informed that an alarm (beep) would randomly go off eight times a day indicating that they had to fill in a momentary assessment consisting of forty-three questions. One of the questions of every momentary assessment was towards measuring a patient's current pain intensity. The level of pain intensity was assessed by means of "Right now, I am in pain". Answer categories were presented in 7-point Likert scale ranging from 1, "not at all" to 7, "very". The question "What was my effort between this and the previous beep?" was used to assess a patient's activity level. The answer categories were: 1 = lying down; 2 = sitting; 3 = standing; 4 = walking; 5 = cycling; 6 = sports; 7 = sports vigorously. The maximum attainable number of completed sets of palmtop questions for the measurement period was 112 . Patients were instructed to answer as many beeps as possible.

\subsubsection{Objective activity in daily life measures collected by the accelerometer}

Physical activity in daily life was assessed using a tri-axial accelerometer (RT3; Stayhealthy Inc., Monrovia, USA). Subjects were instructed to wear the RT3 during waking hours for 14 consecutive days. The accelerometer was not worn during waterbased activities (e.g. swimming, taking a shower), or in case of potential damage to the equipment (e.g. contact sports). The tri-axial accelerometer is a valid instrument for the measurement of physical activity in daily life in patients with LBP (38).

\subsection{Data processing}

To be included as a valid accelerometer score for physical activity in daily life, at least five valid measurement days, including one weekend day, had to be available 
$(14,20)$. A valid measurement day was defined as a registration period for at least 600 consecutive minutes (10 hours). The recorded 3-D acceleration signals were converted into one resultant acceleration signal. Next, the number of occasions (counts) per minute on which this signal exceeded a predefined threshold was stored. Data processing was performed off-line using MATLAB software (The Math Works Inc., Natick, Mass). In order to be able to study the association between the objectively measured activity level and the subsequent pain intensity level, the mean activity signal between the current and previous beep of the diary were calculated. At least 25 valid diary entries had to be available in order to be used in further data analyses. Data of the first completed diary report of that day were excluded from the analysis, since answering a question concerning activities since the last beep, on that moment would include a timeframe in which patients were sleeping and not wearing the accelerometer.

\subsubsection{Daily uptime}

Because patients were instructed to wear the accelerometer the whole day during waking hours, it is possible to define the period between getting up and going to sleep. An algorithm was designed to identify this daily uptime. Firstly, a second order zero time lag low pass Butterworth filter was used to reduce signal noise. Secondly, a predefined threshold was used to identify uptime that is defined as the period between the first and last activity count that exceeded a predefined threshold ( $U_{1}$ and $U_{2}$ respectively; see figure 1$)$.

\subsubsection{Mean total activity score}

The original non-filtered signal data were used to calculate the mean total activity expressed as the mean counts per day (37).

\subsubsection{Characteristics of the avoidance or persistence strategy}

In order to identify if a patient applies an avoidance or persistence strategy, two variables were calculated. First, an algorithm was designed in which the highest activity-score within a 14-day registration (see figure 1 ) could be identified. Subsequently, in order to express the peak activity per person as a representation for persistence, the $80 \%$ power of this maximum score was then calculated and presented as $\mathrm{PA}_{\text {power }}$ In figure 1 , as an example the non-filtered and filtered activity signal, the highest activity peak, the $\mathrm{PA}_{\text {power }}$ of the accelerometer and pain intensity measured in the diary are shown for a restricted period of three measurement days. Second, for every patient a fluctuation score was calculated to express the level of activity fluctuations over time. To study these changes in activity over time, for 15 consecutive minutes, activity counts were summed. Next, the difference scores between a summed activity score as related to one score earlier were calculated. These difference scores can have a positive or a negative value and were therefore 
squared. Thereafter, a mean value was calculated. Finally, the root from this mean value was taken, to achieve a final score for the intensity of activity fluctuations in daily life over time (fluctuations act $_{\text {) }}$.

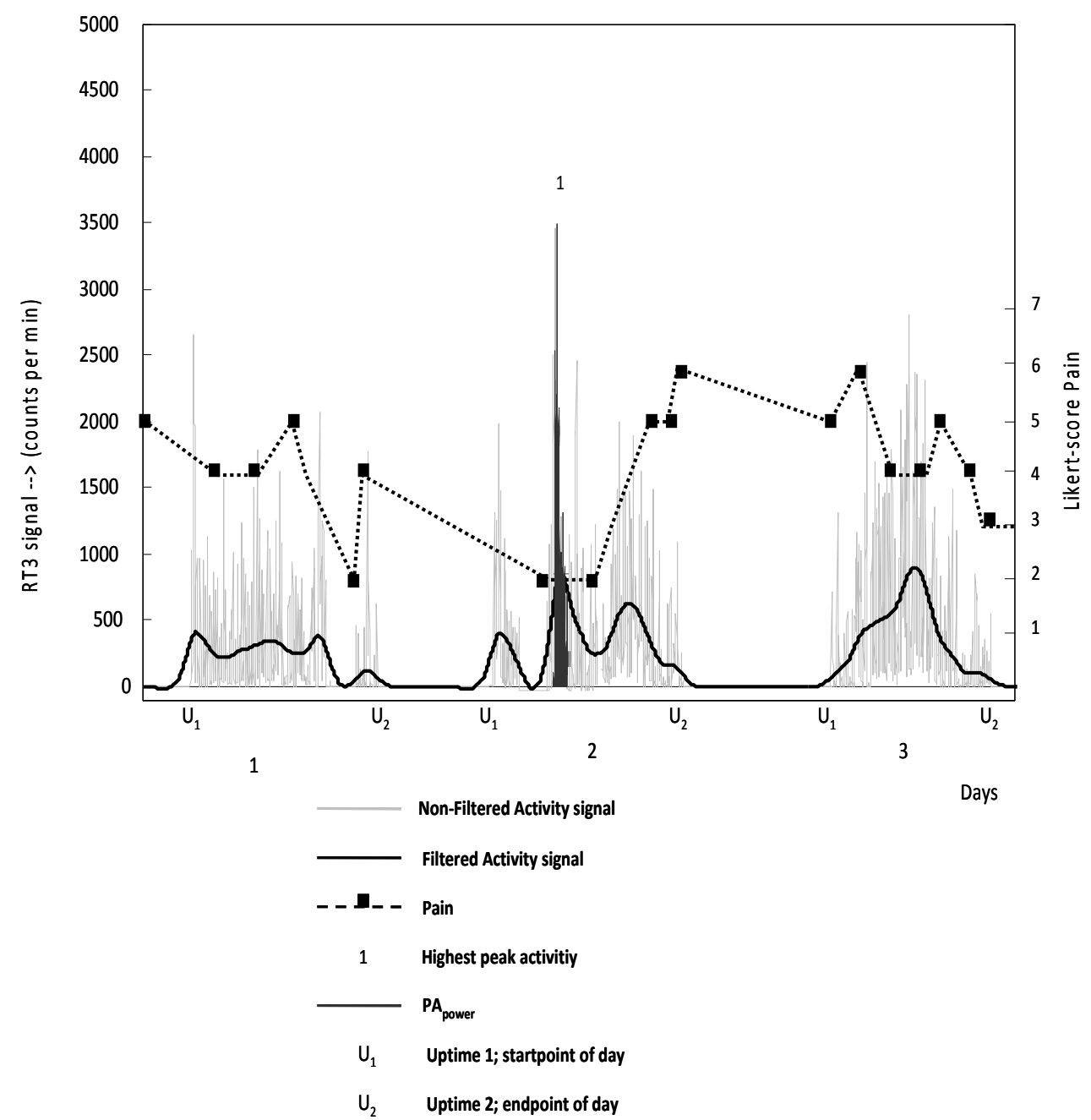

Figure 1: An example of a registration based on the accelerometer and the diary

\subsection{Data analysis}

In order to study the difference in characteristics and activity-related variables between avoiders, persisters, mixed performers and functional performers multiple one way ANOVA's were used in case of a normal distribution. In case of a significant result of the one way ANOVA, a post-hoc Least Significant Difference analysis was 
performed to explore the difference between groups. In case of non-normal distributions of the data, the Kruskall Wallis test was used. Subsequent multiple comparisons included Mann-Whitney tests.

In order to study the association between the level of pain intensity and the objectively measured activity level over time for persisters and avoiders, a two level hierarchical linear regression analysis was performed. In multi-level modelling the repeated observations (in this model the processed activity signal of the accelerometer) are presented as Level 1 units. These observations were organized within Level 2 units, which constitute persons. A critical feature of Level 1 and Level 2 observations are the independency of Level 1 and Level 2 measurements. This method anticipates on the level of variation within and between patients. In model 1 , the pain intensity level was introduced as the dependent variable in the model. In the first step, physical activity based on accelerometry and the type of activity-related strategy (avoider or persister) were introduced as independent variables. In the second step the interaction between the objective activity score and type of activity-related strategy was added. In case of a significant interaction, two additional multi-level analyses were performed, for avoiders and persisters separately. In both additional analyses, the level of pain intensity was again the dependent variable and the objectively assessed physical activity in daily life score was the independent variable. In model 2, the procedure of model 1 was repeated, but with the independent variable being physical activity based on self-report (diary assessment) instead of physical activity based on accelerometry. In all analyses alpha was set at 0.05. Multilevel modelling was performed using Stata 10 software (Stata Corp., 2007. College Station Texas). All other statistical analyses were performed using SPSS software version 16 (SPSS Inc., Chicago, III.).

\section{Results}

One hundred and seven patients participated in the accelerometer assessment. Seven patients who carried an accelerometer had an invalid activity score caused by failure of the RT3. In addition, accelerometer registrations of three patients could not be used for further analysis because the signal to noise ratio was too low. For the remaining 97 patients data were processed and the length of the daily registration of the accelerometer was evaluated. For 84 patients an accelerometer registration that fulfilled all pre-determined validity criteria for activity assessment was available. Of these patients, five patients did not complete the POAM-P questionnaire, which made definition of their activity-related strategy impossible. Data of the remaining 79 patients were used in further analyses. In figure 2, a flow chart is shown, representing the data of patients who were used for further analysis in the current study. Demographic (gender, age, and work status) and pain-related charac- 
teristics (pain duration, level of pain intensity and disability level) of patients, whose data were not used in the analyses, were not different from patients whose data were used. Gender, duration of complaints, work status, pain intensity, and disability level did not differ significantly between patients who entered the study by consultants of rehabilitation medicine or based on inclusion by advertisement. However, patients who responded to the advertisement were significantly older $(53.3$ years, $S D=9.0$ ) compared to patients referred by their consultant in rehabilitation medicine (age $=44.6$ years, $S D=10.3$ ).

107 Patients with CLBP

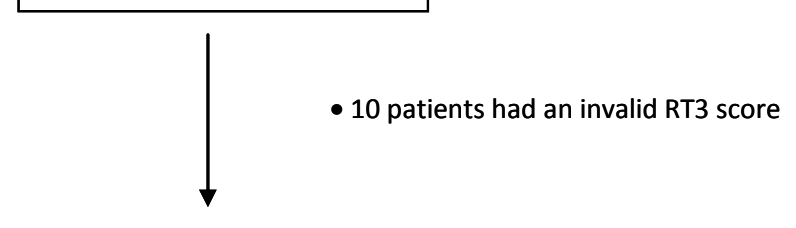

97 Patients with CLBP

- 13 Patients did not meet the pre-determined selection criteria for a valid accelerometer registration (5 days, including 1 weekend day)

84 Patients with CLBP

With a valid physical activity in daily life measurement

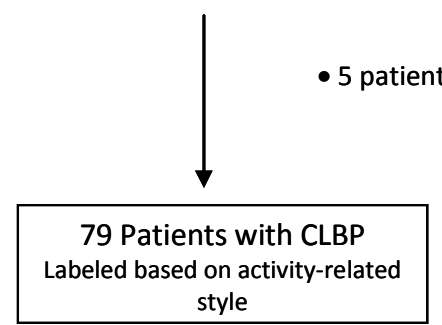

Figure 2: $\quad$ Flow chart

\subsection{Description of the population}

Table 1 presents characteristics of the four subgroups based on the different activity-related strategies. Scores of patients on the avoidance and overdoing subscale 
were not significantly related $(r=-0.05, n s)$. Avoiders, persisters and mixed performers scored significantly higher on fear of movement and depressed mood compared to functional performers. Furthermore, persisters had a lower level of fear of movement compared to avoiders and mixed performers $(p<0.01)$. The percentage of woman is higher in the group of avoiders compared to the mixed performer group $(p<0.01)$. Avoiders were found to have a higher score on the pacing subscale of the POAM-P compared to persisters and functional performers $(p<0.01)$. Furthermore, mixed performers scored also higher on pacing than persisters $(p<0.05)$.

Table 1: $\quad$ Characteristics of the study population of patients with CLBP

\begin{tabular}{|c|c|c|c|c|c|c|}
\hline & $\begin{array}{l}\text { 1. Avoiders } \\
(N=18)\end{array}$ & $\begin{array}{l}\text { 2. Persisters } \\
(\mathrm{N}=19)\end{array}$ & $\begin{array}{l}\text { 3. Mixed } \\
\text { performers } \\
(\mathrm{N}=22)\end{array}$ & $\begin{array}{l}\text { 4. Functional } \\
\text { performers } \\
(\mathrm{N}=20)\end{array}$ & $\begin{array}{l}\text { Test } \\
\text { Statistic }\end{array}$ & p-value \\
\hline Male/Female & $5 / 13^{a}$ & $10 / 9^{a}$ & $17 / 5^{b}$ & $11 / 9^{a b}$ & $x^{2}=9.69$ & 0.02 \\
\hline Age & $45.7(9.8)$ & $48.2(8.4)$ & $44.2(10.9)$ & $50.6(12.5)$ & $F=1.44$ & 0.24 \\
\hline $\begin{array}{l}\text { Duration of complaints } \\
\text { (months) }\end{array}$ & $83(39-261)$ & $68(32-109)$ & $116(36-219)$ & $115(40-232)$ & $x^{2}=2.66$ & 0.45 \\
\hline \multicolumn{7}{|l|}{ Work status (percentage) } \\
\hline - Paid job & $8(44 \%)$ & $10(53 \%)$ & $10(46 \%)$ & $12(60 \%)$ & $\chi^{2}=1.06$ & 0.79 \\
\hline - Sick leave & $2(11 \%)$ & $1(5 \%)$ & $1(5 \%)$ & 0 & $\chi^{2}=2.38$ & 0.50 \\
\hline - Disability payment & $2(11 \%)$ & $3(16 \%)$ & $6(27 \%)$ & $2(10 \%)$ & $x^{2}=3.15$ & 0.37 \\
\hline Fear of movement (TSK) & $41.6(6.8)^{a}$ & $36.6(6.7)^{b}$ & $43.9(6.6)^{a}$ & $32.1(5.5)^{c}$ & $F=13.8$ & $<0.001$ \\
\hline Depressed mood (BDI-II) & $\begin{array}{l}12.5 \\
(9.5-19.0)^{a}\end{array}$ & $12.0(8.0-17.0)^{a}$ & $\begin{array}{l}15.5 \\
(11.0-21.3)^{a}\end{array}$ & $6.5(4.0-9.8)^{b}$ & $x^{2}=21.4$ & $<0.001$ \\
\hline Pain intensity & $48.5(15.8)^{a b}$ & $50.4(17.2)^{a b}$ & $55.7(17.5)^{a}$ & $41.1(14.4)^{b}$ & $F=2.87$ & 0.04 \\
\hline Avoidance (POAM-P) & $26.4(4.7)$ & $12.1(5.5)$ & $25.4(3.7)$ & $13.7(6.0)$ & & \\
\hline Overdoing (POAM-P) & $18.8(4.5)$ & $28.6(3.1)$ & $28.1(2.6)$ & $17.4(5.0)$ & & \\
\hline
\end{tabular}

${ }^{\mathrm{abc}}$ values with the same superscripts represent homogenous subsets

Normally distributed data are represented by means (SD) and not normally distributed data are represented by medians (interquartile ranges).

TSK = Tampa Scale for Kinesiophobia; BDI-II = Beck Depression Inventory II; Avoidance = Score on the avoidance subscale of the POAM-P; Overdoing = Score on the overdoing subscale of the POAM-P

\subsection{Disability, daily uptime, and physical activity in daily life}

Table 2 presents the scores on activity-related variables for the four subgroups. Both avoiders and mixed performers felt significantly more disabled as compared to persisters and functional performers. Persisters had a significantly higher disability level compared to functional performers $(p<0.05)$. Furthermore, avoiders reported to be less active on the BPAQ compared to persisters and functional performers ( $p<$ 0.05). Mean daily uptime of persisters was $889 \mathrm{~min}(S D=65.0)$, which is significantly higher than the uptime for avoiders ( $820 \mathrm{~min}(S D=66.2), p<0.01)$. The objectively 
assessed activity level, the level of activity fluctuations over time, and the power of the highest activity peak did not differ significantly between avoiders and persisters.

Table 2: $\quad$ Scores on activity-related variables for the different activity-related behaviour styles

\begin{tabular}{|c|c|c|c|c|c|c|}
\hline & $\begin{array}{l}\text { 1. Avoiders } \\
(\mathrm{N}=18)\end{array}$ & $\begin{array}{l}\text { 2. Persisters } \\
(N=19)\end{array}$ & $\begin{array}{l}\text { 3. Mixed } \\
\text { performers } \\
(\mathrm{N}=22)\end{array}$ & $\begin{array}{l}\text { 4. Functional } \\
\text { performers } \\
(\mathrm{N}=20)\end{array}$ & $\begin{array}{l}\text { Test } \\
\text { Statistic }\end{array}$ & p-value \\
\hline Disability (RDQ) & $13.6(3.6)^{a}$ & $10.8(3.6)^{b}$ & $13.9(4.1)^{\mathrm{a}}$ & $8.0(3.5)^{c}$ & $F=11.1$ & $<0.001$ \\
\hline $\begin{array}{l}\text { Habitual activity } \\
\text { level (BPAQ) }\end{array}$ & $7.8(6.9-8.9)^{a}$ & $9.2(7.4-10.6)^{b c}$ & $8.3(7.5-9.5)^{a b}$ & $9.0(8.3-10.2)^{c}$ & $x^{2}=8.95$ & 0.03 \\
\hline $\begin{array}{l}\text { Uptime } \\
\text { (in min) }\end{array}$ & $820(66.2)^{a}$ & $889(65.0)^{b}$ & $866(75.5)^{a b}$ & $854(87.0)^{a b}$ & $F=2.76$ & 0.05 \\
\hline $\begin{array}{l}\text { Objective Activity } \\
\text { (in counts } \times 10^{3} \text { ) }\end{array}$ & y $187(133-276)$ & $214(178-247)$ & $196(155-296)$ & $178(138-219)$ & $x^{2}=2.32$ & 0.51 \\
\hline Fluctuations $s_{\text {act }}$ & $310(251-424)$ & $326(273-491)$ & 337 (266-439) & $350(283-504)$ & $\chi^{2}=0.63$ & 0.88 \\
\hline $\begin{array}{l}\mathrm{PA}_{\text {power }} \\
\text { (in counts } \times 10^{3} \text { ) }\end{array}$ & $52.6(39.8-72.8)$ & ) 46.8 (33.2-74.6) & $43.1(35.9-90.6)$ & $47.6(33.7-70.3)$ & $x^{2}=0.70$ & 0.87 \\
\hline
\end{tabular}

\subsection{The association between pain intensity level and activity}

Table 3 presents the results of the multilevel analyses of model 1 with the level of pain intensity as dependent and the objectively assessed activity level, the group variable avoiders/persisters and the interaction between both variables as independent variables. Note that these analyses only included the data of patients that fulfilled the pre-determined validity criteria for diary assessment. Eventually a valid diary assessment was available for 30 of the 37 patients classified as avoider ( $\mathrm{N}=$ 14 ) and persister $(\mathrm{N}=16)$. No significant model, associations or interaction were found. Table 4 shows the results of model 2 including the self-reported activity level based on the diary as independent variable instead of the objectively assessed physical activity level in model 1 . In the first step, a significant model was found in which a higher self-reported physical activity level between two beeps was related to a higher level of pain intensity at the moment of the last beep $(\beta=0.09, p<$ 0.001 , Wald $\left.\chi^{2}=24.99, p<0.001\right)$. In the second step, the interaction term was added which contributed significantly to the model $(\beta=0.15, p<0.001)$. The analysis per subgroup (table 5 ) revealed that the association between the pain intensity level and self-reported activity level in avoiders was not significant. In contrast, in persisters the level of physical activity assessed in the diary significantly explained the level of pain intensity $\left(\beta=0.15, p<0.001\right.$, Wald $\left.\chi^{2}=40.95, p<0.001\right)$. 
Table 3: $\quad$ Multi level analysis with pain intensity as dependent and the objective activity level in daily life, group (avoiders/persisters) and the interaction between both variables as independent variables

\begin{tabular}{|c|c|c|c|c|c|}
\hline & Main Effects & $\beta$ & SE & Z & $\mathbf{P}$ \\
\hline Step 1: & Wald $=1.65, p=0.44$ & & & & \\
\hline \multirow[t]{2}{*}{ Pain intensity } & Objective activity level & 0.02 & 0.02 & 1.25 & 0.21 \\
\hline & Group (avoiders/persisters) & -0.08 & 0.28 & -0.30 & 0.77 \\
\hline Step 2: & Wald $=1.66, p=0.65$ & & & & \\
\hline Pain intensity & Group x objective activity & 0.00 & 0.04 & 0.06 & 0.96 \\
\hline
\end{tabular}

Table 4: $\quad$ Multi level analysis with pain intensity as dependent and the subjectively reported activity level in daily life, group (avoiders/persisters), and the interaction between both variables as independent variables

\begin{tabular}{llcccc}
\hline & Main Effects & $\beta$ & SE & Z & P \\
\hline Step 1: & Wald = 24.99, p $<0.001$ & & & & $<0.001$ \\
Pain intensity & Subjective activity level & 0.09 & 0.02 & 4.99 & 0.72 \\
& Group (avoiders/persisters) & -0.10 & 0.29 & -0.36 & \\
\hline Step 2: & Wald = 42.57, p < 0.001 & & & & \\
Pain intensity & Group x subjective activity & 0.15 & 0.04 & 4.17 & $<.001$ \\
\hline
\end{tabular}

Table 5: $\quad$ The multilevel analyses evaluating the association between pain intensity and the subjectively reported activity level in daily life within the avoiders and persisters subgroup

\begin{tabular}{llllll}
\hline & Main Effects & $\beta$ & SE & Z & P \\
\hline Avoiders & Wald $=0.01, p=0.91$ & & & \\
Pain intensity & Subjective activity level & 0.00 & 0.03 & -0.12 & 0.91 \\
\hline Persisters & Wald $=40.95, p<0.001$ & & & & \\
Pain intensity & Subjective activity level & 0.15 & 0.02 & 6.40 & $<001$ \\
\hline
\end{tabular}

\section{Discussion}

This study aimed to compare characteristics of patients with CLBP based on different activity-related strategies. Furthermore, associations between pain intensity level and self-reported and objectively assessed daily life activity level were evalu- 
ated within patients classified as avoiders and persisters on the basis of their POAMP score.

This study could not confirm a lower mean objectively assessed activity level for avoiders compared to persisters. One might speculate that patients classified as avoiders are especially prone to avoid specific activities or postures that they fear might cause a pain increase. If they do perform other non-feared activities their mean activity level may still be comparable to patients classified as persisters. The accelerometer is not able to register enough details to differentiate between various types of activities (such as standing, walking and cycling). Although accelerometry provides a valid representation of global activities in daily life (38), no information is obtained about specific postures and type of activities. For future research, it is recommended to use an activity monitor, which enables the identification of different types of activities and postures $(8,32)$. It can than be established whether specific types of activities are avoided.

In contrast to objectively assessed mean activity level, self-reported activity level, measured with the BPAQ, was lower in avoiders compared to persisters. Avoiders also reported a higher level of fear of movement, which is in line with the fear-avoidance model (40). Our finding that avoiders have a shorter period of daily uptime compared to persisters is consistent with earlier research that showed that higher levels of pain-related fear were associated with longer periods of bed rest in patients with acute low back pain (36). This suggests that in avoiders, pain-related fear forces a patient to have a shorter daily uptime, whereas in persisters the drive to finish all activities eventually results in a longer daily uptime. Furthermore, previous research also found that the subjectively reported standing and walking time were lower in patients classified as avoiders than in patients with a behavioural pattern that resembles our persister group (27). However, no reference values for daily uptime in healthy individuals are available. Future research on this theme seems recommendable.

Another intriguing finding is that in persisters a higher activity level as reported in the diary, seems to result in an increase of pain, whereas in avoiders no association between pain and activity could be found. This could imply that, during activities, persisters indeed ignore their pain and try to finish the activity which results in a higher level of pain afterwards. The novelty of the current study is that the association between pain and activity within daily life activities were evaluated for persisters and avoiders separately. Other studies evaluating this relationship in patients with pain did not differentiate between differences in activity-related strategies of the individual patients. They indeed reported an association between activity and pain in acute pain, but not in the chronic phase $(26,35)$. In the current study there was no association between the objectively assessed activity level and current pain intensity level, but in patients classified as persister an association was found between self-reported activity level and the level of pain intensity. A possible reason 
for this discrepancy could be that the perception of persisters of their actual daily life activities is distorted (20). When peristers notice an increase in their pain they might infer that this is caused by having been more active in the preceding time period. Another reason for the difference in findings between the objective and diary assessment could again be that the accelerometer cannot differentiate between different activities. For patients with CLBP some activities or postures can cause a pain increase, whereas other activities with similar acceleration signals have no influence on pain intensity.

Both avoiders and persisters felt more disabled in their daily life functioning than functional performers. Furthermore, avoiders reported more limitations in their functioning compared to persisters. This finding could also be based on the fact that the current available disability questionnaires especially focus on avoidance-related disability instead of persistence-related disability. Some items in the RDQ (e.g., "I avoid heavy jobs around the house because of my back.", "I sit down for most of the day because of my back", and "Because of my back, I lie down to rest more often.") will not be positively confirmed by persisters, whereas avoiders will. Although persisters will probably continue with the performance of activities, they can perceive themselves as disabled in performing physical and/or social activities. Therefore, more research is needed to solve the issue whether persisters indeed perceive less limitations or that measuring disability in persisters is more complicated and that the validity of existing questionnaires is limited for this specific patient group.

An unexpected finding was the high number of patients in the mixed performer group. Initially, persistence and avoidance were assumed to be two opposite strategies on a continuum, as proposed in the avoidance-endurance model $(17,18)$. However, a substantial number of patients scored high on both persistence and avoidance behaviour. This mixed performer group showed higher levels of fear of movement, pain intensity, depression, disability, and a lower self-reported activity level compared to the functional performers. In this mixed performer group, it might be that it is context-dependent whether a patient persists or avoids activities. Patients in this mixed performer group seem to be at least as dysfunctional as persisters and avoiders. The characteristics of this mixed performer group shows similarities with the characteristics of the 'extreme cycler' as identified by McCracken et al. (27). The extreme cyclers were characterized by high levels of confronting (resembling persistence), avoidance, and pacing. This group reported more pain, anxiety and physical disability than the medium cycler group (comparable to the functional group in this study). Future studies should gain more insights in a patients' decision for using either avoidance or persistence strategies in their daily life activities.

One limitation of the current study is the limited number of patients in each group. Eventually, the data of 23 patients could not be used for further analyses. Of these 23 patients, 10 had an invalid RT3 score and data of 13 patients did not meet 
the pre-defined data selection criteria for valid physical activity assessment. In addition, seven patients classified as avoider or persister did not have a diary assessment and therefore data of these patients could not be used in the analyses evaluating the association between pain intensity (derived from the diary) and objectively assessed level of physical activity (with accelerometry). For future research it is recommended to further develop the measurement techniques to prevent dropouts due to failure of the accelerometer or electronic diary.

This study has clinical implications. Current cognitive-behavioural treatment approaches of CLBP are predominantly aimed at restoring physical functioning in patients showing avoidance behaviour. Exposure in vivo and graded activity are evidence-based interventions that appear to be highly effective in reducing disability in this subgroup of patients (24). This study demonstrates that not only activity avoidance but also persistence is associated with increased disability. The optimal treatment approach for patients employing a persistent strategy might however be different from that which is being used for patients with an avoidant strategy. A recent study applied tailored treatments for fibromyalgia patients showing either avoidance or persistence behaviour and found that these led to significant improvements in physical and psychological functioning (33). A similar approach might be useful for patients with CLBP showing distinct activity-related behaviour patterns. Developing tailored treatments for all subgroups of patients with CLBP is a future challenge.

\section{Acknowledgements}

This study was supported by the Council for Medical and Health Research of the Netherlands (ZON-MW), Grant No. 14350042. Participation of Dr. Roelofs was supported by the EFIC-Grünenthal-Grant (EGG). The authors have no conflicts of interest relevant to this work. 


\section{References}

(1) Airaksinen O, Brox JI, Cedraschi C, Hildebrandt J, Klaber-Moffett J, Kovacs F, Mannion AF, Reis S, Staal JB, Ursin H, and Zanoli G. Chapter 4. European guidelines for the management of chronic nonspecific low back pain. Eur Spine J 2006; 15 Suppl 2:S192-300.

(2) Baecke JA, Burema J, and Frijters JE. A short questionnaire for the measurement of habitual physical activity in epidemiological studies. Am J Clin Nutr 1982; 36(5):936-42.

(3) Beck AT, Steer RA, and Brown GK. Manual for the Beck Depression Inventory, 2nd ed. San Antonio. TX: The Psychological Corporation 1996.

(4) Beck AT, Steer RA, Brown GK, and Van der Does AJW. BDI-II-NL Handleiding (BDI-II-Dutch Manual). 2002, Lisse: The Netherlands: Psychological Corporation.

(5) Birkholtz M, Aylwin M, and Harman RM. Activity pacing in chronic pain management: One aim, but which method? Part one: Introduction and literature review. Br J Occup Ther 2006; 67(10):447-452.

(6) Bousema EJ, Verbunt JA, Seelen HA, Vlaeyen JW, and Knottnerus JA. Disuse and physical deconditioning in the first year after the onset of back pain. Pain 2007; 130(3):279-86.

(7) Brouwer S, Kuijer W, Dijkstra PU, Goeken LN, Groothoff JW, and Geertzen JH. Reliability and stability of the Roland Morris Disability Questionnaire: intra class correlation and limits of agreement. Disabil.Rehabil. 2004; 26(3):162-165.

(8) Bussmann JB, Martens WL, Tulen JH, Schasfoort FC, van den Berg-Emons HJ, and Stam HJ. Measuring daily behavior using ambulatory accelerometry: the Activity Monitor. Behav Res Methods Instrum Comput 2001; 33(3):349-56.

(9) Cane D, Nielson WR, McCarthy M, and Mazmanian D, Development and preliminary evaluation of a measure of three pain-related patterns of activity, in 27th Annual Canadian Pain Society Meeting. 2007: Ottawa, Ontario.

(10) Csikszentmihalyi M, Larson R. Validity and reliability of the Experience-Sampling Method. J Nerv Ment Dis 1987; 175(9):526-36.

(11) Faas A, Chavannes AW, Koes BW, van den Hoogen JMM, Mens JMA, Smeele LJM, Romeijnders ACM, and van der Laan JR. NHG-standaard M54 lage-rugpijn. 1996.

(12) Gommans JHB, Koes BW, and van Tulder MW. Validiteit en responsiviteit Nederlandstalige Roland Disability Questionnaire. Vragenlijst naar functionele status bij patienten met lage rugpijn. Nederlands Tijdschrift voor Fysiotherapie 1997; 107(2):28-33.

(13) Goubert L, Crombez G, Vlaeyen J, Van Damme S, Van Den Broeck A, and Van Houdenhove B. De Tampa Schaal voor Kinesiofobie: Psychometrische karakteristieken en normering (The Tampa scale Kinesiophobia: Psychometric properties and norms. Gedrag en Gezondheid 2000; 28:54-62.

(14) Gretebeck RJ, Montoye HJ. Variability of some objective measures of physical activity. Med Sci Sports Exerc 1992; 24(10):1167-72.

(15) Harding V, Williams A. Activities training: Intergrating behavioral and cognitive methods with physiotherapy in pain management. J of Occupational Rehabilitation 1998; 8(1):47-60.

(16) Harris CA, D'Eon JL. Psychometric properties of the Beck Depression Inventory--second edition (BDIII) in individuals with chronic pain. Pain 2008; 137(3):609-22.

(17) Hasenbring M, Hallner D, and Klasen B. (Psychological mechanisms in the transition from acute to chronic pain: over- or underrated?). Schmerz 2001; 15(6):442-7.

(18) Hasenbring MI, Plaas H, Fischbein B, and Willburger R. The relationship between activity and pain in patients 6 months after lumbar disc surgery: Do pain-related coping modes act as moderator variables? Eur J Pain 2006; 10(8):701-9.

(19) Hasenbring MI, Verbunt JA. Fear-avoidance and endurance-related responses to pain: new models of behavior and their consequences for clinical practice. Clin J Pain 26(9):747-53.

(20) Huijnen IP, Verbunt JA, Peters ML, Delespaul P, Kindermans HP, Roelofs J, Goossens M, and Seelen HA. Do depression and pain intensity interfere with physical activity in daily life in patients with Chronic Low Back Pain? Pain 2010; 150(1):161-6. 
(21) Kindermans H, Roelofs J, Goossens M, Huijnen I, Verbunt J, and Vlaeyen J. Measuring avoidance, overdoing and pacing in patients with chronic pain: psychemtric properties of the Patterns of Activity Measure-Pain. Eur J Pain 2009; 13(Suppl. 1):S222-S223.

(22) Kuijer W, Brouwer S, Dijkstra PU, Jorritsma W, Groothoff JW, and Geertzen JH. Responsiveness of the Roland-Morris Disability Questionnaire: consequences of using different external criteria. Clin Rehabil 2005; 19(5):488-95.

(23) Leeuw M, Goossens ME, Linton SJ, Crombez G, Boersma K, and Vlaeyen JW. The fear-avoidance model of musculoskeletal pain: current state of scientific evidence. J Behav Med 2007; 30(1):77-94.

(24) Leeuw M, Goossens ME, van Breukelen GJ, de Jong JR, Heuts PH, Smeets RJ, Koke AJ, and Vlaeyen JW. Exposure in vivo versus operant graded activity in chronic low back pain patients: results of a randomized controlled trial. Pain 2008; 138(1):192-207.

(25) Levin S, Jacobs DR, Jr., Ainsworth BE, Richardson MT, and Leon AS. Intra-individual variation and estimates of usual physical activity. Ann Epidemiol 1999; 9(8):481-8.

(26) Liszka-Hackzell JJ, Martin DP. An analysis of the relationship between activity and pain in chronic and acute low back pain. Anesth Analg 2004; 99(2):477-81.

(27) McCracken LM, Samuel VM. The role of avoidance, pacing, and other activity patterns in chronic pain. Pain 2007; 130(1-2):119-25.

(28) Merskey H, Bogduk N. Classification of chronic pain. IASP Task force on taxonomy, ed. S. edition. 1994, Seattle: IASP press.

(29) Price DD, McGrath PA, Rafii A, and Buckingham B. The validation of visual analogue scales as ratio scale measures for chronic and experimental pain. . Pain 1983; 17(1):45-56.

(30) Roland M, Morris R. A study of the natural history of back pain. Part I: development of a reliable and sensitive measure of disability in low-back pain. Spine (Phila Pa 1976) 1983; 8(2):141-4.

(31) Roland M, Morris R. A study of the natural history of low-back pain. Part II: development of guidelines for trials of treatment in primary care. Spine (Phila Pa 1976) 1983; 8(2):145-50.

(32) van den Berg-Emons RJ, Schasfoort FC, de Vos LA, Bussmann JB, and Stam HJ. Impact of chronic pain on everyday physical activity. Eur J Pain 2007; 11(5):587-93.

(33) van Koulil S, van Lankveld W, Kraaimaat FW, van Helmond T, Vedder A, van Hoorn H, Donders R, de Jong AJ, Haverman JF, Korff KJ, van Riel PL, Cats HA, and Evers AW. Tailored cognitive-behavioral therapy and exercise training for high-risk patients with fibromyalgia. Arthritis Care Res (Hoboken) 2010; 62(10):1377-85.

(34) van Weering MG, Vollenbroek-Hutten MM, Tonis TM, and Hermens HJ. Daily physical activities in chronic lower back pain patients assessed with accelerometry. Eur J Pain 2009; 13(6):649-54.

(35) Vendrig AA, Lousberg R. Within-person relationships among pain intensity, mood and physical activity in chronic pain: a naturalistic approach. Pain 1997; 73(1):71-76.

(36) Verbunt JA, Sieben J, Vlaeyen JW, Portegijs P, and Andre Knottnerus J. A new episode of low back pain: who relies on bed rest? Eur J Pain 2008; 12(4):508-16.

(37) Verbunt JA, Sieben JM, Seelen HA, Vlaeyen JW, Bousema EJ, van der Heijden GJ, and Knottnerus JA. Decline in physical activity, disability and pain-related fear in sub-acute low back pain. Eur J Pain 2005; 9(4):417-25.

(38) Verbunt JA, Westerterp KR, van der Heijden GJ, Seelen HA, Vlaeyen JW, and Knottnerus JA. Physical activity in daily life in patients with chronic low back pain. Arch Phys Med Rehabil 2001; 82(6):72630.

(39) Vlaeyen JW, Kole-Snijders AM, Boeren RG, and van Eek H. Fear of movement/(re)injury in chronic low back pain and its relation to behavioral performance. Pain 1995; 62(3):363-72.

(40) Vlaeyen JW, Linton SJ. Fear-avoidance and its consequences in chronic musculoskeletal pain: a state of the art. Pain 2000; 85(3):317-32. 



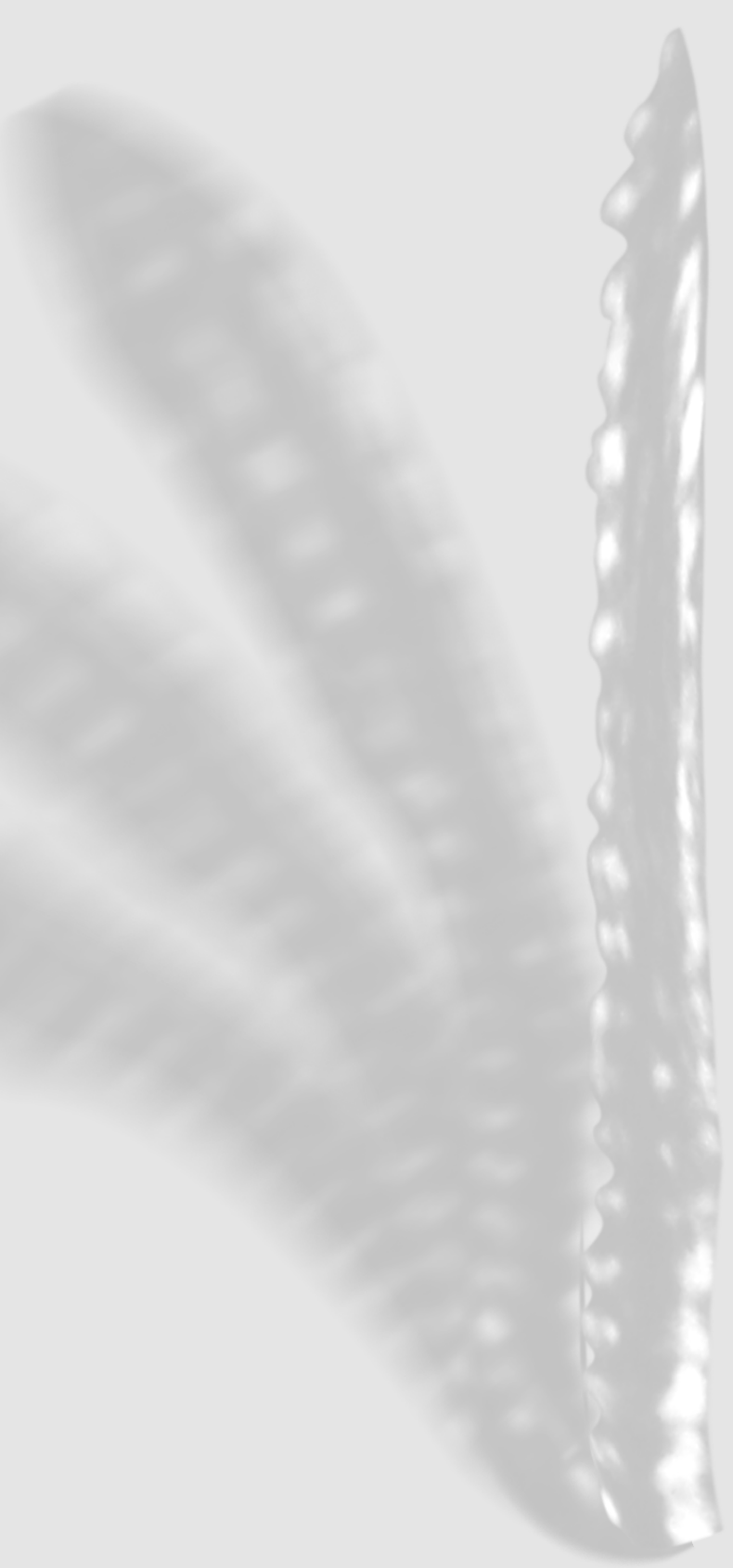


Part III

The self-discrepancy model for chronic pain to explain persistence and avoidance behaviour 


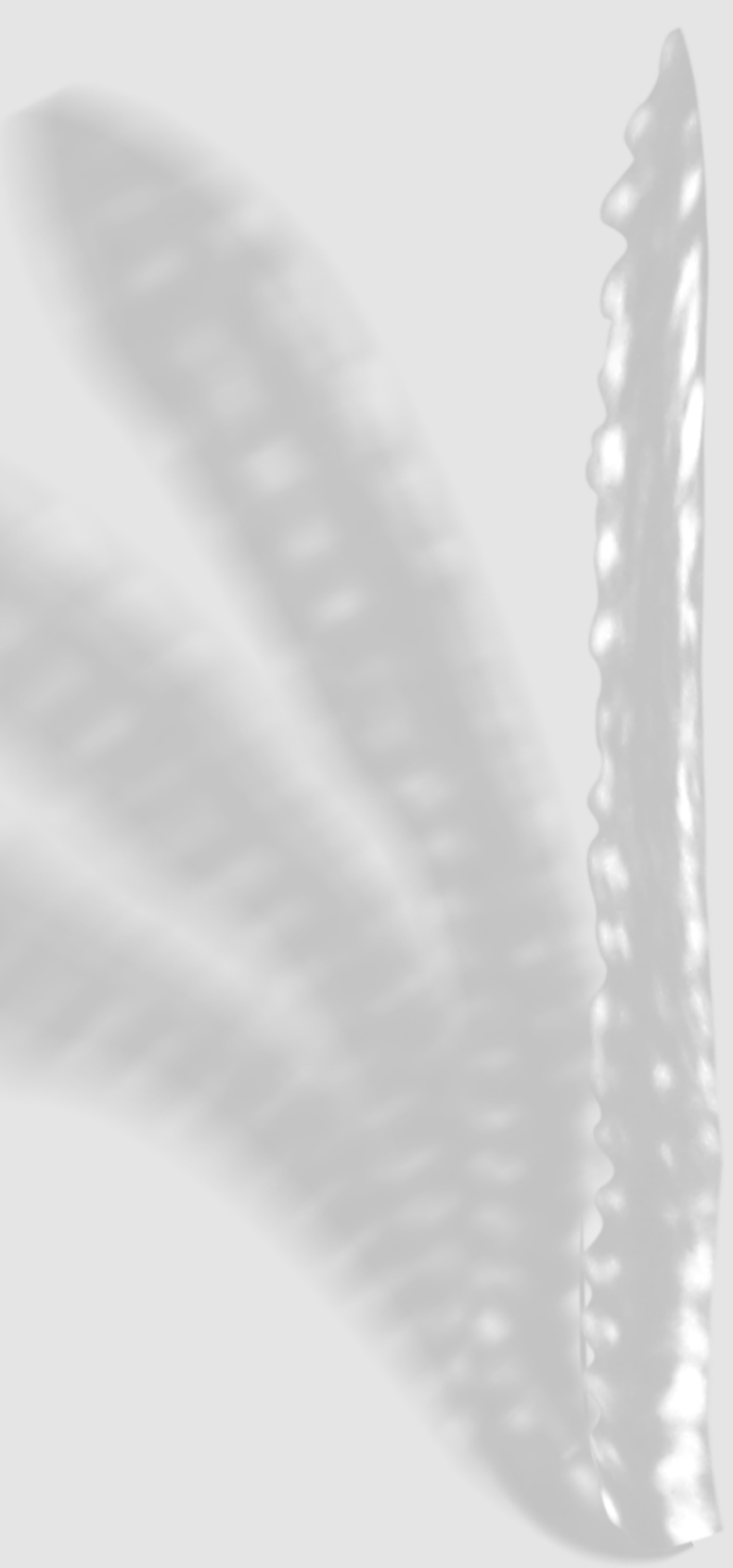




\section{Chapter 8}

\section{"Being" in pain: the role of self- discrepancies in the emotional experience and activity patterns of patients with chronic low back pain}

This chapter is published as:

Kindermans HP, Huijnen IP, Goossens ME, Roelofs J, Verbunt JA, Vlaeyen JW. "Being" in pain: the role of self-discrepancies in the emotional experience and activity patterns of patients with chronic low back pain. Pain 2011;152(2):403-409 


\section{Abstract}

Chronic pain not only interferes with daily activities, it may also have a negative impact on the perceived integrity of one's self through self-discrepancies. Selfdiscrepancies are experienced distances between the actual self and self-guides that can exist from two perspectives (i.e. own and other). Self-discrepancies are associated with negative mood states and incite self-regulatory behaviour in order to reduce these discrepancies. The present study was aimed at replicating the emotional consequences of self-discrepancies in patients with chronic low back pain, and extending current knowledge of the behavioural consequences of selfdiscrepancies (i.e. behavioural activity patterns such as avoidance and persistence).

A cross-sectional design was employed with 83 patients who completed a number of self-report measures. We hypothesized that ideal and ought discrepancies, and feared congruencies were associated with depressed and anxious mood. On the behavioural level, a u-shaped relationship was hypothesized between ideal and ought self-discrepancies and persistence behaviour, whereas feared selfdiscrepancies were hypothesized to be related to avoidance behaviour.

Results were partially in line with the hypotheses. With respect to the emotional consequences, feared (own and other) self-discrepancies were predictive of depressive and anxious mood. With regard to activity patterns, results showed a ushaped relationship between ideal-other self-discrepancies and persistence behaviour and a positive relationship between feared-own self-discrepancies and avoidance-behaviour. In contrast to expectations, none of the other self-discrepancies was related to activity patterns. Of interest was that avoidance, but not persistence behaviour, was predictive of higher levels of disability and lower levels of quality of life.

\section{Introduction}

Pain can interrupt ongoing cognitive and physical tasks, and interferes with daily activities (9). This is especially the case when pain is interpreted catastrophically and when pain-related fear has developed $(8,19)$. When pain persist, such as in chronic musculoskeletal pain, the continued interference and associated disability poses a real challenge to patients, which is reflected in low levels of quality of life and negative perception of one's own identity $(18,22)$. In an attempt to restore daily functioning, patients can alter their performance. This anticipated change in their activity pattern is however often unsuccessful, and can even be counterproductive. For example, a body of research has shown that pain catastrophizing and pain-related fear might lead to unnecessary avoidance of activities and consequently to disuse and disability in the long term (33). Besides activity patterns characterized by avoid- 
ance, researchers and clinicians have suggested that there is also a group of chronic pain patients with disability complaints, who tend to persist in performing activities despite their pain $(15,31,34)$. So far, empirical evidence explaining why some chronic pain patients persist in activities while others avoid activities is lacking.

A possible mechanism explaining both avoidance and persistence behaviour might be derived from the Self-Discrepancy Theory (SDT; 16). SDT explains how selfdiscrepancies, that is, discrepancies between the actual self (i.e. the person you are now) and the ideal self (i.e. the person you ideally would like to be), the ought self (i.e. the person you feel you ought to be) or feared self (i.e. the person you fear to be), lead to negative emotions and distress $(6,16)$. Studies in chronic pain populations have shown that self-discrepancies are associated with higher levels of depression, anxiety, distress, and pain $(11,35)$. Besides emotional consequences, selfdiscrepancies are also thought to be associated with behavioural consequences. That is, self-discrepancies motivate self-regulatory behaviours in order to reduce discrepancies (or enlarge discrepancies in case of the feared self) $(3,7)$.

The first aim of the present study was to replicate earlier findings and investigate the emotional consequences of self-discrepancies in patients with chronic pain. In line with previous studies $(11,35)$, we hypothesize that ideal and ought discrepancies and feared congruencies predict depressive and anxious mood. The second aim was to extend the study of self-discrepancies in chronic pain patients by examining their explanatory function in activity patterns. We hypothesize that ideal or ought self-discrepancies are associated with persistence behaviour because their behaviour is driven by a focus on desired or obliged end states (i.e. ideal or ought self). Yet, persistence behaviour might also be aimed at maintaining an actual-ideal or actual-ought congruency. Therefore, we tested the existence of a U-shaped relationship between ideal and ought self-discrepancies and persistence behaviour. Feared self-congruencies are hypothesized to predict avoidance behaviour since the focus is on an undesired end state (i.e. the feared self). Finally, we hypothesize that both avoidance and persistence are associated with higher levels of disability and inferior quality of life.

\section{Methods}

\subsection{Recruitment of participants}

The present study took place in the Southern area of the Netherlands. Participants were either referred to the study by their consultant in rehabilitation medicine or responded to the advertisement that appeared in local newspapers. Consultants in rehabilitation medicine were asked to refer patients meeting the in- and exclusion criteria for the present study. In case patients responded to the advertisement, 
selection criteria were checked by a consultant in rehabilitation medicine, who performed a medical screening according to the clinical guidelines for low back pain of the Dutch College of General Practitioners (10). Participants were eligible for inclusion in the present study if they suffered from non-specific low back pain for at least three months, were aged between 18 and 65 years and had sufficient knowledge of the Dutch language. Participants, for whom primary psychiatric treatment was indicated, were excluded. For female participants, pregnancy was also an exclusion criterion.

\subsection{Measures}

Next to socio-demographics (i.e. gender, age, education level, occupation) and painrelated information (i.e. pain duration), data were obtained for the following measurement instruments. Reliability coefficients (Cronbach's alpha) of all questionnaires are presented in Table 1.

\subsubsection{Self-discrepancies}

Self-discrepancies were measured by assessing Hardin's Selves Questionnaire (HSQ; 12 ) in the form of a semi-structured interview. Participants were asked to generate attributes for each self-guide (i.e. ideal, ought and feared) from two perspectives, their own perspective and the internalized perspective of someone who is important to them (e.g. spouse). (Originally, the HSQ assesses the undesired self instead of the feared self. For the purpose of our hypotheses, we revised the description of the undesired self and, in concordance with Carver \& Scheier (6), modified it to the feared self.) More specifically, participants listed 5 attributes they ideally would like to possess (Ideal-own), 5 attributes they feel the important other would ideally like them to possess (Ideal-other), 5 attributes they feel they ought to possess (Oughtown), 5 attributes they think the other feels they ought to possess (Ought-other), 5 attributes they fear to possess (Feared-own), and 5 attributes the other fears they possess (Feared-other). After listing all 30 attributes, participants were asked to rate to which extent each attribute currently describes themselves on a scale from 1 (does not describe me at all) to 5 (completely describes me). Self-discrepancy scores were obtained by summing the discrepancy-scores of the five attributes. For the ideal and the ought self, lower scores indicated larger discrepancies reflecting a negative state while for the feared self, lower scores indicated smaller congruencies and therefore reflect a positive state. The HSQ is a valid and reliable instrument to measure self-discrepancies (12). To permit comparisons with previous studies in which the HSQ was used $(11,12)$, the scores presented in Table 1 are the scores per self-guide divided by five (i.e. the number of attributes). 


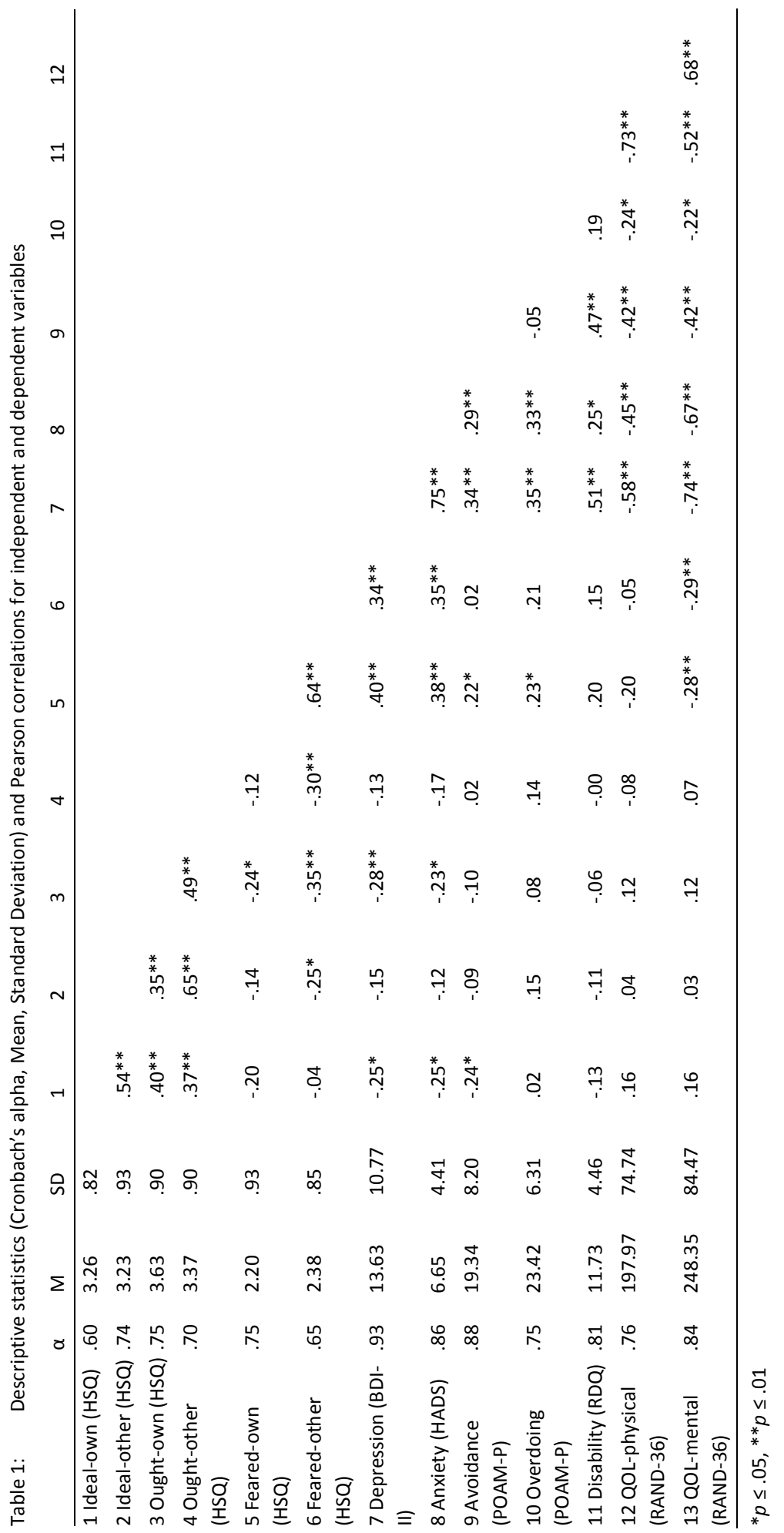




\subsubsection{Depression}

The Dutch version of the Beck Depression Inventory II (BDI-II; 2) was utilized to measure depression. Depressive symptomatology is questioned in 21 items with several possible responses and scores ranging from 0 to 3 . Total scores are obtained by summing the item scores resulting in total scores ranging from 0 (not depressed at all) to 63 (severely depressed). The BDI-II has sound psychometric properties (1) and has been found suitable for administration in chronic pain populations (13).

\subsubsection{Anxiety}

The anxiety subscale of the Hospital Anxiety and Depression Scale (HADS; 36) was used to measure anxiety. The anxiety subscale exists out of 7 items about the frequency of experiencing anxious states on a 4-point scale. The Dutch version of the HADS has been found to be a reliable and valid instrument (27).

\subsubsection{Activity patterns}

To measure avoidance and persistence behaviour a recently developed instrument, the Patterns of Activity Measure-Pain (5) was administered. The POAM-P is a 30item self-report measure, developed to identify three activity patterns in patients with chronic pain, namely avoidance (10 items), overdoing (i.e. persistence behaviour; 10 items) and pacing (10 items). Yet, since the focus of the present study is on avoidance and persistence, no results regarding the pacing-scale will be reported. An example of an avoidance item is "I avoid activities that I know will make my pain worse" while a contrasting item of the overdoing scale is "When I'm doing an activity I don't stop until it is finished". Participants have to indicate to which extend the items applies to them on a five point scale ranging from 0 (not at all) to 4 (always). Total scores per subscale range from 0 to 40 . The three-factor structure of the Dutch version of the POAM-P has been confirmed and the three subscales were found to be highly internal consistent (Cronbach alphas ranging from .80 to .94). Significant and meaningful associations with related constructs such as fear of movement and (re)injury, pain catastrophizing, depression and disability, confirmed the validity of the subscales (Kindermans HPJ, Roelofs J, Goossens M, Huijnen IP, Verbunt JA, Vlaeyen J., unpublished manuscript).

\subsubsection{Disability}

Disability was measured with the Roland Disability Questionnaire (RDQ; 26). The RDQ presents 24 daily activities of which participants have to indicate whether their low back pain interferes with the activity (score 1 ) or not (score 0 ). The item scores are summed leaving total score ranges between 0 and 24, with higher scores reflecting higher levels of disability. The Dutch version of the RDQ is a reliable and valid instrument assessing disability in patients with chronic low back pain (4). 


\subsubsection{Health related quality of life}

The RAND 36-item Health survey (30) was administered to measure health related quality of life. The questionnaire comprises 9 subscales measuring both physical and mental health, and therefore enabling the computation of a physical (physical functioning, physical role limitations, general health perception, and pain) and a mental health (social functioning, emotional role limitations, mental health, and vitality) scale, which will be used in the present study. The ninth, 1-item subscale 'health change' does not belong to one of the aforementioned scales and will not be reported on. Responses to the items are given on a three or six point Likert scale, or with 'yes' or 'no', depending on the subscale. Psychometric properties of the RAND36 are satisfactory $(29,30)$.

\subsubsection{Pain intensity}

Pain intensity was measured on three $100 \mathrm{~mm}$ Visual Analogue Scales (25) on which participants had to indicate their 'worst pain last week', 'least intense pain last week', and 'current pain intensity'. The average of the scores on these three scales was used as a composite score of pain intensity.

\subsection{Procedure and design}

Patients who were interested in participation received a participant information letter and in case they responded that they were willing to participate, they were then contacted by the researchers. Participants who responded to the advertisement also received a participant information letter and, in case of willingness to participate, they were screened by a consultant in rehabilitation medicine to ensure qualification for the present study. After obtaining written informed consent, participants were invited to come to the university to have the HSQ-interview or were interviewed by telephone. Thereafter, participants completed the self-report questionnaires, either on paper or an electronic version presented via internet. The present study was part of a larger study, which also included daily life assessments and follow-up measurements that will be reported elsewhere. Participants received a gift voucher for their participation and were reimbursed for their travel expenses.

The present study was approved by the Medical Ethics Committee of the Maastricht University Medical Centre (MEC 06-3-046) and by the institutions of the rehabilitation units from where patients were referred to the study.

\subsection{Statistical analysis}

Data preparation involved missing data analyses and checks for normality of the variables for which the Statistical Package for Social Sciences (SPSS 15.0) was used. In case of less then 10 percent missing values per (sub-) scale, the missing value was 
estimated by means of regression techniques. Scales with more then 10 percent missing values were dropped from analyses. Two scales, namely the BDI-II and pain duration, did not meet assumptions of normality and were square-root transformed prior to analyses. After transformation, skewness and kurtosis values of both scales were in the acceptable range of -1 and +1 .

Computations of descriptive information, chi-square and $t$-tests, and correlational analyses were carried out in SPSS 15.0. Besides correlational analyses, hierarchical multiple regression analyses were carried out in SPSS to determine the contribution of self-discrepancies to the prediction of negative mood (depression and anxiety) and activity patterns (avoidance and persistence) and the contribution of activity patterns to disability and quality of life. To prevent type I errors due to multiple testing, alpha was set to .01 .

\section{Results}

\subsection{Participants}

\subsubsection{Participants flow}

A total of 116 participants with chronic non-specific low back pain participated in the present study. Yet, due to missing data, 33 participants (28\%) were not included in the analyses. Of these 33 participants, one participant did not complete the HSQinterview and 17 did not complete the self-report questionnaires. The remaining fifteen participants did complete the HSQ-interview and the self-report questionnaires but still had too many missing data (i.e. more than $10 \%$ on the level of individual items) after running missing values analyses. A lack of descriptive information of the 17 participants, who did not fill in the questionnaires, precluded checking for selective drop-out. The reasons for withdrawal were in most cases unknown, yet, some indicated a lack of time due to personal circumstances or experienced the study as too burdensome. In total, 83 participants were included in the analyses of which 58 (70\%) participants were referred to the study by their consultant in rehabilitation medicine and 25 (30\%) responded to the advertisements in local newspapers. Participants who responded to the advertisement were older $(M=52.20$, $\mathrm{SE}=1.94)$ than those referred by their consultant in rehabilitation $(M=44.41$, $\mathrm{SE}=1.31 ; t(81)=-3.29, \mathrm{p}=.001)$. There were no significant differences between both samples on the other independent and dependent variables.

\subsubsection{Descriptive information}

Forty-two women and 41 men were included in the analyses. There were no gender differences on the self-report questionnaires. Age ranged from 22 to 65 with a mean of 46.76 years $(S D=10.46)$. With respect to education level, the majority of 
participants received lower secondary professional education or below (53\%). The rest of the participants received at maximum higher general secondary education (31\%) or higher education (13\%). 53\% was employed (full or part-time), $6 \%$ was on sick leave and $21 \%$ were recipients of disablement insurance benefits. The average duration of the pain complaints was 9.81 years $(S D=8.93)$ and ranged from 5 months to 39 years. Mean pain intensity, measured on $100 \mathrm{~mm}$ VAS scales, was 49.47 (SD=18.73). Furthermore, means and standard deviations of the scores on the self-report questionnaires are presented in Table 1.

\subsection{Self-discrepancies and emotional consequences}

Prior to the hierarchical multiple regression analyses, correlational analyses were carried out to investigate the relationships between the distinct types of selfdiscrepancies and depression and anxiety (Table 1). Results showed that ought-own and feared-own and -other discrepancies were significantly related to depression and feared-own and -other to anxiety in the expected direction. Pearson correlations ranged from $r=-.28$ to $r=.40$ at $p \leq .01$ (see Table 1 ). Thus, the closer participants felt to their ought-own, the less depressive mood they experienced. Regarding feared selves, both feared-own and feared-other congruencies were related to depression and anxiety. This means that participants who felt close to the person they feared to be, or close to the person that another feared them to be, the more feelings of depression and anxiety the participant experienced. Feeling close to the ideal (own nor other) or ought-other self was not significantly related to depressive or anxious mood.

Hierarchical multiple regression analyses were performed predicting depression and anxiety while controlling for socio-demographic variables (gender and age) in the first block and pain-related variables (pain duration and mean pain intensity) in the second block. Each type of self-discrepancy from both perspectives (ideal, ought, and feared) was analyzed separately and was entered in the third block. Ideal-own and ideal-other self-discrepancies were not predictive of depression (respectively $B=-.25, t=-2.08, p=.04$ and $B=-.06, t=-.47, p=.64$ ) nor anxiety (respectively $B=-.27, t=-2.11, p=.04$ and $B=.00, t=.01, p=.99$ ). Neither were ought-own or ought-other self-discrepancies predictive of depression (respectively $b=-.25, t=-2.07, p=.04$ and $B=-.01, t=-.12, p=.90$ ) or anxiety (respectively $b=-$ $.19, t=-1.48, p=.14$ and $B=-.07, t=-.58, p=.57)$. Since ought-own, but not oughtother, self-discrepancies were significantly related to depression in the correlational analyses, separate regression analyses were run for the ought-own predicting depression. Yet, ought-own self-discrepancies were not predictive of depression while controlling for socio-demographic and pain-related variables $(B=-.25, t=-2.50, p=$ $.02)$. Further, as can be seen in table 2 , the addition of feared-own and-other selfdiscrepancies (block $3 a$ ) to the prediction of depression and anxiety resulted in a 
significant $\mathrm{F}$ change while the predictors themselves did not reach statistical significance. Since this might indicate a type II error at the predictor level, regression analyses were conducted for the feared-own and the feared-other self-discrepancy separately (block $3 b$ and $3 c$ ). Results demonstrated that both feared-own and feared-other self-discrepancies were significant predictors of depression and anxiety over and beyond the contribution of socio-demographic and pain-related variables (Table 2). So, feeling far away from the feared self was predictive of lower levels of depression and anxiety.

Table 2: $\quad$ Summary of hierarchical regression analyses for feared self-discrepancies predicting depression and anxiety while controlling for socio-demographic and pain-related variables

\begin{tabular}{|c|c|c|c|c|c|c|c|c|}
\hline Dependent & Blocks & Variables & B & SE B & $\beta$ & $\Delta \mathrm{R}^{2}$ & $\Delta \mathrm{F}$ & $p \Delta \mathrm{F}$ \\
\hline \multirow{8}{*}{$\begin{array}{l}\text { Depression } \\
\text { (BDI) }\end{array}$} & 1 & Gender & -.17 & .23 & -.08 & .01 & .29 & ns \\
\hline & & Age & -.02 & .12 & -.01 & & & \\
\hline & 2 & Pain duration & .06 & .11 & .06 & .16 & 7.68 & $\leq .001$ \\
\hline & & Mean pain intensity & .42 & .11 & $.40 *$ & & & \\
\hline & $3 a$ & Feared-own & .25 & .14 & .24 & .14 & 7.95 & $\leq .001$ \\
\hline & & Feared-other & .20 & .13 & .19 & & & \\
\hline & $3 b$ & Feared-own & .38 & .11 & $.36^{*}$ & .12 & 13.32 & $\leq .001$ \\
\hline & $3 c$ & Feared-other & .35 & .10 & $.34^{*}$ & .11 & 12.08 & $\leq .001$ \\
\hline \multirow{8}{*}{$\begin{array}{l}\text { Anxiety } \\
\text { (HADS) }\end{array}$} & 1 & Gender & -.05 & .23 & -.02 & .01 & 0.23 & ns \\
\hline & & Age & -.08 & .12 & -.07 & & & \\
\hline & 2 & Pain duration & -.01 & .12 & -.01 & .07 & 2.90 & ns \\
\hline & & Mean pain intensity & .27 & .11 & .26 & & & \\
\hline & $3 a$ & Feared-own & .25 & .14 & .23 & .15 & 7.57 & $\leq .001$ \\
\hline & & Feared-other & .22 & .14 & .21 & & & \\
\hline & $3 b$ & Feared-own & .39 & .11 & $.37^{*}$ & .13 & 12.38 & $\leq .001$ \\
\hline & $3 c$ & Feared-other & .37 & .11 & $.36^{*}$ & .12 & 11.88 & $\leq .001$ \\
\hline
\end{tabular}

\subsection{Self-discrepancies and activity patterns, disability, and quality of life}

Results from the correlational analyses (Table 1) did not show significant associations between self-discrepancies and activity patterns, yet, did show associations between avoidance behaviour on the one hand and disability and quality of life (physical and mental) on the other hand. In contrast, persistence behaviour was not significantly related to disability or quality of life.

To further test the contribution of self-discrepancies to activity patterns, three hierarchical multiple regression analyses were carried out. In all regression analyses, socio-demographic variables (gender and age) were entered in the first block and 
pain-related variables (pain duration and pain intensity) in the second block. To explain persistence behaviour, ideal-own and ideal-other self-discrepancies were entered in the third block and, in a second regression analysis, replaced by oughtown and ought-other self-discrepancies. In the fourth block, the quadratic terms of the self-discrepancies were added to test the u-shaped relationship. There were no significant main effects of self-discrepancies on persistence behaviour. Yet, the quadratic term of the ideal-other significantly predicted persistence behaviour (table 3). This means that participants who felt close to their ideal-other as well as those who felt far away from their ideal-other, both showed higher levels of persistence behaviour.

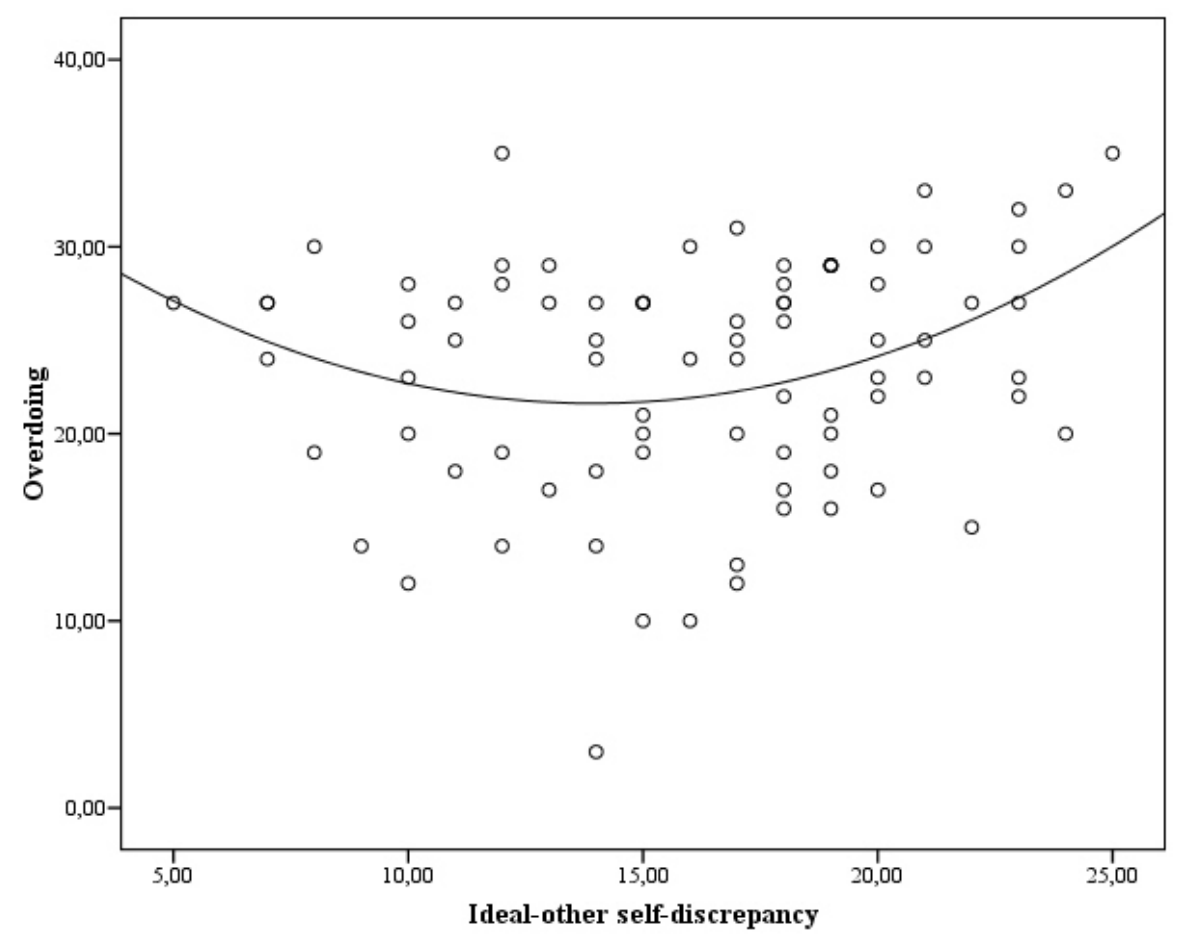

Figure 1: The relationship between overdoing and ideal-other self-discrepancies

With regard to ought self-discrepancies, neither the quadratic terms of the oughtown self-discrepancy, nor ought-other self-discrepancy were significant predictors of persistence behaviour (respectively $B=.05, t=.39, p=.70$ and $B=.14, t=1.08, p$ $=.29$ ). In the regression analysis with avoidance behaviour as the dependent variable, the feared-own and feared-other were entered in the third block. Results showed that the closer participants felt to the person they fear to be, the more likely they were to exert avoidance behaviour (table 3). In line with aforementioned analyses, the feared-own (block $3 b$ ) and the feared-other (block $3 c$ ) were also 
tested separately. As presented in table 3, the feared-own was no longer a significant predictor of avoidance when the effect of the feared-other was not controlled for.

Table 3: $\quad$ Summary of hierarchical regression analyses for self-discrepancies predicting overdoing and avoidance while controlling for socio-demographic and pain-related variables

\begin{tabular}{|c|c|c|c|c|c|c|c|c|}
\hline Dependent & Blocks & Variables & $B$ & SE B & $\beta$ & $\Delta \mathrm{R}^{2}$ & $\Delta \mathrm{F}$ & $p \Delta \mathrm{F}$ \\
\hline \multirow{8}{*}{$\begin{array}{l}\text { Overdoing } \\
\text { (POAM-P) }\end{array}$} & \multirow[t]{2}{*}{1} & Gender & -.02 & .21 & -.01 & \multirow[t]{2}{*}{.01} & \multirow[t]{2}{*}{.29} & \multirow[t]{2}{*}{ ns } \\
\hline & & Age & -.08 & .11 & -.08 & & & \\
\hline & \multirow[t]{2}{*}{2} & Pain duration & -.00 & .11 & -.00 & \multirow[t]{2}{*}{.05} & \multirow[t]{2}{*}{2.04} & \multirow[t]{2}{*}{ ns } \\
\hline & & Mean pain intensity & .22 & .11 & .22 & & & \\
\hline & \multirow[t]{2}{*}{3} & Ideal-own & -.06 & .12 & -.06 & \multirow[t]{2}{*}{.03} & \multirow[t]{2}{*}{1.11} & \multirow[t]{2}{*}{ ns } \\
\hline & & Ideal-other & .24 & .12 & .25 & & & \\
\hline & \multirow[t]{2}{*}{4} & Ideal-own ${ }^{2}$ & .00 & .01 & .09 & \multirow[t]{2}{*}{.10} & \multirow[t]{2}{*}{4.69} & \multirow[t]{2}{*}{$\leq .01$} \\
\hline & & Ideal-other ${ }^{2}$ & .01 & .01 & $.30 *$ & & & \\
\hline \multirow{8}{*}{$\begin{array}{l}\text { Avoidance } \\
\text { (POAM-P) }\end{array}$} & \multirow[t]{2}{*}{1} & Gender & .16 & .22 & .08 & \multirow[t]{2}{*}{.01} & \multirow[t]{2}{*}{.36} & \multirow[t]{2}{*}{ ns } \\
\hline & & Age & -.06 & .12 & -.06 & & & \\
\hline & \multirow[t]{2}{*}{2} & Pain duration & .19 & .12 & .19 & \multirow[t]{2}{*}{.05} & \multirow[t]{2}{*}{1.88} & \multirow[t]{2}{*}{ ns } \\
\hline & & Mean pain intensity & .13 & .11 & .13 & & & \\
\hline & \multirow[t]{2}{*}{$3 a$} & Feared-own & .40 & .15 & $.39 *$ & \multirow[t]{2}{*}{.08} & \multirow[t]{2}{*}{3.69} & \multirow[t]{2}{*}{ ns } \\
\hline & & Feared-other & -.20 & .14 & -.20 & & & \\
\hline & $3 b$ & Feared-own & .26 & .11 & .26 & .06 & 5.29 & ns \\
\hline & $3 c$ & Feared-other & .04 & .11 & .04 & .00 & .14 & ns \\
\hline
\end{tabular}

$* \mathrm{p} \leq 0.01$.

Hypotheses concerning the prediction of disability and quality of life from activity patterns were also tested with hierarchical regression analyses for each activity patterns separately (Table 4). In line with aforementioned analyses, sociodemographic and pain-related variables were controlled for in the first two blocks. In the third block, either persistence or avoidance behaviour was entered. Results showed that avoidance but not persistence behaviour was a significant predictor of disability and mental and physical quality of life. 
Table 4: $\quad$ Summary of hierarchical regression analyses for activity patterns predicting disability and quality of life (QOL) while controlling for socio-demographic and pain-related variables.

\begin{tabular}{|c|c|c|c|c|c|c|c|c|}
\hline Dependent & Blocks & Variables & $B$ & SE B & $\beta$ & $\Delta \mathrm{R}^{2}$ & $\Delta \mathrm{F}$ & $p \Delta \mathrm{F}$ \\
\hline \multirow[t]{6}{*}{ Disability (RDQ) } & 1 & Gender & -.09 & .22 & -.05 & .00 & .10 & ns \\
\hline & & Age & -.01 & .11 & -.01 & & & \\
\hline & 2 & Pain duration & -.00 & .10 & -.00 & .29 & 16.00 & $p<.001$ \\
\hline & & Mean pain intensity & .52 & .09 & $.54^{*}$ & & & \\
\hline & $3 a$ & Overdoing & .07 & .10 & .07 & .00 & .55 & ns \\
\hline & $3 b$ & Avoidance & .41 & .08 & $.43^{*}$ & .17 & 25.11 & $p<.001$ \\
\hline \multirow{6}{*}{$\begin{array}{l}\text { Physical QOL } \\
\text { (RAND-36) }\end{array}$} & 1 & Gender & .18 & .21 & .09 & .07 & 3.01 & ns \\
\hline & & Age & .24 & .11 & .24 & & & \\
\hline & 2 & Pain duration & -.03 & .09 & -.03 & .40 & 29.39 & $p<.001$ \\
\hline & & Mean pain intensity & -.63 & .08 & $-.64 *$ & & & \\
\hline & $3 a$ & Overdoing & -.09 & .09 & -.09 & .01 & 1.04 & ns \\
\hline & $3 b$ & Avoidance & -.34 & .07 & $-.35^{*}$ & .12 & 21.30 & $p<.001$ \\
\hline \multirow{6}{*}{$\begin{array}{l}\text { Mental QOL } \\
\text { (RAND-36) }\end{array}$} & 1 & Gender & .19 & .23 & .09 & .03 & 1.01 & ns \\
\hline & & Age & .12 & .12 & .12 & & & \\
\hline & 2 & Pain duration & -.09 & .11 & -.09 & .23 & 11.90 & $p<.001$ \\
\hline & & Mean pain intensity & -.49 & .10 & $-.47^{*}$ & & & \\
\hline & $3 a$ & Overdoing & -.15 & .10 & -.14 & .01 & 1.23 & ns \\
\hline & $3 b$ & Avoidance & -.38 & .09 & $-.37^{*}$ & .13 & 15.89 & $p<.001$ \\
\hline
\end{tabular}

$* p<0.001$

\section{Discussion}

The aim of the present study was twofold. The first aim was to inspect the emotional consequences of self-discrepancies in patients with chronic pain. The second aim was to extend the study of self-discrepancies in patients with chronic pain by testing self-discrepancies' value in predicting self-reported activity patterns and, as a consequence of these activity patterns, disability levels and quality of life. With regard to the first aim of the study, results showed that feared (own and other) selfdiscrepancies were indeed related to emotional distress. Yet, ought and ideal (own or other) self-discrepancies were not. Regarding the second aim, results showed that the feared-own, but not the feared-other, was associated with avoidance. Furthermore, a U-shaped relationship between the ideal-other and persistence behaviour was demonstrated. Finally, avoidance, but not persistence behaviour, contributed to higher levels of disability and diminished mental and physical health. 
Based on the present results, emotional distress appears strongly related to the experienced proximity to the feared self, since this was associated with and predictive of both anxiety and depression. This is also in line with findings from Goossens and colleagues, who studied patients with chronic pain in the upper extremities and found that patients who felt close to their feared self, reported higher levels of depression and anxiety (11). In contrast with Waters and colleagues (35), who studied chronic low back pain patients, ideal (own and other) self-discrepancies were not related to depression nor anxiety in the present study. Further, ought-own selfdiscrepancies were related to depression but this relationship was no longer significant after controlling for socio-demographic and pain-related variables. The finding that Ought-other self-discrepancies were not related to anxiety or depression is in contrast with previous studies, demonstrating detrimental consequences of ought self-discrepancies, including depressed and anxious mood, in chronic pain patients $(11,35)$. The present results might originate from the dynamics between different types of self-discrepancies. Carver and colleagues (6) already suggested that proximity to the feared self might minimize the importance of approaching desired end states, such as the ideal and ought self, because of the salience of the feared self. This is also supported by other studies, showing that the undesired self, which is closely related to the feared self, is a better predictor of well-being related constructs $(23,24)$. It might be that the feared self was also more salient to participants in the present study.

With respect to behavioural consequences of self-discrepancies, ideal and ought self-discrepancies were hypothesized to be related to persistence behaviour. Results showed that patients who felt close to their ideal-other as well as those who experienced great discrepancies between their actual and ideal-other, both showed higher levels of persistence behaviour. For the participants who feel discrepant from their ideal-other self, persistence behaviour might be an (unsuccesfull) attempt to get closer to their ideal self. For those who feel close to their ideal self, persistence behaviour may reflect the possibility to continue their daily activities despite pain, and in that case persistence behaviour may be inversely related to disability. This ambiguity may be one of the reasons why there is no straightforward relationship between persistence behaviour and disability levels (17). While our hypothesis on the U-shaped relationship between self-discrepancies and persistence behaviour was restricted to the ideal-other, this finding sheds new light on the functional meaning of persistence behaviour when considering selfdiscrepancies.

With regard to avoidance behaviour, results demonstrated feared-own selfdiscrepancies were related to avoidance. It is noteworthy that feared-other selfdiscrepancies acted as a suppressor variable in the regression analysis since the effect of the feared-own was only significant while controlling for the feared-other. Nevertheless, the present results showed that participants who felt close to their 
feared self from their own perspective also reported more avoidance behaviour. In a similar vein, avoidance behaviour as predicted in the fear-avoidance model is also the consequence of fears, yet on a more basic 'do-level'. The object of fear in the present study, namely becoming someone you do not want to be acts on a higher order 'be-level' but seems to have similar consequences. This means that the feared self may be understood in terms of an anti-goal and as anti-goals are likely to instigate safety behaviour (20), in patients with chronic pain it is likely this leads to a tendency to avoid activities. In other words, this is the first study showing that the validity of Fear-Avoidance models appears to generalize to the level of perceived self and identity.

In general, the level of measurement of self-discrepancies might play a role with regard to the limited results between self-discrepancies and activity patterns. Selfdiscrepancies are higher order constructs, meaning that they are the result of cognitive higher order processes, in which an individual reflects on his or her self. A content-analysis of self-discrepancies has also shown that the ideal, ought and feared selves concern general attributes mostly related to the interpersonal domain (e.g. honest) (11). Activity levels, on the other hand, are lower order constructs, measured at a behavioural level, and relate to the intrapersonal domain (e.g. doing household chores). In order to overcome this conceptual distance, selfdiscrepancies might be measured on a lower level by, for example, focusing on activities. It might be discussed however, to what extent this operationalization justifies the use of then term self-discrepancies instead of activity-discrepancies.

Partly in line with our hypotheses, the current results demonstrated that avoidance behaviour was predictive of higher levels of disability and diminished quality of life. Yet, persistence behaviour was not. The results are however in line with findings of previous studies on activity patterns $(14,21)$, in which no detrimental effects of persistence behaviour were found. In the study of McCracken and Samuel (21) persistence behaviour was unrelated to disability. Moreover, Hasenbring and colleagues (14), found that persistence behaviour was associated with lower levels of disability. It is noteworthy that in these three studies, three different measurement instruments were used to assess persistence behaviour. It is possible that, despite the agreement in the theoretical conceptualization of persistence behaviour, different items might tap into different aspects of persistence behaviour. For example, an item focusing on "being highly active" versus an item focusing on "experiencing increased pain as a consequence of being highly active" might be differentially related to disability. The finding of the present study that persistence behaviour was related to being close to, as well as being far away from the ideal-other self, adds up to the importance of taking a closer look at the concept of persistence behaviour.

Future studies should be attentive to the dynamics between types of selfdiscrepancies but might also consider focusing on one type of self-discrepancy in order to gain more insight into direct effects on emotional or behavioural out- 
comes. Furthermore, the perspective on the self should not be neglected as different results emerge from self-discrepancies from the own perspective versus selfdiscrepancies from the other perspective. It might be interesting for future studies to also consider the relationship between the patient and his or her significant other, as listed in the self-discrepancy interview since this might be of importance for the strength of the self-discrepancy. For the study of the role of selfdiscrepancies in activity patterns, future studies might consider possible mediating or moderating variables. For example, flexible goal adjustment has been shown to be protective against negative emotions despite the presence of self-discrepancies (11).

The integration of self-discrepancies in the explanatory mechanism behind emotional and behavioural consequences of chronic pain might have clinical implications. Clinicians should keep in mind that patients may not only be burdened by fears at the level of activities but also at the level of being. Chronic pain patients might benefit from clinical interventions targeting the way patients see themselves and working with the personal goals they set for themselves, which are defined in the ideal and ought self. Self-system therapy (SST) which is derived from SDT has previously been employed in the treatment of depression, has shown promising results $(28,32)$.

The shortcomings of the present study, being that the results rely on self-report and as the design was cross-sectional, no causal relationships could be confirmed, imply that future studies should focus on longitudinal designs to examine associations in time and experimentally testing self-discrepancies in patients with chronic pain. It would be interesting to experimentally activate specific self-discrepancies and determine under controlled circumstances whether and how they influence pain behaviour. Furthermore, caution is needed with respect to generalizing present findings to other pain populations since the present study involved a relatively homogeneous group of chronic low back pain patients only.

Considering this is the first study to investigate this relationship, it is difficult to be conclusive about the role of self-discrepancies in the activity patterns of chronic pain patients. Nevertheless, the present results add to the importance of studying the feared self in patients with chronic pain and to consider both emotional and behavioural consequences, as the feared-own was related to avoidance. On the other hand, ideal self-discrepancies might be important in the light of explaining persistence behaviour. Yet, based on present results, the ought self might be less relevant in explaining emotional or behavioural consequences. Importantly, avoidance, but not persistence behaviour, appeared to predict disability and diminished quality of life. 


\section{Acknowledgements}

The authors wish to thank Stephen Morley for the interesting and fruitful discussions on the study of self-discrepancies in patients with chronic pain. We are also grateful to Erik Schouten and Gerard van Breukelen for their statistical assistance and to Astrid Dello, Truus Uijen, and Sita van Riet for their help in data collection and organization. The study was supported by the Council for Medical and Health Research of the Netherlands (ZON-MW), Grant nr. 14350042. The contribution of Johan W.S. Vlaeyen was supported by the NWO Social Sciences Research Council of The Netherlands, Grant nr. 453-04-003. Participation of Dr. Roelofs was supported by the EFIC-Grünenthal Grant (EGG). The authors have no conflict of interest with regard to the present study. 


\section{References}

(1) Beck AT, Steer RA, and Brown GK. Manual for the Beck Depression Inventory, 2nd ed. San Antonio. TX: The Psychological Corporation 1996.

(2) Beck AT, Steer RA, Brown GK, and Van der Does AJW. BDI-II-NL Handleiding (BDI-II-Dutch Manual). 2002, Lisse: The Netherlands: Psychological Corporation.

(3) Boldero J, Francis J. Ideals, oughts, and self-regulation: Are there qualitatively distinct self-guides? Asian J Soc Psych 1999; 2(3):343-355.

(4) Brouwer S, Kuijer W, Dijkstra PU, Goeken LN, Groothoff JW, and Geertzen JH. Reliability and stability of the Roland Morris Disability Questionnaire: intra class correlation and limits of agreement. Disabil Rehabil 2004; 26(3):162-5.

(5) Cane D, Nielson WR, Ivey B, Ivey R, McCarthy M, and Mazmanian D, Development and preliminary evaluation of a measure of three pain-related patterns of activity., in 27th Annual Canadian Pain Society Meeting. 2007: Ottawa Ontario.

(6) Carver CS, Lawrence JW, and Scheier MF. Self-discrepancies and affect: incorporating the role of feared selves. Pers Soc Psych Bull 1999; 25:783-792.

(7) Carver CS, Scheier FM. On the self-regulation of behavior. 1998: Cambridge University press.

(8) Crombez G, Eccleston C, Baeyens F, and Eelen P. Attentional disruption is enhanced by the threat of pain. Behav Res Ther 1998; 36(2):195-204.

(9) Eccleston C, Crombez G. Pain demands attention: a cognitive-affective model of the interruptive function of pain. Psychol Bull 1999; 125(3):356-66.

(10) Faas A, Chavannes AW, Koes BW, van den Hoogen JMM, Mens JMA, Smeele LM, Romeijnders ACM, and van der Laan JR. NHG-standaard M54 lage-rugpijn (Dutch). Huisarts Wet 1996; 39:18-31.

(11) Goossens ME, Kindermans HP, Morley SJ, Roelofs J, Verbunt J, and Vlaeyen JW. Self-discrepancies in work-related upper extremity pain: relation to emotions and flexible-goal adjustment. Eur J Pain 2009; 14(7):764-70.

(12) Hardin EE, Leong TF. Optimism and pessimism as mediators of the relations between selfdiscrepancies and distress among Asian and European Americans. J Couns Psych 2005; 52(1):25.

(13) Harris CA, D'Eon JL. Psychometric properties of the Beck Depression Inventory-Second Edition (BDIII) in individuals with chronic pain. Pain 2008; 137(3):609-622.

(14) Hasenbring MI, Hallner D, and Rusu AC. Fear-avoidance- and endurance-related responses to pain: development and validation of the Avoidance-Endurance Questionnaire (AEQ). Eur J Pain 2009; 13(6):620-8.

(15) Hasenbring MI, Plaas H, Fischbein B, and Willburger R. The relationship between activity and pain in patients 6 months after lumbar disc surgery: do pain-related coping modes act as moderator variables? Eur J Pain 2006; 10(8):701-9.

(16) Higgins E. Self-discrepancy: a theory relating self and affect. Psych Rev 1987; 94(3):319-40.

(17) Kindermans HP, Goossens ME, Roelofs J, Huijnen IP, Verbunt JA, Morley S, and Vlaeyen JW. A content analysis of ideal, ought, and feared selves in patients with chronic low back pain. Eur J Pain 2010; 14(6):648-53.

(18) Lamé IE, Peters ML, Vlaeyen JWS, Patijn J, and Kleef Mv. Quality of life in chronic pain is more associated with beliefs about pain, than with pain intensity. Eur J Pain 2005; 9(1):15-24.

(19) Leeuw M, Goossens ME, Linton SJ, Crombez G, Boersma K, and Vlaeyen JW. The fear-avoidance model of musculoskeletal pain: current state of scientific evidence. J Behav Med 2007; 30(1):77-94.

(20) Mansell W. Control theory and psychopathology: An integrative approach. Psychol Psychother 2005; 78(2):141-178.

(21) McCracken LM, Samuel VM. The role of avoidance, pacing, and other activity patterns in chronic pain. Pain 2007; 130(1-2):119-25.

(22) Morley S, Eccleston C. The object of fear in pain. In: G.J. Asmundson, J.W. Vlaeyen, and G. Crombez, editors. Understanding and treating fear of pain. Oxford, UK: Oxford University Press; 2004. p. 16388. 
(23) Ogilvie DM. The undesired self: a neglected variable in personality research. Pers Soc Psychol 1987; 52:379-385.

(24) Phillips AG, Silvia PJ, and Paradise MJ. The undesired self and emotional experience: A latent variable analysis. J Soc Clin Psychol 2007; 26(9):1035-1047.

(25) Price DD, McGrath PA, Rafii A, and Buckingham B. The validation of visual analogue scales as ratio scale measures for chronic and experimental pain. Pain 1983; 17(1):45-56.

(26) Roland M, Morris R. A study of the natural history of back pain. Part I: development of a reliable and sensitive measure of disability in low-back pain. Spine 1983; 8(2):141-4.

(27) Spinhoven P, Ormel J, Sloekers PP, Kempen GI, Speckens AE, and Van Hemert AM. A validation study of the Hospital Anxiety and Depression Scale (HADS) in different groups of Dutch subjects. Psychol Med 1997; 27(2):363-70.

(28) Strauman TJ, Vieth AZ, Merrill KA, Kolden GG, Woods TE, Klein MH, Papadakis AA, Schneider KL, and Kwapil L. Self-system therapy as an intervention for self-regulatory dysfunction in depression: a randomized comparison with cognitive therapy. J Consult Clin Psychol 2006; 74(2):367-76.

(29) van der Zee K, Sanderman R, Heyink J, and De Haes H. Psychometric qualities of the RAND 36-item Health Survey 1.0: A multidimensional measure of general health status. Int J Beh Med 1996; 3:104-122.

(30) van der Zee KI, Sanderman R, Het meten van de algemene gezondheidstoestand met de RAND-36: een handleiding (Dutch). 1993: Groningen: Noordelijk centrum voor gezondheidsvraagstukken.

(31) Van Houdenhove B, Neerinckx E. Is "ergomania" a predisposing factor to chronic pain and fatigue? Psychosomatics 1999; 40(6):529-30.

(32) Vieth A-Z, Strauman T-J, Kolden G-G, Woods T-E, Michels J-L, and Klein M-H. Self-System Therapy (SST): A Theory-Based Psychotherapy for Depression. Clin Psych Sci Pract 2003; 10:245-268.

(33) Vlaeyen JW, Linton SJ. Fear-avoidance and its consequences in chronic musculoskeletal pain: a state of the art. Pain 2000; 85(3):317-32.

(34) Vlaeyen JW, Morley S. Active despite pain: the putative role of stop-rules and current mood. Pain 2004; 110(3):512-6.

(35) Waters SJ, Keefe FJ, and Strauman TJ. Self-discrepancy in chronic low back pain: relation to pain, depression, and psychological distress. J Pain Symptom Manage 2004; 27(3):251-9.

(36) Zigmund AS, Snaith RP. The Hospital Anxiety and Depression Scale. Acta Psychiatr Scand 1983; 67:361-370. 


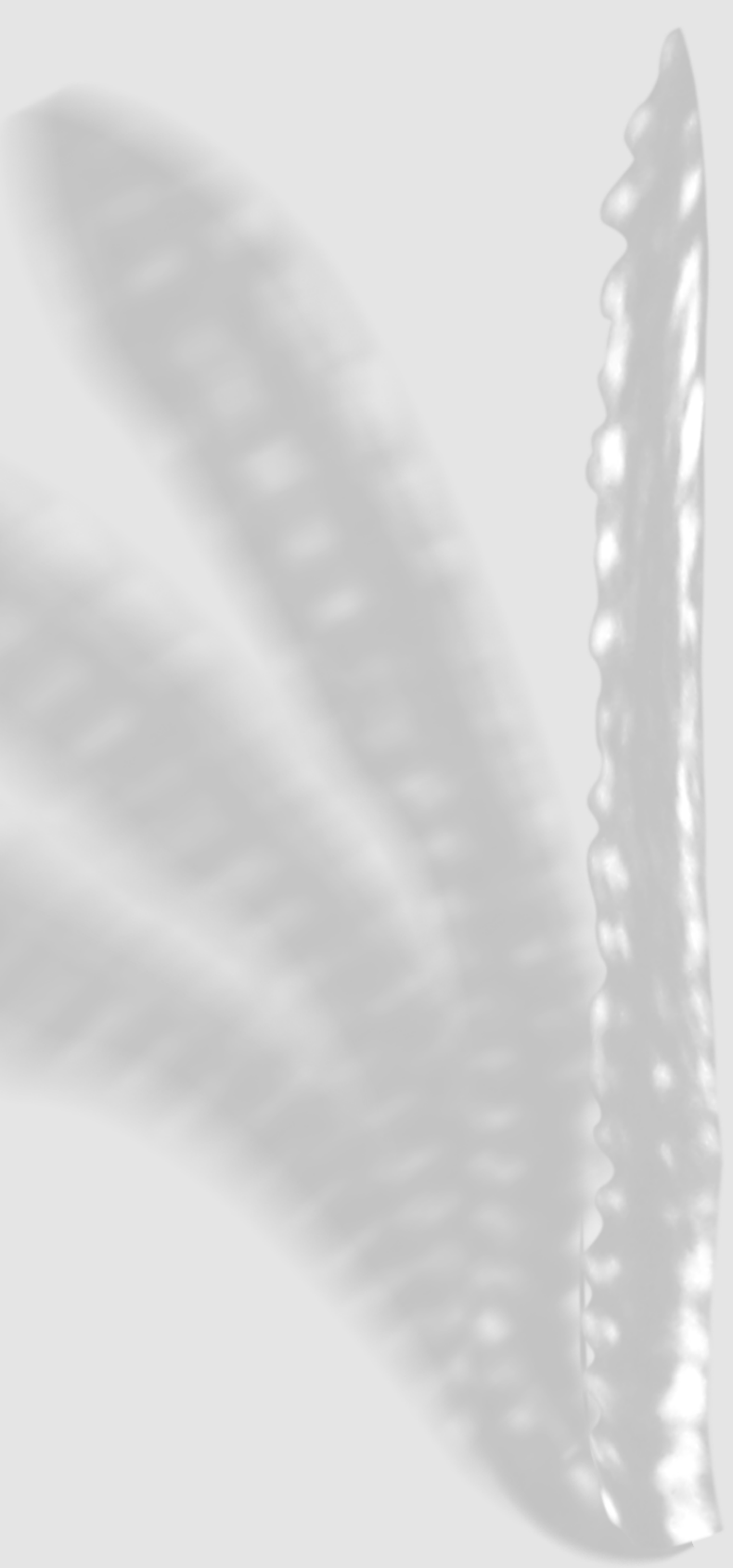




\section{Chapter 9}

\section{Effects of self-discrepancies on}

activity-related behaviour: explaining disability and quality of life in patients with chronic low back pain

This chapter is published in revised form as:

Huijnen IP, Kindermans HP, Seelen HA, Peters ML, Smeets RJ, Serroyen J, Roelofs J, Goossens M, Verbunt JA. Effects of self-discrepancies on activity-related behaviour: explaining disability and quality of life in patients with chronic low back pain. Pain 2011; 152(9):2165-72 


\section{Abstract}

In chronic low back pain (CLBP) research, the self-discrepancy model has been applied to explain dysfunctional avoidance and persistence behaviour. The main aim of the present study was to evaluate whether specific self-discrepancies in patients with CLBP are associated with the abovementioned types of activity-related behaviour and whether changes in self-discrepancies over time are associated with changes in activity-related behaviour. Furthermore, the aim was to evaluate whether avoidance and persistence behaviour are associated with a higher level of disability and a diminished quality of life and whether changes over time in avoidance and persistence behaviour result in changes in disability and quality of life.

A longitudinal cohort study in a sample of patients with CLBP $(N=116)$, in which self-discrepancies, disability, quality of life, and objectively registered characteristics of activity-related behaviour were measured, was performed to evaluate the pathways in the aforementioned self-discrepancy model.

Results indicate that patients with CLBP who feel closer to their ideal-other show more characteristics of persistence behaviour. Patients, who move further away from their ideal-own, also show more characteristics of persistence behaviour. Furthermore, in patients characterized as avoider a decrease in a patients' daily uptime was associated with a decrease of mental health-related quality of life.

\section{Introduction}

The fear-avoidance model describes that in patients with chronic low back pain (CLBP) pain-catastrophizing and pain-related fear lead to avoidance behaviour (32). However, not all CLBP patients who are disabled, avoid activities (4). Several studies indicated that there are also patients who persist in their activities while feeling disabled $(3,18)$.

To explain avoidance and persistence behaviour, recently a self-discrepancy model of chronic pain has been proposed (figure 1) (20). The original SelfDiscrepancy Theory of Higgins states that discrepancies between the 'actual self' (the person you are now) and 'ideal self' (the person you would ideally like to be) or 'ought self' (the person you ought to be) lead to negative emotions and distress (16). Also the role of the 'feared self' (the person you fear to be) was evaluated (6). These selves may exist from the own perspective ("who would I ideally like to be?") and the perspective of a significant other ("who does my spouse want me ideally to be?") (16). As to patients with chronic pain, discrepancies between selves (actual vs. ideal, actual vs. ought, and actual vs. feared self) are associated with negative emotions, depression, anxiety, distress, and pain (10, 20,33). Actual-ideal and actualought discrepancies are hypothesized to be associated with persistence behaviour 
and actual-feared discrepancies with avoidance behaviour (20). Both avoidance and persistence behaviour are expected to result in more disability and a diminished quality of life (20).

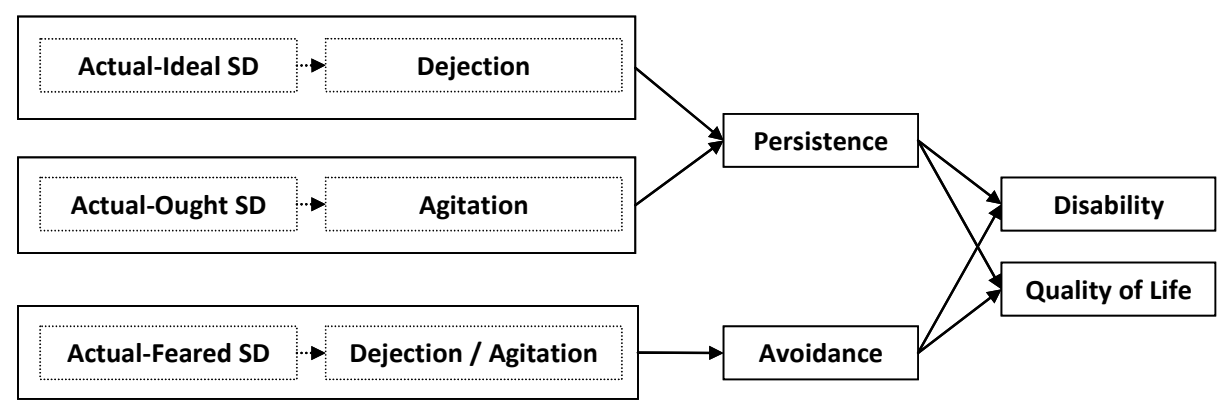

Figure 1: The self-discrepancy model for chronic pain

Results of an earlier article of this project indicate that based on self-report, CLBP patients who feel close to their feared-own show more avoidance behaviour and patients who feel close or far away to their ideal-other showed more persistence behaviour (20). It was assumed that showing persistence behaviour when feeling close to the ideal-other is an adaptive response and may not result in disability, whereas a large discrepancy may be maladaptive and therefore result in more disability (20). No other self-discrepancies were associated with avoidance or persistence behaviour. Furthermore, patients who scored high on avoidance or persistence behaviour felt more disabled compared to patients scoring low on avoidance and persistence behaviour (18).

Earlier research indicated that CLBP patients have difficulties estimating their own daily life activities (17). It therefore seems plausible that self-reported activityrelated behaviour may be biased by a patients' perception. Whether selfdiscrepancies are associated with the objectively registered activity-related characteristics and whether the self-discrepancy model is consistent over time is currently unclear.

Four hypotheses will be tested:

1. A large actual-ideal and actual-ought discrepancy is associated with objectively assessed characteristics of persistence behaviour and a small actualfeared discrepancy is associated with characteristics of avoidance behaviour.

2. Over time, an increase in actual-ideal and actual-ought discrepancy is related to an increase in persistence behaviour. A decrease in the actualfeared discrepancy is associated with increased avoidance behaviour.

3. Both higher levels of avoidance and persistence behaviour are associated with more disability and diminished quality of life. 
4. When the level of persistence or avoidance behaviour increases over time, the disability level increases whereas quality of life decreases.

\section{Methods}

\subsection{Participants}

This study is part of a larger cohort study with a baseline assessment (T1) and follow up measurement at 6 months (T2) in which patients with CLBP participated. Inclusion criteria were: a) low back pain: pain localized below the scapulae and above the gluteal folds lasting over three months (24); b) age 18-65 years; c) low back pain is not attributable to a specific pathology (e.g. infection, tumour, osteoporosis, fracture, structural deformity, inflammatory disorder (e.g. ankylosing spondylitis), radicular syndrome or cauda equina syndrome) (1). Exclusion criteria were a) pregnancy; b) serious psychiatric diseases; c) non-fluency in Dutch. Patients were included in two different ways: 81 patients were referred by consultants in rehabilitation medicine in the southern part of the Netherlands (one rehabilitation centre, six hospital departments of rehabilitation medicine), and 35 patients responded on an advertisement in a local newspaper. In case patients responded to the advertisement, the above mentioned selection criteria were checked by a consultant in rehabilitation medicine who performed a medical screening based on the clinical guideline for LBP of the Dutch College of General Practitioners (8). The Medical Ethics Committee of the Maastricht University / University Hospital Maastricht, the Netherlands, approved the study protocol.

\subsection{Measures}

\subsubsection{Demographic and pain-related information}

Gender, age, work status and duration of complaints were recorded. Pain intensity was measured using a $100 \mathrm{~mm}$ Visual Analogue Scales(VAS; 25). Patients rated their current pain and their highest and lowest pain level during the past week. A composite score was calculated from the mean of the three VAS-scores.

\subsubsection{Self-discrepancies}

Self-discrepancies were measured with Hardin's Selves Questionnaire (HSQ; 12) using a semi-structured interview (19). Participants were asked to generate ideal, ought and feared attributes from two perspectives, their own perspective and the internalized perspective of someone who is important to them (e.g. spouse). More details of the interview are described by Kindermans et al. $(19,20)$. The HSQ is a valid and reliable instrument to measure self-discrepancies (12). 


\subsubsection{Activity-related behaviour style}

To measure a patients' activity-related behaviour style, first the level of physical activity in daily life was assessed using a tri-axial accelerometer (RT3; Stayhealthy Inc., Monrovia, USA). Subjects were instructed to wear the RT3 during waking hours for 14 consecutive days. The accelerometer was not worn during water-based activities (e.g. swimming, taking a shower), or in case of potential damage to the equipment (e.g. contact sports). The tri-axial accelerometer is a valid instrument for the measurement of physical activity in daily life in patients with LBP (31). More details of the signal processing are reported in Huijnen et al. (18). In accordance with the latter study, three activity-related characteristics were calculated to represent a person's activity-related behaviour style (18):

\section{Daily uptime}

Daily uptime, representing the period (in min) between getting up and going to sleep, was identified using a predefined algorithm (18).

\section{Mean total activity score}

The original non-filtered signal data were used to calculate the mean total activity score (activity mean ) expressed as the mean number of counts per day $(18,30)$.

\section{Fluctuations in activity}

For every patient a fluctuation score was calculated based on difference scores between the total number of counts per 15 minutes. These difference scores were squared and subsequently a mean value was calculated. Finally, the root from this mean value was taken to express the level of activity fluctuations over time (fluctuations $\left._{\text {act }}\right)(18)$.

For the present study two different parameters were used to index a patient's activity-related behaviour style:

Daily uptime. Our earlier study found this to best represent activity-related behaviour (18). Higher scores indicate a characteristic of persistence behaviour whereas a lower score indicate a characteristic of avoidance behaviour.

A linear combination of the three activity-related characteristics daily uptime, activity $_{\text {mean, }}$ and fluctuations $s_{\text {act. }}$. Factor analyses showed that all three variables loaded on the first factor, called "activity-related style", explaining $68 \%$ of the variance. The factor loadings of this factor are: activity mean $(0.95)$, fluctuations act $_{\text {( }}(0.87)$, and daily uptime (0.61). Higher scores indicate a characteristic of persistence behaviour, whereas lower scores indicate a characteristic of avoidance behaviour. To evaluate whether changes in activity-related style overtime are related to selfdiscrepancies, disability, or quality of life, the factor loadings from a factor analysis of activitymean, fluctuations act $_{\text {ma }}$ and daily uptime at T1 were multiplied by the stan- 
dardized scores of activity mean, fluctuations $_{\text {act }}$ and daily uptime at $\mathrm{T} 2$. These scores were subsequently summed, resulting in an activity-related style variable at T2.

\subsubsection{Depressive symptoms}

Depressive symptoms are assessed by the Beck Depression Inventory II (BDI-II) (BDIII; 11). The questionnaire has good psychometric properties and is a valid questionnaire to measure the severity of depression in patients with chronic pain $(11,13)$.

\subsubsection{Habitual physical activity in daily life}

To assess the level of daily life activities during the last year the Baecke Physical Activity Questionnaire (BPAQ) is used (2). Three indices of habitual physical activity can be derived: the occupational activity index; the sport activity index and the leisure time index. The reliability of the BPAQ in patients with LBP appears to be sufficient (22).

\subsubsection{Disability}

Low back disability is assessed by using the Roland Disability Questionnaire (RDQ) $(26,27)$. The Dutch version of the RDQ has a high reproducibility and validity and is responsive to change $(5,9,21)$.

\subsubsection{Health-related quality of life}

The RAND 36-item Health survey (RAND-36; 28) is used to measure health-related quality of life. The questionnaire comprises a physical and mental health component. Both components comprise four subscales. The physical health component comprises physical functioning, physical role limitations, general health perception, and pain subscales. The mental health component comprises social functioning, emotional role limitations, mental health, and vitality subscales. A ninth subscale 'health change' does not belong to one of the components. Responses to the items are given on a three or six point Likert scale, or with 'yes' or 'no', depending on the subscale. Psychometric properties of the RAND-36 are satisfactory $(28,29)$.

\subsection{Procedure}

Prior to participation, all subjects were informed about the purpose of the study and signed a consent form. At inclusion (T1) and after 6 months (T2), an identical assessment procedure was performed. Participants completed the self-report measures in either a paper-based or internet-based questionnaire. During a 14 day measurement period patients carried an accelerometer to measure physical activity in daily life. 


\subsection{Data analysis}

To test the first hypothesis, the associations between the three self-discrepancies and the characteristics of activity-related behaviour were evaluated by means of a linear regression model using daily uptime as the dependent variable. In the first step of the analysis we controlled for age and gender, and, in addition in the second step for pain duration and pain intensity, whereas in the third step each type (ideal, ought, and feared self) of self-discrepancy from both perspectives together (own and other separately) were separately introduced as independent variables (20). In addition, identical models were evaluated with the previously defined activityrelated style factor as dependent variable.

In order to study our second hypothesis and to evaluate whether changes in self-discrepancies and changes in activity-related characteristics over time are associated, a two-level hierarchical linear regression analysis was performed. In multilevel modelling, the repeated observations (in this model the self-discrepancies and activity-related style or daily uptime) are presented as Level 1 units. These observations are organized within Level 2 units, which constitute persons. This method accounts for the level of variation both within and between patients. In the first three models, daily uptime was introduced as dependent variable and the different self-discrepancies (actual-ideal (1), actual-ought (2), and actual-feared (3)) both from the own and other perspective, age, and gender were consecutively introduced as independent variables. In addition, to evaluate whether changes in activity-related style were associated with changes in self-discrepancies, activity-related style was introduced as dependent variable and the different types of selfdiscrepancies, age and gender were introduced as independent variables.

Furthermore, to evaluate the third hypothesis three regression analyses were performed to predict disability (RDQ), physical, and mental health-related quality of life. Daily uptime was introduced as the independent variable in the third step, while controlling for age and gender in the first step and pain duration and pain intensity in the second step. In addition, because both a low and high daily uptime were hypothesized to be associated with higher disability levels and lower physical and mental health-related quality of life in the fourth step a quadratic association was introduced. To calculate this, the standardized daily uptime score was squared and added in the fourth step of the three regression models. To test whether activity-related-style predicts disability, physical and mental health-related quality of life three identical models were evaluated. In the third step, instead of daily uptime, activity-related style was introduced. To evaluate the quadratic association, the standardized activity-related style was first squared and then added in the fourth step.

In order to test the fourth hypothesis, to evaluate if changes in perceived disability and health-related quality of life (physical and mental) are associated with changes in characteristics of persistence or avoidance behaviour, firstly the median 
score of daily uptime and activity-related style at T1 was calculated. Then, based on the median score, patients who scored above the median score were identified as showing more persistence behaviour at T1 whereas a score lower than the median score was interpreted as showing more avoidance behaviour at T1. Subgroups were formed because a low score and high score on daily uptime and activity-related style, as a characteristic of avoidance or persistence behaviour, were both assumed to be related to disability and quality of life. Therefore, in patients who were already showing more avoidance behaviour at $\mathrm{T} 1$, an increase in daily uptime or activityrelated style was hypothesized to be related to a decrease in disability and an increase in physical and mental health-related quality of life. In contrast to patients who showed more avoidance behaviour at T1, in patients who already showed more persistence behaviour at $\mathrm{T} 1$, an increase in physical and mental health-related quality of life was hypothesized to be related to an increase in disability and a decrease in physical and mental health-related quality of life. For both subgroups three two-level hierarchical models were fitted with daily uptime as independent variable and three identical models with activity-related style as independent variable. Disability (1) and the physical (2) and mental (3) health-related quality of life subscales were the dependent variables. All statistical analyses were performed using SPSS software version 16 (SPSS Inc. Chicago, III.).

\section{Results}

One-hundred-sixteen patients were included in this study. No significant differences in gender, duration of complaints, work status, pain intensity, and disability level were found between the group of participants entering the study after referral by consultants in rehabilitation medicine and those that were included after responding to an advertisement. However, patients who responded to the advertisement were significantly older (53.3 years, SD $=9.0$ ) compared to patients directly referred by their consultant in rehabilitation medicine (age $=44.6$ years, $S D=10.3$ ).

Nine of the 116 patients included refused to participate in the accelerometer assessment at T1. Seven patients who carried an accelerometer had an invalid activity score caused by failure of the RT3. In addition, accelerometer registrations of three patients could not be used for further analyses, because the signal to noise ratio was too low. For the remaining 97 patients data were processed and the length of the daily registration of the accelerometer was evaluated. For 84 patients an accelerometer registration that fulfilled all pre-determined criteria for activity assessment was available. Data of these patients were used in the regression models in the baseline analyses. In addition, of these 84 patients 4 patients did not complete the HSQ-interview. No disability score at T1 was available for 4 patients and 5 patients did not complete the RAND-36 to measure health-related quality of life. 
Of the 84 patients with a valid activity assessment at T1, 21 refused to participate at T2. In addition, 11 patients who carried the accelerometer at T2 had an invalid activity score caused by failure of the RT3. For the remaining 52 patients data were processed and evaluated in order to be used in repeated-measures analyses. Activity assessment of three patients did not fulfil the predefined selection criteria. Data of the remaining 49 patients were used in the two-level hierarchical linear regression models.

116 Patients with CLBP

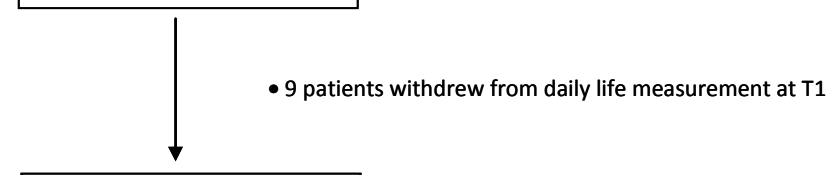

107 Patients with CLBP

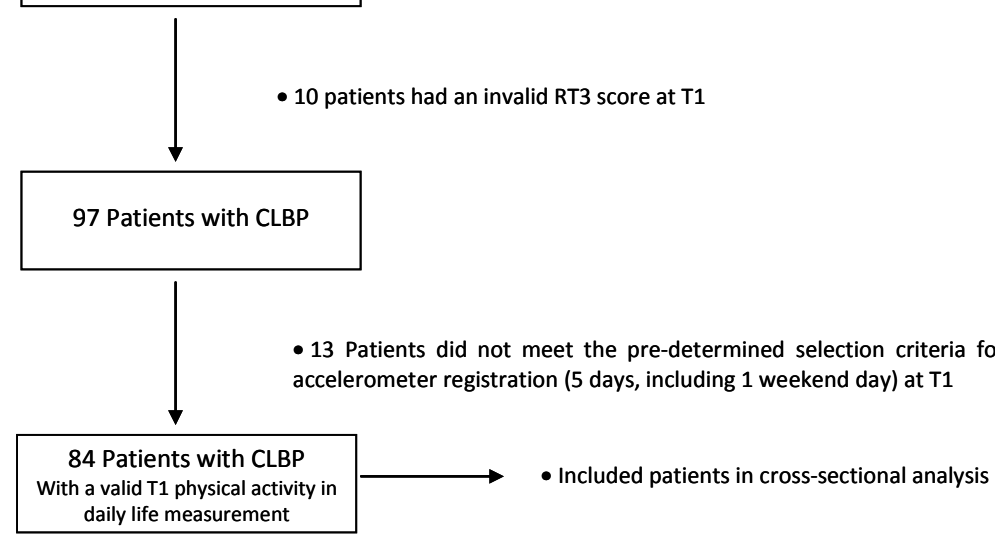

- 21 patients withdrew from T2 measurement and 11 patients had an invalid RT3 score at T2 ( 9 patients caused by failure of the RT3 and of 2 patients RT3 accelerometer got lost during the post delivery process)

52 Patients with CLBP

- 3 Patients did not meet the pre-determined selection criteria for a valid accelerometer registration at $\mathrm{T} 2$ (5 days, including 1 weekend day)

49 Patients with CLBP With a valid $\mathrm{T} 1$ and $\mathrm{T} 2$ physical activity in daily life measurement

Figure 2: Flow chart 
Table 1 presents the characteristics of the 84 patients with a valid activity assessment at T1 and the characteristics of the 49 patients with a valid activity assessment at T1 and T2. In addition, of these 49 patients 2 patients did not complete the HSQ interview and no disability score was available for 2 patients. Furthermore, 3 patients did not complete the RAND-36 to measure health-related quality of life. Age, gender, work status, disability level, and pain intensity were not significantly different between patients who were included in the longitudinal analyses and patients who did have a valid T1 assessment, but had no valid T2 assessment. However, patients who were included in the longitudinal analysis reported a more depressed mood (Mann-Whitney test; $Z=-2.03, P=0.043$ ) compared to patients who only had a valid T1 assessment.

Table 1: $\quad$ Characteristics of the study population of patients with CLBP with a valid activity assessment at T1

\begin{tabular}{lll}
\hline & $\begin{array}{l}\text { Valid T1 } \\
\text { activity assessment }\end{array}$ & $\begin{array}{l}\text { Valid T1 and T2 activity } \\
\text { assessment }\end{array}$ \\
\hline Male/Female (N) & $45 / 39$ & $26 / 23$ \\
Age (years) & $47.5(10.5)$ & $47.8(10.9)$ \\
Work status (N and percentage) & & \\
- Paid job & $41(49 \%)$ & $18(38 \%)$ \\
- Sick leave & $4(5 \%)$ & $2(4 \%)$ \\
- Disability payment & $13(16 \%)$ & $7(15 \%)$ \\
Disability level (RDQ *) & $11.5(4.4)$ & $12.2(4.1)$ \\
Depression (BDI-II **) & $11.0(7.0-17.0)$ & $13.0(8.0-19.3)$ \\
Habitual activity level (BPAQ***) & $8.7(1.7)$ & $8.7(1.3)$ \\
\hline
\end{tabular}

Normally distributed data are represented by a mean score (SD)

Not normally distributed data are represented by a median score (interquartile ranges)

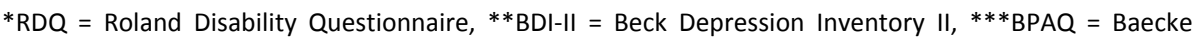
Physical Activity Questionnaire

\subsection{The association between self-discrepancies and objectively registered activity-related style characteristics}

Table 2 presents the outcome of the regression models with daily uptime as dependent variable and the self-discrepancies as independent variables. No significant associations were found that could explain a significant amount of variation in daily uptime and, in addition, no type of self-discrepancy was associated with daily uptime.

Table 3 presents the results of the analysis performed with activity-related style variable instead of daily uptime. Results show that male patients had a higher score on activity-related behaviour style, indicating that men show more persistence behaviour. In addition, it was found that in two models a significant amount of variation in patients' activity-related style could be explained. The ideal-other discrepancy was found to be the only significantly associated self-discrepancy ( $\beta=-$ 
$\left.0.31, p=0.03 ; R^{2}=0.19, p=0.04\right)$, indicating that patients who were close to the ideal-other, show more characteristics of persistence behaviour. In the analysis in model 3c, it appeared that the addition of the feared-own and feared-other discrepancy to model 2 leads in the third step to a model that could significantly explain the activity-related style $\left(R^{2}=0.18, p=0.05\right)$, although the separate discrepancies did not contribute significantly to the model.

Table 2: Hierarchical regression analyses for self-discrepancies predicting daily uptime while controlling for socio-demographic and pain-related variables $(\mathrm{N}=80)$

\begin{tabular}{|c|c|c|c|c|c|c|c|c|}
\hline Dependent & Blocks & Variables & $B$ & SE B & $\beta$ & $\mathrm{R}^{2}$ & $\mathrm{~F}$ & $p$ \\
\hline \multirow[t]{10}{*}{ Daily uptime } & 1 & Age & .17 & .91 & .05 & .02 & .73 & .49 \\
\hline & & Gender & -22.07 & 18.44 & -.15 & & & \\
\hline & 2 & Pain duration & -.09 & .09 & -.13 & .06 & .94 & .45 \\
\hline & & Mean pain intensity & -.63 & .55 & -.14 & & & \\
\hline & $3 a$ & Ideal-own & 3.95 & 2.57 & .22 & .10 & 1.18 & .33 \\
\hline & & Ideal-other & -4.03 & 2.53 & -.23 & & & \\
\hline & $3 b$ & Ought-own & -.36 & 2.51 & -.21 & .06 & .61 & .72 \\
\hline & & Ought-other & .36 & 2.48 & .21 & & & \\
\hline & $3 c$ & Feared-own & 4.62 & 2.76 & .28 & .12 & 1.41 & .23 \\
\hline & & Feared-other & -.38 & 2.89 & -.02 & & & \\
\hline
\end{tabular}

Table 3: Hierarchical regression analyses for self-discrepancies predicting activity-related style while controlling for socio-demographic and pain-related variables $(N=80)$

\begin{tabular}{|c|c|c|c|c|c|c|c|c|}
\hline Dependent & Blocks & Variables & B & SE B & $\beta$ & $\mathrm{R}^{2}$ & $\mathrm{~F}$ & $\mathrm{p}$ \\
\hline \multirow{10}{*}{$\begin{array}{l}\text { Activity-related style } \\
\text { (activity }_{\text {mean }} \text { fluctua- } \\
\text { tions } \\
\text { act, and daily } \\
\text { uptime) }\end{array}$} & 1 & Age & -.00 & .01 & -.04 & .08 & 2.66 & .08 \\
\hline & & Gender & -.54 & .24 & $-.27^{*}$ & & & \\
\hline & 2 & Pain duration & -.00 & .00 & -.15 & .12 & 2.20 & .08 \\
\hline & & Mean pain intensity & -.01 & .01 & -.17 & & & \\
\hline & $3 a$ & Ideal-own & .04 & .03 & .16 & .19 & 2.35 & $.04^{*}$ \\
\hline & & Ideal-other & -.07 & .03 & $-.31^{*}$ & & & \\
\hline & $3 b$ & Ought-own & .01 & .03 & .03 & .12 & 1.43 & .22 \\
\hline & & Ought-other & -.00 & .03 & -.01 & & & \\
\hline & $3 c$ & Feared-own & .05 & .04 & .24 & .18 & 2.29 & $.05^{*}$ \\
\hline & & Feared-other & .01 & .04 & .03 & & & \\
\hline
\end{tabular}

$* p \leq 0.05$ 


\subsection{The association between self-discrepancies and objectively registered activity-related style characteristics over time}

The change in a person's daily uptime, appeared to be significantly associated with the change in discrepancy between the actual and ideal self from the own perspective $(\beta=0.26, S E=0.13, p=0.04)$. Patients whose actual self becomes further away from their ideal self will have an increase in their daily uptime, whereas patients who become closer to their ideal self from their own perspective will have a decrease in daily uptime. In addition, a trend was found for the association between the actual-ideal discrepancy from the other perspective and daily uptime $(\beta=-0.22$, $S E=0.13, p=0.09$ ). No other significant associations for daily uptime were found.

No significant associations were found between changes in patient's activityrelated style and either one of the three types of self-discrepancies (the discrepancy between the actual and ideal, ought, and/or feared self).

\subsection{The association between disability, health-related quality of life and objectively registered activity-related style characteristics}

Table 4 presents the outcome of the regression models with disability, physical and mental health-related quality of life as dependent variable and daily uptime $(3 a, 4 a)$ and activity-related style (3b, $4 b)$ as independent variables. In the first block controlling was done for age and gender. In the second block pain duration and pain intensity were controlled for. Pain intensity was positively associated with disability $(\beta=0.52, p<0.01)$, and negatively associated with physical $(\beta=-0.56, p<0.01)$ and mental health-related quality of life $(\beta=-0.42, p<0.01)$. In addition, an increase of age was associated with a higher score on physical $(\beta=0.34, p<0.01)$ and mental health-related quality of life $(\beta=0.24, p=0.05)$. However, no significant associations were found between daily uptime or activity-related style and disability, physical or mental health-related quality of life.

\subsection{The association between disability, physical, and mental health-related quality of life and activity-related style characteristics over time}

To test the hypotheses that both avoidance and persistence behaviour are associated with higher disability levels and a diminished quality of life over time, subgroups had to be formed first. Avoiders were defined based on a lower daily uptime or activity-related style score then the median score of the total group at T1, whereas persisters were defined based on a higher daily uptime of activity-related style score. In patients characterized as avoider an increase in daily uptime predicted an increase in mental health-related quality of life $(\beta=0.62, \mathrm{SE}=0.25, p=$ $0.02 ;-2 \mathrm{LL}=98.16)$. This indicates that patients characterized as avoider, who have an increase in daily uptime, show an increase in mental health-related quality of life, 
whereas patients who have a decrease in daily uptime show a decrease in perceived mental health. No other significant associations were found explaining changes in the disability level or physical or mental health-related quality of life for both subgroups.

Table 4: Hierarchical regression analyses for daily uptime and activity-related style predicting disability, physical and mental health-related quality of life while controlling for sociodemographic and pain-related variables

\begin{tabular}{|c|c|c|c|c|c|c|c|c|}
\hline Dependent & Blocks & Variables & $B$ & SE B & $\beta$ & $\mathrm{R}^{2}$ & $\mathrm{~F}$ & $\mathrm{p}$ \\
\hline \multirow{8}{*}{$\begin{array}{l}\text { Disability (RDQ) } \\
(\mathrm{N}=80)\end{array}$} & 1 & Age & -.06 & .05 & -.15 & .04 & 1.28 & .29 \\
\hline & & Gender & -1.01 & 1.01 & -.12 & & & \\
\hline & 2 & Pain duration & .00 & .00 & .04 & .31 & 7.36 & $.00 * *$ \\
\hline & & Mean pain intensity & .13 & .03 & $.52 * *$ & & & \\
\hline & $3 a$ & Daily uptime & -.01 & .00 & -.16 & .33 & 6.51 & $.00 * *$ \\
\hline & $4 a$ & Daily uptime $^{2}$ & -.23 & .42 & -.06 & .33 & 5.41 & $.00 * *$ \\
\hline & $3 b$ & Activity-related style & -.48 & .44 & -.12 & .32 & 6.14 & $.00 * *$ \\
\hline & $4 b$ & Activity-related style ${ }^{2}$ & -.20 & .27 & -.10 & .32 & 5.17 & $.00 * *$ \\
\hline \multirow{8}{*}{$\begin{array}{l}\text { Physical QOL } \\
(\mathrm{N}=79)\end{array}$} & 1 & Age & 2.43 & .79 & $.34^{* *}$ & .14 & 5.44 & $.01 * *$ \\
\hline & & Gender & 20.94 & 16.18 & .15 & & & \\
\hline & 2 & Pain duration & -.04 & .06 & -.06 & .45 & 13.46 & $.00 * *$ \\
\hline & & Mean pain intensity & -2.40 & .39 & $-.56 * *$ & & & \\
\hline & $3 a$ & Daily uptime & .01 & .09 & .01 & .45 & 10.61 & $.00 * *$ \\
\hline & $4 a$ & Daily uptime ${ }^{2}$ & .91 & 6.49 & -.01 & .45 & 8.72 & $.00^{* *}$ \\
\hline & $3 b$ & Activity-related style & -2.17 & 6.73 & -.03 & .45 & 10.64 & $.00 * *$ \\
\hline & $4 b$ & Activity-related style ${ }^{2}$ & -1.87 & 4.12 & -.05 & .45 & 8.80 & $.00 * *$ \\
\hline \multirow{8}{*}{$\begin{array}{l}\text { Mental QOL } \\
(N=79)\end{array}$} & 1 & Age & 1.88 & .92 & $.24 *$ & .06 & 2.28 & .11 \\
\hline & & Gender & 13.32 & 18.85 & .08 & & & \\
\hline & 2 & Pain duration & -.14 & .08 & -.19 & .27 & 6.21 & $.00 * *$ \\
\hline & & Mean pain intensity & -2.05 & .51 & $-.42 * *$ & & & \\
\hline & $3 a$ & Daily uptime & .03 & .11 & .02 & .27 & 4.91 & $.00 * *$ \\
\hline & $4 a$ & Daily uptime ${ }^{2}$ & .55 & 8.32 & .01 & .27 & 4.03 & $.00 * *$ \\
\hline & $3 b$ & Activity-related style & -9.27 & 8.57 & -.12 & .28 & 5.22 & $.00 * *$ \\
\hline & $4 b$ & Activity-related style ${ }^{2}$ & .89 & 5.24 & .02 & .28 & 4.29 & $.00 * *$ \\
\hline
\end{tabular}

\footnotetext{
$* \mathrm{p} \leq 0.05, * * \mathrm{p}<0.01$.
}

Activity-related style contains activitymean, fluctuations act, $_{\text {, and daily uptime }}$ 


\section{Discussion}

This study aimed to evaluate whether self-discrepancies are associated with activity-related behaviour and whether changes in self-discrepancies over time are associated with changes in activity-related behaviour of patients with CLBP. Furthermore, the aim was to evaluate whether avoidance and persistence behaviour is associated with a higher disability level and a diminished quality of life and whether changes in avoidance and persistence behaviour results in changes in disability and quality of life.

It appears that only the actual-ideal discrepancy from the other perspective is related to a person's activity-related style. Patients who feel close to the idealother, show more characteristics of persistence behaviour. In addition, a trend was found that a change towards the ideal-other is associated with an increase in daily uptime. This could imply a shift to an activity-pattern that is characterized by a higher level of persistence behaviour. These findings are partly in line with the findings of a recent study of Kindermans et al., who found that patients who felt either close or far away from the ideal-other show persistence behaviour (20). Maybe patients strive to be the ideal person out of the perspective of others and thus try to fulfil all daily life goals to be the ideal person for the people around them. To achieve this, they have a longer daily uptime, in order to reach a decrease in the discrepancy between the actual and ideal self from the other perspective.

For the actual-ideal discrepancy from the own perspective a different picture emerged. In line with the hypothesis, a change in discrepancy in which a person moves further away from the ideal self was associated with an extension of their daily uptime. This indicates a shift towards an activity pattern that is characterized by a higher level of persistence behaviour. This may explain the activity-related behaviour of the so-called endurance copers subgroup in the avoidance-endurance model $(14,15)$. In order to complete their tasks, endurance copers will work until physical overexertion, resulting in a physical overload with an increased pain intensity as a result (15). Probably this task completion may result in an extension of their daily uptime to finish all their activities.

The hypothesized associations between the actual-ought discrepancy and persistence behaviour and the actual-feared discrepancy and avoidance behaviour could not be confirmed in the current study. Yet, Kindermans et al. found that the actual-feared discrepancy from the own perspective was the most prominent discrepancy in the association with self-reported avoidance behaviour (20). This is in line with the fear-avoidance model, which states that fear of movement leads to avoidance behaviour, characterized by a lower daily life activity level (32). However, based on objective activity-related outcomes in the current study the association between the actual-feared discrepancy and avoidance behaviour could not be replicated. This might be due to the distorted estimation of a patient's own daily life 
functioning (17). Evaluating the associations between self-discrepancies and activity-related behaviour in patients with CLBP based on the results of the current study and the study of Kindermans et al., it could be concluded that limited evidence is found that confirms the hypothesized pathways from self-discrepancies to persistence and avoidance behaviour. A possible reason for this could be that in the current study self-discrepancies are measured as specific personality attributes and not specified in the domain of activities in daily life functioning (19). An attribute mentioned for the ought self was, for example, "being friendly". Moderating and mediating steps between the attributes, for example in the interpersonal attributes category, and activity-related behaviour have not been explored yet. When a patient mentions attributes in the domain of physical, emotional and psychological wellbeing, it was found to be related to disability (19). The attributes in this domain were most frequently mentioned for the ideal self (19). This might be an explanation why only the actual-ideal discrepancies are found to be related to the actual behaviour in the present study and the study of Kindermans et al. (20).

An intriguing finding is that in patients with CLBP characterized as avoiders, a decrease in daily uptime is associated with a decrease in mental health-related quality of life. Huijnen et al. found that uptime is a potential differentiating factor between persistence and avoidance behaviour (18). In patients who already have a lower than average daily uptime and thus seem to show more avoidance behaviour, a further decrease is related to decrease in mental health-related quality of life. However, no association between persistence behaviour and mental health-related quality of life are found. Furthermore, no associations are found between characteristics of avoidance and persistence behaviour and disability and health-related quality of life. Although other studies found an association between disability and the self-reported activity level $(7,23)$, the association between a patients' disability level and the objectively assessed mean daily life activity level is rather low $(23,30$, 31). Both low and high levels of daily life activity, as included in activity-related style, have been assumed to be related to disability. That might be an explanation for the low or non-existent associations between physical activity in daily life and disability in earlier research. Therefore, in the present study, a higher disability level in both persistence and avoidance behaviour was hypothesized. However, no significant quadratic term which could indicate a higher disability level in patients who show more persistence and avoidance behaviour, was found. One explanation for this may be the fact that patients with CLBP have difficulties estimating their own daily life activity level. Patients may experience their own daily life activity level as disabling, although their actual activity level is not related to his limitations in daily life functioning. In addition this perception is influenced by the daily life activity level before the onset of pain and depressed mood $(17,30)$.

In the current study, daily uptime and activity-related style were used as two objectively assessed outcome measures to represent activity-related behaviour. In 
an earlier study, daily uptime could differentiate between avoidance and persistence behaviour; a higher daily uptime appeared to be a characteristic of persistence behaviour, whereas a lower daily uptime represented avoidance behaviour (18). To reduce the three activity-related characteristics, one factor was identified from the patients' daily uptime, mean daily life activity level, and fluctuations in daily life activities. Interpreting this factor, a higher score on this factor indicates a higher level of persistence behaviour, whereas a lower score indicates a higher level of avoidance behaviour. Whether uptime and activity-related style indeed provide the assumed representation of avoidance and persistence behaviour and whether this score is a continuum with avoidance behaviour at one extreme and persistence behaviour at the other extreme is currently not yet confirmed. However, till now, this is the first study clustering characteristics of the different activity-related styles in order to represent activity-related behaviour.

One particular topic that should be mentioned as a limitation of the current study is the considerable number of drop-outs at T1 and T2. However, to our opinion, it is of high importance to use strict selection criteria in order to obtain a valid representation of a patient's daily life activities $(17,18)$. And since in the current study changes over time are studied, multiple assessments for every person are needed to be able to perform calculations. For 21 patients only one of the two assessments was available, which resulted in an additional drop-out of patients in the repeated-measures analyses. However, as far as we know this is the first study that evaluates changes in a daily life activity level based on two objective assessments.

At this moment it is not yet possible to formulate clinical implications. More research is needed to further evaluate the hypothesized pathways and mediating and moderating processes between the pathways. So far, the theoretical evidence explaining the pathway from persistence and avoidance to disability and a diminished quality of life is scarce. Although the results are not conclusive, this study is one of the first that studies both pathways of activity-related behaviour. Future studies should confirm, further refine or decline the presented model. This can lead to a theoretical foundation which can be used to further develop a tailored treatment for patients with CLBP.

Based on the results of the current study, in patients with CLBP the actual-ideal discrepancy from the other perspective is found to be related to characteristics of persistence behaviour. Patients, who have an increase in the ideal-own discrepancy, show also an increase in their daily uptime. In addition, an increase of a patients' daily uptime in patients with CLBP characterized as avoider is associated with an increase in mental health-related quality of life. 


\section{Acknowledgements}

This study was supported by the Council for Medical and Health Research of the Netherlands (ZON-MW), grant nr. 14350042. Participation of Dr. Roelofs was supported by the EFIC-Grünenthal-Grant (EGG). The authors have no conflicts of interest. 


\section{References}

(1) Airaksinen O, Brox JI, Cedraschi C, Hildebrandt J, Klaber-Moffett J, Kovacs F, Mannion AF, Reis S, Staal JB, Ursin H, and Zanoli G. Chapter 4. European guidelines for the management of chronic nonspecific low back pain. Eur Spine J 2006; 15 Suppl 2:S192-300.

(2) Baecke JA, Burema J, and Frijters JE. A short questionnaire for the measurement of habitual physical activity in epidemiological studies. Am J Clin Nutr 1982; 36(5):936-42.

(3) Birkholtz M, Aylwin M, and Harman RM. Activity pacing in chronic pain management: One aim, but which method? Part one: Introduction and literature review. British Journal of Occupational Therapy 2006; 67(10):447-452.

(4) Bousema EJ, Verbunt JA, Seelen HA, Vlaeyen JW, and Knottnerus JA. Disuse and physical deconditioning in the first year after the onset of back pain. Pain 2007; 130(3):279-86.

(5) Brouwer S, Kuijer W, Dijkstra PU, Goeken LN, Groothoff JW, and Geertzen JH. Reliability and stability of the Roland Morris Disability Questionnaire: intra class correlation and limits of agreement. Disabil.Rehabil. 2004; 26(3):162-165.

(6) Carver CS, Lawrence JW, and Scheier MF. Self-Discrepancies and affect: Incorporating the role of feared selves. Personality and social psychology bulletin 1999; 25 (7):783-792.

(7) Elfving B, Andersson T, and Grooten WJ. Low levels of physical activity in back pain patients are associated with high levels of fear-avoidance beliefs and pain catastrophizing. Physiother Res Int 2007; 12(1):14-24.

(8) Faas A, Chavannes AW, Koes BW, van den Hoogen JMM, Mens JMA, Smeele LM, Romeijnders ACM, and van der Laan JR. NHG-standaard M54 lage-rugpijn. 1996.

(9) Gommans JHB, Koes BW, and van Tulder MW. Validiteit en responsiviteit Nederlandstalige Roland Disability Questionnaire. Vragenlijst naar functionele status bij patienten met lage rugpijn. Nederlands Tijdschrift voor Fysiotherapie 1997; 107(2):28-33.

(10) Goossens ME, Kindermans HP, Morley SJ, Roelofs J, Verbunt J, and Vlaeyen JW. Self-discrepancies in work-related upper extremity pain: relation to emotions and flexible-goal adjustment. Eur J Pain 2010; 14(7):764-70.

(11) Gretebeck RJ, Montoye HJ. Variability of some objective measures of physical activity. Med Sci Sports Exerc 1992; 24(10):1167-72.

(12) Harding V, Williams A. Activities training: Intergrating behavioral and cognitive methods with physiotherapy in pain management. J of Occupational Rehabilitation 1998; 8(1):47-60.

(13) Harris CA, D’Eon JL. Psychometric properties of the Beck Depression Inventory--second edition (BDI-II) in individuals with chronic pain. Pain 2008; 137(3):609-22.

(14) Hasenbring M, Hallner D, and Klasen B. (Psychological mechanisms in the transition from acute to chronic pain: over- or underrated?). Schmerz 2001; 15(6):442-7.

(15) Hasenbring MI, Plaas H, Fischbein B, and Willburger R. The relationship between activity and pain in patients 6 months after lumbar disc surgery: Do pain-related coping modes act as moderator variables? Eur J Pain 2006; 10(8):701-9.

(16) Higgins ET. Self-discrepancy: a theory relating self and affect. Psychol Rev 1987; 94(3):319-40.

(17) Huijnen IP, Verbunt JA, Peters ML, Delespaul P, Kindermans HP, Roelofs J, Goossens M, and Seelen HA. Do depression and pain intensity interfere with physical activity in daily life in patients with Chronic Low Back Pain? Pain 2010; 150(1):161-6.

(18) Huijnen IP, Verbunt JA, Peters ML, Smeets RJ, Kindermans HP, Roelofs J, Goossens M, and Seelen HA. Differences in activity-related behaviour among patients with chronic low back pain. Eur J Pain 2010:Accepted.

(19) Kindermans HP, Goossens ME, Roelofs J, Huijnen IP, Verbunt JA, Morley S, and Vlaeyen JW. A content analysis of ideal, ought, and feared selves in patients with chronic low back pain. Eur J Pain 2010; 14(6):648-53. 
(20) Kindermans HP, Huijnen IP, Goossens ME, Roelofs J, Verbunt JA, and Vlaeyen JW. "Being" in pain: the role of self-discrepancies in the emotional experience and activity patterns of patients with chronic low back pain. Pain 2010: Accepted.

(21) Kuijer W, Brouwer S, Dijkstra PU, Jorritsma W, Groothoff JW, and Geertzen JH. Responsiveness of the Roland-Morris Disability Questionnaire: consequences of using different external criteria. Clin Rehabil 2005; 19(5):488-95.

(22) Levin S, Jacobs DR, Jr., Ainsworth BE, Richardson MT, and Leon AS. Intra-individual variation and estimates of usual physical activity. Ann Epidemiol 1999; 9(8):481-8.

(23) Lin CC, McAuley JM, Macedo L, Barnett D, Smeets RJ, and Verbunt J. The relationship between physical activity and disability in low back pain: a systematic review and meta-analysis. Pain 2010: Accepted.

(24) Merskey H, Bogduk N. Classification of chronic pain. IASP Task force on taxonomy, ed. S. edition. 1994, Seattle: IASP press.

(25) Price DD, McGrath PA, Rafii A, and Buckingham B. The validation of visual analogue scales as ratio scale measures for chronic and experimental pain. . Pain 1983; 17(1):45-56.

(26) Roland M, Morris R. A study of the natural history of back pain. Part I: development of a reliable and sensitive measure of disability in low-back pain. Spine 1983; 8(2):141-4.

(27) Roland M, Morris R. A study of the natural history of low-back pain. Part II: development of guidelines for trials of treatment in primary care. Spine 1983; 8(2):145-50.

(28) van der Zee K, Sanderman R, Het meten van de algemene gezondheidstoestand met de RAND-36: een handleiding. 1993: Groningen: Noordelijk centrum voor gezondheidsvraagstukken.

(29) van der Zee K, Sanderman R, Heyink J, and De Haes H. Psychometric qualities of the RAND 36-item Health Survey 1.0: A multidimensional measure of general health status. International Journal of Behavioral Medicine 1996; 3:104-122.

(30) Verbunt JA, Sieben JM, Seelen HA, Vlaeyen JW, Bousema EJ, van der Heijden GJ, and Knottnerus JA. Decline in physical activity, disability and pain-related fear in sub-acute low back pain. Eur J Pain 2005; 9(4):417-25.

(31) Verbunt JA, Westerterp KR, van der Heijden GJ, Seelen HA, Vlaeyen JW, and Knottnerus JA. Physical activity in daily life in patients with chronic low back pain. Arch Phys Med Rehabil 2001; 82(6):72630.

(32) Vlaeyen JW, Linton SJ. Fear-avoidance and its consequences in chronic musculoskeletal pain: a state of the art. Pain 2000; 85(3):317-32.

(33) Waters SJ, Keefe FJ, and Strauman TJ. Self-discrepancy in chronic low back pain: relation to pain, depression, and psychological distress. J Pain Symptom Manage 2004; 27(3):251-9. 


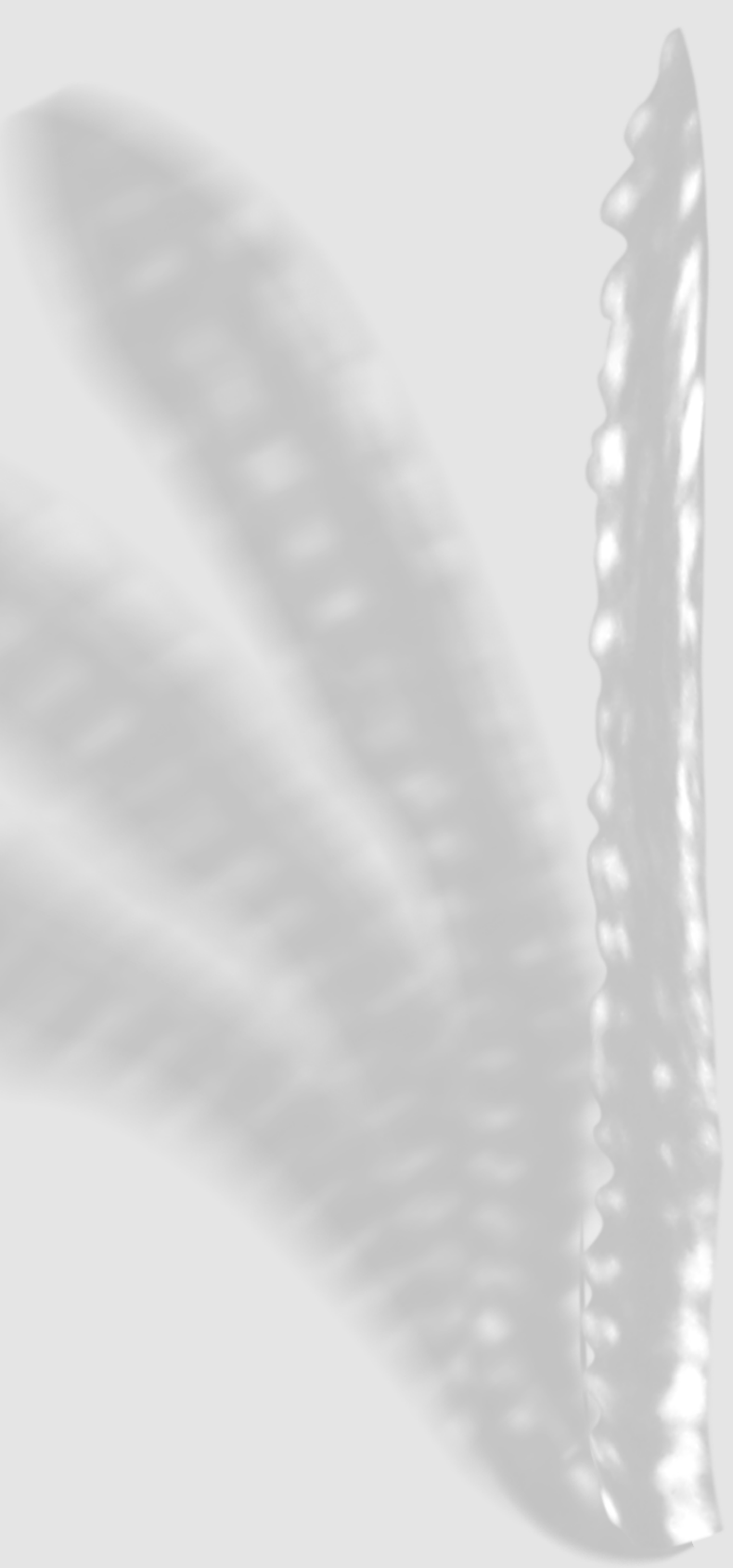


Chapter 10

General discussion 


\section{General discussion}

\subsection{Scope of this thesis}

In patients with CLBP avoidance behaviour has often been identified as a negative consequence of chronic pain. More recently, an additional activity-related behaviour style, defined as persistence behaviour, has been proposed. However, a model explaining both avoidance and persistence behaviour has not been developed. Before starting to research this, adequate assessment methods to identify both activity-related behaviour styles are needed. The main objective of this thesis has been whether we can identify different activity-related behaviour within the population of patients with CLBP and to explore whether the self-discrepancy model for chronic pain could offer an explanation for these individual differences in activity-related behaviour. This thesis is divided in three parts with three specific aims:

1. To evaluate assessment methods to measure a patients' activity-related behaviour during performance testing and in daily life situations.

2. To identify specific characteristics in a person's activity pattern reflecting his activity-related behaviour style (i.e. avoidance or persistence).

3. To evaluate whether the self-discrepancy model for chronic pain can explain differences in activity-related behaviour styles.

In this general discussion, first the main results presented in this thesis will be summarized. In addition, knowledge will be integrated and discussed in relation to the current scientific evidence for each of the abovementioned topics. Then, methodological considerations are formulated, followed by the clinical implications. And finally, conclusions will be drawn.

\subsection{Assessment of activity-related behaviour}

The main aim of the topical review presented in chapter 2 was to discuss the influence of both physiological factors (age, gender, muscle strength, aerobic capacity, etc,) and non-physiological (environmental and psychological) factors on physical performance in patients with CLBP. In addition, the study presented in chapter 3 was aimed at evaluating whether in patients with sub acute low back pain who overpredict activity-related pain, pain-related fear is associated with physical performance. Moreover, it was evaluated whether patients who overpredict pain and have a higher level of pain-related fear during performance in the laboratory also show an activity decline in daily life activities. Based on the results of chapter 2 and 3 it can be concluded that physical performance of patients with low back pain seems not only to be influenced by physiological factors. Although strongly dependent on the type of performance, compared to pain-free volunteers, the influence of 
psychological factors, like fear of movement during physical performance, seems more prominent in patients suffering from low back pain.

The scientific literature currently available discussing the influence of psychological factors (e.g. fear of movement) on physical functioning in patients with chronic pain, is however not unequivocal. Whereas some studies indicate that patients scoring lower on physical performance tests due to fear of movement, can indeed be distinguished from those who function as healthy individuals $(2,11,28$, $41)$, others found no influence of fear on functional capacity and maximum oxygen consumption in patients with pain $(25,29)$. This ambiguity in scientific evidence may have two reasons. First, it has been discussed in chapter 2 that the extent to which both physiological and psychological factors contribute to the eventual test outcome strongly depends on the type of performance test used. The outcome of a (sub)maximal exercise test is mainly influenced by physiological factors and thus best represents a person's maximum level of physical performance defined as one's physical capacity. However, during performance of a holding endurance task psychological factors are more important and the outcome seems more influenced by a person's behaviour. Therefore in studies evaluating the influence of fear of movement while using a physical performance task in which the influence of psychological factors is not prominent (e.g. (sub)maximal exercise testing and in a functional capacity evaluation), the association between test outcome and the patient's fear to move is expected to be limited.

Second, non-physiological factors may reinforce each other and therefore result in a lower test performance. Chapter 3 describes the moderating effect of a patient's pain prediction in the association between fear of movement and physical performance in patients with sub acute low back pain. Patients were classified based on their ability to accurately predict their level of activity-related pain. It appeared that in "overpredictors", in contrast to "correct predictors", fear of movement was negatively associated with performance. Classifying patients, for example based on correct and overprediction of activity-related pain, may reveal the negative influence of pain-related fear in a subgroup of patients. This classification may even reveal the negative influence of fear of movement on a physical performance task which is aimed to represent a patient's physical capacity (as in (sub)maximal exercise testing and in a functional capacity evaluation). However, early test termination in patients with higher scores on fear of movement may obscure the association between fear of movement and physical performance.

The hypothesis that higher pain-related fear levels are associated with lower physical activity levels, as presented in chapter 3 , was only partly confirmed. Although patients with a higher level of pain-related fear who overpredict their activity-related pain during test performance in a laboratory setting did show a lower test outcome, their higher level of pain-related fear appeared to be positively associated with a the objectively measured daily life activity level. A possible explanation 
for this may be that patients who overpredict activity-related pain and are more afraid may apply alternative activities to reach their goals. For example, a patient may avoid cycling and will choose an alternative activity (e.g. walking) that necessitates even more energy. This assumption is in accordance with the influence that fear of movement has in the alteration of the activity pattern in patients with sub acute low back pain (32). In this study of Thomas et al. motion of the thoracic spine, lumbar spine, and hip were recorded during reaching for three targets. It appeared that patients with a higher level of pain-related fear used a different strategy during movement compared to patients with a lower level of pain-related fear; they avoided motion of their lumbar spine (32). Moreover, in the study of Al-Obaidi et al. a higher level of pain-related fear was associated with a lower comfortable speed (2). It is hypothesized that patients with low back pain who fear an increase in pain show altered and less efficient movement patterns in order to prevent pain. Due to this, patients with CLBP execute daily life performances less efficient as compared to healthy people. The optimal way to test this assumption would be to test differences in energy expenditure during performance testing using measurement techniques such as gas exchange measurements. Whether next to fear of movement also other psychological factors such as pain catastrophizing and self-efficacy could ultimately lead to less efficient energy expenditure and whether energy expenditure is also different between patients applying avoidance or persistence behaviour should be further explored.

In order to be able to identify different activity-related styles in future studies, it is important to unravel the influence of both physiological and psychological factors on physical performance. Measurement techniques like the interpolated twitch technique and surface EMG may discern the individual influence of both physiological and psychological factors during performance testing and are necessary to confirm whether deconditioning or sub-maximal performance will influence test outcome most. For this purpose, Verbunt et al. used an interpolated twitch technique during isometric quadriceps muscle strength testing in patients with CLBP (41). This measurement technique allows differentiation between the impact of physiological and psychological factors during muscle strength testing. The reason of a patient to stop during muscle strength performance can be investigated using surface electromyography (EMG). This technique may reveal whether a shift to median frequencies in the lower frequency part of the spectrum is present, indicating physiological muscle fatigue $(6,24,26)$. This technique may specify the extent to which physical fatigue contribute to test termination. As far as we know in patients with CLBP no study has evaluated the reason behind quitting a performance test. It may be assumed that a patient will terminate the test either due to fatigue or due to the influence of psychological factors that will force him to terminate the test before fatigue is reached. In patients applying different activity-related behaviour styles distinct reasons for quitting a performance test are hypothesized. We hypothesize 
that patients with CLBP, who have an activity-related style characterized by fear to move, will have a lower level of EMG registered fatigue at test termination representing that muscle strength performance is at a sub-maximal level at the moment of test termination. In patients who persist in activities, the level of EMG registered fatigue reached at the moment of test termination will be higher, indicating that muscle strength testing was performed at a level close to or even the maximal level of performance of the individual. We hypothesize that after controlling for age, gender, and body mass, patients with persistence behaviour will show higher levels of muscle strength performance compared to patients who avoid activities. Our future studies will evaluate the formulated hypothesis in experimental studies in patients with CLBP.

In Chapter 4 an overview of self-reported and objective measurement techniques for assessing physical activity in daily life in patients with musculoskeletal pain were presented. Based on this review, it has been concluded that regarding patients with musculoskeletal pain currently only limited evidence is available on psychometric properties of instruments for physical activity assessment. For patients with CLBP, the association between their perceived daily life activity level and the actual level of daily life activities is rather low, $(20,39)$. In Chapter 5 it has been found that especially patients with CLBP, who feel more depressed, underestimate their actual daily life activity level. Based on the results of chapter 4 and 5 and the evidence currently available, it is recommended to evaluate a patient's daily life activity level with an objective registration tool. But in addition, a further consensus for activity assessment in chronic pain seems recommendable.

\subsection{Identification of subgroups based on activity-related behaviour}

As described in the introduction of this thesis, one of the most prominent models to explain disability in patients with CLBP is the fear-avoidance model (46). Although the role of fear-avoidance has been confirmed in a wide range of patients with pain (21), this model may not be applicable for all patients suffering from CLBP. There seems to be a subgroup of patients who, although they feel disabled, have a daily life activity level comparable to healthy volunteers $(34,40,43)$. Clinicians assume that, next to avoidance behaviour, there may be an alternative activity-related style, characterized by persistence in activities. 'Persisters' tend to continue their activities despite pain, until completion is reached. After activity completion, pain will increase, which in turn will force persisters to take rest until pain subsides $(3,13)$. In persisters these activity fluctuations are discernable as a saw-tooth pattern in a multiple day activity registration. Several scientific models did already propose this additional activity-related style, characterized by persistence in activities despite pain $(14,15,36,47)$. 
Whether activity fluctuations over time, as a possible characteristic of persistence behaviour, are related to the disability level was evaluated in chapter 6 . Results showed that, besides pain intensity, fluctuations in the daily life activity level instead of the mean activity level were significantly associated with the level of disability. These results may support the existence of a subgroup of persisters by showing that some patients have fluctuating levels of daily life activities and that these fluctuations are associated with feeling or being more disabled in daily life functioning.

In chapter 7 activity-related characteristics of patients with different activityrelated behaviour styles, classified on their scores on the Patterns of Activity Measure-Pain (POAM-P), were identified. Patients scoring high on the avoidance subscale and low on the persistence subscale were classified as avoider and patients scoring high on the persistence subscale and low on the avoidance subscale as persister. In addition, patients scoring high on both the avoidance and persistence subscale were classified as mixed performer and patients who scored low on both subscales were classified as functional performers. Results showed that avoiders, persisters, and mixed performers felt more disabled than functional performers. Moreover, avoiders and mixed performers felt more disabled than persisters. Furthermore, persisters reported a higher level of daily life activities in self report and presented a longer daily uptime in objective assessment compared to avoiders. The objectively measured total level of physical activity however, did not differ between persisters and avoiders. A higher self-reported daily life activity level was followed by a pain increase in persisters, whereas no such association was found in avoiders.

Just recently, a first study explored the underlying dimensions of persistence behaviour by using various self-reports measuring persistence behaviour and identified three different types: task-contingent persistence (completing activities despite pain), pain-contingent persistence (performing activities is determined by pain), and excessive persistence (doing too much, not respecting one's physical limits and experiencing the rebound effect of heightened activity levels) (19). Excessive persistence was the only type of persistence behaviour that was found to be related to disability and depression. A remarkable finding was the negative relation between task-contingent persistence behaviour and a patient's disability level (19). As discussed in chapter 7 , a possible reason for the finding that some persisters report a lower disability level might be that the currently used disability questionnaires especially focus on avoidance-related disability instead of persistence-related disability. For example, items in the Roland Disability Questionnaire (RDQ) such as "I avoid heavy jobs around the house because of my back" and "I sit down most of the day because of my back" are items that a patient scoring high on task-contingent persistence will probably not affirm. In addition, the ability to participate in essential daily life activities, as measured with the Pain Disability Index, used in the study of Kindermans et al. (19), will be scored differently by patients applying excessive persis- 
tence than by those applying task-contingent persistence. Patients applying taskcontingent persistence behaviour probably will still perform these activities despite pain and hence the experienced disabilities in daily life functioning are not so prominent as in patients applying excessive persistence. It would be of interest to identify these different types of persistence behaviour in the sample of patients in the study presented in chapter 7. However, we used the POAM-P used to identify a patient's activity-related behaviour style and the persistence subscale of this scale contains only items covering task-contingent and pain-contingent persistence, respectively and no items regarding excessive persistence making the differentiation impossible. More research of the different types of persistence behaviour is recommended.

Avoidance and persistence behaviour are often assumed as two opposite activity-related styles. For example in a study in patients with fibromyalgia, patients were categorized as persisters and avoiders based on their scores on avoidance behaviour measured by the 5 -item scale "resting when in pain" of the Pain Coping Inventory and a judgment of a therapist $(37,38)$. Results of chapter 7 however, showed that in our study a substantial number of patients scored high on both avoidance and persistence behaviour. This mixed performers category reported a lower daily life activity level, a higher level of depressed mood, showed more limitations in daily life functioning, fear of movement, and pain intensity than patients scoring both low on avoidance and persistence behaviour (the functional performers). Given the fact that a substantial number of patients show high avoidance and high persistence, it can be concluded that classifying patients in persisters and avoiders based on their score on avoidance behaviour might not be an adequate method. In clinical practice, these mixed performers report that they avoid some activities, whereas during other activities they will persist in activities despite pain. The underlying mechanism why patients sometimes avoid and sometimes persist is unknown and should be further explored. Knowledge on this theme will be useful in order to improve the treatment for patients applying this mixed activity-related style.

The heterogeneity of activity-related styles within a population of patients with CLBP may influence the eventual association between the level of daily life activity and a patient's self-reported disability level of this population. In a study of Lin et al., associations between activity and disability in different studies were systematically reviewed (22). The included meta-analysis showed a moderate, negative relationship between physical activity in daily life and disability in chronic but not in acute pain (22). However, in the interpretation of the results the quality of the assessment instrument used was not taken into account. Almost all studies in which a person's daily life activity level was assessed with an objective assessment instrument could not confirm that a lower daily life activity level is related to a higher level of pain-related disability, whereas studies using self-reports to measure the 
daily life activity level did indeed report a negative association between the daily life activity level and disability $(4,22,27,40,42,43)$. An explanation for this discrepancy in findings between studies in which subjective and objective measurement tools to assess physical activity were used might be that CLBP patients have difficulties estimating their own daily life activity level (22). As reported in chapter 5 and in a recent study of van Weering et al., the association between a patient's estimation of his daily life activity level and their actual daily life activity level is rather low (39). The patients who are more depressed probably judge their activity level lower than their actual, objectively assessed, daily life activity level, which can influence the relation of physical activity with disability. Furthermore, patients' perception of their current daily life activities seems to be based on their recollection of their activity level before they were in pain (42).

As shown in chapter 7 persisters and avoiders may be characterized based on differences in objectively daily uptime and their self-reported daily life activity level. Both subgroups also felt more disabled in daily life functioning compared to patients classified as functional performers. Although avoiders perceive their daily life activity level as lower compared to persisters, the actual, objectively assessed characteristics of daily life activities, such as the mean daily life activity level and fluctuations in activity, are not different. As mentioned earlier in this discussion, this discrepancy between the actual and perceived daily life activity level might be caused by a mismatch between the perceived and actual daily life activity level. However, there might be an explanation why no differences in the actual daily life activity level and fluctuations in activity between persisters and avoiders were found. Patients classified as avoiders are especially prone to avoid specific activities or postures that they fear, but they might continue to perform other non-feared activities. Consequently, a decline in the general level of daily life activities may not be detected as it is simply not there.

Although an accelerometry assessment is proven to be a valid method to assess daily life activities (43), this assessment method cannot identify specific activities and postures. A future challenge would be to identify specific postures and activities. As a result of the avoidance of specific fearful activities and postures, this might reveal that an avoider, in contrast to a persister, will have a different distribution of activities and postures over time. For future research, it is recommended to use an activity monitor, which will enable the identification of different types of activities and postures (34). For example, the distribution of active vs. passive postures/activities and the length of periods the patient is physically active during the day may further indentify characteristics of patients applying different activityrelated behavioural styles.

Although several studies found similar objectively assessed mean daily life activity levels among patients with CLBP and healthy volunteers, the distribution of activities over the day appeared to be different. Patients with CLBP were found to be 
less physically active during the evening $(27,30,40)$. As presented in chapter 7 , patients classified as avoiders have a shorter period of daily uptime, compared to persisters. Whether this shorter daily uptime also means that in avoiders a lower activity level during the evening is present, seems plausible, but should be further explored. Regarding the results of persisters it can be concluded that persisters are active for a longer time period, but no information is available on the intensity of activities during the evening. It may be that, due to fatigue, the intensity of activities will decrease during the day resulting in a lower activity level in the evening. The additional information gathered with an activity monitor, may help to improve the differentiation between persisters and avoiders. This might result in a new diagnostic tool for identifying a patient's activity-related behavioural styles, which in turn may be helpful in choosing the optimal treatment for each individual patient.

\subsection{Adapted self-discrepancy model to explain persistence and avoidance behaviour}

The existence of persistence behaviour in chronic pain has been proposed in several models. Hasenbring and colleagues proposed the avoidance-endurance model (1416). This model describes that within the population of patients with CLBP, patients may apply different activity-related behaviour styles. In addition, van Houdenhove assumed the ergomania model, which postulates that hyperactivity in chronic pain is an expression of unfulfilled dependency needs, excessive bodily narcissism, and masochism (35-37). Furthermore, Vlaeyen and Morley proposed the mood-as-input model (47). This model postulates that a combination of mood and goal pursuit motivates patients to show avoidance and persistence behaviour. However, empirical evidence explaining the existence of avoidance and persistence behaviour in patients with CLBP is still lacking.

Based on the Self-Discrepancy Theory of Higgins (17) a self-discrepancy model for chronic pain is proposed to explain underlying mechanisms and different activity-related behaviour styles in chronic pain. In the proposed self-discrepancy model for chronic pain it is hypothesized that actual-ideal and actual-ought discrepancies are associated with persistence behaviour, whereas actual-feared discrepancies are hypothesized to be associated with avoidance behaviour. Both avoidance and persistence behaviour are expected to be related to higher disability levels and a diminished quality of life. Results of chapter 8 showed that the actual-feared discrepancy from the own and other perspective were both predictive of depressive and anxious mood. In contrast to the proposed model, the actual-ideal and actual-ought discrepancies from the own and other perspective were not related to depressive mood or anxiety. These results are not in accordance with findings of Waters et al. who did find an association between depressed mood and the actual-ideal discrepancy and distress and the actual-ought discrepancy (49). In addition, Goossens et al. 
reported that in patients with work-related upper extremity pain a larger ought discrepancy and a smaller feared discrepancy were related to more depression and anxiety (10).

In accordance with the self-discrepancy model of pain, in chapter 8 it was found that the feared-own discrepancy indeed was associated with the level of selfreported avoidance-behaviour, as measured with the POAM-P. In addition, the actual-ideal self-discrepancy from the other perspective was associated with a person's level of persistence behaviour, whereas the actual-ought discrepancy was not associated with persistence behaviour. With respect to the association between the actual-ideal discrepancy from the other perspective and persistence behaviour a $\mathrm{U}$ Shaped association was found, indicating that patients who felt close and patients who felt far away from their ideal self both show persistence behaviour. Of interest was that self-reported avoidance, but not persistence behaviour, predicted a person's level of disability and quality of life.

As described in chapter 4 and chapter 5 patients with CLBP have difficulties estimating their own daily life activities. It may be assumed that a patient's perception of his self-reported activity-related behaviour which was assessed based on a questionnaire, is also subject to bias. In order to avoid this bias, in chapter 9, the type of a patient's activity-related behaviour style was evaluated based on objective activity-related characteristics. This study evaluates whether self-discrepancies are associated with the objectively registered activity-related characteristics and whether the associations in the self-discrepancy model are consistent over time. Results indicated that, in line with the self-discrepancy model and the results of chapter 8 , patients with CLBP who feel close to their ideal-other show more characteristics of persistence behaviour. Over time, patients who move further away from their idealown, also show an increase in the level of persistence behaviour. Furthermore, in patients who already have a lower than average daily uptime and have thus been characterized as avoider, a further decrease of daily uptime is related to an additional decrease in mental health-related quality of life. However, no association between persistence behaviour and mental health-related quality of life is found.

In the current thesis, an association between self-discrepancies and negative emotions could indeed be confirmed. However the proposed associations between all different self discrepancies with specific emotions as has been found been in a study by Higgins and colleagues could not all be confirmed $(17,31)$. In addition, the hypothesized associations between the type of self-discrepancies and avoidance and persistence behaviour respectively, could not be confirmed unambiguously. A possible reason for this may be that self-discrepancies are higher order constructs measured at the be-level (e.g. being a good parent), in contrast to avoidance and persistence behaviour, which are lower order constructs at a do-level (5) A content analysis of self-discrepancies already showed that self-discrepancies contain general personality attributes and are not specified in the domain of activities in daily life 
functioning. This confirms the conceptual distance between both constructs $(5,18)$. Possibly, influencing factors such as flexible goal adjustment, which was found to be a moderator in the association between self-discrepancies and emotions, might also influence the association between the type of self-discrepancy (being) and both activity-related behaviour styles (doing) (10). In the study of Kindermans et al. the general personality attributes were categorized in several domains (18). The domain of physical, emotional and psychological well-being was found to be related to disability. The attributes in this domain were most frequently mentioned for the ideal self (18). Whether this also is an explanation why the actual-ideal discrepancy was most frequently associated with persistence behaviour, should be further explored.

Furthermore, the results regarding the association between persistence behaviour and disability and quality of life were not conclusive. Whereas a higher disability level was found for persisters compared to patients showing both low avoidance and persistence behaviour (functional performers), no association between characteristics of persistence behaviour and disability or quality of life were found. As mentioned earlier in the discussion, a possible reason for this finding might be that the current available disability questionnaires specifically focus on avoidancerelated disability instead of persistence-related disability.

Future studies should verify the proposed model. This may lead to a refined theory-based model on activity-related behaviour in pain, which may be used to further develop a tailored treatment for patients with CLBP.

\subsection{Methodological considerations}

\subsubsection{Drop-out of the daily life assessment}

In the studies using daily life assessments, described in chapter 5, 7 and 9, data of a considerable number of patients could not be used for further analysis. Several reasons could be identified explaining this high drop-out rate. Firstly, a daily life assessment with a diary and accelerometer could provide some burden for the participant. Secondly, due to technical problems data of an additional number of patients could not be used. Thirdly, the strict criteria we used for a valid assessment resulted in a further drop of the number of participants in the data analysis. To be included as a valid score on physical activity in daily life, at least 5 valid measurement days, including 1 weekend day, had to be available $(12,33)$. In addition, a valid measurement day was defined as a registration period for at least $600 \mathrm{~min}(10 \mathrm{~h})$. Due to these strict criteria, data of a high number of patients could not be used for analyses. To our opinion, it is however of high importance to use these strict criteria to ensure a valid representation of daily life functioning in order to be able to draw conclusions on the role of physical activity in chronic pain. 


\subsubsection{Methods of measurement}

In chapter 6, 7, and 8 new variables (e.g. daily uptime, fluctuations in activity, peak activity) in CLBP research were introduced based on the analyses of the diary and accelerometry data. For these data a Root Mean Square (RMS) score was calculated to reflect the intensity of activity fluctuations in daily life activities. Activity fluctuations were hypothesized to be a characteristic of persistence behaviour. In addition, in chapter 7 and 9 based on the accelerometer assessment, daily uptime was calculated as a representation of the period (in min) between getting up and going to sleep and also in chapter 7 a score was calculated to express the highest peak intensity of physical activity in the measurement period. These variables were introduced because they cover the hypothesized characteristics of avoidance and persistence behaviour. Although all these variables are new and no reference values are yet available, they will have an additional value, since no other outcomes representing characteristics of activity-related behaviour in daily life assessments are currently available.

\subsection{Implications for clinical practice}

\subsubsection{Measuring physical functioning}

In clinical practice, the level of functioning of a patient with CLBP is often evaluated with a physical performance test. As described in the guidelines of the American College of Sports Medicine, appropriate test equipment and protocols are crucial to measure the patient's level of physical capacity (1). Ideally, maximal exercise testing with gas analyses, heart rate and lactate measurements are used to determine whether a maximum performance is achieved. Because these methods are timeconsuming and expensive, this is not often applied in clinical practice $(1,7)$.

Till now, in clinical practice, several performance tests have been used to estimate a patient's maximum physiological possibilities, but it seems questionably whether during testing the patient's maximum physical performance is reached. In case a patient performed sub-maximally, a clinician might interpret the test result as a sign of physical deconditioning. However, as described in chapter 2, next to the physiological factors, also psychological factors and pain intensity can explain a lower performance level. Psychological factors, such as the level of avoidance behaviour, should therefore be measured also. This additional assessment provides information which is helpful to distinguish between deconditioning and sub maximal performance.

Interpreting the difference in outcome on a performance test as treatment effect might be difficult. Exposing patients to physical exercises during treatment might change a patient's activity-related behaviour. After a treatment episode, the scoring on a performance test may be increased, although the actual physical capacity may still not have changed. Measuring psychological factors pre- and post- 
treatment might reveal whether this better performance can be attributed to an increase in physical capacity and/or changes in activity-related behaviour or pain.

\subsubsection{Design of treatments for patients applying persistence behaviour}

Based on the fear-avoidance model, graded activity and graded exposure in vivo are nowadays two frequently used treatments in the management of CLBP. Both treatments are aimed to increase a patient's level of physical activities and decrease one's daily life limitations. Graded activity aims at improving functional ability by positively reinforcing healthy behaviour based on operant learning principles $(8,9)$. Exposure in vivo treatment tries to achieve this goal by reducing pain-related fear by extinction of the Pavlovian conditioning $(44,45)$. This treatment is hypothesized to be especially effective for a subgroup of patients reporting a high level of painrelated fear; the avoiders. Therefore, not all patients will report improvement after graded activity or exposure treatment. A recent systematic review showed only limited evidence for the additional effectiveness of graded activity and graded exposure in vivo compared to other forms of active treatment (23). A possible reason for this rather restricted evidence for the additional effectiveness of both treatments might be that patients in the various studies included in the review, were not adequately selected for this specific treatment. Characteristics of activity-related behaviour might support the decision which treatment should be offered.

The optimal treatment approach for patients with a persistent activity-related behaviour style may be assumed to be different from the programs currently available for avoiders. For the future, a challenge will be to develop a tailored treatment for both defined subgroups. Recently, in a study of van Koulil et al. patients with fibromyalgia were characterized as persister and avoider and received a tailored treatment (38). Although, as previously discussed the method used in this study to classify a patient's activity related behaviour style should be further developed, this study contains some interesting ideas. The fact that they offered a tailored treatment specific for a patient's activity-related behaviour style is novel. For patients with fibromyalgia showing avoidance behaviour, treatment was aimed at increasing daily life activities and diminishing avoidance behaviour by stimulating patients to gradually increase their daily life activities and expose them to fear-related situations. The treatment of patients showing persistence behaviour contains gradually increases of daily life activities and learning to pace their activities and alternate between activity and inactivity (38). Results showed that specific treatments in both subgroups led to significant improvements in physical and psychological functioning (38). However, based on these results it is not clear whether these tailored treatments show a different level of effectiveness in patients with different activityrelated behaviour styles. Vlaeyen and Morley discussed that before this conclusion can be drawn, it should first be evaluated whether this tailored treatment works better than non-specific treatments (48). 
A patient-tailored treatment to reduce a patient's limitations specifically applied to his momentary functioning seems the ultimate goal. From this patient-tailored treatment, patients who show an alternative activity-related behaviour type such as the mixed performers' style, might also benefit. Before this goal can be reached, more research is needed to indentify characteristics of the different activity-related behaviour styles, and next adequate tailored treatments should be developed and evaluated.

\subsection{Conclusions}

From the studies presented in this thesis several conclusions can be drawn. What became clear from chapter 2 and 3 is that the extent in which physiological and psychological factors influence the outcome on a physical performance test differs between performance tests but also between subgroup of patients. Furthermore, in patients with CLBP the physical activity assessments in daily life should be performed with objective registration tools, because the patient's perception of their daily life activity level is often distorted, resulting in an inadequate presentation of one's actual level of daily life activities.

With respect to the activity-related behaviour styles, this thesis showed that distinct characteristics may be identified between patients applying avoidance or persistence behaviour. Dividing patients based on their activity-related style may support the decision-making process, leading to a more patient-tailored choice for the most appropriate treatment for him.

The self-discrepancy model for chronic pain is a promising approach to explain the negative emotions in patients with chronic pain. Future studies should investigate whether the self-discrepancy model for chronic pain can also explain why some patients avoid activities and others persist in activities. This may lead to the theoretical foundation for a patient-tailored and more effective treatment for patients with CLBP. 


\section{References}

(1) ACSM, ACOSM. ACSM's guidelines for exercise testing and prescription. 2006, Philadelphia: Lippincott Williams \& Wilkins.

(2) Al-Obaidi SM, Al-Zoabi B, Al-Shuwaie N, Al-Zaabie N, and Nelson RM. The influence of pain and pain-related fear and disability beliefs on walking velocity in chronic low back pain. Int J Rehabil Res 2003; 26(2):101-8.

(3) Birkholtz M, Aylwin M, and Harman RM. Activity pacing in chronic pain management: One aim, but which method? Part one: Introduction and literature review. Br J Occup Ther 2006; 67(10):447452.

(4) Bousema EJ, Verbunt JA, Seelen HA, Vlaeyen JW, and Knottnerus JA. Disuse and physical deconditioning in the first year after the onset of back pain. Pain 2007; 130(3):279-86.

(5) Carver CS, Scheier MF. On the self-regulation of behavior. 1998, Cambridge, UK: Cambridge University Press.

(6) Coorevits PL, Danneels LA, Ramon H, Van Audekercke R, Cambier DC, and Vanderstraeten GG. Statistical modelling of fatigue-related electromyographic median frequency characteristics of back and hip muscles during a standardized isometric back extension test. J Electromyogr Kinesiol 2005; 15(5):444-51.

(7) Duque I, Parra JH, and Duvallet A. Maximal aerobic power in patients with chronic low back pain: a comparison with healthy subjects. Eur Spine J 2011; 20(1):87-93.

(8) Fordyce WE. Learned pain; pain as behaviour. In: J.D. Loeser, S.H. Butler, C.R. Chapman, and D.C. Turk, editors. Bonica's management of pain. Lippincott: Williams \& Wilkins; 2001. p.

(9) Fordyce WE. Operant or contingency therapies. In: J.D. Loeser, S.H. Butler, C.R. Chapman, and D.C. Turk, editors. Bonica's management of pain. Lippincott: Williams \& Wilkins; 2001. p.

(10) Goossens ME, Kindermans HP, Morley SJ, Roelofs J, Verbunt J, and Vlaeyen JW. Self-discrepancies in work-related upper extremity pain: relation to emotions and flexible-goal adjustment. Eur J Pain 2010; 14(7):764-70.

(11) Goubert L, Crombez G, and Lysens R. Effects of varied-stimulus exposure on overpredictions of pain and behavioural performance in low back pain patients. Behav.Res.Ther. 2005; 43(10):1347-1361.

(12) Gretebeck RJ, Montoye HJ. Variability of some objective measures of physical activity. Med Sci Sports Exerc 1992; 24(10):1167-72.

(13) Harding V, Williams A. Activities training: Intergrating behavioral and cognitive methods with physiotherapy in pain management. J Occup Rehabil 1998; 8(1):47-60.

(14) Hasenbring M, Hallner D, and Klasen B. (Psychological mechanisms in the transition from acute to chronic pain: over- or underrated?). Schmerz 2001; 15(6):442-7.

(15) Hasenbring MI, Plaas H, Fischbein B, and Willburger R. The relationship between activity and pain in patients 6 months after lumbar disc surgery: Do pain-related coping modes act as moderator variables? Eur J Pain 2006; 10(8):701-9.

(16) Hasenbring MI, Verbunt JA. Fear-avoidance and endurance-related responses to pain: new models of behavior and their consequences for clinical practice. Clin J Pain 2010; 26(9):747-53.

(17) Higgins ET. Self-discrepancy: a theory relating self and affect. Psychol Rev 1987; 94(3):319-40.

(18) Kindermans HP, Goossens ME, Roelofs J, Huijnen IP, Verbunt JA, Morley S, and Vlaeyen JW. A content analysis of ideal, ought, and feared selves in patients with chronic low back pain. Eur J Pain 2010; 14(6):648-53.

(19) Kindermans HP, Roelofs J, Goossens ME, Huijnen IP, Verbunt JA, and Vlaeyen JW. Activity patterns in chronic pain: underlying dimensions and associations with disability and depressed mood. Submitted.

(20) Kremer EF, Block A, and Gaylor MS. Behavioral approaches to treatment of chronic pain: the inaccuracy of patient self-report measures. Arch Phys Med Rehabil 1981; 62(4):188-91.

(21) Leeuw M, Goossens ME, Linton SJ, Crombez G, Boersma K, and Vlaeyen JW. The fear-avoidance model of musculoskeletal pain: current state of scientific evidence. J Behav Med 2007; 30(1):77-94. 
(22) Lin CC, McAuley JM, Macedo L, Barnett D, Smeets RJ, and Verbunt J. The relationship between physical activity and disability in low back pain: a systematic review and meta-analysis. Pain 2010:Accepted.

(23) Macedo LG, Smeets RJ, Maher CG, Latimer J, and McAuley JH. Graded activity and graded exposure for persistent nonspecific low back pain: a systematic review. Phys Ther 2010; 90(6):860-79.

(24) Mannion AF, Dolan P. Electromyographic median frequency changes during isometric contraction of the back extensors to fatigue. Spine 1994; 19(11):1223-9.

(25) Reneman MF, Schiphorts Preuper HR, Kleen M, Geertzen JH, and Dijkstra PU. Are pain intensity and pain related fear related to functional capacity evaluation performances of patients with chronic low back pain? J Occup Rehabil 2007; 17(2):247-58.

(26) Roy SH, De Luca CJ, and Casavant DA. Lumbar muscle fatigue and chronic lower back pain. Spine 1989; 14(9):992-1001.

(27) Ryan CG, Grant PM, Dall PM, Gray H, Newton M, and Granat MH. Individuals with chronic low back pain have a lower level, and an altered pattern, of physical activity compared with matched controls: an observational study. Aust J Physiother 2009; 55(1):53-8.

(28) Slaboda JC, Boston JR, Rudy TE, and Lieber SJ. Classifying subgroups of chronic low back pain patients based on lifting patterns. Arch Phys Med Rehabil 2008; 89(8):1542-9.

(29) Smeets RJ, Wittink H, Hidding A, and Knottnerus JA. Do patients with chronic low back pain have a lower level of aerobic fitness than healthy controls?: are pain, disability, fear of injury, working status, or level of leisure time activity associated with the difference in aerobic fitness level? Spine 2006; 31(1):90-7; discussion 98.

(30) Spenkelink CD, Hutten MM, Hermens HJ, and Greitemann BO. Assessment of activities of daily living with an ambulatory monitoring system: a comparative study in patients with chronic low back pain and nonsymptomatic controls. Clin Rehabil 2002; 16(1):16-26.

(31) Strauman TJ, Higgins ET. Self-discrepancies as predictors of vulnerability to distinct syndromes of chronic emotional distress. J Pers 1988; 56(4):685-707.

(32) Thomas JS, France CR. Pain-related fear is associated with avoidance of spinal motion during recovery from low back pain. Spine 2007; 32(16):E460-6.

(33) Trost SG, Mclver KL, and Pate RR. Conducting accelerometer-based activity assessments in fieldbased research. Med Sci Sports Exerc 2005; 37(11 Suppl):S531-43.

(34) van den Berg-Emons RJ, Schasfoort FC, de Vos LA, Bussmann JB, and Stam HJ. Impact of chronic pain on everyday physical activity. Eur J Pain 2007; 11(5):587-93.

(35) Van Houdenhove B. Prevalence and psychodynamic interpretation of premorbid hyperactivity in patients with chronic pain. Psychother Psychosom 1986; 45(4):195-200.

(36) Van Houdenhove B, Neerinckx E. Is "ergomania" a predisposing factor to chronic pain and fatigue? Psychosomatics 1999; 40(6):529-530.

(37) Van Houdenhove B, Onghena P, Neerinckx E, and Hellin J. Does high 'action-proneness' make people more vulnerable to chronic fatigue syndrome? A controlled psychometric study. J Psychosom Res 1995; 39(5):633-40.

(38) van Koulil S, van Lankveld W, Kraaimaat FW, van Helmond T, Vedder A, van Hoorn H, Donders R, de Jong AJ, Haverman JF, Korff KJ, van Riel PL, Cats HA, and Evers AW. Tailored cognitive-behavioral therapy and exercise training for high-risk patients with fibromyalgia. Arthritis Care Res (Hoboken) 2010; 62(10):1377-85.

(39) van Weering MG, Vollenbroek-Hutten MM, and Hermens HJ. The relationship between objectivity and subjectivity measured activity levels in people with chronic low back pain. Clin Rehabil 2010.

(40) van Weering MG, Vollenbroek-Hutten MM, Tonis TM, and Hermens HJ. Daily physical activities in chronic lower back pain patients assessed with accelerometry. Eur J Pain 2009; 13(6):649-54.

(41) Verbunt JA, Seelen HA, Vlaeyen JW, Bousema EJ, van der Heijden GJ, Heuts PH, and Knottnerus JA. Pain-related factors contributing to muscle inhibition in patients with chronic low back pain: an experimental investigation based on superimposed electrical stimulation. Clin J Pain 2005; 21(3):23240. 
(42) Verbunt JA, Sieben JM, Seelen HA, Vlaeyen JW, Bousema EJ, van der Heijden GJ, and Knottnerus JA. Decline in physical activity, disability and pain-related fear in sub-acute low back pain. Eur J Pain 2005; 9(4):417-25.

(43) Verbunt JA, Westerterp KR, van der Heijden GJ, Seelen HA, Vlaeyen JW, and Knottnerus JA. Physical activity in daily life in patients with chronic low back pain. Arch Phys Med Rehabil 2001; 82(6):72630.

(44) Vlaeyen JW, de Jong J, Sieben JM, and Crombez G. Graded exposure in vivo for pain-related fear. In: D.C. Turk and R.J. Gatchel, editors. Psychological approaches to pain management. A practitioners handbook. New York: The Guilford Press; 2001. p.

(45) Vlaeyen JW, de Jong J, Sieben JM, and Crombez G. Fear reduction in chronic pain: graded exposure in vivo with behavioural experiments. In: G.J. Asmundson, J.W. Vlaeyen, and G. Crombez, editors. Understanding and treating fear of pain. New York: Oxford University Press; 2004. p. 313-343.

(46) Vlaeyen JW, Linton SJ. Fear-avoidance and its consequences in chronic musculoskeletal pain: a state of the art. Pain 2000; 85(3):317-32.

(47) Vlaeyen JW, Morley S. Active despite pain: the putative role of stop-rules and current mood. Pain 2004; 110(3):512-516.

(48) Vlaeyen JW, Morley SJ. Tailored treatment: It's not what you think it is: comment on the article by Van Koulil et al. Arthritis Care Res (Hoboken) In press.

(49) Waters SJ, Keefe FJ, and Strauman TJ. Self-discrepancy in chronic low back pain: relation to pain, depression, and psychological distress. J Pain Symptom Manage 2004; 27(3):251-9. 


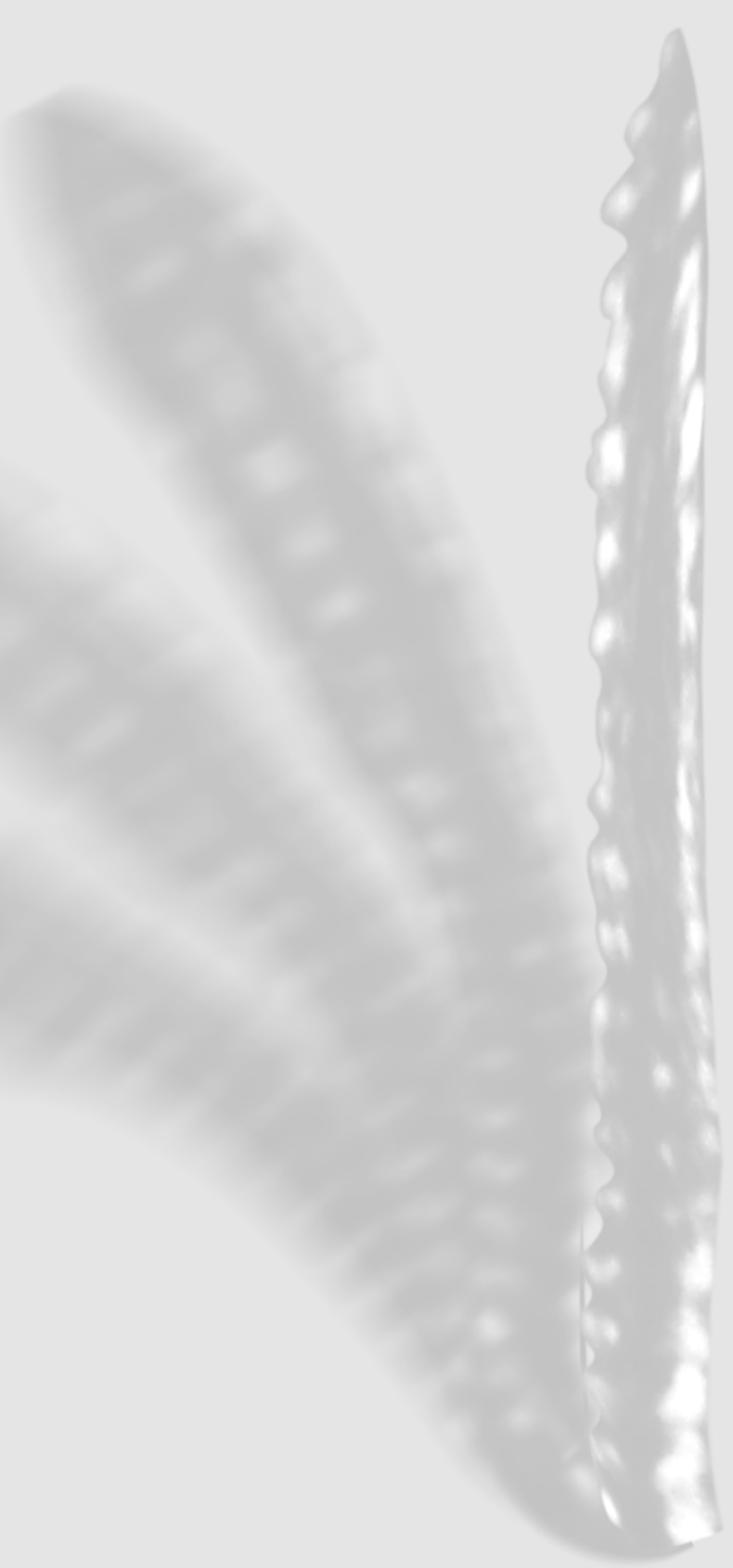


Chapter 11

Summary 


\section{Summary}

Chronic low back pain (CLBP) is a major health problem. The impact for the individual patient is considerable: Patients suffering from CLBP perceive limitations in daily life functioning and a lower quality of life. In addition, the societal impact of CLBP accounts for high health care and socio-economic costs. For years, the focus has been set on creating biomedical models to explain the development and maintenance of nonspecific CLBP. However, not for all patients with pain syndromes, a biomedical explanation for their complaints can be found. In the last decades cognitive-behavioural models have been postulated to explain the development and persistence of disability in nonspecific chronic pain patients. One of the most prominent cognitive behavioural models is the fear-avoidance model. This model proposes that catastrophic interpretations about pain and pain-related fear lead to avoidance behaviour. In the long run this activity-related behaviour style, characterized by activity avoidance, may lead to a chronic pain problem, resulting in disability in daily life functioning, depression, and a lower daily life activity level. However, not all patients suffering from CLBP have a lower daily life activity level. There seems to be a subgroup of patients that persist in activities. Persisters are hypothesized to have a similar level of daily life activities as healthy volunteers. Their activity-related behaviour style can be characterized by a continuation of activities despite pain, until completion of the task has been reached. When a persister eventually completes the activity, pain will increase due to overload, which, in turn, will force him to take rest until the pain subsides. Both activity-related behaviour styles, i.e. avoidance and persistence, seem to be associated with high disability levels and lower quality of life.

The underlying mechanisms explaining both avoidance and persistence behaviour have not yet been identified. A model that might explain both types of activityrelated behaviour is the self-discrepancy model for chronic pain. The SelfDiscrepancy theory which was originally developed by Higgins, proposes that discrepancies exist between the attributes one actually possesses ('actual self'), and the attributes one ideally possesses ('ideal self') or ought to possess ('ought self'). In addition, Carver et al. evaluated the discrepancy between the actual and the 'feared self' (the attributes one fears to possess). The adapted self-discrepancy model for chronic pain is proposed to explain the pathway from the three self-discrepancies to activity-related behaviour. In this model, it is hypothesized that both ideal and ought self-discrepancies lead to persistence behaviour. In contrast, the actual versus feared discrepancy is hypothesized to predict avoidance behaviour. The main aim of the combined studies presented in this thesis is to identify and explain the different types of activity-related behaviour within the population of patients with CLBP.

After the introduction (chapter 1), Part I of this thesis (chapter 2-5) evaluates assessment methods to identify a patient's activity-related behaviour during per- 
formance testing and during activities in daily life. In Part II of the thesis (chapter 6 and 7) specific characteristics in a person's activity pattern reflecting his activityrelated behaviour style (i.e. avoidance and persistence) are explored. In Part III (chapter 8 and 9) the self-discrepancy model for chronic pain is tested as explanatory model for avoidance and persistence behaviour. A further aim is to evaluate whether both activity-related behaviour styles are related to higher disability levels and to a diminished quality of life.

\section{Part I: Assessment of activity-related behaviour}

Chapter 2 reports to what extent physiological and non-physiological factors influence performance testing in patients with CLBP. In all types of performance tasks the final outcome will be influenced by physiological factors as well as nonphysiological factors. However, to what extent both factors influence test outcome differs between various performance tests. Whereas the outcome of a (sub)maximal exercise test will mainly be influenced by physiological factors and thus best represents a patient's maximum physiological possibilities, a holding endurance task evaluating the duration a patient can carry a specific weight, is an example of a performance task that is mainly influenced by psychological factors and can reflect a patient's behaviour during testing. Chapter 3 evaluates whether a patient's prediction of activity-related pain is associated with task performance. Furthermore, it is evaluated whether in patients overpredicting activity-related pain, fear of movement has a negative influence on performance. Results show that in contrast to patients who are able to predict the level of pain associated with activity correctly, in patients who tend to overpredict activity-related pain, fear of movement is negatively related to the level of performance during performance testing. In daily life, it appears that patients who overpredict their activity-related pain and experience more fear show a higher total daily life activity level. This last finding may be related to an alternative but more inefficient strategy in which everyday activities are carried out.

Chapter 4 presents an overview of assessment instruments to measure the activity level in daily life of patients with musculoskeletal pain. In pain research, physical activity in daily life is measured using questionnaires, diaries or objective measurement techniques. However, only limited research has been performed on psychometric properties of these instruments. Based on a comparison of different assessment tools for physical activity, it is recommended to evaluate a patient's daily life activity level with an objective registration tool such as an accelerometer or activity monitor. Results presented in chapter 5 confirm that a patient's estimation of his daily life functioning level may be biased. It is found that the association between the self-reported and objectively assessed activity level in daily life in patients with CLBP is rather low. In addition, it appeared that patients with CLBP, who 
are more depressed, underestimate their daily life activity level, although their actual activity level is not influenced by their level of depressed mood. Since it thus appeared that self-report can be biased by a patient's opinion, it is recommended to measure a patient's daily life activity level with an objective registration tool.

\section{Part II: Identification of subgroups, based on activity-related behaviour}

In chapter 6 the influence of pain intensity, pain-related fear, the level of physical activity and fluctuations in the activity, assessed by self-report (diary), on the level of disability in patients with CLBP is studied. Results show that, in addition to pain intensity, the fluctuation in the daily life activity level instead of the mean activity level over time is associated with disability. This finding seems in line with the hypothesis that patients applying persistence behaviour will present a sawtooth pattern in a registration of their activity level overtime. In chapter 7 characteristics of both activity-related behaviour styles are explored using accelerometry. Patients scoring high on avoidance and persistence behaviour show a higher level of disability compared to patients who score low on both avoidance and persistence behaviour. Results show that persisters, as compared to avoiders, have a higher selfreported daily life activity level and a longer daily uptime, assessed by accelerometry. The objectively measured level of physical activity does not differ between the groups. Furthermore, self-reported activities in daily life are positively related to a pain increase in persisters, whereas no such association is found in avoiders. These findings seem to support the hypothesis that different activity-related behaviour styles are present within the population of patients with CLBP.

\section{Part III: The self-discrepancy model for chronic pain to explain persistence and avoidance behaviour}

Chapter 8 evaluates the self-discrepancy model for chronic pain. The first aim is to evaluate whether self-discrepancies are associated with avoidance and persistence behaviour, measured by self-report. A further aim is to evaluate whether both persistence and avoidance behaviour are associated with a higher level of disability and a diminished quality of life. With regard to both types of activity-related behaviour, results show that the magnitude of the feared discrepancy is predictive of avoidance behaviour. In addition, actual-ideal self-discrepancies are predictive of persistence behaviour. Of interest is the finding that avoidance, but not persistence behaviour, is predictive for a higher level of disability and a lower level of quality of life. In this study, some associations in the self-discrepancy model for chronic pain could indeed be confirmed, whereas no confirmation was found for others. Chapter 9 evaluates whether self-discrepancies are associated with the objectively registered activity-related characteristics of persistence and avoidance behaviour and 
whether these associations are also consistent over time. Results indicate that patients with CLBP who felt close to their ideal show more characteristics of persistence behaviour. Over time, patients who move further away from their ideal also show more characteristics of persistence behaviour. Furthermore, in patients who are characterized as avoider, a further decrease of daily uptime is related to a decrease in mental health-related quality of life. However, persistence behaviour and mental health-related quality of life are not related. In the current study the associations between different types of self-discrepancies and avoidance or persistence behaviour could not unambiguously be confirmed.

Based on the results of part III of this thesis some support was found that the actual-feared discrepancy is associated with avoidance behaviour and the actualideal discrepancy is associated with persistence behaviour. However, no association between the actual-ought discrepancy and activity-related style could be found.

Chapter 10 contains the general discussion. Based on the results of this thesis, it became clear that the extent in which physiological or psychological factors influence the outcome on a physical performance test is not only different between tests but also between subgroups of patients. In future research, measurement techniques like a twitch technique and surface EMG are recommended to unravel to what extent physiological and to what extent psychological factors influence test outcome. Furthermore, the physical activity assessments in daily life should be performed with objective registration tools, because the self-reported daily life activity level are biased and will therefore not adequately represent the patient's daily life activity level.

With respect to the activity-related behaviour styles, this thesis shows that distinct characteristics can be identified between patients applying avoidance or persistence behaviour. For future research, activity monitoring might support the differentiation between persisters and avoiders. An activity monitor, which will enable identification of specific postures and activities during a patient's daily life activities, may be used to further differentiate between persisters and avoiders. Once we are able to classify patients based on their activity-related style, we can start to develop and test new treatment techniques which will help us to provide a patient-tailored treatment.

The self-discrepancy model for chronic pain is a promising model to explain the negative emotions in patients with chronic pain. Some evidence was found that the actual-feared discrepancy is associated with avoidance behaviour and the actual-ideal discrepancy is associated with persistence behaviour. However, no association between the actual-ought discrepancy and activity-related style could be found. Future studies should assess whether the self-discrepancy model for chronic pain can also explain why some patients avoid activities whereas others persist in activities. This may lead to a theoretical foundation for a tailored treatment for patients with CLBP. 


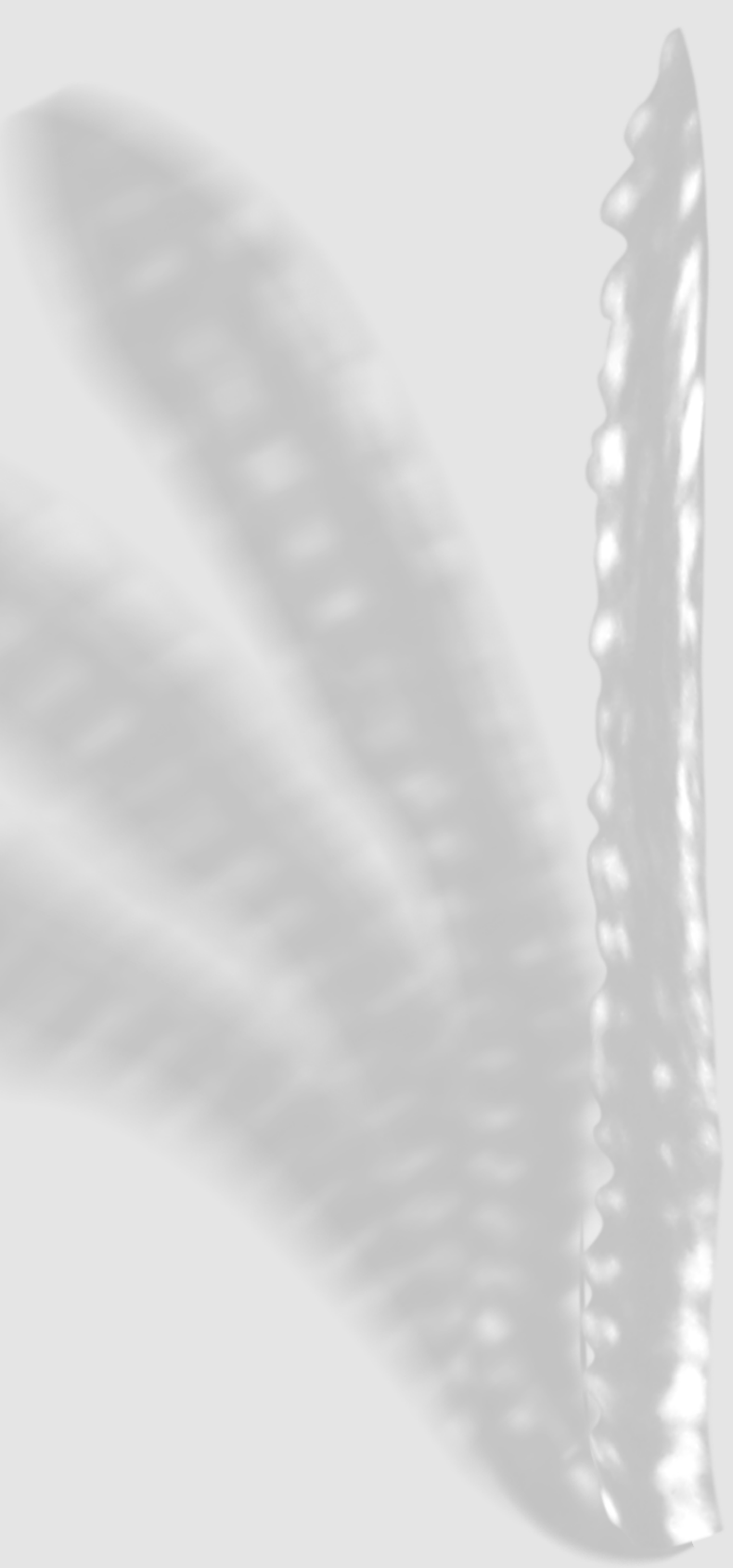


Samenvatting 


\section{Samenvatting}

Chronische lage rugklachten (CLRK) zijn een veel voorkomend probleem. Het hebben van CLRK leidt voor elke individuele patiënt tot beperkingen in het dagelijks functioneren en een verminderde kwaliteit van leven. Daarnaast leiden deze klachten tot enorm hoge maatschappelijke en sociale kosten. Jarenlang is getracht een biomedisch model te ontwikkelen waarmee het ontstaan en in stand houden van aspecifieke CLRK kon worden verklaard. Echter, niet bij alle patiënten met pijnsyndromen kan een biomedische oorzaak worden aangetoond. In de laatste decennia zijn cognitief-gedragsmatige modellen voorgesteld om het ontstaan en voortduren van de ervaren beperkingen bij patiënten met chronische pijn te kunnen verklaren. Eén van de meeste bekende cognitief-gedragsmatige modellen is het vreesvermijdingsmodel. Dit model beschrijft dat patiënten die catastroferende gedachten hebben over hun pijn, pijn-gerelateerde vrees ontwikkelen. Deze vrees wordt gekenmerkt door vermijdingsgedrag. Op de lange termijn kan deze stijl van beweeggedrag leiden tot een chronisch pijnsyndroom, gekenmerkt door depressieve gevoelens, hoge mate van ervaren beperkingen en verminderde activiteiten in het dagelijks leven. Echter, niet alle patiënten met CLRK hebben een lager activiteitenniveau. Er lijkt een subgroep van patiënten die doorgaat met de activiteiten (persisteren). Het wordt verondersteld dat deze persisteerders een vergelijkbaar activiteitenniveau hebben als gezonde controlepersonen. Het beweeggedrag van een persisteerder kan worden gekarakteriseerd door het volharden in de uitvoer van activiteiten, totdat de activiteit is afgerond. Als de activiteit is afgerond, wordt de persisteerder gedwongen rust te nemen, omdat de pijn ondraaglijk is geworden. Dit resulteert in een zaagtand patroon waarin periodes van intensieve activiteit worden afgewisseld met gedwongen rust ten gevolge van de toename in pijnintensiteit. Beide stijlen van beweeggedrag (vermijden en persisteren) lijken geassocieerd met meer beperkingen in het functioneren en een verminderde kwaliteit van leven.

Het onderliggende mechanisme dat zowel vermijden alsook persisteren, zou kunnen verklaren is nog niet geïdentificeerd. Een model dat mogelijk beide stijlen van beweeggedrag kan verklaren is het zelf-discrepantiemodel voor chronische pijn. De Zelf-Discrepantie theorie, oorspronkelijk ontwikkeld door Higgins, veronderstelt dat discrepanties bestaan tussen de eigenschappen die iemand werkelijk bezit ('actuele zelf') en de eigenschappen die iemand ideaal gezien zou willen bezitten ('ideale zelf'), of denkt te moeten bezitten ('opgelegde zelf'). Carver e.a. onderzochten ook nog de discrepantie tussen de actuele zelf en de gevreesde zelf (de eigenschappen die je niet wilt bezitten). Vanuit het zelf-discrepantiemodel voor chronische pijn wordt voorgesteld, dat vanuit de drie zelf-discrepanties het beweeggedrag kan worden verklaard. In dit model wordt verondersteld dat discrepanties tussen de actuele en ideale zelf en tussen de actuele en opgelegde zelf leiden tot persisterend beweeggedrag. De discrepantie tussen de actuele en gevreesde zelf wordt veron- 
dersteld vermijdingsgedrag te kunnen voorspellen. Het doel van de gecombineerde studies in dit proefschrift is het identificeren en verklaren van de verschillende stijlen van beweeggedrag binnen de populatie van patiënten met CLRK.

$\mathrm{Na}$ de introductie (hoofdstuk 1), wordt in het eerste deel (hoofdstuk 2-5) van dit proefschrift meetmethoden bestudeerd waarmee het beweeggedrag tijdens fysieke testen en in het dagelijks leven kan worden geïdentificeerd. In het tweede deel van dit proefschrift (hoofdstuk 6 en 7) worden de specifieke kenmerken in een activiteitenpatroon als kenmerk van beweeggedrag (vermijden en persisteren) onderzocht. In het derde deel van dit proefschrift (hoofdstuk 8 en 9) wordt het zelfdiscrepantiemodel voor chronische pijn geëvalueerd als verklaringsmodel voor vermijden en persisteren bij patiënten met CLRK. Verder wordt geëvalueerd of beide stijlen van beweeggedrag zijn geassocieerd met meer ervaren beperkingen in het dagelijks leven en een verminderde kwaliteit van leven.

\section{Deel 1: Het meten van beweeggedrag}

Hoofdstuk 2 beschrijft in welke mate fysiologische en psychologische factoren de uitslag op fysieke testen beïnvloeden bij patiënten met CLRK. In alle fysieke taken wordt de uitslag beïnvloed door zowel fysiologische alsook psychologische factoren. Echter, in welke mate deze factoren de uitslag beïnvloeden verschilt tussen de verschillende taken. Waar de uitkomst van een (sub)maximale inspanningstest vooral wordt beïnvloed door fysiologische factoren en dus het beste de maximale fysiologische mogelijkheden weergeeft, is een tiltaak waarbij een specifiek gewicht zo lang mogelijk moet worden vastgehouden, een voorbeeld van een taak waarbij de uitslag vooral wordt beïnvloed door psychologische factoren en dus het beweeggedrag van de patiënt weergeeft. Hoofdstuk 3 evalueert of de voorspelling van een patiënt met subacute lage rugklachten over de mate van pijn, die een fysieke taak oplevert, is geassocieerd met de uitslag op de taak. Bovendien wordt geëvalueerd of bij patiënten die hun pijn gerelateerd aan de fysieke taak overschatten, de vrees om te bewegen een negatieve invloed heeft op de uitslag op de taak. De resultaten laten zien dat, in tegenstelling tot de patiënten die hun pijn goed kunnen inschatten, bij de patiënten die hun pijn overschatten meer bewegingsvrees leidt tot een minder goede uitslag op de fysieke taak. In het dagelijks leven blijkt dat patiënten die hun pijn overschatten en meer bewegingsvrees hebben, meer actief zijn. Deze laatste bevinding is mogelijk gerelateerd aan een alternatieve, maar inefficiënte strategie die gebruikt wordt voor het uitvoeren van activiteiten in het dagelijks leven.

Hoofdstuk 4 presenteert een overzicht van meetinstrumenten waarmee het activiteitenniveau in het dagelijks leven van patiënten met pijnklachten aan het bewegingsapparaat kan worden gemeten. In pijnonderzoek wordt het fysieke activiteitenniveau in het dagelijks leven gemeten met vragenlijsten, dagboeken en objectieve meetinstrumenten. Echter, slechts weinig onderzoek is uitgevoerd om de psy- 
chometrische eigenschappen van deze instrumenten vast te stellen. Het doel van dit onderzoek was de in de literatuur gepresenteerde methoden die het fysieke activiteitenniveau in het dagelijks leven meten te identificeren en de psychometrische eigenschappen van deze methoden te presenteren. Na een vergelijking tussen de methoden wordt aanbevolen het dagelijks activiteitenniveau van patiënten met pijnklachten aan het bewegingsapparaat te meten met een objectief meetinstrument zoals een accelerometer of een activiteitenmonitor. De resultaten gepresenteerd in hoofdstuk 5 bevestigen dat de inschatting van het activiteitenniveau in het dagelijks leven door de patiënt vertekend kan zijn. De overeenstemming tussen het zelfgerapporteerde en objectief gemeten activiteitenniveau is bij patiënten met CLRK tamelijk laag. Verder bleek dat patiënten met CLRK die meer depressief waren, hun eigen activiteitenniveau onderschatten, terwijl hun werkelijke activiteitenniveau niet beïnvloed werd door hun depressieve stemming. Aangezien blijkt dat zelfrapportages vertekende resultaten kunnen geven, wordt aanbevolen om het fysieke activiteitenniveau in het dagelijks leven te meten met een objectief meetinstrument zoals een accelerometer of activiteitenmonitor.

\section{Deel 2: Identificatie van subgroepen, gebaseerd op beweeggedrag}

Het doel van het in hoofdstuk 6 gepresenteerde onderzoek is de invloed van pijn intensiteit, pijn gerelateerde vrees, het niveau van fysieke activiteiten en fluctuaties in activiteiten, gemeten met zelfrapportage, op het beperkingenniveau bij patiënten met CLRK te evalueren. De resultaten laten zien dat naast de pijn intensiteit, de fluctuaties in de dagelijkse activiteiten in plaats van de gemiddelde activiteit geassocieerd zijn met de ervaren beperkingen. Deze bevinding lijkt in lijn met de veronderstelling dat patiënten die persisteren een zaagtand patroon laten zien in een registratie in de tijd. In hoofdstuk 7 worden kenmerken van de verschillende stijlen van beweeggedrag onderzocht met een accelerometer. Patiënten met CLRK die zowel hoog scoren op vermijden als persisteren hebben een hoger beperkingenniveau in vergelijking met patiënten die laag scoren op vermijden en persisteren. Resultaten laten verder zien dat persisteerders in vergelijking met vermijders een hoger zelfgerapporteerd activiteitenniveau en een langere dagduur (tijd tussen opstaan en gaan slapen) hebben, gemeten met de accelerometer. Het objectief gemeten activiteitenniveau is niet verschillend tussen de groepen. Verder is het zelfgerapporteerde activiteitenniveau in het dagelijks leven positief gerelateerd aan een pijntoename bij persisteerders, terwijl geen verband werd gevonden in vermijders. Deze bevindingen lijken de veronderstelling te ondersteunen dat verschillende stijlen van beweeggedrag aanwezig zijn binnen de populatie patiënten met CLRK. 


\section{Deel 3: Het zelf-discrepantiemodel voor chronische pijn om persisterend en vermijdend gedrag te verklaren}

Hoofdstuk 8 evalueert het zelf-discrepantie model voor chronische pijn. Het eerste doel is om te bestuderen of zelf-discrepanties zijn geassocieerd met persisterend en vermijdend gedrag, gemeten met een zelfrapportage. Een volgend doel is na te gaan of zowel persisterend als vermijdend gedrag zijn geassocieerd met de ervaren beperkingen in het dagelijks leven en een verminderde kwaliteit van leven. Wat betreft de beide stijlen van beweeggedrag laten de resultaten zien dat de discrepantie grootte van de gevreesde zelf, vermijdingsgedrag voorspelt. Verder voorspelt de discrepantie tussen de actuele en ideale zelf persisterend gedrag. Een interessante bevinding is verder dat vermijden en niet persisteren voorspellend is voor een hoger beperkingenniveau en een lagere kwaliteit van leven. In deze studie konden verwachte associaties in het zelf-discrepantiemodel voor chronische pijn tussen de actuele en ideale zelf-discrepantie en actuele en gevreesde zelf-discrepantie en beweeggedrag worden bevestigd, terwijl geen bevestiging werd gevonden voor de associatie tussen de actuele en opgelegde discrepantie en beweeggedrag. Hoofdstuk 9 evalueert of zelf-discrepanties samenhangen met objectief gemeten kenmerken van persisterend en vermijdend gedrag en of deze verbanden constant blijven in de tijd. Resultaten laten zien dat patiënten met CLRK die zich dichtbij hun ideale zelf voelen, meer kenmerken van persisterend gedrag presenteren. In de tijd wordt gevonden dat patiënten die verder weg schuiven van hun ideaal ook meer kenmerken van persisterend gedrag presenteren. Uit de resultaten bleek verder dat in patiënten die gekarakteriseerd werden als vermijder, een verdere afname in de mentale kwaliteit van leven geassocieerd was met een kortere dagduur. Dat komt tot uiting in het later opstaan en/of eerder naar bed gaan. Echter, persisterend gedrag en mentale kwaliteit van leven zijn niet gerelateerd. In deze studie konden de verbanden tussen de verschillende types zelf-discrepanties en persisterend en vermijdend gedrag niet eenduidig worden gevonden.

Op basis van de resultaten uit het derde deel van dit proefschrift kan worden geconcludeerd dat enige ondersteuning was gevonden dat de actueel-gevreesde discrepantie is geassocieerd met vermijdend gedrag en de actueel-ideaal discrepanctie is geassocieerd met persisterend gedrag. Echter, geen verband kon worden gevonden tussen de actueel-opgelegde discrepantie en beweeggedrag.

Hoofdstuk 10 beschrijft de algemene discussie. Op basis van de resultaten uit dit proefschrift werd duidelijk dat de mate waarin fysiologische of psychologische factoren de uitslag op een fysieke taak beïnvloeden niet alleen verschilt tussen de verschillende testen, maar ook tussen subgroepen van patiënten. Voor vervolgonderzoek wordt aanbevolen meettechnieken zoals een twitch techniek of oppervlakte EMG te gebruiken zodat de mate waarin fysiologische en psychologische factoren invloed hebben, kan worden ontrafeld. Voorts zou het fysieke activiteitenniveau in 
het dagelijks leven gemeten moeten worden met een objectief meetinstrument, omdat het zelfgerapporteerde activiteitenniveau vertekend kan zijn en dus het activiteitenniveau van de patiënt niet adequaat zal weergeven.

Wat betreft de verschillende stijlen van beweeggedrag laat dit proefschrift zien dat kenmerken van persisterend en vermijdend beweeggedrag kunnen worden geïdentificeerd voor patiënten met CLRK. Een activiteitenmonitor, die het mogelijk maakt om specifieke houdingen en activiteiten tijdens het dagelijks leven te onderscheiden, zou in toekomstig onderzoek gebruikt kunnen worden om te kunnen differentiëren tussen persisteerders en vermijders. Op het moment dat het mogelijk is patiënten te classificeren op basis van beweeggedrag, kan een screeninginstrument worden ontwikkeld waarmee de keuze voor de verschillende behandelvormen objectiever kan worden bepaald. Dit kan bijdragen aan het verkrijgen van een behandeling op maat.

Het zelf-discrepantiemodel voor chronische pijn is een veelbelovend model om negatieve emoties bij patiënten met chronische pijn te verklaren. Enig bewijs was gevonden dat de actueel-gevreesde discrepantie is geassocieerd met vermijdend gedrag en de actueel-ideaal discrepantie is geassocieerd met persisterend gedrag. Echter, geen verband tussen de actueel-opgelegde discrepantie en beweeggedrag kon worden gevonden. Vervolgonderzoek zou moeten evalueren of het zelfdiscrepantiemodel voor chronische pijn ook kan verklaren waarom sommige patiënten activiteiten vermijden terwijl andere patiënten persisteren in activiteiten. Dit zou kunnen leiden tot een theoretische basis voor de behandeling op maat voor patiënten met CLRK. 



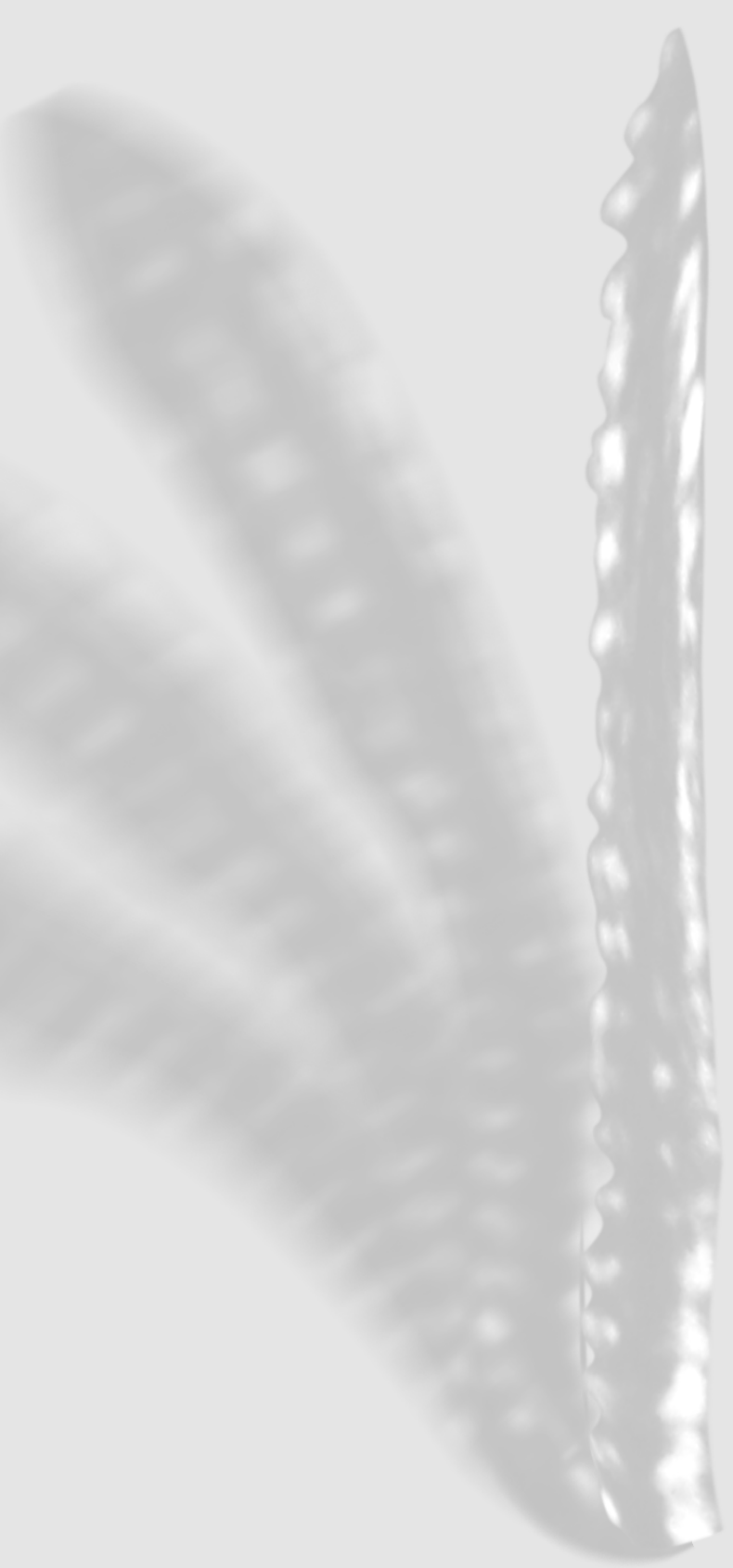




\section{Dankwoord}


Eindelijk kan ik starten met het schrijven van het laatste hoofdstuk van mijn proefschrift; het dankwoord. Het combineren van een promotietraject met het werk als fysiotherapeut heeft ertoe geleid dat de afgelopen jaren op sommige momenten behoorlijk druk waren. In de periode van mijn promotietraject is daarnaast ook op het privé vlak behoorlijk wat veranderd. Met hulp en ondersteuning van een aantal mensen is het toch gelukt om hier goed doorheen te komen. In dit hoofdstuk wil ik graag iedereen bedanken die hier een rol in hebben gespeeld. Een aantal personen wil ik hiervoor specifiek bedanken, al realiseer ik me, dat ik ook mensen zal vergeten die wel een rol hebben gehad!

Dr. J.A. Verbunt, beste Jeanine, jij bent de persoon die ik het meest moet bedanken dat dit proefschrift hier uiteindelijk ligt en ook het traject goed is verlopen. Jij was het hele traject een motivator, begeleider, vertrouwenspersoon en collega in één. Je energie, inzet en gedrevenheid werkte en werkt nog steeds aanstekelijk. Ondanks dat jouw agenda steeds voller werd, had je elke week tijd om met mij te brainstormen, mijn artikelen te lezen of gewoon een kop koffie te drinken! Ik vind het een eer dat ik de eerste promovendus ben die onder jouw begeleiding gaat promoveren! Ik ben blij dat we in de toekomst samen blijven werken! Bedankt voor alles Jeanine!

Dr. H.A.M Seelen, beste Henk, jij hebt je altijd een beetje op de achtergrond gehouden, omdat pijn niet jouw topic is. Echter, jouw rol in het project was belangrijk. Je kennis van de Engelse taal en van meerdere analyse- en bewerkingstechnieken maakt dat samen met jouw kritische blik op de inhoud, onze discussies weer stof tot nadenken gaven. Je vriendelijkheid en open deur beleid heb ik altijd enorm gewaardeerd. Ik ben blij dat je ook als copromotor betrokken bent gebleven bij mijn promotie en hoop ook in de toekomst projecten op het gebied van activiteitenmonitoring met je samen te kunnen doen! En Henk, besef dat pijn nu steeds meer ook jouw topic is geworden...

Prof.dr. R.J.E.M. Smeets, beste Rob, jouw rol in mijn promotietraject kwam pas op een later moment toen je hoogleraar Revalidatiegeneeskunde werd. Vantevoren was je wel al als verwijzer en vanuit de onderzoeksgroep LOBADIS bij het project betrokken. Ondanks jouw overvolle agenda hebben we vanaf het moment dat je bij het project betrokken bent intensief contact gehad. Jouw inhoudelijke kennis en opmerkingen waren een zinvolle aanvulling bij de discussies. Ik ben trots dat ik de eerste ben die vanuit de vakgroep Revalidatiegeneeskunde gaat promoveren. Laat er nog vele volgen! Rob, ik heb onze samenwerking als prettig ervaring en ik hoop dat we dit in de toekomst zo gaan voortzetten. 
Prof.dr. M.L. Peters, beste Madelon, onze eerste kennismaking gaat al flink wat jaren terug en vanaf toen ben ik onder de indruk geraakt van jouw theoretische kennis en jouw vermogen om dit toe te passen in de verschillende contexten. Vanaf het moment dat bekend was dat ik zou gaan promoveren wilde jij hier graag aan meewerken. Ook jij had het erg druk, maar altijd had jij tijd om even van gedachten te wisselen. Je constructieve opmerkingen gaven altijd veel stof tot nadenken! Madelon, ik ben vereerd dat jij mijn promotor bent bij mijn promotie. Ik heb heel veel van je geleerd!

I furthermore would like to express my gratitude to the members of the examination board Johan Vlaeyen, Rob de Bie, Hans Bussmann, Monika Hasenbring, and Andre Knottnerus for taking time and effort to read and evaluate my thesis.

Dank ook aan al die mensen met chronische lage rugklachten die hebben deelgenomen aan de onderzoeken zonder dat ze hier zelf direct iets aan hadden. Ook wil ik de afdeling revalidatie van de verwijzende ziekenhuizen in Maastricht (azM), Heerlen (Atrium MC), Sittard (Orbis MC), Venlo (Viecuri) en Veldhoven (Maxima MC) en de revalidatiecentra Blixembosch en Adelante bedanken voor het attenderen van patiënten op dit onderzoek.

De eerste jaren van mijn promotie was ik werkzaam vanuit het toenmalige DMKEP. Alle collega's van toen wil ik graag bedanken voor hun hulp met statistiek (Erik), ondersteuning bij het onderzoek (Astrid, Truus en Sita) en alle andere zaken. De onderbrekingen met tafeltennis leverden uiteindelijk weer energie op om hard door te werken! Daarnaast ook de collega's van het toen nog SOMATO overleg (nu BMoverleg); het is een luxe om met zoveel enthousiaste onderzoekers te mogen werken en samen naar congressen te kunnen gaan. Speciaal woord van dank voor Karoline voor de samenwerking in haar MaNeS-project. Vanuit deze groep kom ik automatisch uit bij Hanne. Hanne, we hebben samen het cohort opgezet en uitgevoerd waarin we de relatie probeerden na te gaan tussen een persoonlijkheidskenmerk en fysiek, objectief gemeten, gedrag. We hebben er menig uur over moeten nadenken hoe we dit konden verklaren! Ook de praktische uitvoering van het cohort was lastig onder andere door de combinatie van mijn beide banen. Ik ben erg blij dat we het allebei goed hebben afgerond en nu weer opnieuw collega's en kamergenoten zijn bij Revalidatiegeneeskunde. Bedankt dat je me als paranimf terzijde wil staan bij mijn promotie. Ik geef de helft van het promotiestokje aan jou door! Ik wil ook de begeleiders van Hanne, Marielle, Jeffrey en Johan bedanken voor hun ideeën en adviezen rondom onze projecten.

In de periode na DMKEP kwam ik in dienst van de vakgroep Revalidatiegeneeskunde. Op dat moment was ik nog de enige werknemer en mijn werkplek werd het 
kenniscentrum van Adelante. Hier zit een groep enthousiaste collega's op verschillende onderzoekslijnen. Bedankt allemaal voor de leuke gesprekken, gezelligheid en steun! Speciaal woord van dank voor mijn kamergenoten Annemie, Annick, Patrick, Veronique, Rachma, Ananda, Vera en Ryanne. Patrick, we deelden samen een tafel en we probeerden elkaar bij te staan met alles wat we tegenkwamen in het traject én daar buiten. Dank voor je hulp en gezelligheid en fijn dat je mij als paranimf wil bijstaan bij het verdedigen van mijn proefschrift. Ik geef de andere helft van het promotiestokje aan jou door!

De laatste fase van mijn promotietraject was ik weer terug in Maastricht, waar we een werkplek vanuit de vakgroep revalidatiegeneeskunde hebben gekregen (en uiteindelijk hele mooie plekken!!). Hier een speciaal woord van dank voor Margareth. Fijn dat je altijd zo behulpzaam bent.

Naast mijn promotiewerkzaamheden ben ik ook werkzaam gebleven als fysiotherapeut in de klinische praktijk. Idealiter wil je dat wetenschap en praktijk dicht tegen elkaar liggen, maar dat is niet altijd even makkelijk. Dank aan mijn werkgever en collega's uit de eerste lijn. Kees, Ans, Fidesca en Adriënne, ik heb het leuk gevonden om met jullie samen te werken! Sinds anderhalf jaar werk ik als fysiotherapeut op de afdeling revalidatiegeneeskunde van het azM. Ik wil alle collega's hier bedanken voor hun steun en hulp in de laatste fase van mijn promotie. Het is prettig om in een enthousiast en ambitieus team te werken en ik hoop dat we dit samen verder kunnen opbouwen.

Ik wil ook alle vrienden en familieleden bedanken voor de interesse en betrokkenheid die zij hebben getoond voor waar ik mij mee bezig hield. Martijn, we moeten nu echt weer gaan fietsen. Guido, we gaan mee! Bert en Pia, dank voor jullie goede zorgen en hulp! Martijn, Pia en Jesse, dank voor jullie interesse. Papa en mama bedankt voor de opvoeding die jullie ons hebben gegeven. Dat heeft ons gemaakt tot wat we nu zijn. Fijn ook dat jullie altijd voor ons klaar staan. Erik en Lonneke dank voor de ontspannende momenten. Egon jammer dat je nu niet heel dicht meer in de buurt bent, maar het is prettig om samen iets te ondernemen. We mogen trots zijn op wat we hebben bereikt!

En ik wil dit dankwoord besluiten met wat het allerbelangrijkste voor mij is. Marielle, we hebben een erg drukke periode gehad. Jij met jouw opleiding, ik met mijn promotie en tussendoor kregen we ook nog ons lieve kleine prinsesje Meike. Ik ben hartstikke trots op wat jij allemaal hebt bereikt en ik ben hartstikke blij hoe we nu alles samen doen. Zonder jouw hulp en steun was deze promotie niet gelukt. Meike, je bent mijn grote schat. Jouw vrolijkheid blijft fantastisch.

En nu..Let the party begin! 



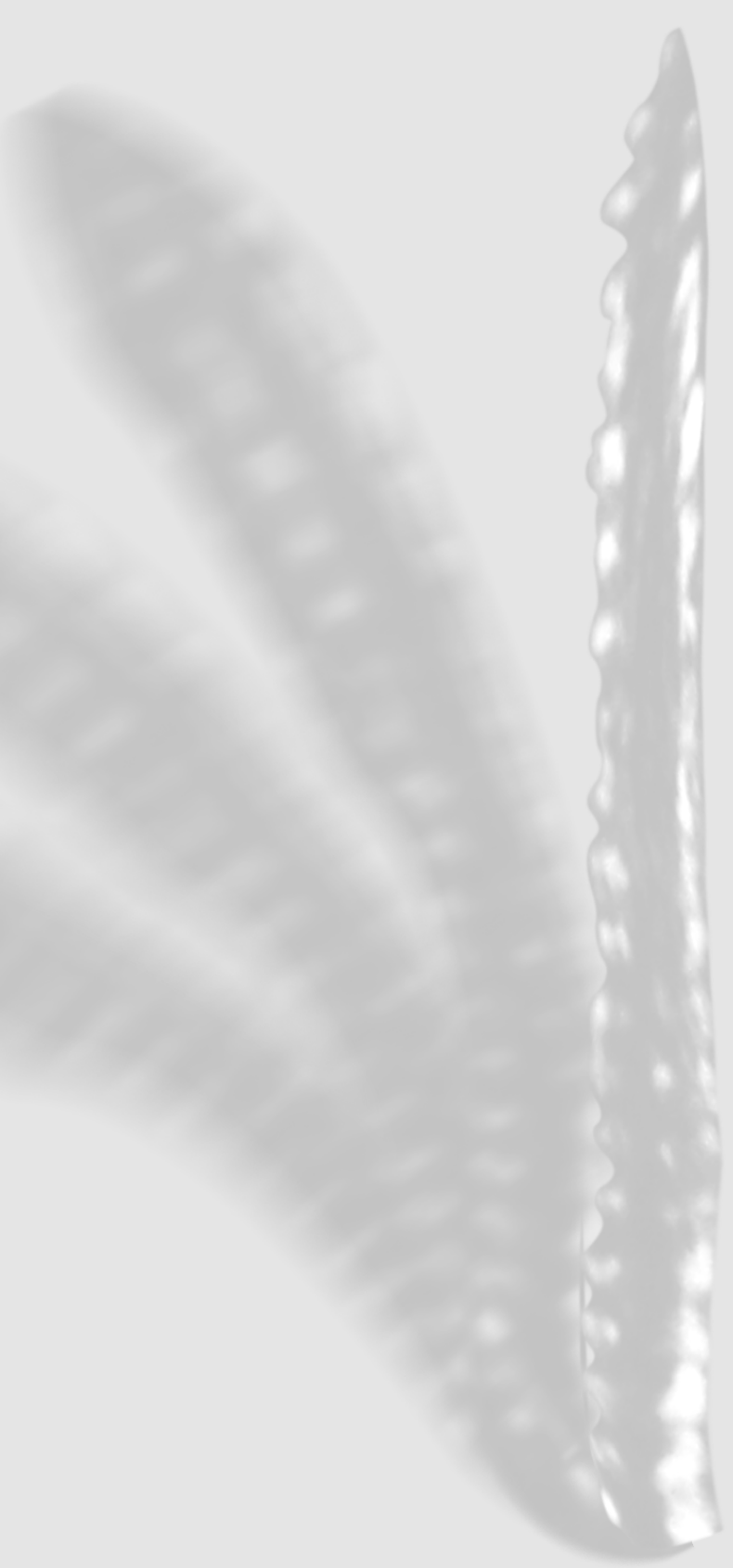


About the author 
Ivan Huijnen was born on October 5th, 1978 in Heerlen, the Netherlands. He grew up in Trintelen, a small village near Heerlen. From 1992 he attended secondary education at the Sintermeertencollege in Heerlen; he obtained his Lyceum diploma in 1997. He then started his study in Health Sciences at Maastricht University (Maastricht) and specialized in Movement Sciences. In addition, in 2000 he started to study Physiotherapy at Zuyd University of Applied Sciences (Heerlen) and completed his bachelor degree in Physiotherapy in 2002. He received his master degree in Movement Sciences in 2003. In September 2003 he started as a research assistant in the Maastricht Neck Study at the Department of Medical, Clinical and Experimental Psychology of the Maastricht University. In January 2006 he was first appointed as a junior researcher at the Department of Medical, Clinical and Experimental Psychology of Maastricht University and from July 2008 as PhD researcher at the Department of Rehabilitation Medicine on the project "Experienced disability of the activity level of chronic low back pain patients; the role of self-discrepancies". Since January 2011 he is affiliated within the same department as a senior researcher. His current research activities are part of the CAPHRI research program "Rehabilitation Medicine" of the cluster "Primary Care". From 2003 till May 2010 he combined his (PhD) research with clinical work as physiotherapist in two primary care settings (in Meerssen and Brunssum). Since May 2010 he works as physiotherapist at Adelante and is second to the multidisciplinary rehabilitation team at the department of rehabilitation medicine of the Maastricht University Medical Centre. At present he still combines his research activities with clinical work. 



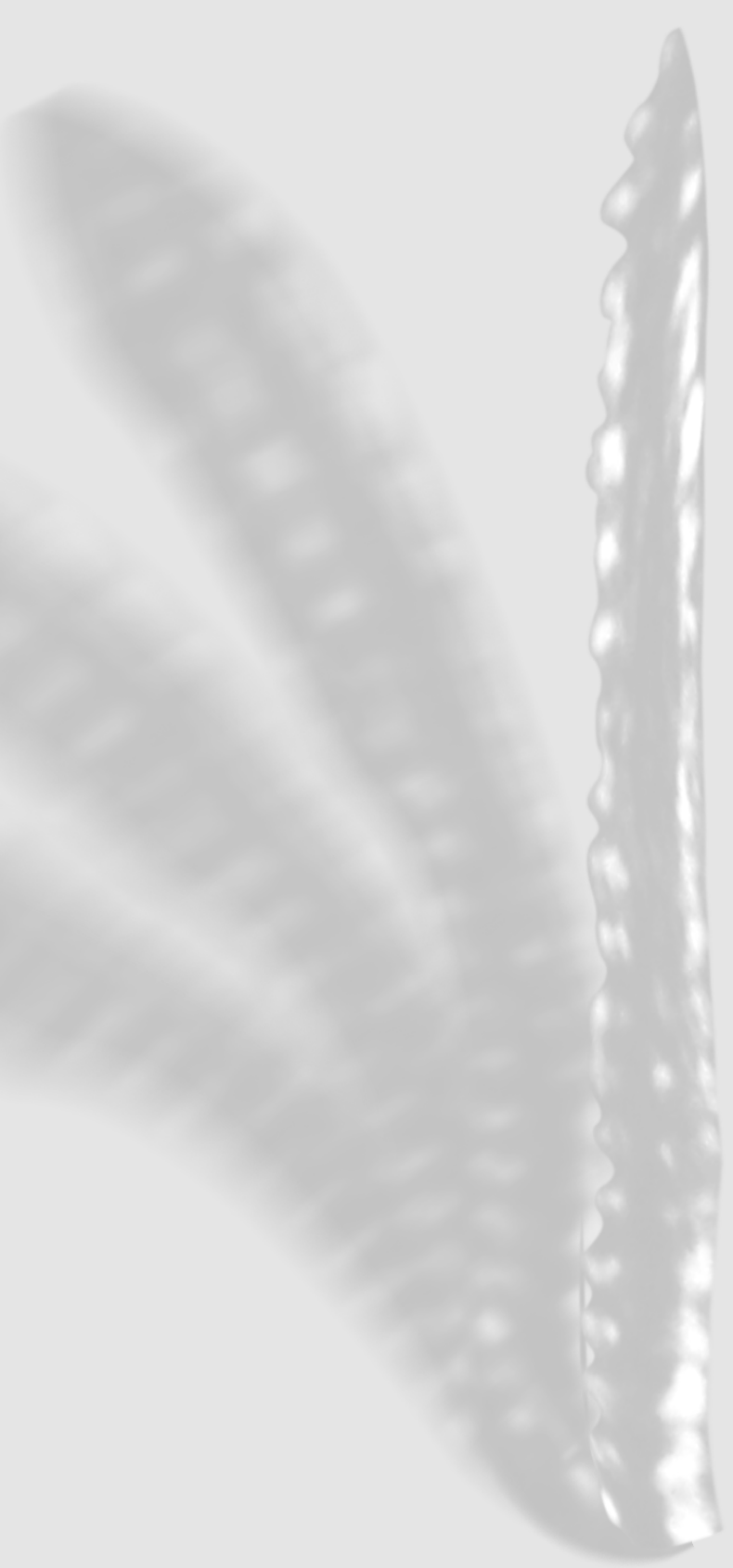


Publications 


\section{Publications}

\section{Articles published}

- Huijnen IP, Kindermans HP, Seelen HA, Peters ML, Smeets RJ, Serroyen J, Roelofs J, Goossens M, and Verbunt JA. Effects of self-discrepancies on activity-related behaviour: explaining disability and quality of life in patients with chronic low back pain. Pain 2011; 152(9):2165-72.

- Huijnen IP, Verbunt JA, Peters ML, Delespaul P, Kindermans HP, Roelofs J, Goossens $\mathrm{M}$, and Seelen HA. Do depression and pain intensity interfere with physical activity in daily life in patients with Chronic Low Back Pain? Pain 2010; 150(1):161-6.

- Huijnen IP, Verbunt JA, Peters ML, and Seelen HA. Is physical functioning influenced by activity-related pain prediction and fear of movement in patients with subacute low back pain? Eur J Pain 2010; 14(6):661-6.

- Huijnen IP, Verbunt JA, Peters ML, Smeets RJ, Kindermans HP, Roelofs J, Goossens M, and Seelen HA. Differences in activity-related behaviour among patients with chronic low back pain. Eur J Pain 2011; 15(7):748-55.

- Huijnen IP, Verbunt JA, Roelofs J, Goossens M, and Peters M. The disabling role of fluctuations in physical activity in patients with chronic low back pain. Eur J Pain 2009; 13(10):1076-9.

- Kindermans HP, Goossens ME, Roelofs J, Huijnen IP, Verbunt JA, Morley S, and Vlaeyen JW. A content analysis of ideal, ought, and feared selves in patients with chronic low back pain. Eur J Pain 2010; 14(6):648-53.

- Kindermans HP, Huijnen IP, Goossens ME, Roelofs J, Verbunt JA, and Vlaeyen JW. "Being" in pain: the role of self-discrepancies in the emotional experience and activity patterns of patients with chronic low back pain. Pain 2011; 152(2):403-9.

- Verbunt JA, Huijnen IP, and Koke A. Assessment of physical activity in daily life in patients with musculoskeletal pain. Eur J Pain 2009; 13(3):231-42.

\section{Articles accepted}

- $\quad$ Kindermans HP, Roelofs J, Goossens ME, Huijnen IP, Verbunt JA, and Vlaeyen JW. Activity Patterns in Chronic Pain: Underlying Dimensions and Associations With Disability and Depressed Mood. J Pain 2011.

- Verbunt JA, Huijnen IP, Seelen HA. Assessment of physical activity by movement registration systems in chronic pain: Methodological considerations. Clin. J Pain 2011. 


\section{Article submitted}

- Huijnen IP, Verbunt JA, Peters ML, Wittink HM, and Smeets RJ. Physical performance measurement in pain: measuring physical capacity or painrelated behaviour? 